\title{
WestVirginiaUniversity
}

THE RESEARCH REPOSITORY @ WVU

Graduate Theses, Dissertations, and Problem Reports

2017

\section{Hydraulics and Well Control Complications in Unconventional Shale Laterals}

Tawfik A Elshehabi

Follow this and additional works at: https://researchrepository.wvu.edu/etd

\section{Recommended Citation}

Elshehabi, Tawfik A, "Hydraulics and Well Control Complications in Unconventional Shale Laterals" (2017). Graduate Theses, Dissertations, and Problem Reports. 7174.

https://researchrepository.wvu.edu/etd/7174

This Dissertation is protected by copyright and/or related rights. It has been brought to you by the The Research Repository @ WVU with permission from the rights-holder(s). You are free to use this Dissertation in any way that is permitted by the copyright and related rights legislation that applies to your use. For other uses you must obtain permission from the rights-holder(s) directly, unless additional rights are indicated by a Creative Commons license in the record and/ or on the work itself. This Dissertation has been accepted for inclusion in WVU Graduate Theses, Dissertations, and Problem Reports collection by an authorized administrator of The Research Repository @ WVU.

For more information, please contact researchrepository@mail.wvu.edu. 


\title{
Hydraulics and Well Control Complications in Unconventional Shale Laterals
}

\author{
Tawfik A. Elshehabi \\ Dissertation submitted \\ to the Benjamin M. Statler College of Engineering and Mineral Resources \\ at West Virginia University \\ in partial fulfillment of the requirements for the degree of \\ Doctor of Philosophy in \\ Petroleum and Natural Gas Engineering \\ H. Ilkin Bilgesu, Ph.D., Chair \\ Sam Ameri, M.S. \\ Kashy Aminian, Ph.D. \\ Tim Carr, Ph.D. \\ Keith A. Heasley, Ph.D. \\ Department of Petroleum and Natural Gas Engineering \\ Morgantown, West Virginia \\ 2017
}

Keywords: Hydraulics, Well Control, Unconventional Shale, Gas Solubility, Drilling with Casing, Inclined Upward Laterals.

Copyright $\odot 2017$ Tawfik Elshehabi 


\title{
ABSTRACT \\ Hydraulics and Well Control Complications in Unconventional Shale Laterals
}

Tawfik A. Elshehabi

\begin{abstract}
Unconventional shale resources are drilled horizontally following the geologic bed dip upward or downward to maximize reservoir contact. Despite the efforts to control formation pressures, well control emergencies arise. Wellbore communication with high pressure zones through natural or induced fractures is a major cause of blowouts in unconventional shales. The philosophy of well control is to maintain the bottomhole pressure while balancing the formation pressure; however, it is a challenging process.
\end{abstract}

The objective of this study is to investigate mud hydraulics and well control complications in unconventional shale laterals. This included the impact of wellbore configuration (inclined upward or downward laterals), drilling fluid type (water or oil based mud), and drillstring configuration (drillpipe, casing, or liner). This research employed an interactive drilling and well control full-scale simulator for more than 500 hours of real-time operations. It also utilized a robust steady-state hydraulics and multiphase dynamic well control program. A hydraulics base model was developed and verified with field data from a recently drilled Marcellus Shale well in Monongalia County, WV.

Static and dynamic pressure profiles were examined at drilling flow rates, and compared to slow pump rates in inclined upward and downward laterals. This study compared kicks experienced at shallow, middle, and deep zones in the lateral section. It examined the impact of gas solubility in oil based muds compared to water based muds. In addition, this research investigated pressure loss profiles in tight annular spaces around casing or liner strings. Also included was the impact of various circulation rates and well control methods. The study examined influx characteristics such as size, intensity, and type (dry gas, rich condensate, and black oil). Furthermore, it examined kick handling in different well types and string configurations, for instance drillpipe, casing, or liner. Finally, the study investigated the influence of reservoir characteristics on kick behavior in the Marcellus Shale and compared it to the Utica Shale.

Results showed that the hydraulics model successfully predicted the pump pressure with a regression coefficient of 0.974 . The impact of drilling rate of penetration, mud rheological properties and drilled cuttings characteristics on hydraulics was significant. Annular pressure loss, equivalent circulating density, and critical flow rate were higher in inclined downward laterals, as a result of lower cutting transport ratio and cuttings accumulation. When a gas kick is encountered in oil based mud, it dissolves under the bottomhole conditions. While gas-entrained mud is circulated out of the hole, wellbore pressure drops below the bubble-point pressure, and gas bubbles are liberated near the surface. Consequently, surface pressures and volumes are not representative of the actual downhole conditions, and this unexpected volume of gas at the choke challenges well control procedures.

In tight annulus cases, such as running casing or liner strings, the pressure loss profile is inverted. This means, annular pressure loss is higher than the friction inside the string and the friction at the bit combined. Therefore, the reduced two-stage step-down (R2SD) model was developed and validated taking high annular pressure losses into account. This enabled kick circulation with lower surface and downhole pressures which mitigated wellbore integrity and reduced the risk of fracturing the formations. In lateral sections, the closer the kick location is to the vertical wellbore, the shorter the gas removal times. However, kicks experienced near the vertical section resulted in higher pit gain, gas discharge rate, choke, and casing shoe pressure. 
In inclined upward laterals, gas bubbles migrated and accumulated at the lateral end. Consequently, the choke experienced lower pressure, volume, and gas discharge rate for extended periods of time. Thus, higher circulation rates and longer operation times were essential to flush-out the dispersed and trapped gas bubbles. The deeper and over-pressurized Utica Shale presents more challenges compared to Marcellus Shale wells. Well integrity was verified by monitoring surface choke, casing shoe, and bottomhole pressures throughout the entire well control operations.

This research revealed that it is crucial to identify accurate hydraulics and well control complications for unconventional shale laterals. Some examples were drilling inclined upward and downward laterals using different string and fluid configurations. This improves rig and personnel safety and diminishes the environmental risks and hazards associated with blowouts.

Keywords: Hydraulics, Well Control, Unconventional Shale, Gas Solubility, Drilling with Casing, Inclined Upward Laterals. 


\section{DEDICATION}

"to my parents, my wife, and my kids" 


\section{ACKNOWLEDGMENTS}

The author wishes to acknowledge some special people helped making this dissertation possible. First and foremost, I would like to extend my utmost appreciation and sincerest thanks to my adviser Dr. Ilkin Bilgesu for his tremendous support, guidance, and dedication.

I'm grateful to the department of Petroleum and Natural Gas Engineering faculty and staff, especially the chairperson Prof. Sam Ameri for his endless help and support that made everything run smoothly. I would like to thank my committee members Dr. Khasy Aminian, Dr. Tim Carr and Dr. Keith A. Heasley for their appreciated inputs throughout the course of my research that kept me on track.

The author would like to acknowledge that the data used as part of this research was funded through the U.S.DOE National Energy Technology, Marcellus Shale Energy and Environmental Laboratory (MSEEL) (DOE Award No.: DE-FE0024297).

My deepest appreciation goes to my respected parents, without their unlimited love, support, and confidence, I could never have made it to where I am today. My wonderful wife and my beloved kids are the real heroes who supported me in all tangible and intangible ways throughout this journey. 


\section{TABLE OF CONTENTS}

ABSTRACT
DEDICATION
ACKNOWLEDGMENTS.
TABLE OF CONTENTS
LIST OF FIGURES
LIST OF TABLES
LIST OF SYMBOLS / NOMENCLATURE

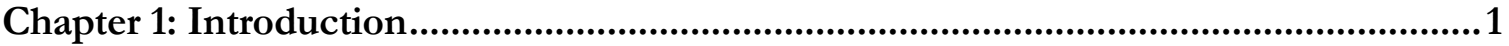

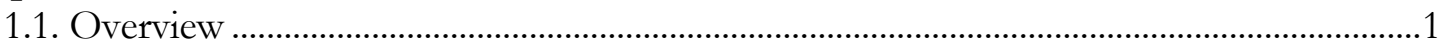

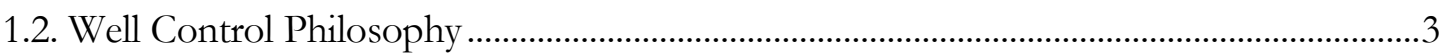

1.3. Background on Gas Solubility in Oil Based Mud...............................................................

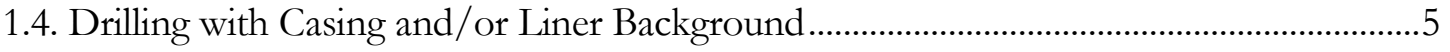

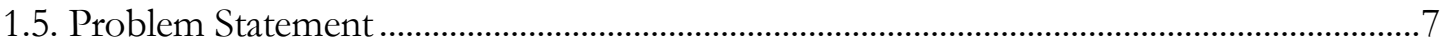

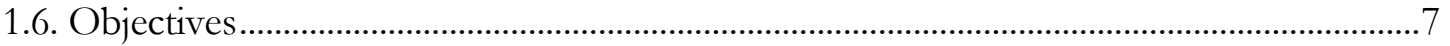

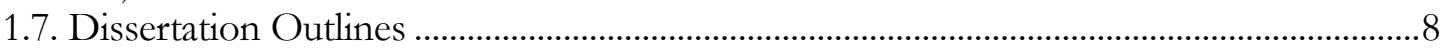

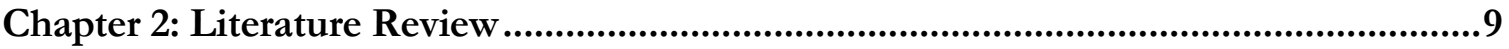

2.1. Kicks and Blowouts in Unconventional Shale Players .......................................................

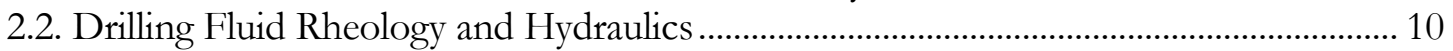

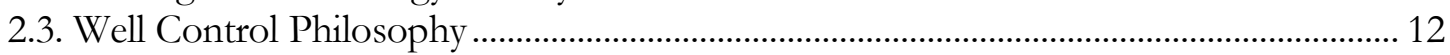

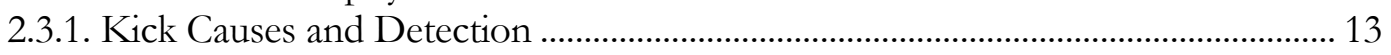

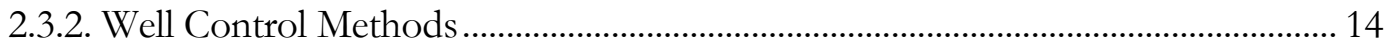

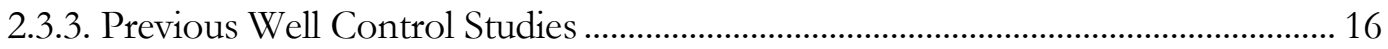

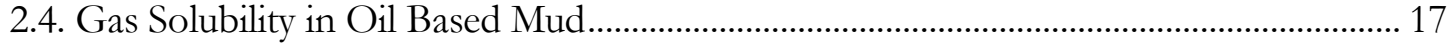

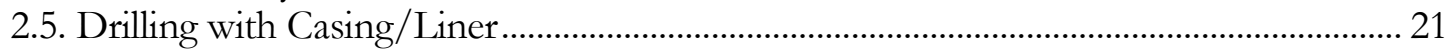

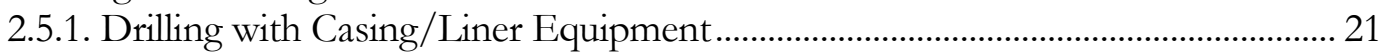

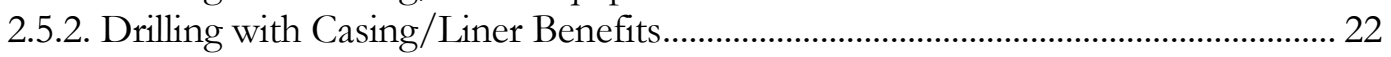

2.5.3. Drilling with Casing/Liner Limitations ................................................................ 23

2.5.4. Previous Studies of Drilling with Casing/Liner ....................................................... 24

Chapter 3: Methodology and Wellbore Configurations ..............................................26

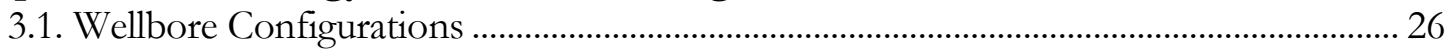

3.1.1. Marcellus Shale Lateral Well Configuration .............................................................. 26

3.1.2. Horizontal Well drilled with Oil Based Mud Configuration ...................................... 27

3.1.3. Drilling with Casing/Liner Configuration .................................................................... 28

3.1.4. Inclined Upward/Downward Lateral Well Configuration ....................................... 29

3.1.5. Marcellus/Utica Lateral Configuration ........................................................................ 30

3.2. Full-Size Rig-Floor Drilling and Well Control Facility at WVU ...................................... 31

3.3. Drillbench Steady-State Hydraulics and Dynamic Well Control Software...................... 33

3.4. Pump and Bottomhole Pressure Calculations..................................................................... 34

3.5. U-tube Model in Vertical and Horizontal Wells ................................................................... 36

3.6. The Reduced Two-Stage Step-Down (R2SD) Model........................................................... 38 


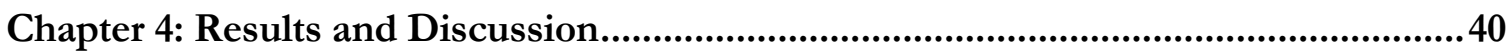

Part 1: Hydraulics Results ...............................................................................................40

4.1. Hydraulics Study in Marcellus Shale Lateral ..................................................................... 40

4.1.1. Hydraulics Model Verification .................................................................................... 40

4.1.2. Impact of Well Type on Pressure Profile ................................................................ 42

4.1.3. Slow Pump Rate and Shut-in Pressure profiles ....................................................... 43

4.2. Hydraulics Results for Drilling with Casing and Liner...................................................... 45

4.2.1. Drilling with Casing/Liner in Water Based Mud ..................................................... 45

4.2.2. Drilling with Casing/Liner in Oil Based Mud ......................................................... 50

4.3. Hydraulics Results for Inclined Upward and Downward Laterals.................................... 51

4.3.1. Pressure and ECD Profiles in Inclined Downward Lateral .................................... 51

4.3.2. Pressure and ECD Profiles in Inclined Upward Lateral......................................... 53

4.3.3. Comparison between Inclined Upward and Downward Laterals........................... 54

Part 2: Well Control Results ........................................................................................57

4.4. Well Control Study in Marcellus Shale Lateral................................................................. 57

4.4.1. Impact of Well Type on Typical Surface Measurements......................................... 57

4.4.2. Impact of Well Type on Slow Pump Rate and Shut-in Pressure Profile.............. 58

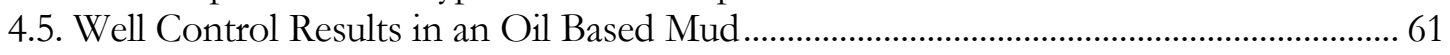

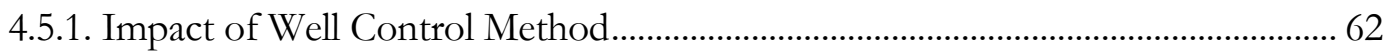

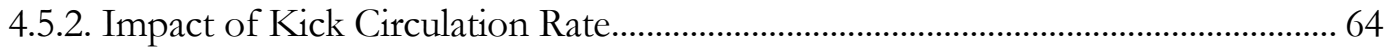

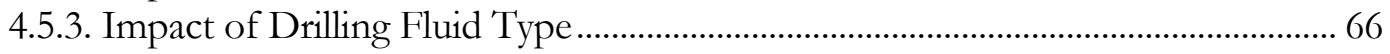

4.5.4. Impact of the Degree of Gas Solubility in Oil Based Mud ...................................... 68

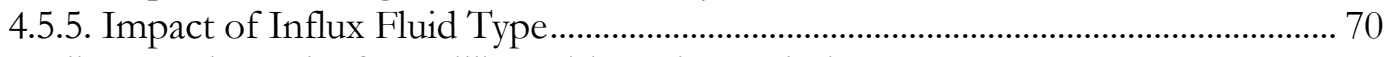

4.6. Well Control Results for Drilling with Casing and Liner.................................................. 72

4.6.1. Vertical Well Drilled with Casing/Liner ...................................................................... 72

4.6.2. Directional Well Drilled with Casing/Liner............................................................. 74

4.6.3. Horizontal Well Drilled with Casing/Liner using WBM......................................... 76

4.6.4. Horizontal Well Drilled with Casing/Liner using OBM .......................................... 79

4.7. Well Control in Inclined Upward/Downward Laterals ....................................................... 83

4.7.1. Impact of Kick Location........................................................................................... 83

4.7.2. Impact of Influx Size ............................................................................................... 86

4.7.3. Impact of Kick Circulation Rate............................................................................ 89

4.8. Marcellus and Utica shales Comparative Study and Sensitivity Analysis ........................ 93

4.8.1. Impact of Wellbore Profile...……………………………………………………...... 93

4.8.2. Impact of Well Control Method............................................................................. 95

4.8.3. Impact of Drilling Fluid Type …………………………………………………….... 96

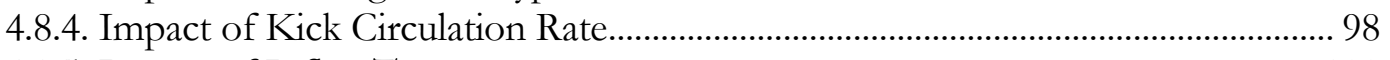

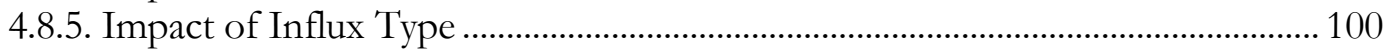

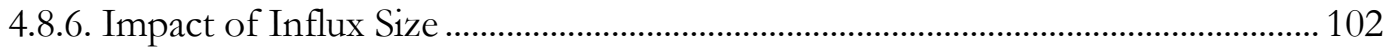

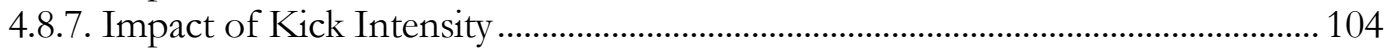

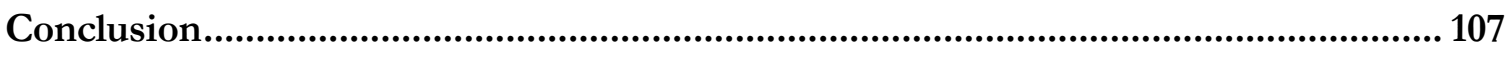

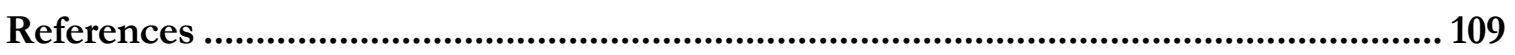

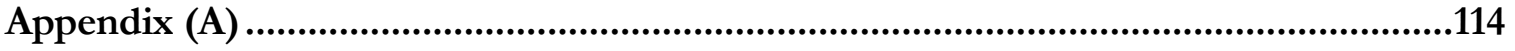

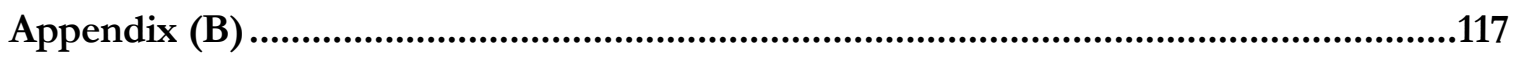




\section{LIST OF FIGURES}

Figure 2.1: Linear shear stress-shear rate plot for different hydraulics models (API RP13D, 2010)........11

Figure 2.2: Gas solubility in SBM at moderate pressures after (Lima et al., 1999). ......................................19

Figure 2.3: Gas solubility in SBM at high pressures after (Lima et al., 1999)..............................................19

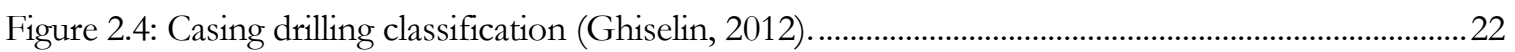

Figure 3.1: Trajectory of Marcellus X1 lateral drilled in Monongalia county, WV in 2015. .....................27

Figure 3.2: Trajectory and configuration of the horizontal well drilled with oil based mud........................28

Figure 3.3: Trajectory of the horizontal wellbore configuration for drilling with casing/liner.................29

Figure 3.4: Wellbore trajectory for flat horizontal, inclined upward, and downward laterals....................29

Figure 3.5: Wellbore trajectory for Marcellus and Utica comparative study and sensitivity analysis.........30

Figure 3.6: Full-size rig-floor drilling and well control facility at WVU..................................................... 31

Figure 3.7: Analogy between a shut-in vertical well (on left) and a U-tube model (on right).....................36

Figure 3.8: Analogy between shut-in flat horizontal well, inclined downward, and inclined upward

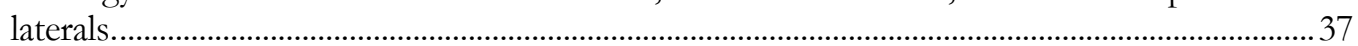

Figure 3.9: Pump pressure step-down approaches for vertical and horizontal wells..................................39

Figure 4.1: Hydraulics model verification in Marcellus X1 lateral drilled in Monongalia county, WV in

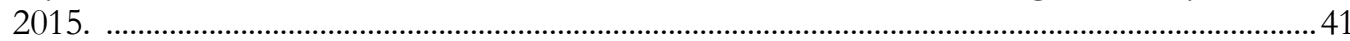

Figure 4.2: Hydraulics model correlation in Marcellus X1 lateral drilled in Monongalia county, WV in 2015.

Figure 4.3: Pressure and ECD profiles in horizontal, short, and long vertical wells................................... 43

Figure 4.4: Pressure and ECD profiles in MRCX1 at 100, 300, and 500 gpm flow rates.......................... 44

Figure 4.5: Standpipe pressure and annular pressure loss at slow pump rates in MRC X1 ........................ 45

Figure 4.6: ECD profile for vertical, directional, and horizontal wells drilled with drillpipe, casing, and liner at normal drilling flow rates up to 800 gpm............................................................................ 46

Figure 4.7: Pressure loss profiles inside the string, at bit and APL in a vertical well (a) drilled with pipes, (b) drilled with liner and (c) drilled with casing. ............................................................................4

Figure 4.8: Pressure loss profiles inside the string, at bit and APL in a directional well (a) drilled with pipes, (b) drilled with liner and (c) drilled with casing. ..............................................................4 47

Figure 4.9: Pressure loss profiles inside the string, at bit and APL in a horizontal well (a) drilled with pipes, (b) drilled with liner and (c) drilled with casing.

Figure 4.10: ECD profile and pressure loss ratio $(\mathrm{R})$ at slow pump rates in a vertical well drilled with

DwP, DwL, and DwC.

Figure 4.11: ECD profile and pressure loss ratio $(\mathrm{R})$ at slow pump rates in a directional well drilled with

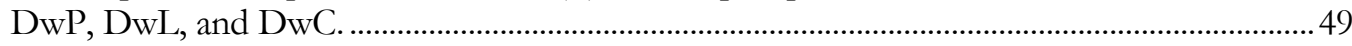

Figure 4.12: ECD profile and pressure loss ratio $(\mathrm{R})$ at slow pump rates in a horizontal well drilled with DwP, DwL, and DwC.

Figure 4.13: Pressure loss profiles inside the string, at bit and APL in horizontal well (a) drilled with pipes, (b) drilled with liner and (c) drilled with casing in OBM.................................................5 50

Figure 4.14: ECD profile and pressure loss ratio $(\mathrm{R})$ at slow pump rates in horizontal wells....................51

Figure 4.15: Pressure and ECD profiles in an inclined downward at 100, 300, and 500 gpm flow rates.

Figure 4.16: Standpipe pressure and annular pressure loss at slow pump rates in an inclined downward well... 
Figure 4.17: Pressure and ECD profiles in inclined upward at 100, 300, and 500 gpm flow rates. 53

Figure 4.18: Standpipe pressure and annular pressure loss at slow pump rates in an inclined upward well.

Figure 4.19: ECD, hydrostatic and circulating pressure profiles in $86^{\circ}$ inclined downward, $90^{\circ}$ flat and 940 inclined upward laterals.

Figure 4.20: Impact of flow rate on ECD and cutting transport ratio in inclined upward and downward laterals.

Figure 4.21: Pump pressure, choke pressure and pit gain in a horizontal well and a vertical well with the same TVD with a 20 bbls gas kick circulated at $150 \mathrm{gpm}$. 57

Figure 4.22: Choke pressure and pit gain in a horizontal well, a vertical well with the same TVD, and a vertical well with the same TD with a 20 bbls gas kick circulated at $150 \mathrm{gpm}$........................... 58

Figure 4.23: Pressure profiles at drilling (460 gpm), slow pump rate (150 spm), and shut-in conditions in a vertical well with a 20 bbls gas kick.

Figure 4.24: Pressure profiles at drilling (460 gpm), slow pump rate $(150 \mathrm{spm})$, and shut-in conditions in MRC X1 horizontal well with a 20 bbls gas kick.

Figure 4.25: Impact of pressure step-down (SD) schedule on a 20 bbls gas kick circulated at $40 \mathrm{spm}$ using Wait-and-Weights method.

Figure 4.26: A comparison between Driller's and Wait-and-Weight for 20 bbls kick circulated at $40 \mathrm{spm}$ in WBM.

Figure 4.27: A comparison between Driller's and Wait-and-Weight for 20 bbls kick circulated at $40 \mathrm{spm}$ in OBM.

Figure 4.28: Impact of circulation rates of 20, 40, and $60 \mathrm{spm}$ on pump and bottomhole pressures......65

Figure 4.29: Impact of circulation rates of 20, 40, and $60 \mathrm{spm}$ on choke and casing shoe pressures........65

Figure 4.30: Surface and downhole pressures comparison at 20, 40, and $60 \mathrm{spm}$ for 20 bbls gas kick in OBM.

Figure 4.31: A comparison between gas kick in oil based and water based muds using Driller's method at $40 \mathrm{spm}$.

Figure 4.32: A comparison between gas kick in oil based and water based muds using Wait-and-Weight

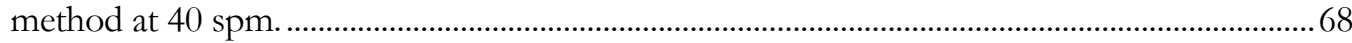

Figure 4.33: Impact of gas solubility in OBM on the choke and casing shoe pressures. ............................69

Figure 4.34: Impact of gas solubility in OBM on choke pressure when gas reaches the surface. ..............70

Figure 4.35: A comparison between water and gas kicks in an OBM using Driller's method at $40 \mathrm{spm}$.

Figure 4.36: A comparison between water and gas kicks in an OBM using Wait-and-Weight method at $40 \mathrm{spm}$.

Figure 4.37: Pump and bottomhole pressures for a vertical well controlled with Driller's method at 40 spm.

Figure 4.38: Choke and casing shoe pressures for a vertical well controlled with Driller's method at 40 spm.

Figure 4.39: Pump and bottomhole pressures for a directional well controlled with Driller's method at

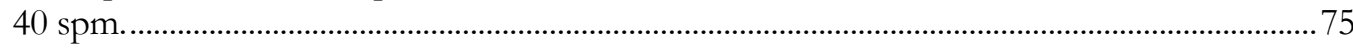

Figure 4.40: Choke and casing shoe pressures for a directional well controlled with Driller's method at $40 \mathrm{spm}$.

Figure 4.41: Pump pressure comparison for a horizontal well using Driller's method with conventional step-down and R2SD at $40 \mathrm{spm}$ in WBM................................................................................. 77

Figure 4.42: Pump and bottomhole pressures for a horizontal well controlled with Driller's method at

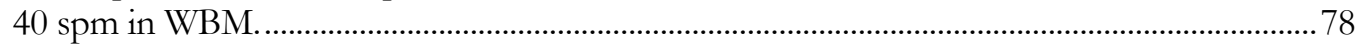


Figure 4.43: Choke and casing shoe pressures for a horizontal well controlled with Driller's method at $40 \mathrm{spm}$ in WBM.

Figure 4.44: Pump pressure comparison for a horizontal well using Driller's method at $40 \mathrm{spm}$ OBM. 80

Figure 4.45: Pump and bottomhole pressures for a horizontal well drilled with DwP, DwL and DwC and controlled with R2SD model in OBM.

Figure 4.46: Choke and casing shoe pressures for a horizontal well drilled with DwP, DwL and DwC

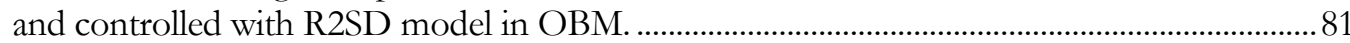

Figure 4.47: Comparison OBM and WBM in DwC 2SD Horizontal well. .................................................82

Figure 4.48: Choke pressure and pit gain at heel, midway, and toe in inclined downward lateral.............84

Figure 4.49: Choke pressure and pit gain at heel, midway, and toe in inclined upward lateral. .................84

Figure 4.50: Surface and bottomhole pressures at heel, midway, and toe in inclined upward/downward

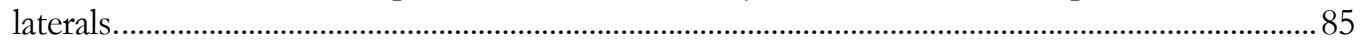

Figure 4.51: Choke pressure and pit gain comparison in an inclined downward at different kick sizes. .86

Figure 4.52: Choke pressure and pit gain comparison in an inclined upward at different kick sizes.........86

Figure 4.53: Pump and choke pressure or 20 and 40 bbls in upward/downward lateral............................ 88

Figure 4.54: Pit gain and flow rate for 20 and 40 bbls in upward/downward lateral..................................8 88

Figure 4.55: Surface and bottomhole pressures comparison at different kick sizes in inclined upward/downward laterals.

Figure 4.56: Effect of flow rate on choke pressure and pit gain in an inclined downward lateral. ...........90

Figure 4.57: Effect of flow rate on choke pressure and pit gain in inclined upward lateral. ...................... 90

Figure 4.58: Pump and choke pressures at 50 and 100 gpm flow rate in upward/downward lateral. ..... 91

Figure 4.59: Pit gain and flow rate at 50 and 100 gpm flow rate in upward/downward lateral................ 91

Figure 4.60: Surface and bottomhole pressures at different flow rates in inclined upward/downward

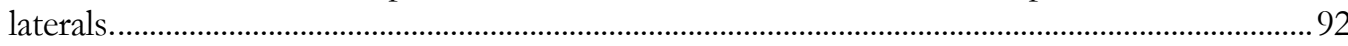

Figure 4.61: Impact of wellbore profile on choke pressure and pit gain in MRC and UTC drilled with

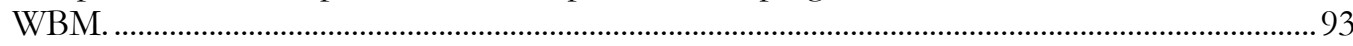

Figure 4.62: Comparison of pressures for Marcellus and Utica wellbore profiles drilled with WBM and

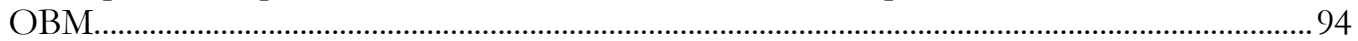

Figure 4.63: Impact of well control method on downhole and surface pressures in MRC and UTC...... 95

Figure 4.64: Comparison of pressures for Marcellus and Utica wells circulated with Driller's and W\&W

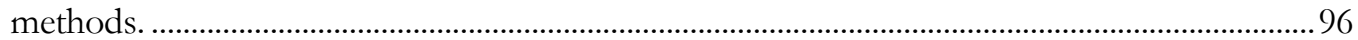

Figure 4.65: Impact of drilling fluid type on choke pressure and pit gain in MRC and UTC...................97

Figure 4.66: Comparison of pressures for Marcellus and Utica wells drilled with WBM and OBM........98

Figure 4.67: Impact of circulation rate on choke pressure and pit gain in WBM. ........................................99

Figure 4.68: Comparison of pressures for Marcellus and Utica wells at 20, 40 and $60 \mathrm{spm}$...................100

Figure 4.69: Impact of influx type on choke pressure and pit gain in OBM. ..........................................101

Figure 4.70: Comparison of pressure for Marcellus and Utica wells with different influx types.............102

Figure 4.71: Impact of influx size on choke pressure and pit gain in OBM............................................103

Figure 4.72: Comparison of pressures for Marcellus and Utica wells at different influx sizes..................104

Figure 4.73: Impact of kick intensity on choke pressure and pit gain in WBM........................................105

Figure 4.74: Comparison of pressures for Marcellus and Utica wells with different kick intensities $(1,2$

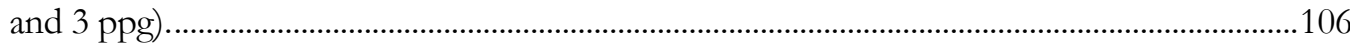




\section{LIST OF TABLES}

Table 3.1: Marcellus X1 lateral wellbore/string configurations..................................................................26

Table 3.2: Horizontal well configuration and gas kick data for oil based mud study...................................28

Table 3.3: Configurations for vertical, directional, and horizontal wells drilled with casing/Liner. .........29

Table 3.4: Marcellus and Utica wellbore configurations and sensitivity analysis parameters. ....................30

Table 4.1: Recorded surface and downhole parameters at 20, 40, and $60 \mathrm{spm}$ for 20 bbls gas kick in OBM.

Table 4.2: Surface and downhole recorded data at different gas solubility values in OBM...

Table 4.3: Surface and downhole measurements for DwP, DwL, and DwC in a vertical well controlled with Driller's method at $40 \mathrm{spm}$.................................................................................................. 72

Table 4.4: Surface and downhole measurements for DwP, DwL, and DwC in a directional well controlled with Driller's method at $40 \mathrm{spm}$...

Table 4.5: R2SD Model calculations for DwL and DwC in a horizontal well using Driller's method at $40 \mathrm{spm}$

Table 4.6: Surface and downhole measurements for DwP, DwL, and DwC in a horizontal well drilled

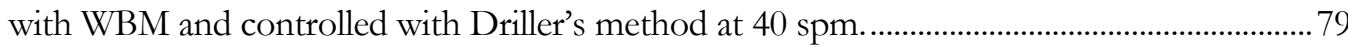

Table 4.7: Model calculations for DwL, DwC in a horizontal well using Driller's method at $40 \mathrm{spm}$.....80

Table 4.8 Surface and downhole measurements for DwP, DwL, and DwC in horizontal well drilled with OBM and controlled with Driller's method at $40 \mathrm{spm}$

Table 4.9: Surface and down-hole recorded data for different kick locations in inclined downward, flat horizontal, and inclined upward wells.

Table 4.10: Surface and down-hole recorded data for different kick sizes in inclined downward, flat horizontal, and inclined upward wells.

Table 4.11: Surface and down-hole recorded data for different circulation rates in inclined downward, flat horizontal, and inclined upward wells.

Table 4.12: Surface and down-hole recorded data for inclined upward and downward in Marcellus and Utica Shales.

Table 4.13: Surface and down-hole recorded data for Driller's and Wait-and-Weight methods in Marcellus and Utica Shales.

Table 4.14: Surface and down-hole recorded data for WBM and OBM in Marcellus and Utica Shales. 97

Table 4.15: Surface and down-hole recorded data for 20, 40, and $60 \mathrm{spm}$ in Marcellus and Utica Shales.

Table 4.16: Surface and down-hole recorded data for dry gas, condensate, and black oil kicks in Marcellus and Utica Shales.

Table 4.17: Surface and down-hole recorded data for 10, 30, and 50 bbls influx size in Marcellus and Utica Shales.

Table 4.18: Surface and down-hole recorded data for 1, 2, and 3 ppg kick intensity in Marcellus and Utica Shales. 


\section{LIST OF SYMBOLS / NOMENCLATURE}

$\begin{array}{ll}\text { APL } & \text { Annulus pressure loss, (psi) } \\ \text { BHP } & \text { Bottomhole pressure, psi } \\ \text { BOP } & \text { Blowout Preventer } \\ \text { DR } & \text { Driller's method of well control } \\ \text { DwC } & \text { Drilling with casing, casing drilling (CD) and casing while drilling (CwD) } \\ \text { DwL } & \text { Drilling with liner, liner drilling (LD) and liner while drilling (LwD) } \\ \text { DwP } & \text { Drilling with conventional drillstring (drillpipe and drill collars) } \\ \text { ECD } & \text { Equivalent circulating density, ppg } \\ \text { FCP } & \text { Final circulating pressure, psi } \\ \text { FCP' } & \text { Reduced final circulating pressure, (psi) } \\ \text { GPM } & \text { Gallons per minute (gpm) } \\ \text { ICP } & \text { Initial circulating pressure, psi } \\ \text { ICP' } & \text { Reduced initial circulating pressure, (psi) } \\ \text { KMW } & \text { Kill mud weight, ppg } \\ \text { KOP } & \text { Kick-off point depth, ft. } \\ \text { MAASP } & \text { Maximum anticipated annular surface pressure (psi) } \\ \text { MRC } & \text { Marcellus shale } \\ \text { OBM } & \text { Oil based mud } \\ \text { SBM } & \text { Synthetic based mud } \\ \text { SICP } & \text { Shut-in casing pressure, psi } \\ \text { SIDPP } & \text { Shut-in drillpipe pressure, psi } \\ \text { SPM } & \text { Strokes per minute } \\ \text { SPR } & \text { Slow pump rate } \\ \text { SPRP } & \text { Slow pump rate pressure, psi } \\ \text { STB } & \text { Surface to bit strokes } \\ \text { TMD } & \text { Total measured depth, total depth (TD), ft. } \\ \text { TU/TD } & \text { toe-up / toe-down laterals } \\ \text { TVD } & \text { Total (true) vertical depth, ft. } \\ \text { UTC } & \text { Utica shale } \\ \text { W\&W } & \text { Wait-and-Weight method of well control } \\ \text { WBM } & \text { Water based mud } \\ & \end{array}$ 


\section{CHAPTER 1: INTRODUCTION}

\subsection{Overview}

The world is facing a deficiency in conventional oil and gas resources. Consequently, the petroleum industry is moving towards development of unconventional reservoirs and the application of unconventional drilling techniques. In spite of the efforts to control formation pressures, unexpected well control emergencies still arise such as the 2010 Macondo blowout. Horizontal drilling technology is largely utilized in unconventional shale gas plays (namely: Barnett, Fayetteville, Haynesville, and Marcellus) development. When this technology is coupled with multi-stage hydraulic fracturing, it can reach trapped hydrocarbons in very low permeability shales (Kaufman et al., 2013). Basically, horizontal wells are applicable in fractured reservoirs, thin and low permeability formations, and heavy oil reservoirs (Belvalkar and Oyewole, 2010). However, kick and blowout incidents are likely to happen during drilling lateral sections when induced fractures are encountered (Ridley et al., 2013). In unconventional shale gas reservoirs, formation pressure can dramatically increase over short intervals which, if not controlled properly could lead to kicks and possibly blowouts. In the Bossier and Haynesville formations, a study of 54 kicks resulted in a kick derived pore pressure model that was utilized to predict the abnormal pressure spots and reduce drilling risks (Zhang and Wieseneck, 2011).

Shale gas production commenced in 2000 and rose to 7.5 TCF in 2011, that is $30 \%$ of USA production, and is expected to increase to $50 \%$ by 2040 (EIA, 2016). Marcellus shale activity has been ongoing since 2003, and more recently 12,000 wells were drilled by 2011 (Carr et al., 2013). The combined production of Marcellus and Utica players located in the states of Ohio, Pennsylvania, and West Virginia is about 19 BCF per day (Ozkan and Duman, 2015). Utica shale is challenging due to its high reservoir heterogeneity, complex bedding planes, high clay content, high pressure and temperature with hydrocarbon fluids ranging between oil, condensate, and dry gas (Can et al., 2014). 
Recently, low gas prices imposed multi-well pads with complex profiles and as a result drilling various sections in one bit run with a negative vertical section is intensely applied (Livingston et al., 2016). Operators achieved drilling records in extended laterals of a mile in a 24-hr period (El Hakam et al., 2014; Maranuk et al., 2014). Nevertheless, there are drawbacks, for instance, in Marcellus shale between 2008 and 2010, records show that 2,600 violations have been committed and $80 \%$ are environment potential threats. Inadequate safety devices and no certified Blowout Preventer (BOP) operator represent $10 \%$ of violations with the highest value in risk-ranking (Olawoyin et al., 2012). In addition, surface impact of drilling infrastructure and pads necessitates obligatory federal and state permits for water streams in Pennsylvania (Krauss, 2013). Gas bubble migration through unset cement jeopardizes well integrity and zonal isolation. However, mechanical damage and gas migration through unset cement results in sustained casing pressure which needs costly remediation and reduces productivity (McDaniel et al., 2014).

The wellbore is orientated, toe-up or toe-down (TU/TD) to maximize reservoir contact by following the dip of geologic beds. Browning and Jayakumar (2016) studied the impact of toe-up or toe-down orientation and lateral total vertical depth (TVD) change on $300+$ wells in Oklahoma. Toe-up wells present high production rates, flat wells present low production rates, and toe-down laterals present even lass production rates. Drilling downward laterals results in a significant production loss of $30 \%$ of the estimated ultimate recovery at the economic limit (Browning and Jayakumar, 2016). Experimental results showed that under stable production conditions, toe-up is the best configuration for liquid production (Brito et al., 2016a). However, at very slow gas flow rates, liquid slug accumulates at the heel and gas accumulates at the toe. Gas pressure built up until overcoming the liquid hydrostatic pressure, then the gas blew out and cause production surges. These unstable cycles cause significant fluctuations in pressure, liquid holdup and gas and liquid flow rates which reduces recoverable reserves (Brito et al., 2016b). Meanwhile, toedown laterals present the largest liquid surge challenge with the lowest efficiency in production from toe to heel (Brito et al., 2016a). 


\subsection{Well Control Philosophy}

Several conditions can result in a kick, including: insufficient mud weight, abnormal pressure zones, improper swabbing, severe loss of circulation, and improper hole fill-up during tripping out (Watson et al., 2003). Upon receiving an influx, an increase in the mud return flow rate is a direct sign of the kick. A positive flow check which means there is a return flow when the pumps are stopped is a solid kick indicator. Early kick detection is critical in minimizing the influx volume and to subsequently reducing surface and casing shoe pressure during the kill operation (Nas, 2011). Once the wellbore goes underbalanced, the formation fluid will start kicking. The blowout preventer (BOP) should be immediately closed using soft or hard shut-in method. This is to secure the well and to minimize the kick size and associated surface and downhole pressures (Jardine et al., 1993).

The mud displacement in a wellbore can be visualized as a U-tube model. Starting with mud pump, the drillpipe and drilling assembly are on one side, and the annular sections ending with the variable choke is on the other side of the U-tube. The bit is at the mid-point and located at the lowermost section of U-tube representing the bottomhole at total depth (TD). The main goal in well control is to keep the bottomhole pressure constant during kick circulation in order to prevent new kick fluids from entering the wellbore (Grace, 2003). The two commonly used methods for kick control are Driller's and the Wait-and-Weight methods.

The advantages of the Driller's method are the simple calculations and the lack of waiting time due to mud preparations. Additionally, it can control swabbed gases without the need to increase mud weight (Choe et al., 2005). The drawbacks are longer circulation time, and higher pressures in the annulus and at the casing shoe with the risk of fracturing the formation. The benefit of the Wait-and-Weight method is the lower annulus pressure because the heavy mud reaches the annulus before the kick reaches the casing shoe. The disadvantage of the Wait-and-Weight method is the waiting time for mud preparation which may result in gas migration in water based mud and gas solubility in oil based mud. Furthermore, a step-down chart calculation is difficult in deviated wells (Grace, 2003). 
Without proper well control knowledge and implementation, an uncontrolled kick can be financially catastrophic for the company. It can result in rig time and/or equipment loss, injury or loss of life for workers, and environmental disaster. This creates a negative image of the industry such as the Macondo blowout in the Gulf of Mexico (Turley, 2014). The possibility of taking a kick in a horizontal well is higher than a vertical well and the specific wellbore geometry affects the well control operations. One of the major differences between vertical and horizontal sections in a wellbore is the gas migration rates. Furthermore, circulation rates may not be high enough to move gas bubbles along the horizontal sections. Studies show that the gas slip velocity is highest when the inclination angle is $45^{\circ}$, and it will decrease to zero in a horizontal wellbore with a $90^{\circ}$ of inclination angle (Watson et. al. 2003).

In extended reach horizontal wells, the drilled length is greater than the vertical depth starting at a build section. Another important aspect of the horizontal wellbore is the high equivalent circulating density (ECD) values due to increased annulus pressure loss with increase in wellbore length at the same vertical depth. Well control simulators are used as a tool for drilling, well control planning, and operations. In the well planning phase, the simulator evaluates different designs based on specified limits such as kick tolerance. In operations, the simulator supports critical decisions when the designed operational parameters change. It can also be used to evaluate difficult well control scenarios and improve kick handling skills $(\mathrm{Ng}, 2005)$.

\subsection{Background on Gas Solubility in Oil Based Mud}

Analysis of 225 Marcellus and 238 Haynesville horizontal wells from 20062011 showed that oil based mud (OBM) was applied in $75 \%$ of the wells. This high use of OBM is attributed to its high drilling performance, shale inhibition, and stability at higher pressures and temperatures. Though, strict environmental regulations introduced high performance water based muds (WBM) in 36\% of Marcellus wells. In the Haynesville and Marcellus wells, the main drilling problems are poor hole cleaning and lost circulation. The intersection of natural and induced fractures during drilling resulted in controllable kicks in the Haynesville Shale (Guo et al., 2012b). 
Field reports show that the mud density window is between 12 to $15 \mathrm{ppg}$ in Marcellus and 15 to 17 ppg in Haynesville (Guo et al., 2012b). Analysis of 203 wells in the Eagle Ford Shale drilled between 2008 and 2011, shows $76 \%$ of the wells were drilled with OBM with a wide range of mud weight from 9 to $16 \mathrm{ppg}$. In shales, OBM performs better than WBM with 20 to $40 \%$ less drilling time, while saturated salt mud has 30 to $35 \%$ less drilling time (Guo et al., 2012a). Synthetic oil based mud (SBM) was used over the last decade in offshore drilling as its environmental impact is less compared to OBM, but the gas solubility is higher. SBM is an oil-water emulsion with $60-70 \%$ oil (Monteiro et al., 2010). The main disadvantage of drilling with OBM/SBM is the significant degree of gas solubility. Dissolved gas in oil masks the surface responses, and kick undetectably migrates. Dangerous volumes of gas are released over short periods of time which is a challenge for the drilling crew (Lima et al., 1999; Ribeiro et al., 2006).

\subsection{Drilling with Casing and/or Liner Background}

Recently, as the oil prices dropped, the oil and gas industry considered the application of unconventional drilling techniques. Drilling with casing (DwC) and drilling with liner (DwL) technologies have been used to minimize drilling time and total costs. In DwC and DwL, surface and downhole equipment are different than conventional drilling with drillpipe and drill collars (Salehi et al., 2013). A standard oilfield casing/liner attached to a special bottomhole assembly (BHA) is used as a drillstring so that a well is simultaneously drilled and cased. The main advantage of $\mathrm{DwC} / \mathrm{DwL}$ technology is eliminating the costs of purchasing, handling, inspecting, transporting, and tripping related problems of drillpipe (Aadnoy et al., 2009).

In small annular clearances where the pipe/hole diameter ratio is high, drilling fluid hydraulics and cutting circulation are unconventional. For instance, the smear (plastering) effect is the action of drilled cuttings being smeared and compressed against the borehole wall creating a low permeable barrier. This solid mud cake improves fracture gradient and minimizes formation damage. It also contributes to wellbore strengthening and stability and prevents drilling fluid loss to depleted zones by sealing micro cracks (van Oort and Razavi, 2014). 
Although the exact mechanism of the smear effect is not known, pipe size, annular clearance, rotary speed, mud type and penetration rate are the parameters that affect it (Kiran et al., 2014). Researchers reported that DwC technology showed a 10\% reduction in cost and 30\% savings in time (Lopez and Bonilla, 2010; Sánchez et al., 2012). Other investigators showed that lost circulation was significantly reduced (Fontenot et al., 2003; Karimi et al., 2011) and stated that fracture gradient and wellbore strengthening were improved (Salehi et al., 2013). Examples of successful field application of DwC technology were published (Aadnoy et al., 2009; Radwan and Karimi, 2011). Different approaches to simulate the smear "plastering" effect associated with the success of DwC/DwL technologies has been presented by several researchers (Arlanoglu, 2011; Mokhtari et al., 2013; Satkan, 2013; Kiran et al., 2014). A recent study investigated well control procedures in horizontal wells drilled with casing and proposed a neural network model for real-time application (Elshehabi, 2015).

In contrast, casing/liner dynamic loads (like torque and drag) are high due to string weight and large pipe diameter. Lateral vibration of whirl is the most damaging vibration mode which cause fatigue failure at the coupling. Furthermore, torsional oscillation is relatively common in harder rocks which damages the connections, and in the worst case it initiates stick/slip scenario (Aadnoy et al., 2009). Centralization of casing during cementing is a major operational concern (Galloway, 2004). As the pump starts and flow rate increases the hook-load starts decreasing due to the hydraulic lift force acting on the bottom of the casing string which reduces the weight on bit. Also, pipe movement during connections might cause severe surge and swab if the flow rate is not reduced. In a tight annulus situation, fluid flow characteristics and drilling fluid rheological properties influence the friction loss profile, equivalent circulation density (ECD) and resultant annulus pressure loss (APL) (Aadnoy et al., 2009). 


\subsection{Problem Statement}

In fact, the philosophy of well control is to keep the bottomhole pressure constant by balancing the formation pressure throughout kick removal and heavy mud displacement. In conventional vertical well control practices, annular pressure loss (APL) is commonly considered negligible at slow pump rates. As a result, while the heavy mud density s filling the drillstring, pump pressure is stepped down as a straight line from initial to final values. This was considered as a hidden safety factor to overbalance the formation pressure. Nevertheless, in horizontal wells, there are well control challenges such as the hole deviation, high annular pressure loss, gas solubility in oil based mud, and wellbore configuration. In horizontal wells, friction loss is a function of the measured depth; however, heavy mud backpressure is a function of the true vertical depth. In addition, in tight annulus situations such as in drilling with casing or liner, APL is relatively high at slow pump rates and the pressure loss profile is inverted. Furthermore, drilling horizontal wells with OBM with gas solubility creates additional challenge since surface measurements do not represent the downhole conditions. Drilling inclined upward lateral presents an additional hydraulics and well control concern. Thus, as a step towards better understanding well control, it is crucial to examine pressure profiles and hydraulics at slow pump rates. It is also critical to develop and verify a reduced pump pressure step-down model that takes high APL into consideration.

\subsection{Objectives}

The main objective of this study was to investigate mud hydraulics and well control complications in unconventional shale laterals. The specific objectives are:

1. Build a hydraulics base model and verify it with the actual data from the Marcellus lateral drilled in Monongalia County, WV in 2015.

2. Utilize this hydraulics model to examine static and dynamic pressure profiles for drilling at high flow rates and compare it to well control slow pump rates and shut-in conditions.

3. Investigate mud hydraulics and hole cleaning parameters in inclined upward laterals and compare them to the parameters in inclined downward laterals. 
4. Study pressure loss profiles and hydraulics in relatively tight annulus cases such as drilling with casing and liner strings.

5. Investigate the impact of gas solubility in oil based mud on surface and downhole measurements and gas influx behavior.

6. Apply different pump pressure step-down schedules while the heavy mud is displacing the drillstring in wells drilled with casing or liner.

7. Develop and verify a model that takes into consideration the high annular pressure loss.

8. Study well control complications in inclined upward laterals and compare them with the complications in inclined downward laterals.

9. Perform a comparative study and sensitivity analysis for Marcellus and Utica Shale laterals including various kick characteristics and operational parameters.

\subsection{Dissertation Outlines}

The dissertation is organized into four main chapters. It starts with chapter one which provides an introduction, background, problem statement, and objectives. Chapter two is the literature review and it describes the work by previous authors. This includes well control, gas solubility in oil base mud, and drilling with casing/liner technology. Chapter three illustrates wellbore configurations, the detailed methodology, and the reduced two-stage step-down model derivation. Chapter four presents the results and the discussion of hydraulics and well control complications. This includes inclined upward and downward laterals, gas solubility in oil based mud, and drilling with casing/liner. In addition, it includes well control comparative and sensitivity analysis in Marcellus and Utica shale laterals. Chapter four is followed by the conclusion, references citations, and appendices. 


\section{CHAPTER 2: LITERATURE REVIEW}

\subsection{Kicks and Blowouts in Unconventional Shale Players}

Kick and blowout incidents are undoubtedly occurred during drilling horizontal sections when natural and induced fractures are encountered. In the Haynesville shale, a study of 54 kicks showed pore pressure dramatically rise over short intervals to a surprisingly elevated geopressure equivalent to $18 \mathrm{ppg}$ which leads to dangerous kicks and potential blowouts (Zhang and Wieseneck, 2011). In Texas, in unconventional shale, blowouts frequency from 2009 to 2013 was higher than in conventional wells. Blowouts in 2013, in unconventional gas wells, were $200 \%$ higher than in conventional gas wells. In unconventional oil wells, blowouts rate was $300 \%$ higher (Bidiwala and Orr, 2014). Reports claimed that blowouts frequency is between 25 - 31 per 10,000 well in shale gas wells. In the Barnett Shale between 2004 and 2014, blowouts frequency was 1.3 per 10,000 well. While, in the Bakken Shale, the frequency varied from 1 to 30 per 10,000 well (Duncan, 2016).

The Eagle Ford field reports indicate well control non-productive time (NPT) is $20 \%$ of total well cost with a pore pressure of 14 ppg while underbalanced drilling was used with $11 \mathrm{ppg}$ OBM (Ridley et al., 2013). Kicks and loss of circulation through induced and micro-fractures challenge drilling operations (Guo et al., 2012a). Induced fractures in the Eagle Ford caused by offset shut-in wells undergoing hydraulic fracture resulted in well control problems. This is because hydrocarbons prefer to flow towards the least resistance path. Well control challenges were faced in the form of increased gases in the mud while drilling. Excessive return flow rates were observed before pulling out of hole $(\mathrm{POOH})$ due to reservoir connectivity via nearby hydraulic fractures. Likewise, high mud flow rates caused self-induced losses because of wellbore breathing and ballooning. However, the ballooning effect can be distinguished from reservoir kicks by means of Horner plots. Therefore, in the Eagle Ford, fracture strength at the casing shoe is $17 \mathrm{ppg}$ which is considered sufficient for kick tolerance (Ridley et al., 2013). 


\subsection{Drilling Fluid Rheology and Hydraulics}

Rheology studies the flow or deformation of liquids in particular nonNewtonian fluids. Normally, it defines fluid flow in terms of shear stress and shear rate. Hydraulic models define the drilling mud flow behavior using mathematical equations. Basically, these models define the pressure drop as a function of flow rate for a given fluid properties and conduit geometry. In addition, this pressure-flow rate relationship depends on the type of flow regime (Guo and Liu, 2011). The flow regime directly affects the behavior of drilling fluid and its capability to accomplish essential functions. Based on the fluid velocity, density and viscosity, the flow regime can be defined as laminar, transition or turbulent. In the laminar flow regime, fluid moves in smooth lines that are parallel to the walls of the conduit. Higher fluid velocity and viscosity require higher pressure (Mitchell and Miska, 2011). In the turbulent flow regime, fluid is spinning while moving. Wall roughness, high velocity and low viscosity increase the amount of fluid turbulence. The higher the fluid density, the higher the pressure needed to sustain flow. However, the pressure increase is a function of the square of velocity. At the critical velocity, the flow regime changes from laminar to transitional. This occurs at Reynolds number range between 2,000 and 4,000 (API RP13D, 2010).

The primary functions of the drilling fluid are overbalancing formation pressures and cleaning the drilled cuttings. In addition, drilling fluid improves wellbore and shale stability through mud properties, flow, and associated pressures. If mud circulating pressure exceeds the formation strength, lost circulation occurs and drilling cost increases. However, if the hydrostatic pressure drops below the formation pressure, a kick develops from formation fluids. The risk of an uncontrolled blowout arises If the kick is not controlled properly (Bourgoyne et al., 1991; Mitchell and Miska, 2011). Drilling fluid rheological properties are essential in hydraulics calculations. These properties are measured using 6-speed viscometers and defined by rheological models (Aadnoy et al., 2009). Analytical rheological models such as Newtonian, Bingham Plastic, and Power Law are shown in Figure 2.1. Rheological models are intended to provide assistance in characterizing fluid flow. 


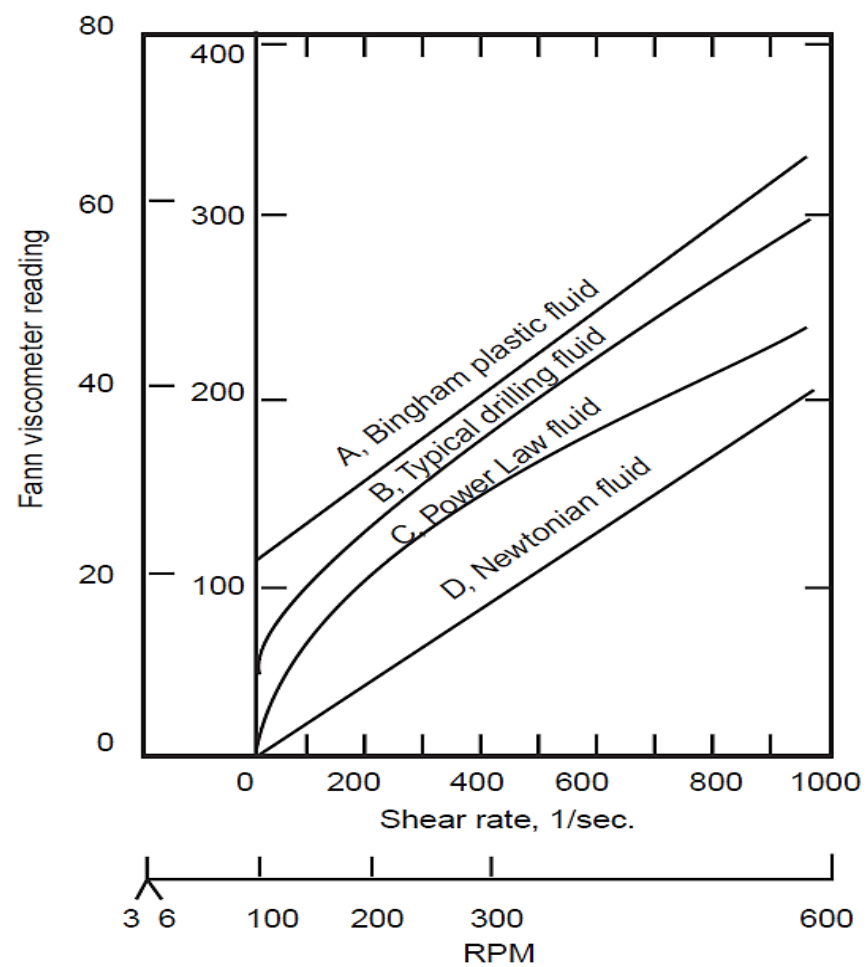

Figure 2.1: Linear shear stress-shear rate plot for different hydraulics models (API RP13D, 2010).

The Bingham Plastic model (shown as straight line, A) defines a linear shear stress-shear rate ratio after exceeding a threshold shear stress. Basically, this model depends on two parameters known as "plastic viscosity" and "yield point". This model characterizes fluids in the higher shear-rate range (Guo and Liu, 2011). The Power Law describes shear thinning or pseudo-plastic drilling fluids (shown as curve, C). When plotted on a log-log graph, this model is a straight line. Since a true Power Law fluid does not exhibit a yield stress, this line has no intercept. The Power Law model depends on constants known as $\mathrm{n}$ and $\mathrm{K}$. The majority of drilling fluids are not well approximated by neither the Bingham Plastic or the Power Law models. No single two-parameter model entirely describes realistic drilling fluids rheological characteristics over the whole shear rate range (Mitchell and Miska, 2011). However, the Herschel-Bulkley model, known as the "Yield-Power Law", is a threeparameter model that represents many drilling fluids (Aadnoy et al., 2009). This model describes the pseudoplastic drilling fluids that require a yield stress to initiate flow (API RP13D, 2010). 
Fruhwirth et al. (2006) suggested the use of neural networks to predict realtime drilling hydraulics. Likewise, Wang and Salehi (2015) proposed a neural network model to accurately predict pump pressure in vertical wells. However, in horizontal wells with complex wellbore/drillstring geometry, there is a need for advanced models to predict the hydraulics on a real-time basis.

\subsection{Well Control Philosophy}

Abnormal pressure zones and using improper mud density are the main causes of kicks during drilling. In addition, while tripping, moving the drillstring too fast results in gas swabbing or surge and total loss of circulation and can consequently develops a kick. However, early kick detection through monitoring the increase in surface mud volume and flow rate is critical. This way, the influx size and resultant wellbore pressures are minimized (Mitchell and Miska, 2011). Once a kick is detected, the BOP is closed to prevent further kicks, and the stabilized drillpipe and casing pressures are recorded. Then, the selected well control method keeps the bottomhole pressure constant by overbalancing the formation pressure, while circulating the influx out of the hole, and filling the wellbore with the heavy mud (Watson et al., 2003). Operation delays for any reason permit gas bubbles migration in water based mud. In addition, gas dissolves in oil based drilling fluids with a possibility of exceeding casing shoe pressure (Tarvin et al., 1991).

In water based mud, during gas migration in a closed well, the assumption of kick remains as a continuous gas slug is unacceptable (Matthews and Bourgoyne, 1983). According to Rader et al.'s (1975) experimental work, the critical factors affecting bubble rise velocity are annulus/drillstring configuration and gas expansion rate. In addition, gas migration speed is impacted by wellbore deviation angle, gas and liquid viscosities and densities. Neglecting wellbore elasticity and mud compressibility results in gas migration speed inaccuracy. Gas migrates at a speed of $6000 \mathrm{ft} . / \mathrm{hr}$ when the gas concentration is more than $10 \%$ of the void fraction. Thus, mud compressibility increases because a trail of suspended stationary gas bubbles is trapped by mud. Gas bubble velocity of $900 \mathrm{ft} . / \mathrm{hr}$ or slower and in some cases, it remains stationary is reported in the oilfield (Johnson et al., 1995). 
In contrast, gas dissolves in synthetic oil based mud at high pressure and temperature conditions downhole. Gas solubility impacts surface kick indicators and kick circulation procedure. While dissolved gas is circulated out, massive free gas volumes are released at the bubble point. This always happen in the upper part of the wellbore between 1,000 to 2,000 ft (Adams and Kuhlman, 1994). In fact, the higher the wellbore pressure and gas specific gravity, the higher the degree of solubility. However, increasing temperature, solid content and water/oil ratio decreases gas solubility (O'Bryan et al., 1988). Methane is fully miscible in diesel, mineral, synthetic, and ester oils when pressure is above the miscibility pressure and paraffinic oil shows higher solubility than ester oil (Monteiro et al., 2010).

\subsubsection{Kick Causes and Detection}

Despite the best well control practices to keep formation fluids under control, kicks still occur and may even be anticipated in the well design. The primary well control line of defense is the hydrostatic pressure of the drilling fluid. If this barrier fails, the secondary well control barrier includes detecting the kick, shutting the well in using the BOP, then removing the influx using a proper well control technique. The primary reason for taking a kick while drilling is insufficient drilling fluid density. This happens either by using a lighter weight mud or by excessive gas bubbles contaminating the mud. In addition, kicks can occur as a result of fluid column height reduction during total loss of circulation. Furthermore, during tripping out, moving the pipes too fast creates a vacuum, causing the bottomhole pressure to drop and consequently swabbing starts. However, the main cause of kicks when tripping the drillpipe out is not filling the hole with enough mud to maintain the mud level. Wellbore collision with a producing well is another reason for kicks. Finally, encountering an unpredicted abnormal pressure zones also leads to a kick (Adams and Kuhlman, 1994; Watson et al., 2003). Among these causes of kick, only the swabbing and the improper hole filling during tripping can be controlled by upholding the tripping standard procedure. All surface indications of underbalanced bottomhole pressure that leads to a kick or blowout should be closely monitored. 
A sudden increase in the drilling rate of penetration (ROP) can indicate a soft formation or underbalance conditions. An increase in mud pit volume and return flow rate are also considered positive indicators of a kick. In fact, a flow check performed by detecting the existence of a return flow while pumps are stopped is the most solid evidence of kicks (Watson et al., 2003). In a floating offshore rig, kick observation is difficult due to currents and wave motions. In addition, this is coupled with long marine risers and deeper water depths (Johnson et al., 2014).

Early kick detection is vital in minimizing the kick size and subsequently reducing surface and bottomhole pressures during well control operations. A recent example is the Macondo well where a major blowout occurred at the Deepwater Horizon offshore drilling rig. It is reported that the crew changed the wellbore fluids with salt water for temporary abandonment. Hence, reducing the hydrostatic pressure was the main cause of the events that resulted in a catastrophe where loss of life occurred. There was a positive indicator of the kick when the flow of formation fluids far exceeded the pumped seawater injection rate. Crew was too late to recognize the events which prevented proper closing of the BOP (Turley, 2014).

\subsubsection{Well Control Methods}

Once a kick is confirmed, the well must be shut-in via one of the two widely used methods. These methods are soft shut-in and hard shut-in. In a soft shut-in, the remote choke should be in the open position. Then, the BOP is closed, the high closing ration (HCR) valve is opened, and the remote choke is closed followed by recording pressures. On the other hand, in a hard shut-in, with the remote choke is already close, the BOP is shut-in and the HCR is opened and followed by recording of pressures (Watson et al., 2003). Whereas, closing the BOP with a closed choke creates a backpressure wave in the form of "water hammer". This water hammer has been claimed to fracture depleted zones and results in underground blowouts. However, studies show that the water hammer is negligible in deep water and long wellbores. In contrast, the soft shut-in extends closing time and increases kick volume and eventually results in higher wellbore pressures (Jardine et al., 1993). 
Mud displacement in a wellbore can be visualized as a u-tube (Watson et al., 2003). Starting with mud pump, the drillpipe and drilling bottomhole assembly is on one left side and on the right side of the u-tube there are the annular sections between drillstring and openhole/casing ending with the variable choke. The drill bit nozzles are at the mid-point located at the total depth. Well control main objective is to maintain a constant bottomhole pressure based on the u-tube model. This way, it prevents secondary kicks or casing shoe fracturing during well control operations (Mitchell and Miska, 2011).

The industry adopted two well control methods known as the Driller's (the two circulations) method and the Wait-and-Weight (W\&W) (the one circulation or the Engineer's) method. In first circulation of the Driller's method, the influx is removed from the hole, and then the heavy mud is pumped in the second circulation (Bill, 1995). The Driller's method needs simple pressure calculations, and it starts immediately after shutting-in the BOP. The Driller's method controls the swabbed gases in one circulation without the need to increase the mud weight. The drawbacks of the Driller's method are the longer operation time needed for two circulations and the higher pressures experienced at the choke and the casing shoe (Watson et al., 2003).

In the Wait-and-Weight method, the heavy mud is pumped to circulate the kick out simultaneously. A pump pressure step-down scheme from initial to final circulating pressure is calculated. A waiting period is needed to increase the mud density (Bill, 1995). Pumping the heavy mud into the wellbore while circulating the kick out decreases the downhole and surface pressures. This only happens when heavy mud reaches the annulus before gas influx passes the casing shoe. Waiting for mud preparation escalates the chance of gas migration and pressurizing the wellbore (Grace, 2003). Moreover, the step-down chart calculations in deviated wells are complicated (Santos, 1991b; Choe et al., 2005). Although, in vertical wells, Wait-and-Weight method decreases wellbore pressures, in horizontal wells Driller's method is applied to avoid delay time. In addition, it avoids step-down chart complications and circulates swabbed gas in the first circulation only. 
In horizontal wells, kick tolerance is greater. In addition, wellbore geometry, influx size and flow rate influence well control procedures (Santos, 1991a). The selection of the proper pump pressure step-down chart while heavy mud is displacing the drillstring section is critical and depends on wellbore/string configurations. Hence, a vertical well step-down is invalid for horizontal wells (Santos, 1991a). In multilateral trajectories, step-down charts are complex and need to be computer generated (Choe et al., 2005). Driller's and W\&W methods assume the gas invades the wellbore as a continuous slug and remains at the bottomhole with no migration. These methods also assume that gas mass is constant, therefore, there is no absorption to mud or adsorption to solids. Further, these methods assume that frictional pressure losses in the annulus are negligible at slow pump rates (Bill, 1995; Watson et al., 2003).

\subsubsection{Previous Well Control Studies}

Ekrann and Rommetveit (1985) simulated gas kicks behavior in oil based mud in a vertical well. Pressure, flow velocities, and free/dissolved gas content were the dependent variables. The algorithm successfully simulated the kick development. However, the choke operation caused numerical solution convergence problems. Santos (1991b) studied well control in horizontal wells and deep water wells. He developed a two-phase well control simulator for water based drilling fluids. He concluded that in horizontal wells, choke pressure remains constant at a value close to shut-in casing pressure for a longer period. Kick size, annulus geometry, and kick circulation rate are the main factors affecting choke pressure. However, as a result of well geometry, well control operations are harder in horizontal wells as well as a more complex pump pressure step-down schedule. Yet, horizontal wells have greater tolerance to take a kick without exceeding casing shoe fracture in comparison to vertical wells (Santos, 1991a). Wang et al. (1994) studied gas kicks in a water based mud while drilling horizontal wells. Their model couples the gas influx from the kicking formation with fluid flow along the horizontal section. This flow occurs during kick development and shut-in phases. 
Wang et al. (1994) concluded that mud return flow rate is the most sensitive kick detection parameter. Also, in horizontal wells, the Wait-and-Weight method is not effective. The reason is the heavy mud reaches the annulus after gas reaches the surface and the maximum choke pressure have already occurred. Rommetveit et al. (1995) studied two phase flow in horizontal wells using surface flow loop experiments. Their examination showed that for horizontal wells, vertical and inclined wells gas transport models are not valid. They derived new gas transport velocity and frictional pressure loss correlations based on the flow loop data.

Choe (1995) developed a dynamic two-phase flow simulator for horizontal wells and multilateral trajectories. The finite difference numerical scheme was used to solve the conservation of mass, momentum equations, and equation of state. He concluded that gas velocity, wellbore geometry, and formation permeability impact kick pressure behavior. Moreover, pressure build-up during initial shut-in period is accurately represented considering drilling fluid compressibility (Choe, 1995; Choe, 2001; Choe et al., 2005).

Gjorv (2003) studied well control in extended reach wells. He recommended the hard shut-in method followed by the Driller's method for kick circulation. A high pump rate was proposed to remove the gas kick from the horizontal section. During gas circulation, once the casing pressure starts increasing, the kill rate should be reduced to $1 / 2$ to $1 / 3$ of normal drilling rate. He concluded that the kick size and circulation rate significantly impact wellbore and surface pressures.

\subsection{Gas Solubility in Oil Based Mud}

Gas tends to dissolve in drilling fluids, however, in water base mud the solubility is insignificant. Gas Solubility (scf/bbl) defines the amount of dissolved gas in solution at a given pressure and temperature. Soluble gases include $\mathrm{CO}_{2}$ and $\mathrm{H}_{2} \mathrm{~S}$ that are soluble in both water and oil. Nevertheless, solubility in oil based mud is higher. Temperature, pressure, and composition define the degree of gas solubility (Watson et al., 2003). Thomas et al. (1984) studied gas solubility in oil based mud experimentally. They concluded that mud pit gain is still a reliable indicator of kicks. However, pit levels should be designed to detect less than 5 bbls. 
In water based mud, gas solubility is less than $1 \%$ compared to oil based mud. Therefore, the solubility of gases in water based mud can be safely ignored. Free gas migrates and exceeds the mud speed, meanwhile dissolved gas does not migrate. In oil based mud, gas dissolves into the mud and masks the actual mud return rate. Thus, an existing kick might be ignored if only the mud return flow rate was considered as the kick indicator (Thomas et al., 1984).

O'Bryan et al. (1988) concluded that in the last 2,000 ft. of a wellbore, the gas liberation problems occur. Solubility of gas in oil based mud increases with downhole pressure and gas specific gravity. Nevertheless, the higher the temperature, solids content, and water/oil ratio the lower the gas solubility. Additionally, at low pressures, the oil composition has an insignificant impact on the degree of gas solubility (O'Bryan et al., 1988). Swanson et al. (1988) studied solubility in invert emulsion drilling fluids at pressures and temperatures up to $15,000 \mathrm{psi}$ and $350^{\circ} \mathrm{F}$. Their model showed that kick volume, mud flow rate, downhole pressure and temperature define surface pit gain. Adams and Kuhlman (1994) stated that gas dissolves in the oil and pit gain is not representing the actual kick size. For example, a 4-6 bbls surface pit gain can only be detected while a 20 bbls kick is developed at the downhole conditions (Adams and Kuhlman, 1994).

Berthezene et al. (1999) studied the solubility of methane in diesel, mineral, synthetic, and ester oils. The Peng-Robinson equation was used to model the critical parameters and to extrapolate the experimental data. They concluded that below the critical pressure the methane solubility depends slightly on oil composition. The critical pressure is the pressure where complete miscibility occurs. This pressure is between 7,252 and 10,152 psi at $190^{\circ} \mathrm{F}$. However, the miscibility pressure in ester oil is the highest. Above the miscibility pressure, gas is fully miscible in oils. Lima et al. (1999) concluded that in synthetic oil based mud, gas solubility is a linear function at low pressures as shown in Figure 2.2. However, Figure 2.3 shows the miscibility pressure for methane-synthetic oil mixture around the critical pressure of 7,600 psi. This chart shows that methane solubility goes to infinity above 7,600 psi. 


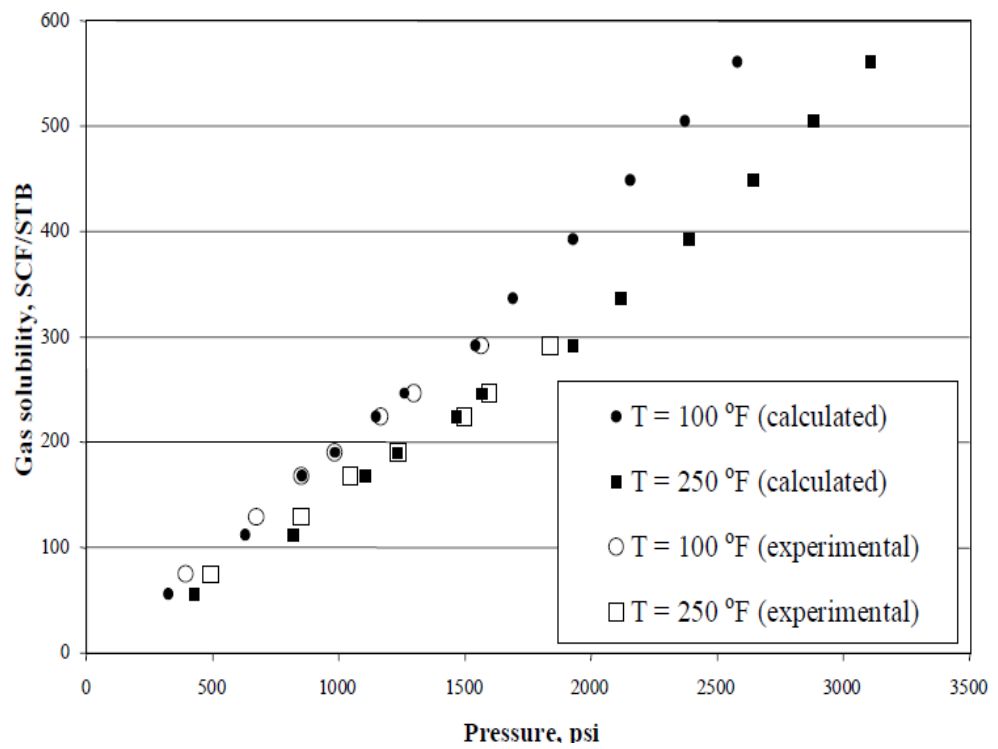

Figure 2.2: Gas solubility in SBM at moderate pressures after (Lima et al., 1999).

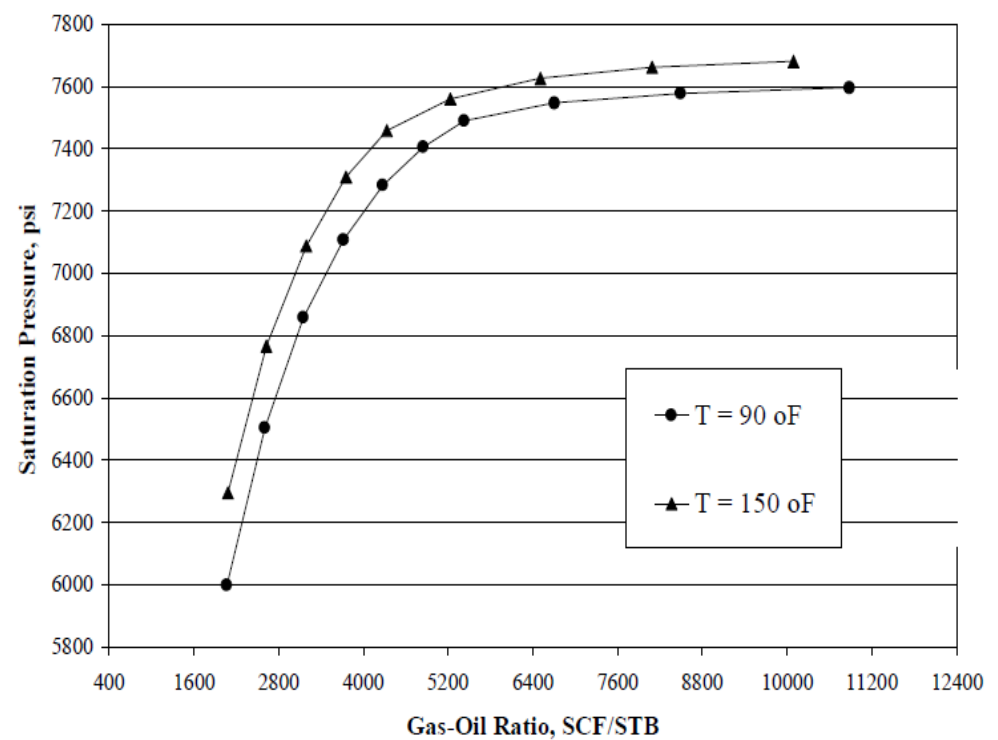

Figure 2.3: Gas solubility in SBM at high pressures after (Lima et al., 1999).

Lima et al. (1999) claimed that a 10 bbls influx at the bottomhole conditions shows only as 8.5 bbls at the surface regardless of mud compressibility. Bradley et al. (2002) studied gas diffusion in horizontal wells drilled with oil based mud. They concluded that gas diffuses into the wellbore if mud is undisturbed for a period of time. For instance, in an 8.5" hole, 5 bbls of methane can diffuse in 6 hours. In addition, 18 bbls diffuses in 24 hours with an influx rate of $0.9 \mathrm{bbl} / \mathrm{hour}$. 
The facts that gas diffusion deteriorates the mud properties and that the gas ratio increases regardless of the overbalance pressure are alarming and should be carefully considered (Bradley et al., 2002). Silva et al. (2004) experimentally studied methane-liquid thermo-dynamical properties. This included bubble point pressure, solubility, density, and formation volume factor at temperatures of 158 and $194{ }^{\circ} \mathrm{F}$. They considered three mixtures of methane with ester and iso+n-paraffin. $\mathrm{N}$-paraffin compared to ester based fluids showed higher solubility and formation volume factor accompanied by lower bubble point pressure. Therefore, in n-paraffin based mud, gas kick detection is harder than in ester based fluids (Silva et al., 2004). Ribeiro et al. (2006) extended this work for deep water drilling. A thermodynamic modeling based on Krichevsky-Kasarnovsky correction of Henry's law was used to verify the experimental results. They concluded that gas solubility is the highest in iso+nparaffin, then solubility decreases in n-paraffin, and solubility is the lowest in ester due to the high polarity of the ester group (Ribeiro et al., 2006).

Monteiro et al. (2010) studied gas PVT properties in synthetic oil based drilling fluid mixtures at higher temperatures. The equation of Peng-Robinson was used to fit methane and $n$-paraffin system experimental data. They concluded that below 5,000 psi, the temperature effect is insignificant. Also, as a result of the small volumetric fractions, drilling fluid additives show a negligible impact on solubility. For example, a 20 bbls surface pit gain of methane means that $45 \%$ more gas entered the wellbore in OBM compared to WBM at a depth of 8,000 ft. Flatab et al. (2015) investigated methane solubility in mineral and paraffin oil in pressures up to 14,500 psi and temperatures up to $392{ }^{\circ} \mathrm{F}$. They concluded that the PVT simulator underestimates the temperature influence on saturation pressure compared to experimental results. Moreover, they recommended upgrading dynamic well control simulators based on comprehensive experimental results. 


\subsection{Drilling with Casing/Liner}

Drilling with casing/liner are innovative techniques that eliminated the need for a conventional drillstring. These technologies utilize a casing or a liner string with a special bottomhole assembly. Applications of DwC/DwL have accelerated in the recent decades due to its benefits, but some unknowns also appeared (Aadnoy et al., 2009).

\subsubsection{Drilling with Casing/Liner Equipment}

Drilling with casing and/or liner use API standard casing strings to drill the well and run the casing instantaneously. This includes utilizing either non-retrievable or retrievable bottomhole assemblies. The non-retrievable BHA consists of a drillable drill bit and float collar that opens a pathway for the next casing string run (Satkan, 2013). Otherwise, a retrievable bit and BHA are attached to the drillpipe or wireline with a drill lock assembly. This enables changing the drill bit or the directional bottomhole assembly. This BHA consists of pilot bit followed by an underreamer. This way the BHA runs through the casing and can drill a hole with sufficient clearance for casing and cementing. To prevent damage to the connection threads and to handle casing strings faster, DwC rigs are equipped with a casing drive assembly (CDA) (Aadnoy et al., 2009). Formation drillability defines the BHA selection. Offset bit records and trajectory requirements control the suitable BHA for a single run (Satkan, 2013). Ghiselin (2012) categorized DwC/DwL into three levels as shown in Figure 2.4. Level 1 defines when a reaming shoe is used with a casing/liner string. This type is common in horizontal wells to facilitate running the casing to the bottom. Level 2 implements a non-retrievable BHA to drill and place casing string with no directional drilling capability. Level 3 uses a retrievable BHA with/without directional drilling assembly that can be run on wireline, coiled tubing or drillpipe (Ghiselin, 2012). 


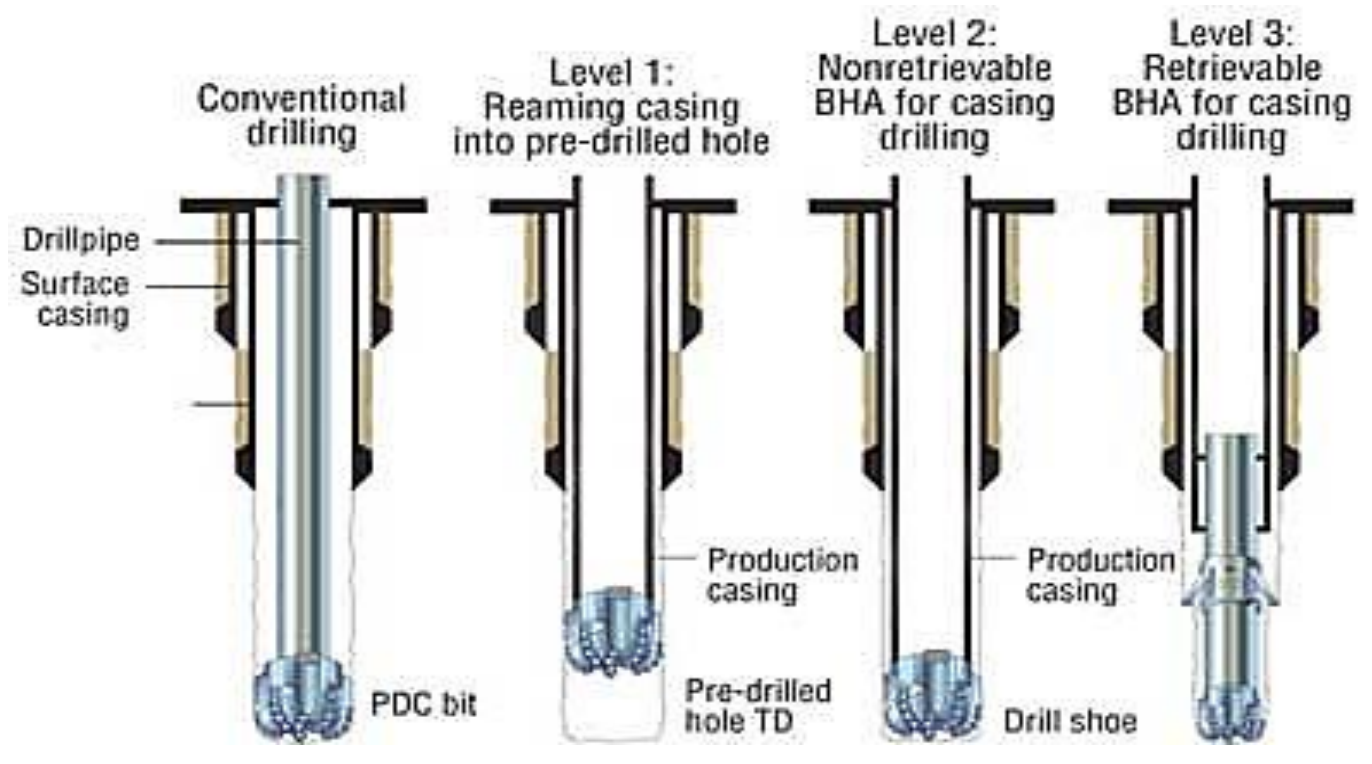

Figure 2.4: Casing drilling classification (Ghiselin, 2012).

\subsubsection{Drilling with Casing/Liner Benefits}

- Reduce non-productive time (NPT) and well cost: As the casing/liner is already on bottom, there is no need for a round-trip. This eliminates surge and swab piston effects associated with tripping. Additionally, it diminishes the time for wiper trips and hole conditioning before running the casing. Lopez and Bonilla (2010) reported a $30 \%$ saving in time and 10\% reduction in cost compared to conventional drilling techniques. In addition, Sánchez et al. (2012) claimed that in Oman DwC reduced cost per meter more than 25\% by accelerating well delivery time up to $58 \%$.

- Minimize lost circulation problems: Field reports show that smearing (plastering) effect decreases loss of circulation problems and improves wellbore stability. For instance, Fontenot et al. (2003) reported that loss of circulation was significantly reduced in the Lobo field, South Texas. Likewise, the smoothing motion of casing string creates gauged holes which prevents washouts and break downs. The greater the contact area and the smaller the contact angle, the greater the casing string smoothing effect. When these conditions are coupled with casing side forces and momentum, it potentially fills hole washouts and breakouts (Karimi et al., 2011). 
Sánchez et al. (2012) reported an improvement in the cement operations because of gauged wellbores. Salehi et al. (2013) claimed fracture gradient enhancement in narrow pore-fracture pressure sedimentary basins and deep offshore applications.

- Improve Drilling Performance: Field application showed an improvement in that the total drilling performance. This included improving hole cleaning by means of cuttings circulation at high velocities in narrow annular spaces. Furthermore, the well control problems associated with tripping operations such as surge and swab have been minimized. With this technology, casing setting depth can be driven deeper than conventional drilling with less number of casing strings. This can be achieved by excluding the increase in mud density to accommodate surge and swab margins while tripping (Radwan and Karimi, 2011). The DwC/DwL technique is considered safer as personnel exposure to pipe handling is reduced (Aadnoy et al., 2009).

\subsubsection{Drilling with Casing/Liner Limitations}

This technology requires rig modification, special bits, casing connection wear band, and accessories (Satkan, 2013). Oilfield casing strings are intended for static wellbore conditions. However, casing strings used while drilling are subjected to dynamic loads such as rotational motion, cyclic fatigue, torsion cycles, and compressive forces (Galloway, 2004). Alternatively, in these critical wellbore sections, heavy casings with thicker walls can be used. In addition, centralization of casing string during cementing is another major operational concern. The regular centralizers do not withstand dynamic downhole conditions. Therefore, the rigid centralizers are used for wear management, nevertheless this is limited by the extra torque and cost. In retrievable systems, once the BHA is retrieved, there is no tool in the casing string to prevent cement u-tubing. In addition, cementing tools have the tendency to fail (Aadnoy et al., 2009). Differential sticking is the most sever limitation as a result of drilling fluid specifications and hydraulics especially in low pressured permeable formations. 
Selecting the optimum flow rate is critical. Higher flow rates result in higher ECD values. This leads to formation fractures and destructs filter cake uniformity. However, lower flow rates jeopardize the jetting action, cleaning bit face and cuttings from the bottomhole (Gupta, 2006). Furthermore, hook load decreases while the pump is starting and flow rate increases. This challenges the process of applying weight to the bit because of the hydraulic lift force acting on the casing string bottom.

Also, sudden pipe movement during connections causes severe surge and swab. Drilling gumbo-type sticky shales results in bit balling (Aadnoy et al., 2009). The most harmful vibration is the lateral vibration of whirl which cause coupling fatigue failure. Furthermore, in harder rocks, torsional oscillation can damage the string connections. In the worst case, torsional oscillation initiates a stick/slip scenario (Aadnoy et al., 2009).

\subsubsection{Previous Studies of Drilling with Casing/Liner}

At the normal flow rates, the relatively narrow casing/borehole space increases the annular pressure loss (APL). Fully eccentric pipe reduces APL by approximately $30 \%$ and pipe rotation increases APL up to $40 \%$. APL depends on the flow regime such as laminar, transient, and turbulent flow. Equivalent Circulating Density (ECD) is always higher than static mud weight. Instead of 550 GPM in conventional drilling, the flow rate should be deceased to 300 GPM in DwC to maintain the same ECD (Aadnoy et al., 2009). Arlanoglu (2011) investigated the smearing mechanism and parameters affecting near wellbore stress distribution using finite element analysis. This included micro fracture creation, bridging material accumulation in fracture mouth, hoop stress improvement and lost circulation minimization at high horizontal stress anisotropy. Mokhtari et al.'s (2013) numerical study showed that the reduction of breakout occurrences using casing drilling compared to conventional drilling. However, they assumed a $50 \%$ reduction in the exposure time. Also, the permeability is assumed to decrease from $10^{-4} \mathrm{md}$ to $5^{-6}$ md. Further, the compressive strength was assumed to improve by $10 \%$ in casing drilling compared to a $50 \%$ reduction with conventional drilling. 
Salehi et al. (2013) studied the near wellbore area and hoop stress changes considering the formation poro-elastic properties. In addition, frictional pressure losses were evaluated using Computational Fluid Dynamics (CFD). The annular clearance and pipe size are the critical parameters affecting wellbore strengthening. However other parameters such as rotary speed, mud type, time, stress anisotropy, mud hydraulics, thermal effects and penetration rate showed limited impact. Likewise, Satkan (2013) studied hydraulics, pressure, and velocity profiles at different eccentricity values using CFD. He concluded that hydraulics and annular pressure distributions are unique and are considered as the main contributor to plastering effect. Nevertheless, higher the string eccentricity, lower the annular frictional pressure loss since the viscosity is dependent on shear rate (Satkan, 2013).

Van Oort and Razavi (2014) defined different mechanisms for wellbore strengthening. They concluded that the most consistent mechanism is fracture propagation resistance (FPR). They claimed that stress cage and fracture closure stress mechanisms are unproven and unrelated to laboratory experiments and field practice results. Kiran et al. (2014) investigated the hypothesis of hoop stress change considering casing/wellbore contacts using finite element analysis. Wellbore stress equations include parameters such as wellbore geometry, pore pressure, and far-field stresses. However, these equations neglected pipe contact and eccentricity. Results suggested BHA design should consider casing contact in maximum horizontal stress direction. Naveen and Babu (2014) conducted experimental studies to understand the impact of the plastering effect. They related this plastering effect to the development of a thin strong mud cake layer to prevent fluid loss. They concluded that at high concentration of fine grains, centrifugal, drag forces, and acceleration due to centrifugal forces are the main factors affecting plastering effect. 
CHAPTER 3: METHODOLOGY AND WELLBORE CONFIGURATIONS

Wellbore configurations used in this study are discussed in Section 3.1 below for five different cases. Section 3.2 discusses the features of WVU Rig-Floor Drilling and Well Control Facility. The well control software used in this study is presented in Section 3.3. Relevant equations are given in Section 3.4 and Section 3.5 describes the u-tube models employed in this study. A new step-down model is presented in Section 3.6

\subsection{Wellbore Configurations}

\subsubsection{Marcellus Shale Lateral Well Configuration}

Figure 3.1 shows the Marcellus X1 lateral drilled in Monongalia County, WV in 2015. The kick-off point (KOP) depth is $6,742 \mathrm{ft}$ and the total drilled depth is 14,455 $\mathrm{ft}$. The total vertical depth (TVD) at the lateral heel is $7,536 \mathrm{ft}$, and at the toe is 7,452 $\mathrm{ft}$. The inclination angle in the lateral section varies between 88 and 94 degrees. A $70 \%$ oil based mud was used to drill the 8.5 " lateral with an average density of 12.5 ppg, plastic viscosity of $24 \mathrm{cp}$, and yield point of $10 \mathrm{lb} / 100 \mathrm{ft}^{2}$. The average drilling rate of penetration was $150 \mathrm{ft} / \mathrm{hr}$, and pump flow rate was in the range of 350-460 gpm with a corresponding pump pressure of 1,900-3,600 psi. Table 3.1 shows wellbore and drill string configurations used to drill the Marcellus (MRC) X1 lateral. In addition, it shows the drilling fluid density and rheological properties.

Table 3.1: Marcellus X1 lateral wellbore/string configurations.

\begin{tabular}{|l|l|l|}
\hline Property & Value & Unit \\
\hline Drillpipe (OD $\times$ ID) & $5.0 \times 4.28$ & in. \\
\hline Drill collars (OD x ID) & $6.875 \times 2.875$ & in. \\
\hline Previous casing (OD $\times$ ID) & $9.625 \times 8.835$ & in. \\
\hline Casing shoe depth & 1,781 & ft. \\
\hline Bit diameter & 8.5 & in. \\
\hline Total vertical depth (TVD) & 7,452 & ft. \\
\hline Total measured depth (TMD) & 14,455 & ft. \\
\hline Mud density & 12.5 & $\mathrm{ppg}$ \\
\hline Plastic viscosity & 24.0 & $\mathrm{cp}$ \\
\hline Yield point & 10.0 & $\mathrm{lbs} . / 100 \mathrm{ft}^{2}$ \\
\hline Bit nozzle size & $5 \times 11+1 \times 10$ & $1 / 32 \mathrm{in.}$ \\
\hline
\end{tabular}




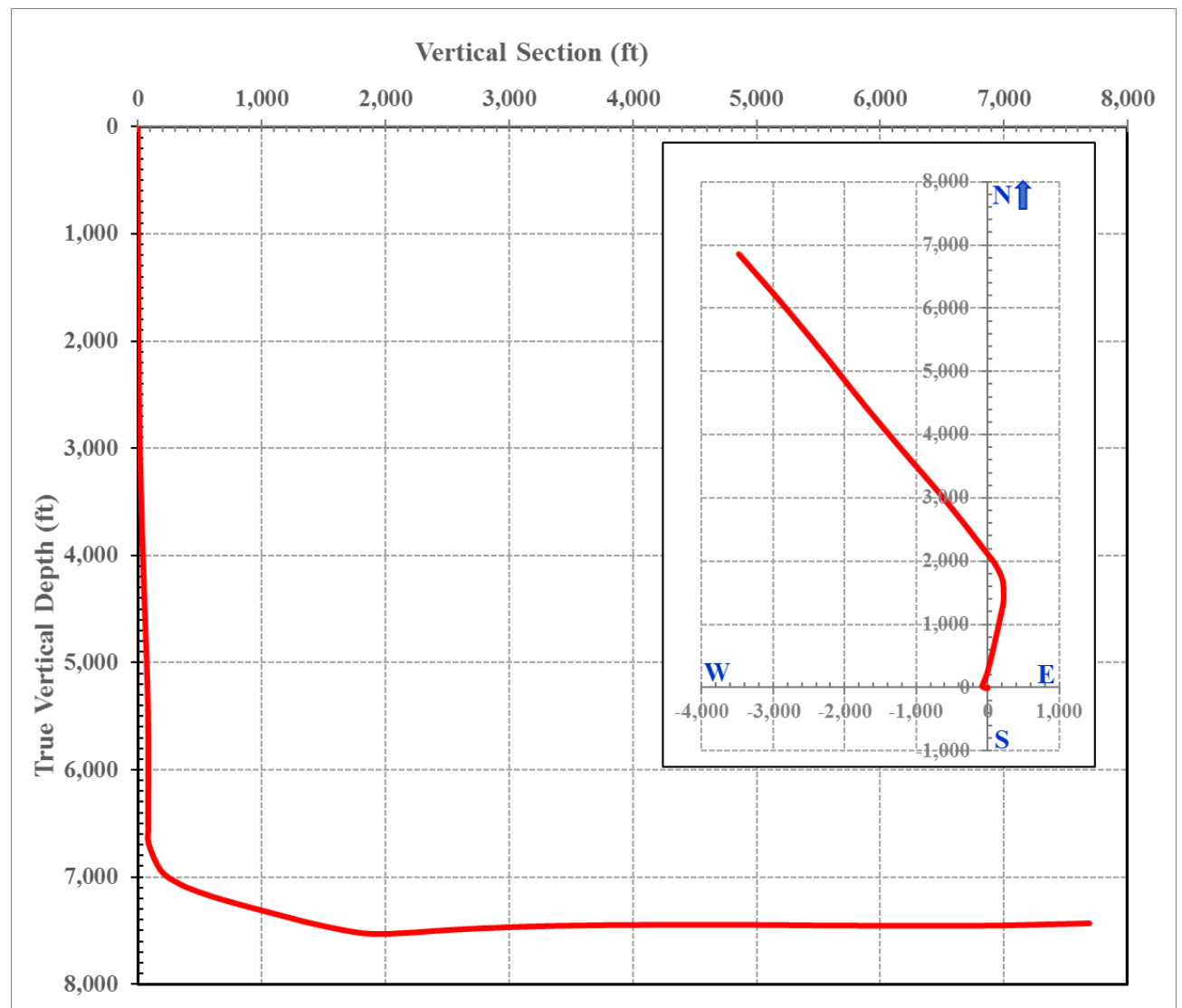

Figure 3.1: Trajectory of Marcellus X1 lateral drilled in Monongalia county, WV in 2015.

\subsubsection{Horizontal Well drilled with Oil Based Mud Configuration}

A commonly used inclined downward wellbore configuration in shale gas formations was selected for the study of the gas solubility in oil based mud and the details are shown in Figure 3.2 and Table 3.2. An oil based mud was used to investigate the impact of gas kick solubility on well control practices. Different values of solubility and bubble point pressure were studied for an OBM with $75 \%$ oil and $25 \%$ water. Also, the impact of circulation rate was investigated using 20,40 , and $60 \mathrm{spm}$, and two well control methods were examined. These methods are the Driller's and Wait-and-Weight techniques. A kill mud density of $13.0 \mathrm{ppg}$ was used in all runs. Finally, water kick behavior was studied and compared to gas kick in an oil based mud. 


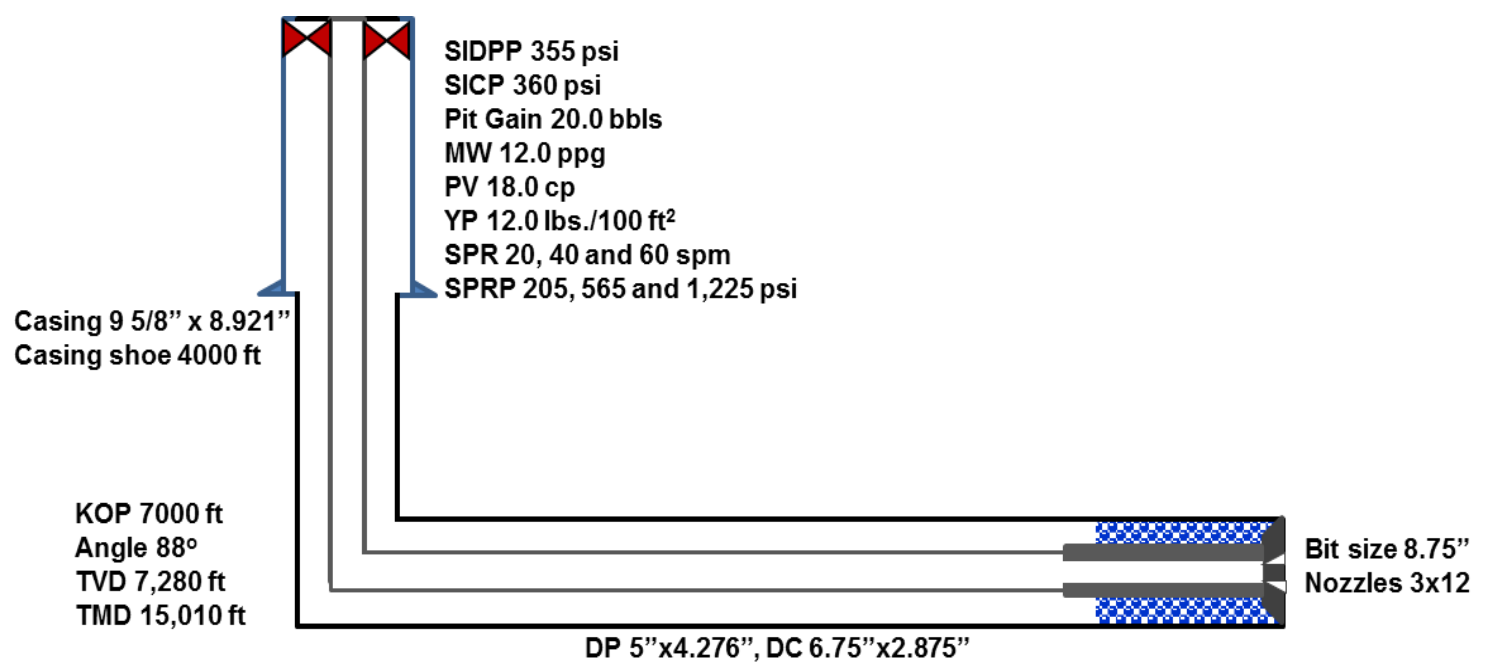

Figure 3.2: Trajectory and configuration of the horizontal well drilled with oil based mud.

Table 3.2: Horizontal well configuration and gas kick data for oil based mud study.

\begin{tabular}{|l|l|l|}
\hline Property & Value & Unit \\
\hline Drillpipe (OD x ID) & $5.0 \times 4.276$ & in. \\
\hline Drill collars (OD x ID) & $6.75 \times 2.875$ & in. \\
\hline Previous casing (OD x ID) & $9.625 \times 8.921$ & in. \\
\hline Casing shoe depth & 4,000 & $\mathrm{ft}$. \\
\hline Fracture gradient at casing shoe & 0.85 & $\mathrm{psi} / \mathrm{ft}$. \\
\hline Bit diameter & 8.75 & $\mathrm{in.}$ \\
\hline Kick-off point (KOP) & 7,000 & $\mathrm{ft}$. \\
\hline Inclination angle & 88.0 & degree \\
\hline Total vertical depth (TVD) & 7,280 & $\mathrm{ft.}$ \\
\hline Total measured depth (TMD) & 15,010 & $\mathrm{ft.}$ \\
\hline Mud density & 12.0 & $\mathrm{ppg}$ \\
\hline Plastic viscosity & 18.0 & $\mathrm{cp}$ \\
\hline Yield point & 12.0 & $\mathrm{lbs} . / 100 \mathrm{ft}^{2}$ \\
\hline Bit nozzle size & $3 \times 12$ & $1 / 32$ in. \\
\hline Pump displacement & 0.09967 & $\mathrm{bbls} / \mathrm{stroke}^{2}$ \\
\hline Shut-in drillpipe pressure SIDPP & 355 & $\mathrm{psi}$ \\
\hline Shut-in casing pressure SICP & 360 & $\mathrm{psi}$ \\
\hline Pit Gain & 20.0 & $\mathrm{bbls}$. \\
\hline
\end{tabular}

\subsubsection{Drilling with Casing/Liner Configuration}

Figure 3.3 and Table 3.3 illustrate the trajectory and configurations for drilling with casing/liner. The wellbore, mud properties, and influx characteristics are the same as the case with oil based mud which is shown in Table 3.2. 


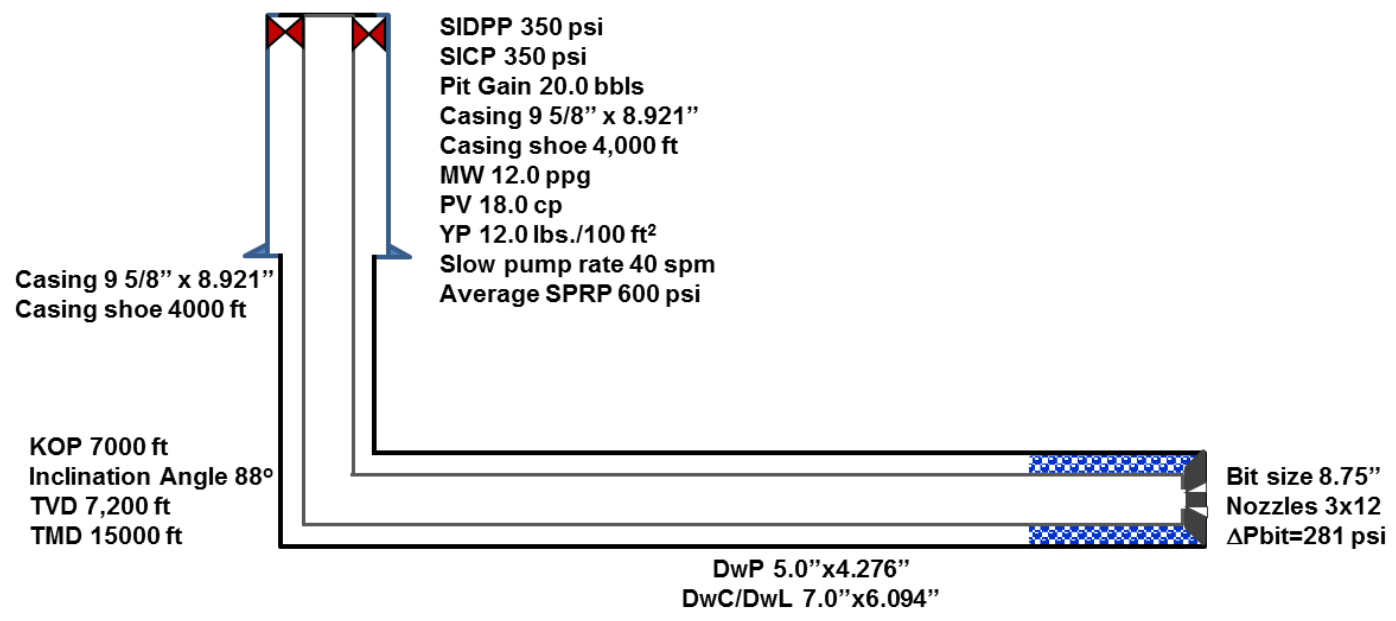

Figure 3.3: Trajectory of the horizontal wellbore configuration for drilling with casing/liner.

Table 3.3: Configurations for vertical, directional, and horizontal wells drilled with casing/Liner.

\begin{tabular}{|l|l|l|}
\hline Property & Value & Unit \\
\hline Casing/liner (OD x ID) & $7.00 \times 6.094$ & in. \\
\hline Inclination angles & $0^{\circ}-50^{\circ}-90^{\circ}$ & Degree \\
\hline True vertical depth (TVD) & 7,200 & $\mathrm{ft}$. \\
\hline Total measured depth (TMD) & $7,000-8,390-15,000$ & $\mathrm{ft}$. \\
\hline
\end{tabular}

\subsubsection{Inclined Upward/Downward Lateral Well Configuration}

For hydraulics and well control comparison, three lateral configurations were considered as shown in Figure 3.4. First, flat horizontal well with an inclination angle of $90^{\circ}$ and a TVD of $7,516 \mathrm{ft}$. Then, an inclined downward lateral with a TVD of 7,980 $\mathrm{ft}$ and $86^{\circ}$ inclination angle. Finally, an inclined upward well with an inclination angle of $94^{\circ}$ and a TVD of 7,022 Ft. The measured depth of each lateral is $15,000 \mathrm{ft}$.

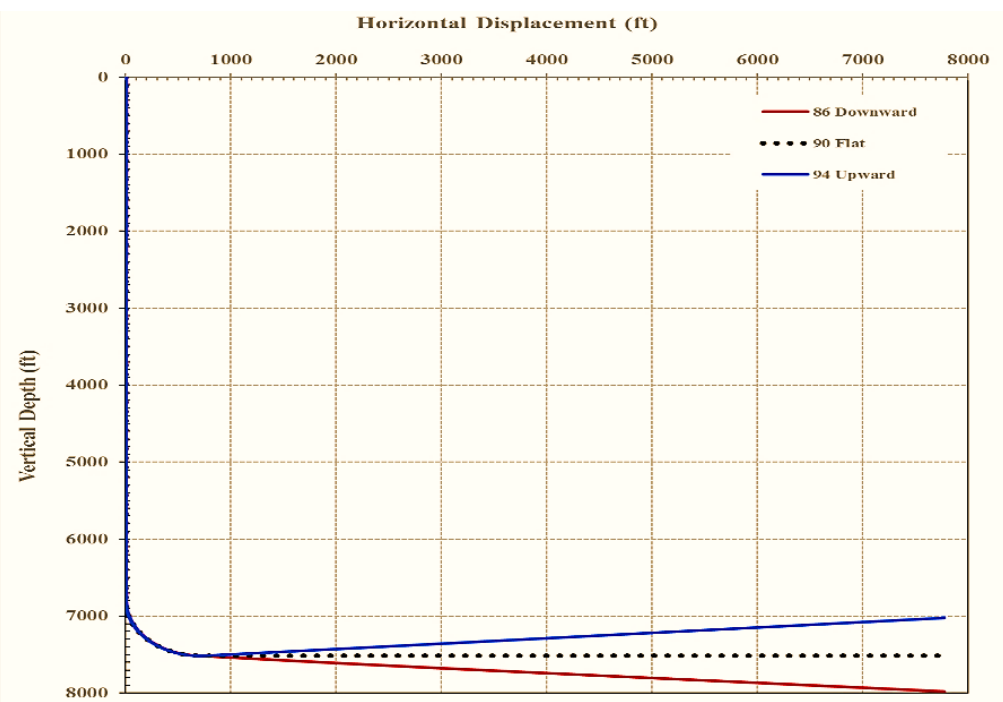

Figure 3.4: Wellbore trajectory for flat horizontal, inclined upward, and downward laterals. 


\subsubsection{Marcellus/Utica Lateral Configuration}

For the Marcellus and Utica comparative study, Figure 3.5 and Table 3.4 illustrate a typical wellbore configuration for inclined upward and downward laterals. These laterals were utilized to compare operational parameters, influx, and reservoir characteristics in inclined downward $\left(88^{\circ}\right)$ and inclined upward $\left(92^{\circ}\right)$ wellbore configurations. This comparison included dry gas, rich condensate, and black oil influxes with different kick sizes of 10,30, and 50 bbls, and various kick intensities of 1,2 , and 3 ppg circulated at altered pump rates of 100,200 , and $300 \mathrm{gpm}$.

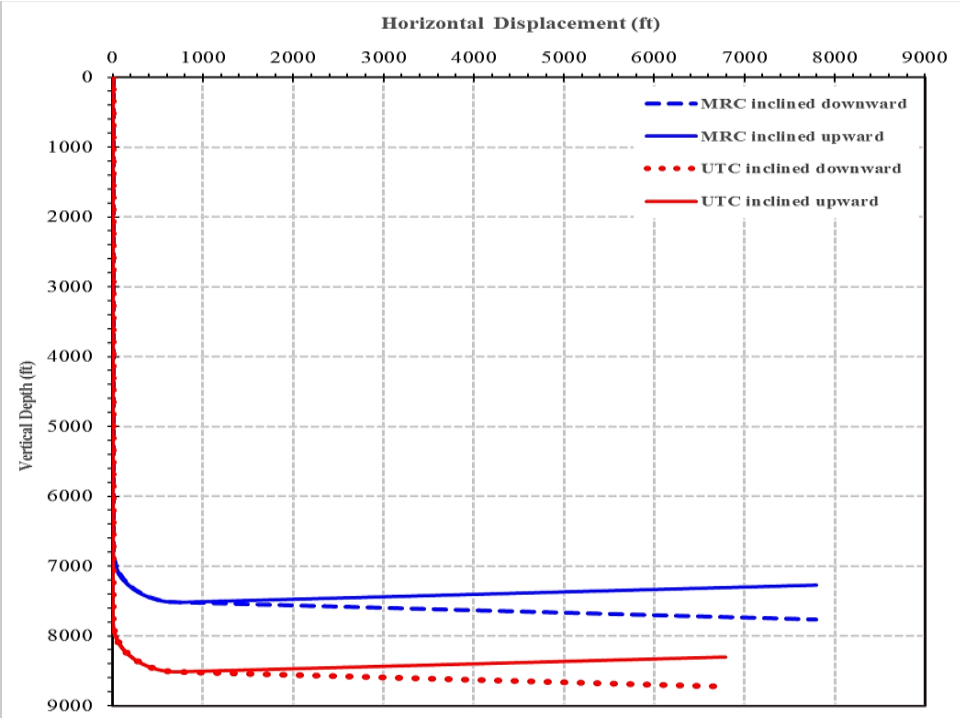

Figure 3.5: Wellbore trajectory for Marcellus and Utica comparative study and sensitivity analysis.

Table 3.4: Marcellus and Utica wellbore configurations and sensitivity analysis parameters.

\begin{tabular}{|l|l|}
\hline Property, Unit & Value \\
\hline Drillpipe (OD x ID), in. & $5.0 \times 4.276$ \\
\hline Drill collars (OD x ID), in. & $6.75 \times 3.250$ \\
\hline Previous casing (OD x ID), in. & $9.625 \times 8.835$ \\
\hline Casing shoe depth, ft. & 2,000 \\
\hline Bit diameter, in. & 8.5 \\
\hline Inclination angles & $88^{\circ-92^{\circ}}$ \\
\hline Kick-off-point (KOP), ft. & 6,800 (Marcellus) $-7,800$ (Utica) \\
\hline True vertical depth (TVD), ft. & 7,500 (Marcellus) $-8,500$ (Utica) \\
\hline Total measured depth (TMD), ft. & 15,000 \\
\hline Mud density, ppg & 12.5 (Marcellus) -15.0 (Utica) \\
\hline Reservoir pressure gradient, psi/ft. & 0.7 (Marcellus) -0.85 (Utica) \\
\hline Slow pump rate, gpm & 100,200 and 300 \\
\hline Influx size, bbls & 10,30 and 50 \\
\hline Influx intensity, ppg & 1,2 and 3 \\
\hline Influx fluid and Gas/Oil Ratio, scf/stb & Black oil, GOR = 600, \\
& Rich condensate, GOR = 2 x 104 \\
& Dry gas \\
\hline
\end{tabular}




\subsection{Full-Size Rig-Floor Drilling and Well Control Facility at WVU}

This study utilized the WVU drilling and well control simulator (CS Inc., 2011) shown in Figure 3.6. This simulator is designed to provide training and research for drilling, completion, and production operations; in particular blowout prevention and well control. The system illustrated in Figure 3.6 consists of 11 panels in addition to two computers and a display monitor. These units from left to right are the cement head, x-tree, choke manifold, surface BOP stack, standpipe manifold, remote choke panel, Driller's console, Driller's data display, pit flow alarms, wave compensator, and offshore (deepwater) BOP stack. Each individual panel and console contains a digital microprocessor and status indicator lights.

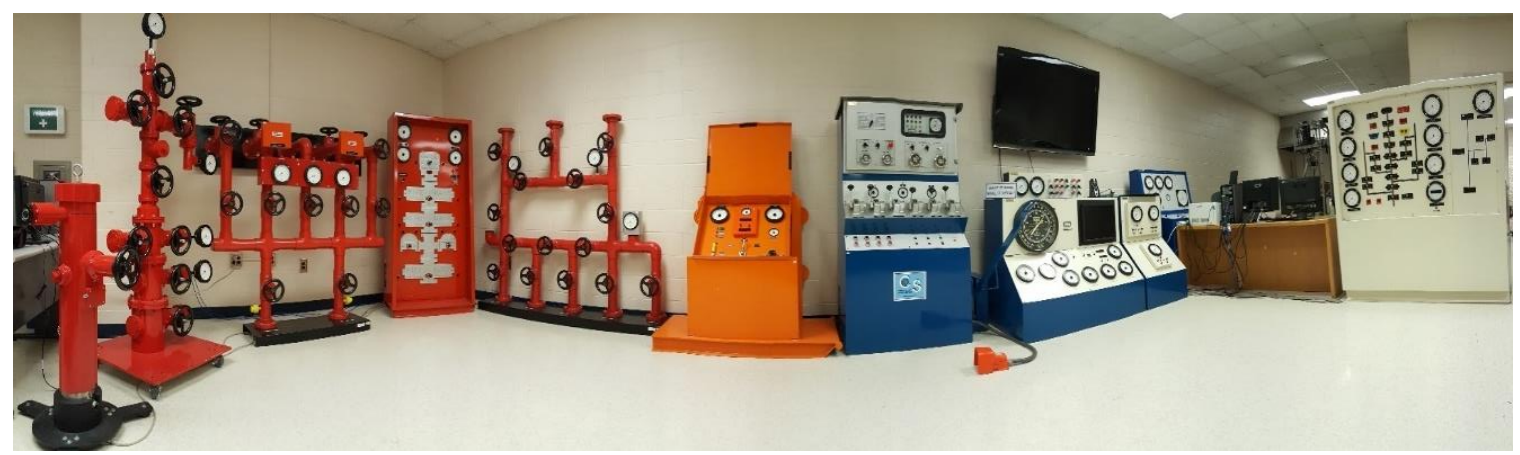

Figure 3.6: Full-size rig-floor drilling and well control facility at WVU.

The main brain of the simulator is the CS software that enables the design of the wellbore and drillstring configurations. In addition, it assigns drilling fluid properties, drilled formation properties, and influx characteristics. Therefore, real field complications can be simulated through time or drilled distance with failures of equipment such as pumps and BOP. While running an exercise, 35 parameters are logged at the specified sampling time interval as shown in Appendix B. This includes, drilling and well control surface and downhole parameters such as pressures, volumes, and flow rates (CS Inc., 2011). Upon setting up the formation/kick, to configure the well control scenario, the following procedure is utilized:

- Start by performing slow pump rate pressure (SPRP) for each of the rig pumps at different slow pump rates (20, 30 or $40 \mathrm{spm})$.

- Drill ahead until a positive kick indicator is detected such as pit gain, increase in return flow rate, and/or a sudden increase in the drilling rate (drilling break). 
- Perform a flow check; this includes spacing the tool joint out of the BOP with the bit is off of the hole bottom and the weight on bit indicator reading zero. Then, turn-off rotation and stop the pumps, set the slips, transfer the hookload to the slips, and monitor mud return.

- If flow check is positive, follow the hard shut-in procedure. This includes closing the upper pipe ram and open the choke line (HCR) valve while the remote choke is already in the closed position.

- Upon stabilization of surface pressures, record SIDPP, SICP, and pit gain.

- Select the desired well control method and estimate the proper kill sheet including pump pressure step-down schedule.

- If the Driller's method is selected, slowly bring the pump up to the kill speed at $5 \mathrm{spm}$ intervals, keeping the casing pressure constant. Pump pressure should be allowed to increase while the pump rate is increasing.

- Remember that while adjusting the remote choke, accommodate for the delay time of 2 seconds $/ 1000 \mathrm{ft}$ of the hole depth. This means that pressure change is noticed first on the casing pressure gauge then after the delay time, it impacts the pump pressure gauge.

- Once the pump is at the kill speed, maintain the pump pressure at estimated initial circulating pressure (ICP) until the gas reaches the choke and is entirely circulated out of the wellbore. As the influx is circulated toward the surface, casing pressure is expected to increase due to gas expansion. Monitor the casing pressure and keep it below the maximum allowable surface pressure (MAASP). Once the influx reaches the choke, the casing pressure is expected to decrease while the gas is circulated out of the hole.

- Upon kick removal, slowly shut-down the pump while holding the casing pressure constant. Close the remote choke to trap pressure that represents the initial SIDPP. The casing and drillpipe pressures should be equal to the initial SIDPP; otherwise, continue circulating the remaining gas influx.

- Once the estimated heavy density kill mud is prepared, start the second circulation of the Driller's method to displace the old mud with the heavy mud. 
- Slowly bring the pump up to the kill speed keeping the new casing pressure constant and allowing pump pressure to increase.

- Decrease the pump pressure from ICP to FCP following the step-down schedule by adjusting the remote choke. If the proper step-down was applied, it should avoid over-pressuring the bottomhole, and casing pressure should be constant while the heavy mud is filling the drillstring.

- Once the heavy mud reaches the TVD of the horizontal well, keep the pump pressure constant at FCP until the mud reaches the bit, displaces the lateral and vertical annulus sections, then reaches the surface.

- Once the heavy mud reaches the vertical annulus, casing pressure starts to decrease. However, choke line friction and exaggerated safety factors apply backpressure on the wellbore. At this point, step-down the pump rate slowly trying to keep FCP constant until the heavy mud fills the hole.

- Once heavy mud evidently reaches the surface, shut-down the pump slowly keeping casing pressure constant and close the remote choke.

- Upon a successful well control operation, both pump and choke pressures must be zero. Now, open the BOP and commence the normal drilling operations.

\subsection{Drillbench Steady-State Hydraulics and Dynamic Well Control Software}

This study implemented the Drillbench steady-state hydraulics and dynamic well control software. This realistic multiphase simulator is capable of modeling gas migration in water based mud as well as gas solubility in oil based mud with a compositional PVT model. Multiphase flow correlations and Equation-of-State (EOS) are used to evaluate dynamic fluid properties, gas bubble migration in WBM and solubility in synthetic OBM. During influx circulation, bottomhole pressure is kept constant and the choke opening is adjusted accordingly. Steady-state hydraulics inputs include wellbore trajectory and survey, drilled formations top and bottom depths. Also, it includes pore pressure and fracture gradient as well as previous casing strings, drill bit, bottomhole assembly, and string components. 
Furthermore, the software considers water and oil based mud density, rheological and themophysical properties of fluids and PVT model. Wellbore geothermal gradient and dynamic temperature modeling are also included. Simulation set-up includes number of grids in the flow direction, drillstring eccentricity model, surface pipeline, choke line, and separator configurations. Outputs include wellbore pressure, temperature, equivalent viscosity, cutting velocity, cutting transport ratio, and associated equivalent circulating density profiles.

The dynamic multiphase well control simulator inputs include wellbore trajectory and survey. It also considers previous casing strings, drill bit, bottomhole assembly, and string components. Surface equipment includes: choke and kill lines, pumps and BOP specifications. In addition, inputs include fracture pressure gradient, fracture initiation and closing pressure. Water and oil based mud density, rheology, and gas solubility are defined. Moreover, it includes reservoir depth, formation porosity and permeability, influx characteristics, geothermal gradient, and dynamic temperature model. Simulation set-up defines the number of grids in the flow direction, depth of observation points, mud gas separator, two-phase pressure loss model, and PVT model. Further, it allows kick detection, flow check, shut-in and influx circulation batch configurations. Simulation control parameters include: rate of penetration, pit alarm level, pump rate, BOP, and circulation mode. Constant bottomhole pressure mode adjusts the remote choke opening accordingly. The software provides 46 different outputs such as surface and downhole pressures, gas-liquid volumes, velocities, and flow rates. These results can be plotted in terms of circulation time, number of strokes, or pumped mud volume.

\subsection{Pump and Bottomhole Pressure Calculations}

During the drilling operations, pump pressure (standpipe pressure $=$ SPP) equals the sum of frictional pressure losses, surface back pressure, and hydrostatic imbalance between drillstring and annulus (API RP13D, 2010). Wellbore/string configuration, mud rheology, flow rate and flow regime define pump pressure. Standpipe pressure during drilling can be expressed with Equation 3.1. 


$$
S P P=\Delta P_{S}+\Delta \boldsymbol{P}_{D P}+\Delta \boldsymbol{P}_{D C}+\Delta \boldsymbol{P}_{B H A}+\Delta \boldsymbol{P}_{B i t}+\Delta \boldsymbol{P}_{D C-O H}+\Delta \boldsymbol{P}_{D P-O H}+\Delta \boldsymbol{P}_{D P-C S G}+\Delta \boldsymbol{P}_{C H}+\Delta \boldsymbol{P}_{H D}
$$

Where, $\Delta P_{s}$ is surface equipment friction loss, $\Delta P_{D P}$ is drillpipe pressure drop, $\triangle \mathrm{P}_{D C}$ is pressure drop in the collars, $\triangle \mathrm{P}_{\mathrm{BHA}}$ is the pressure loss due to bottomhole assembly such as motor and MWD pressure drop. In addition, $\Delta \mathrm{P}_{\mathrm{Bit}}$ is the pressure drop across the bit, $\triangle \mathrm{PDC}_{\mathrm{OH}}$ is pressure loss in the drill collar/openhole annulus, $\triangle \mathrm{PDP}_{\mathrm{DPH}}$ is pressure loss in the drillpipe/openhole annulus, $\triangle \mathrm{PDP}_{\mathrm{DPSG}}$ is pressure loss in the drillpipe/casing annulus. Furthermore, $\Delta \mathrm{P}_{C H}$ is the choke line friction and surface back pressure and $\triangle \mathrm{PHD}$ is the hydrostatic difference between annulus and drillstring. The bottomhole pressure (BHP) is the sum of annular hydrostatic pressure, annular pressure losses (APL), and surface back pressure (API RP13D, 2010; Guo and Liu, 2011). The bottomhole pressure can be expressed as following:

$$
B H P=\Delta P_{D C-O H}+\Delta P_{D P-O H}+\Delta P_{D P-C S G}+\Delta P_{C H}+P_{H y d-A n n}
$$

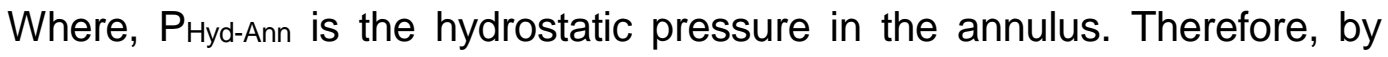
definition, using Equations 3.1 and 3.2, BHP is the sum of SPP and drillpipe hydrostatic pressure minus the drillstring friction.

$$
B H P=S P P-\left(\Delta P_{S}+\Delta P_{D P}+\Delta P_{D C}+\Delta P_{B H A}+\Delta P_{B i t}\right)+P_{H y d-D S}
$$

Where, $P_{\text {Hyd-DS }}$ is the hydrostatic pressure inside the drillstring. Hydrostatic pressure $\left(P_{h}\right)$ depends on true vertical depth (TVD) and equivalent static mud density (ESD) under bottomhole conditions. However, frictional pressure losses depend on measured depth, fluid, and flow characteristics (Mitchell and Miska, 2011). The mud hydrostatic pressure can be estimated with Equation 3.4.

$$
P_{h}=0.052 \times E S D \times T V D
$$

The mud density during circulation is expressed as the equivalent circulating density (ECD). ECD at the total depth is equivalent to extra annular pressure loss added to the bottomhole pressure as shown in equation 3.5 (API RP13D, 2010).

$$
E C D=E S D+\frac{A P L}{0.052 \times T V D}
$$




\subsection{U-tube Model in Vertical and Horizontal Wells}

The mud displacement in a wellbore can be visualized as a U-tube model (Watson et al., 2003). Starting with the mud pump, the drillpipe and bottomhole assembly $(\mathrm{BHA})$ are on one side and various annular sections ending with an adjustable choke are on the other side as shown in Figure 3.7. The drill bit is located at the mid-point that is the lowermost section at the borehole TVD for a vertical wellbore. Figure 3.8 represents an analogy between flat horizontal lateral, inclined downward, and inclined upward laterals and U-tube model. The well control objective is to keep the bottomhole circulating pressure constant by balancing the formation pressure throughout the well control operation. Thus, neither a secondary influx is allowed to kick into the wellbore, nor bottomhole pressures exceed the fracture gradient.
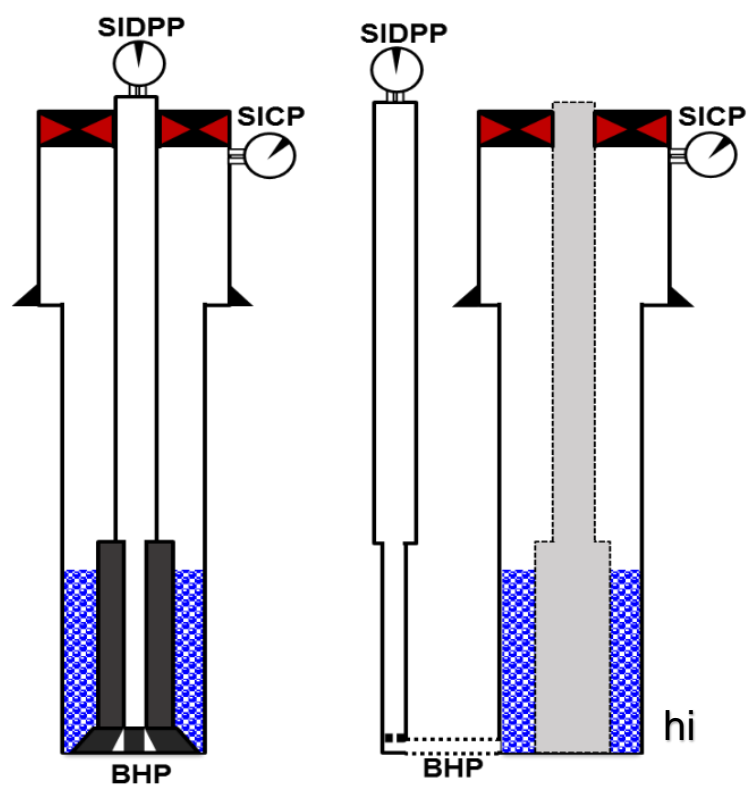

Figure 3.7: Analogy between a shut-in vertical well (on left) and a U-tube model (on right).

During a kick, with the BOP closed, surface pressure builds-up to equalize the formation pressure (Mitchell and Miska, 2011). Therefore, the shut-in bottomhole pressure (BHP) can be defined based on any of the u-tube sides as following:

$$
\begin{aligned}
& B H P=S I D P P+0.052 \times M W \times T V D \\
& B H P=S I C P+0.052 \times M W \times\left(T V D-h_{i}\right)+\left(h_{i} x g_{i}\right)
\end{aligned}
$$

Where, $h_{i}$ is the influx height, and $g_{i}$ is the influx gradient. 

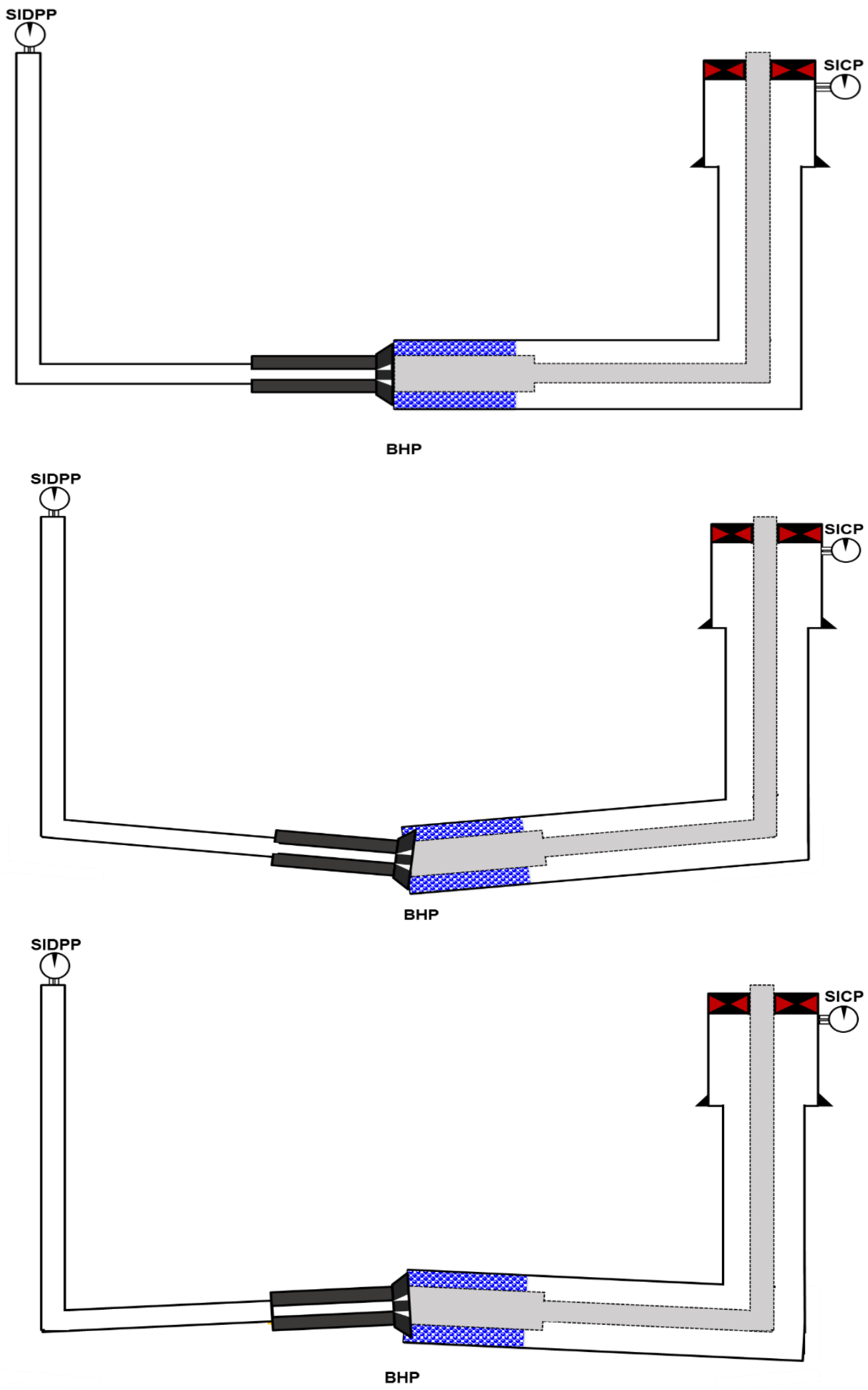

Figure 3.8: Analogy between shut-in flat horizontal well, inclined downward, and inclined upward laterals. 


\subsection{The Reduced Two-Stage Step-Down (R2SD) Model}

Basically, in well control, pump pressure on the left side of the U-tube is adjusted with the variable choke on the right side of the U-tube. While circulating a kick, pump pressure consists of two components. The static-head pressure component which is the backpressure introduced by the kill mud weight while balancing the formation pressure. This static-head increases linearly as a function of the true vertical depth (TVD). However, the dynamic-frictional pressure component is a linear function of the wellbore measured depth. The displacement of the old mud with a heaver mud density creates additional friction. In vertical wells, at slow pump rates, it is a common practice to neglect the annular pressure loss (APL) and assume dynamic-frictional pressure is linearly distributed inside the drillstring. Therefore, as shown as line 1 in Figure 3.9, while heavy mud displaces the drillstring, pump pressure is stepped-down from initial circulating pressure (ICP) to final circulating pressure (FCP). The following formulas can be used to determine kick circulation parameters in vertical wells (Lyons et al., 2012):

$$
\begin{aligned}
& K M W=O W M+\frac{S I D P P}{0.052 \times T V D} \\
& I C P=S I D P P+S P R P \\
& F C P=S P R P x \frac{K M W}{O M W} \\
& \triangle P / 100 \text { strokes }=\frac{(I C P-F C P)}{S T B} \times 100
\end{aligned}
$$

Applying equation 3.9 results in BHP overbalancing the formation pressure by an amount equivalent to the neglected APL. In fact, APL is a hidden built-in overbalance safety factor (Santos, 1991b; Watson et al., 2003). In cases where APL is high such as extended reach horizontal wells and slimhole drilling this assumption of negligible APL is invalid (Santos, 1991b; Choe et al., 2005). Therefore, the stepdown schedule needs to be re-evaluated, since high APL at slow pump rate creates additional challenges (Elshehabi, 2015; Elshehabi and Bilgesu, 2016). Santos (1991b) and Choe et al. (2005) proposed a computer generated step-down schedule, shown as line 2 in Figure 3.9. Applying this exact step-down is a challenge to the rig crew. 


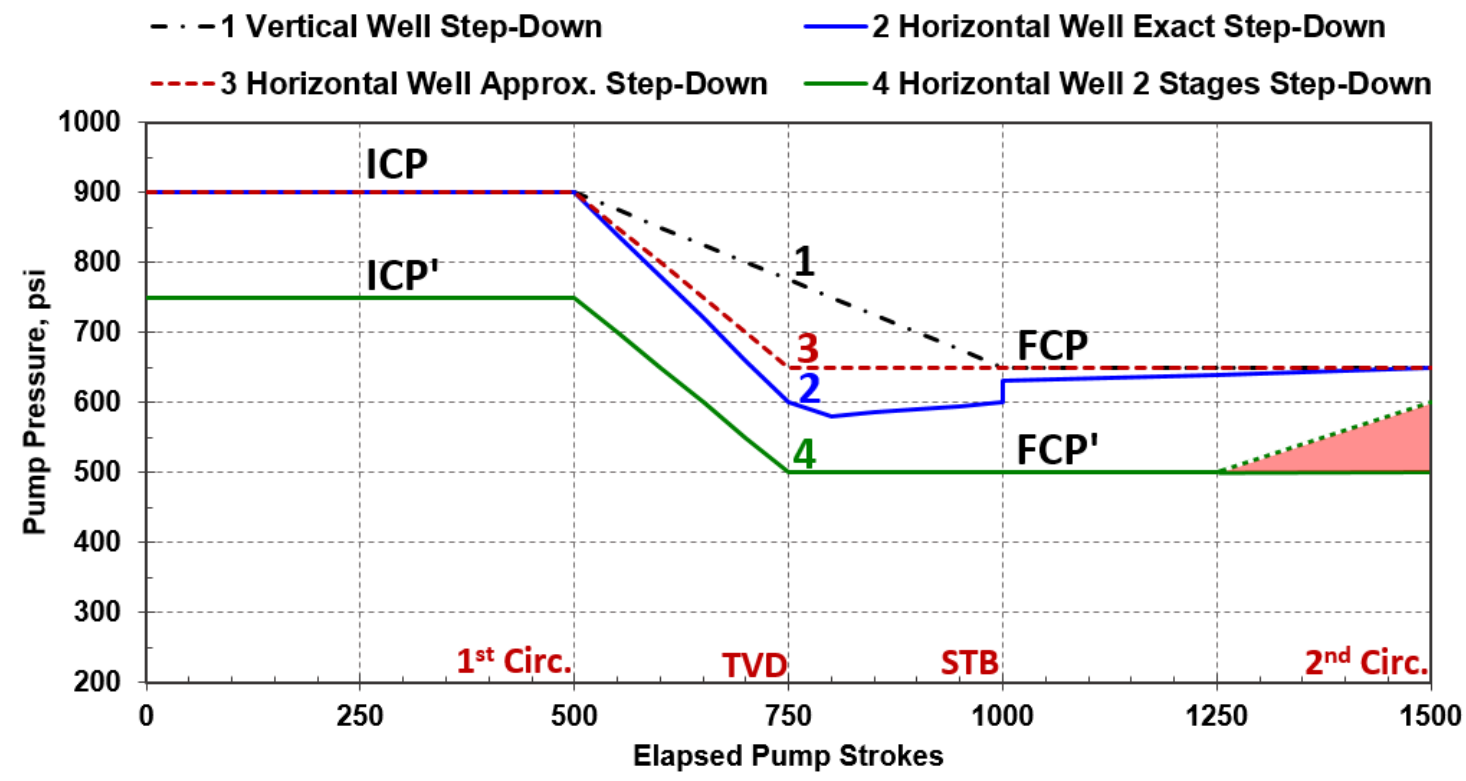

Figure 3.9: Pump pressure step-down approaches for vertical and horizontal wells.

In fact, in horizontal wells, static-head backpressure does not change after the heavy mud reaches the TVD. Therefore, an approximated step-down schedule shown as line 3 in Figure 3.9 is proposed. This approximated step-down assumes that FCP is reached when the heavy mud reaches the TVD, then it is kept constant. Furthermore, in tight annulus cases such as drilling with casing or liner, pumping pressure should be reduced with an amount equivalent to the APL. This reduced two-stage step-down model (R2SD), shown as line 4, takes high APL and hole deviation into account. It starts with a reduced ICP (ICP') and finishes with a reduced FCP (FCP'). When heavy mud reaches vertical annulus section, a backpressure on the wellbore is experienced with the remote choke fully open. At this point, a secondstage pump rate step-down is considered to maintain the FCP constant at the end. Reducing the initial and final pump pressure can be formulated as following:

$$
\begin{gathered}
I C P^{\prime}=S I D P P+[S P R P-A P L] \\
I C P^{\prime}=S I D P P+\left(\Delta P_{D S}+\Delta P_{B i t}\right) \\
F C P^{\prime}=[S P R P-A P L] x \frac{K M W}{O M W} \\
F C P^{\prime}=\left(\Delta P_{D S}+\Delta P_{B i t}\right) x \frac{K M W}{O M W} \\
\Delta P / 100 \text { strokes }=\frac{\left(I C P \prime-F C P^{\prime}\right)}{\text { strokes-to-TVD }} x 100
\end{gathered}
$$




\section{CHAPTER 4: RESULTS AND DISCUSSION}

This chapter presents the results for hydraulics and well control study in unconventional shale laterals. This includes hydraulics results at normal drilling flow rates and at slow pump rates in inclined upward or downward laterals in addition to wells drilled with casing or liner string using water or oil based mud. Also, this chapter shows the results of well control complications due to well type, gas solubility in oil based mud, kicks while running casing/liner, and inclined upward/downward configuration.

\section{Part 1: Hydraulics Results}

\subsection{Hydraulics Study in Marcellus Shale Lateral}

\subsubsection{Hydraulics Model Verification}

Figure 4.1 illustrates the verification of the hydraulics model for MRC X1 wellbore in the lateral section. The average measured flow rate was $450 \mathrm{gpm}$ and pump pressure was linearly increasing with the drilled depth. Figure 4.1 compares the estimated pump pressure with the field recorded values and also shows drilling rate of penetration, mud properties and flow rate. The results show a direct impact of drilling rate and cuttings loading on pump pressure. The hydraulics model successfully estimated the standpipe pressure (SPP) with a regression coefficient $\mathrm{R}^{2}$ of 0.9738 as shown in Figure 4.2. For instance, at 9,000 $\mathrm{ft}$ the drilling rate of penetration decreased to $73 \mathrm{ft} / \mathrm{hr}$; therefore, the model accurately predicted the pump pressure of 2,752 psi. This is consistent with the actual pump where the pressure decreased to $2,728 \mathrm{psi}$. In addition, at the total depth, the model estimated the pump pressure to be 3,760 psi compared to 3855 psi with an accuracy of $-2.5 \%$. This can be contributed to the uncertainty about the cuttings shape, size and concentration, the corresponding density, and plastic viscosity. This verified model was implemented to study hydraulics complications in different wellbore/drillstring configurations. 


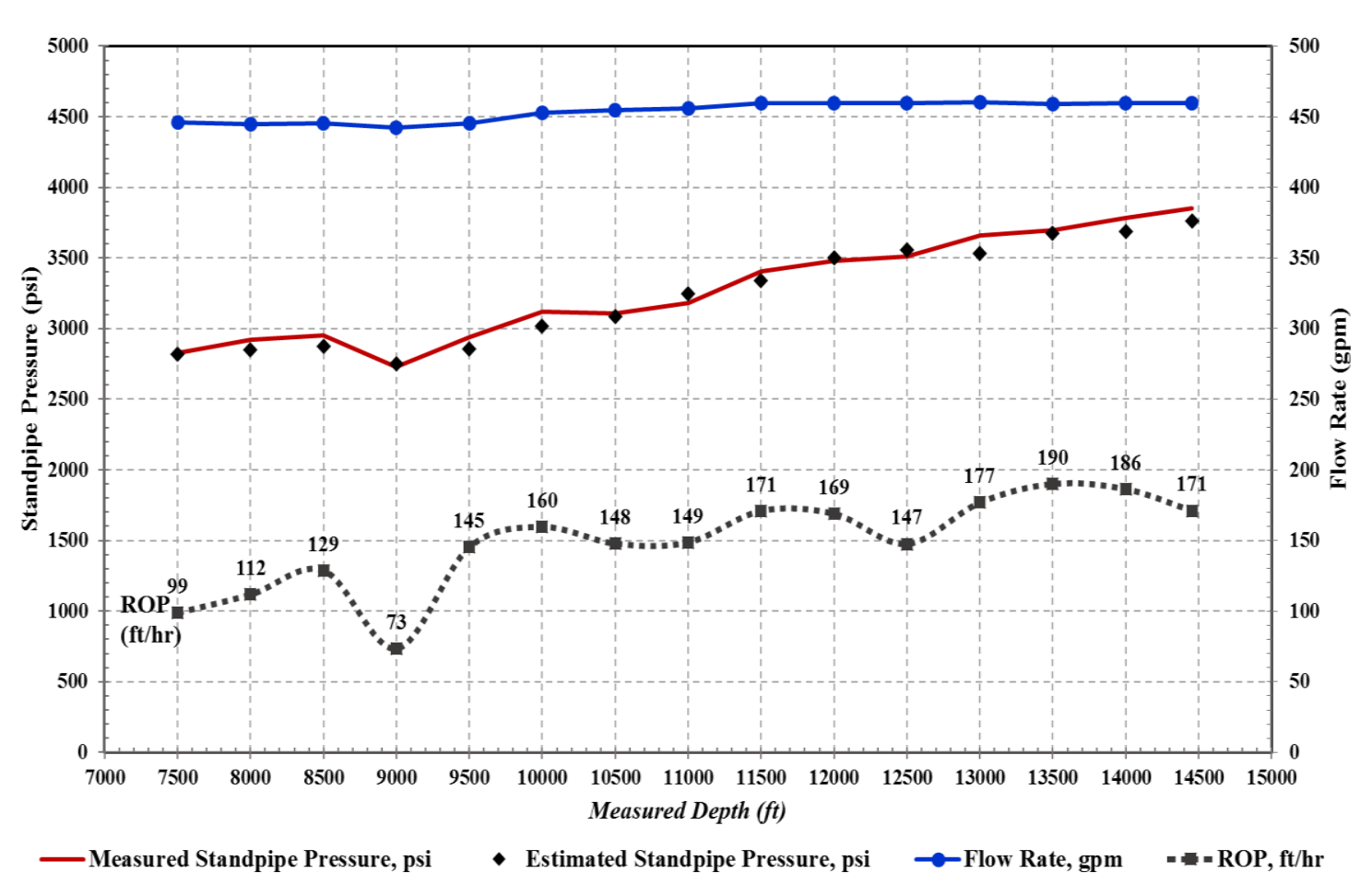

Figure 4.1: Hydraulics model verification in Marcellus X1 lateral drilled in Monongalia county, WV in 2015.

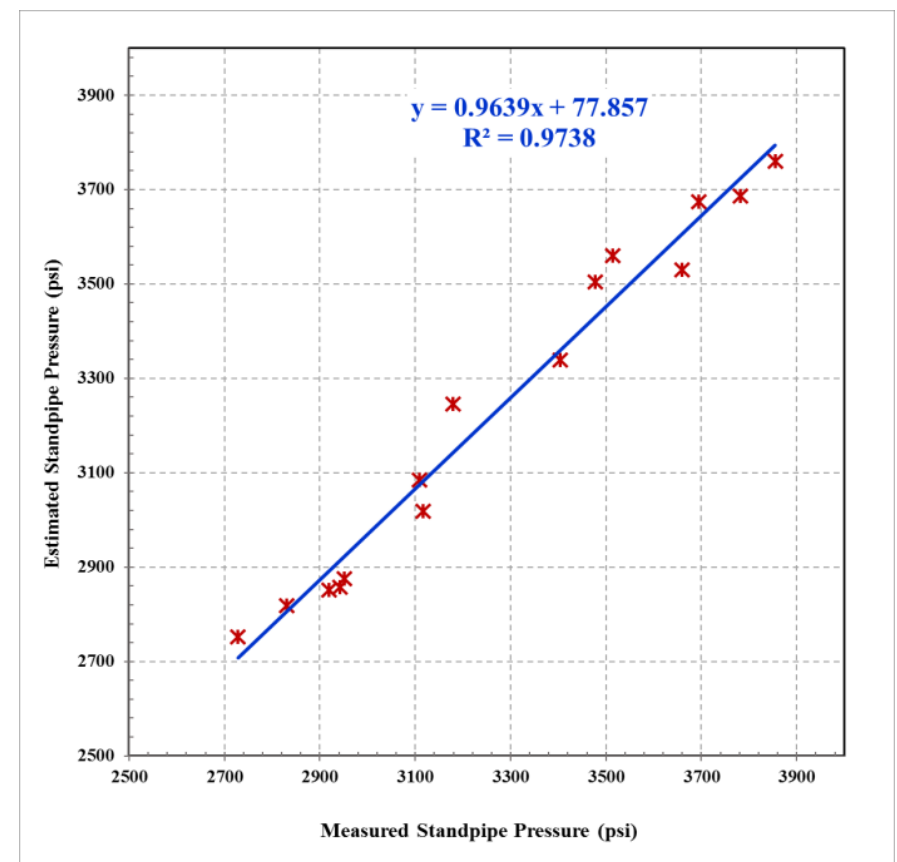

Figure 4.2: Hydraulics model correlation in Marcellus X1 lateral drilled in Monongalia county, WV in 2015. 


\subsubsection{Impact of Well Type on Pressure Profile}

Figure 4.3 shows circulating and hydrostatic pressure profiles for a horizontal well, a vertical well with the same TVD (short), and a vertical well with the same TD (long). The hydrostatic pressure is a function of mud density and total vertical depth. In vertical wells, hydrostatic pressure normally increases until it reaches the maximum at the bottomhole. However, in horizontal wells, the hydrostatic pressure does not change inside the lateral section unless there is a variation in the vertical depth between the heel and toe. By definition, pump (standpipe) pressure is the sum of the system frictional pressure losses, surface back pressure, and hydrostatic pressure imbalance between annulus and drillstring arising from cuttings loading (API RP13D, 2010).

As shown in Figure 4.3, the circulating pressure profile starts at the surface with standpipe pressure, then it changes in response to hydrostatic pressure, friction losses variations. For instance, in the horizontal well at a flow rate of $460 \mathrm{gpm}$ and ROP of $180 \mathrm{ft} / \mathrm{hr}$, the surface pressure is $3,793 \mathrm{psi}$. Then, as hydrostatic pressure increases until it reaches the maximum at the lateral TVD, the circulating pressure increases to 8,067 psi. Then, it decreases because of the high BHA friction losses until it passes the drill bit. Therefore, the circulating pressure drops to 5,358 psi which is still higher than the hydrostatic pressure of 4,856 psi by a value equal to the APL of 502 psi. Then, circulating pressure decreases slightly inside the annulus of the lateral section. In the vertical annulus section, it decreases gradually to the atmospheric pressure as it travels to the surface.

In contrast, Figure 4.3 illustrates that Equivalent Static Density (ESD) is decreasing with depth due to the impact of downhole pressure and temperature on the oil based mud properties. This observation is consistent with Mitchell and Miska (2011). Clearly, the bottomhole pressure is less in the horizontal well compared to the long vertical. However, the ECD is higher in the lateral section because the same APL (502 psi) occurs at a TVD of 7,500 ft in the horizontal well compared to 15,000 $\mathrm{ft}$ in the long vertical well. 

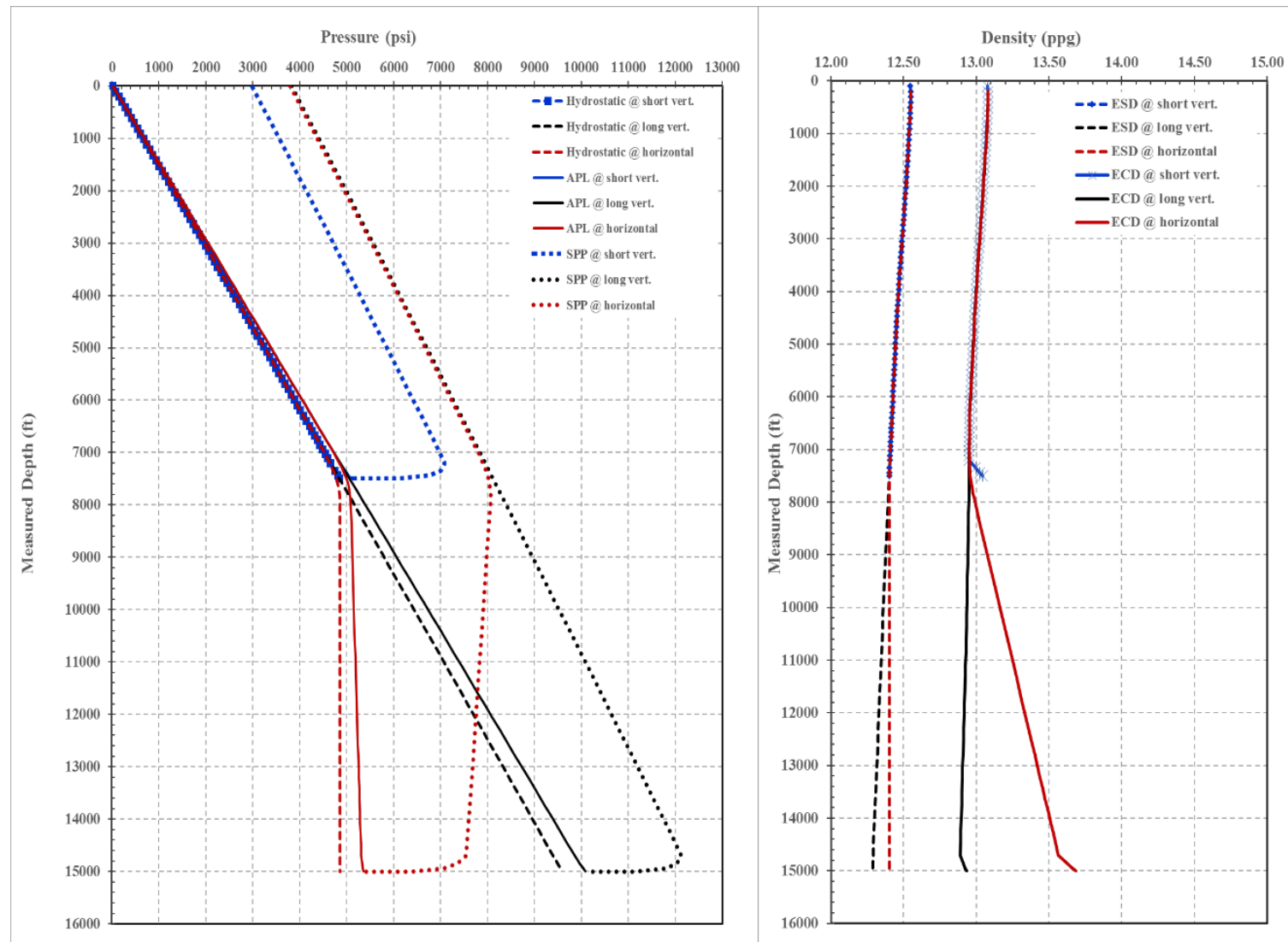

Figure 4.3: Pressure and ECD profiles in horizontal, short, and long vertical wells.

\subsubsection{Slow Pump Rate and Shut-in Pressure profiles}

It is a common practice to circulate kicks at a slow pump rate (SPR), between one-third and one-half of the normal drilling flow rate. A slow pump rate decreases annular friction loss and surface/downhole pressure fluctuations in response to choke adjustments. Also, it reduces the risk of pump break down and mechanical problems, and it enables better control over the instantaneous gas expansion at the choke manifold and mud/gas separator. This offers enough time to analyze surface pressure/volume measurements which leads to better judgment and wiser decisions (Watson et al., 2003). Slow pump rate pressure (SPRP) for each active pump on the drilling rig is recorded at two different slow rates periodically. The driller should record the SPRP at least once every work shift or every $500 \mathrm{ft}$ drilled (Grace, 2003). 
Figure 4.4 shows static and dynamic pressure profiles for MRC X1 well at 100,300 , and $500 \mathrm{gpm}$ flow rates. Obviously, the higher the pump rate, the higher the system friction including APL and the associated ECD values. For instance, at $500 \mathrm{gpm}$, the pump pressure is 4,379 psi with an ECD of $13.75 \mathrm{ppg}$. However, when the flow rate reduces to $100 \mathrm{gpm}$, the pump pressure decreases to $692 \mathrm{psi}$ with ECD of $13.22 \mathrm{ppg}$. Further, Figure 4.4 depicts that ECD decreases with depth as a result of the downhole pressure and temperature effect. Then, ECD increases in the lateral section it reaches the maximum at the bit because of the high friction and cutting concentration.
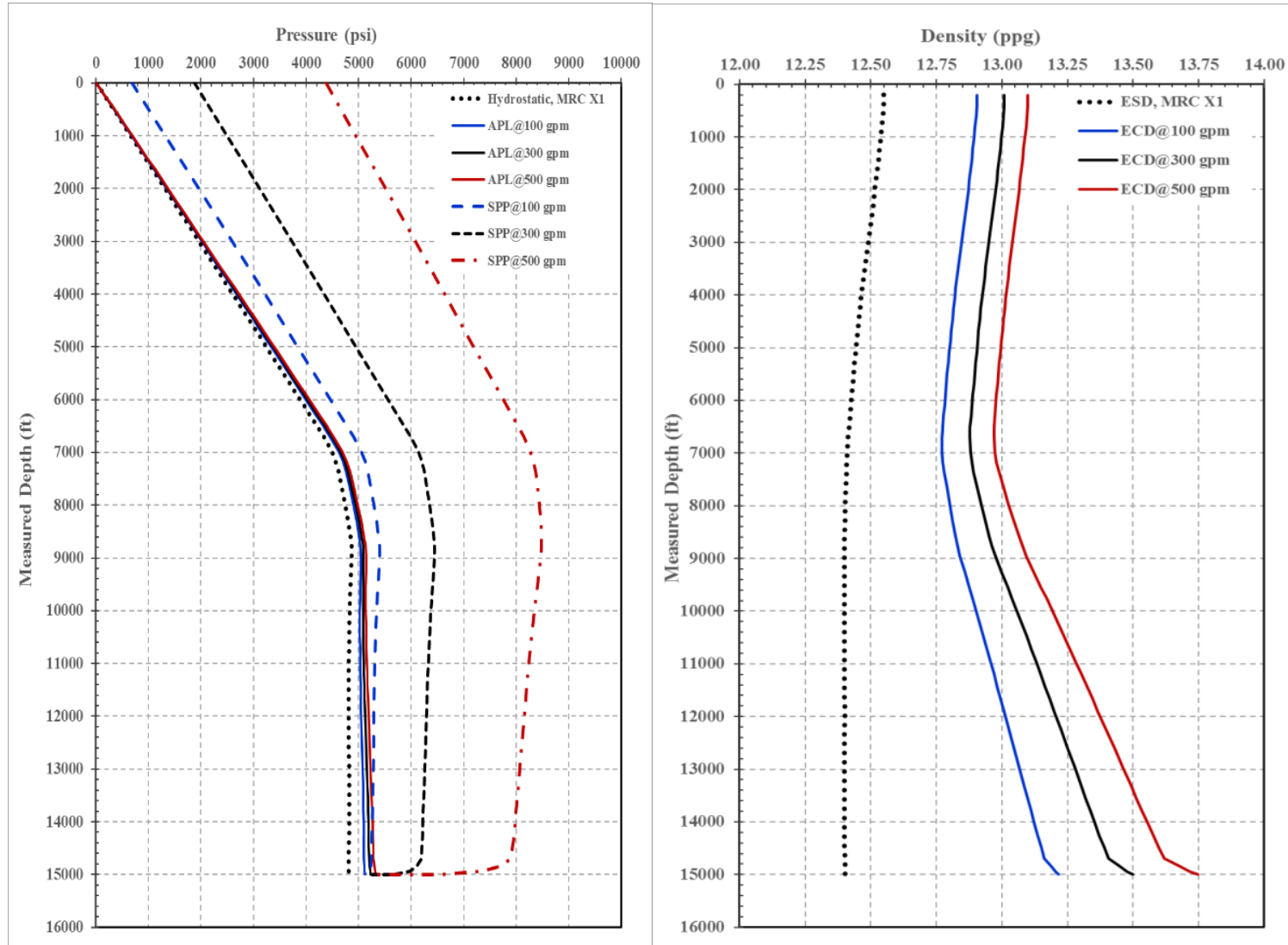

Figure 4.4: Pressure and ECD profiles in MRCX1 at 100, 300, and $500 \mathrm{gpm}$ flow rates.

Figure 4.5 shows standpipe pressure, annulus pressure loss and their ratio at pump rates up to $500 \mathrm{gpm}$. Clearly, ECD increases from $13.22 \mathrm{ppg}$ to $13.75 \mathrm{ppg}$ at $500 \mathrm{gpm}$. However, at $500 \mathrm{gpm}$, APL represents $12 \%$ of the pump pressure; while at a very slow pump rate of $100 \mathrm{gpm}$, the APL accounts for $45 \%$ of the system friction losses. 
It is common to neglect the APL at slow pump rates in vertical wells. However, in horizontal wells, APL represents a large portion of the system losses as seen in Figure 4.5. Neglecting APL on the surface can be considered as a safety factor added to the bottomhole pressure (Choe, 2001; Choe et al., 2005). Unless the neglection of APL jeopardizes wellbore integrity, the pump pressure should be reduced to account for APL particularly in wells with tight annulus (Elshehabi and Bilgesu, 2016).

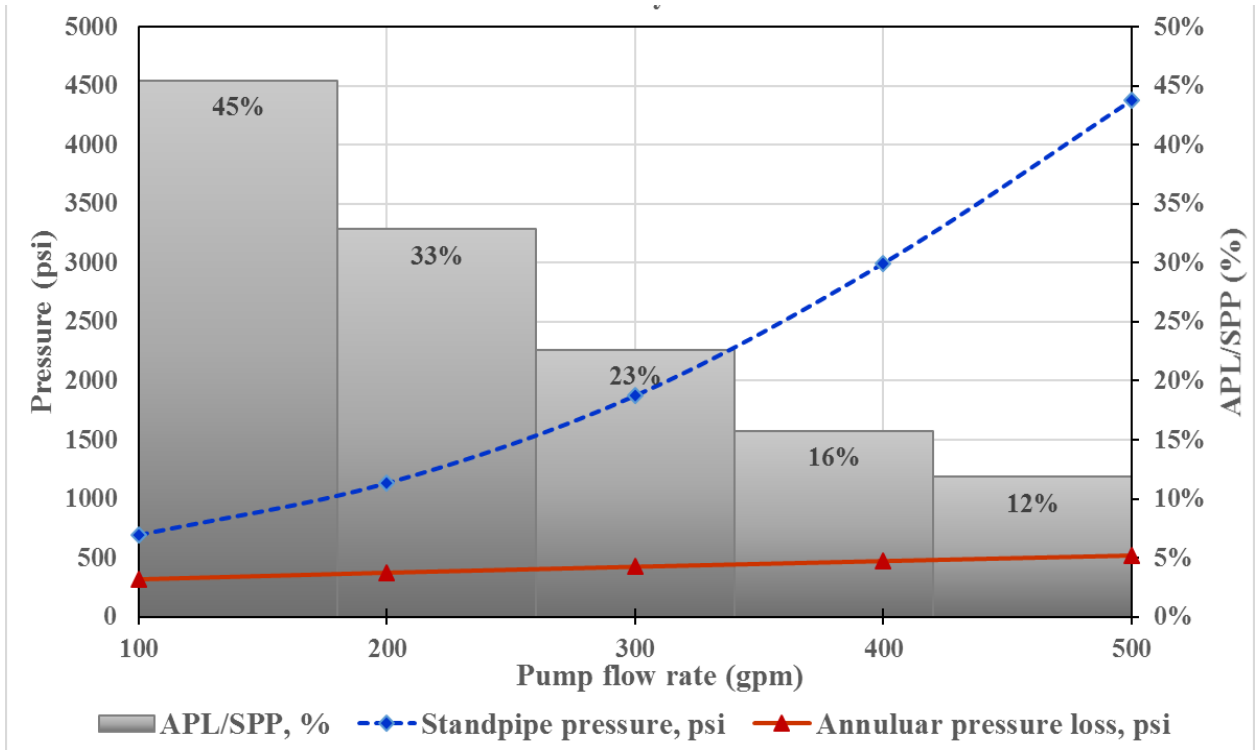

Figure 4.5: Standpipe pressure and annular pressure loss at slow pump rates in MRC X1.

\subsection{Hydraulics Results for Drilling with Casing and Liner}

\subsubsection{Drilling with Casing/Liner in Water Based Mud}

Figure 4.6 provides ECD profiles at normal drilling flow rates up to $800 \mathrm{gpm}$ in vertical, directional, and horizontal wells. These wells were drilled with different string configurations such as drillpipe, casing, and liner. A dramatic change in ECD is observed at pump rates above $500 \mathrm{gpm}$ in directional well, and above $400 \mathrm{gpm}$ in horizontal wells. The ECD curve shows 3 slopes that are attributed to the different flow regimes (laminar, transition and turbulent flow). With a tight annulus, as in drilling with casing/liner, ECD increases exponentially at higher flow rates compared to conventional drillpipe. A great advantage of drilling with casing/liner is the achievement of optimum hole cleaning at lower circulation rates. 
It is essential to reduce the circulation rate to prevent excessive friction losses that jeopardize wellbore integrity and results in loss circulation in depleted zones. In DwC, the same annular velocity can be achieved at $50 \%$ of the conventional flow rate in DwP. In deviated wells, the higher the difference between the vertical and measured depth, the greater the deviation in ECD values between DwC/DwL and DwP.

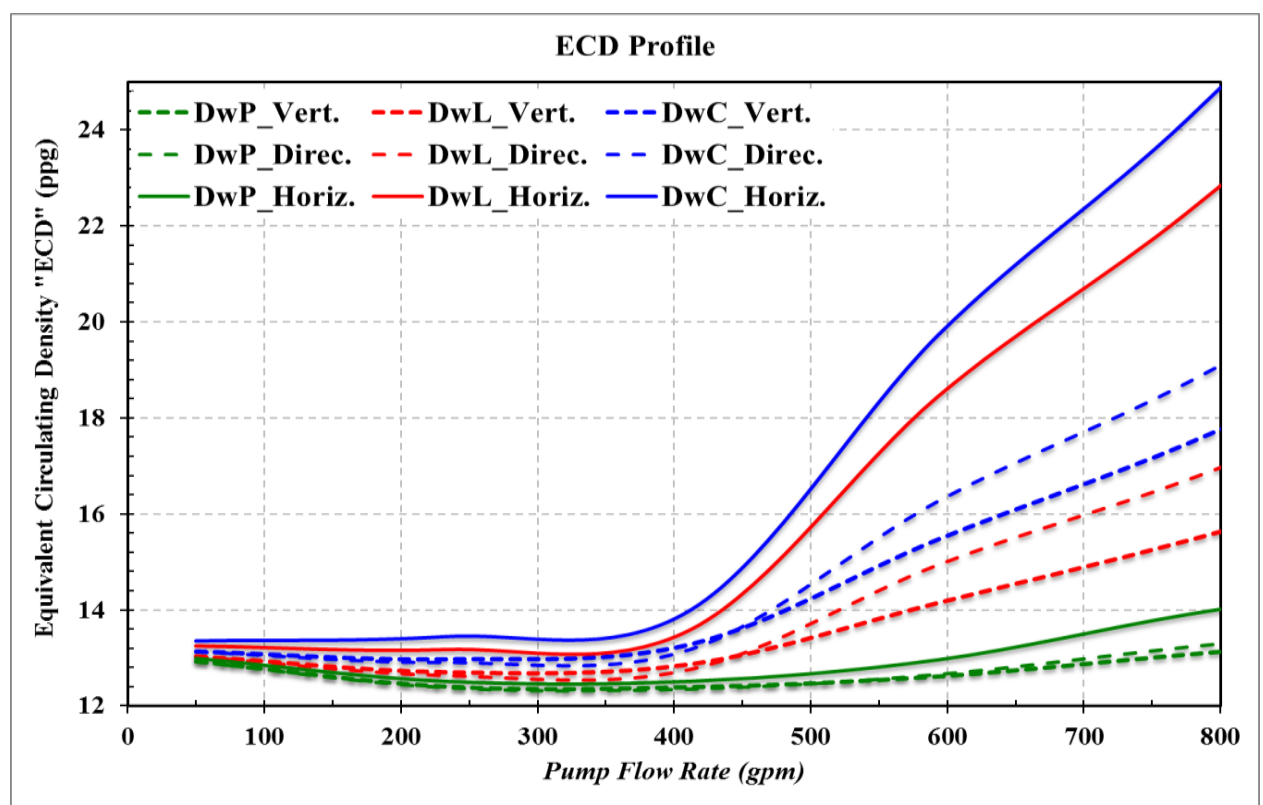

Figure 4.6: ECD profile for vertical, directional, and horizontal wells drilled with drillpipe, casing, and liner at normal drilling flow rates up to $800 \mathrm{gpm}$.

Figure 4.7 through Figure 4.9 show pressure loss profiles inside the drillstring, at the bit, and in the annulus (APL). These figures include vertical, directional, and horizontal wells drilled with drillpipe, casing, and liner. In DwP, as shown in Figure 4.7a, the APL is mostly lower than the drill bit and drillpipe pressure losses. However, the APL ratio increases at slower pump rates. For instance, at $60 \mathrm{spm}$, APL is $8 \%$, while at $10 \mathrm{spm}$ it is $41 \%$. Meanwhile, in DwC, the APL is significantly greater than DwP and DwL (Figure 4.7c). Similarly, in directional and horizontal wells shown in Figure 4.8 and Figure 4.9, the APL in DwP is usually lower compared to DwC. In DwL at $60 \mathrm{spm}$, the APL increases from $20 \%$ to $25 \%$ to $42 \%$ in vertical, directional, and horizontal wells, respectively. 
Furthermore, in DwP (Figure 4.9a) at $60 \mathrm{spm}$, the APL ratio is $12 \%$ and it can be safely neglected. In contrast, in DwC (Figure 4.9c), the APL at $60 \mathrm{spm}$ is $49 \%$ of pump pressure and increases to $80 \%$ at $10 \mathrm{spm}$. Therefore, neglecting APL in pressure step-down calculations might lead to unexpected consequences. This highlights the need to adjust the pumping schedule taking APL into account (Elshehabi and Bilgesu, 2016).
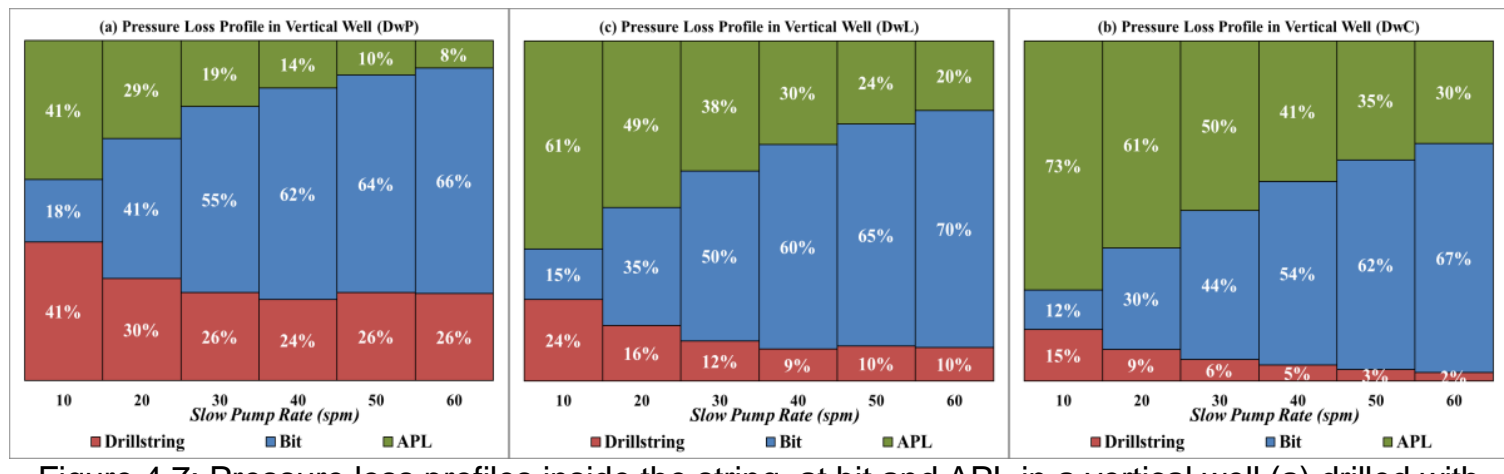

Figure 4.7: Pressure loss profiles inside the string, at bit and APL in a vertical well (a) drilled with pipes, (b) drilled with liner and (c) drilled with casing.
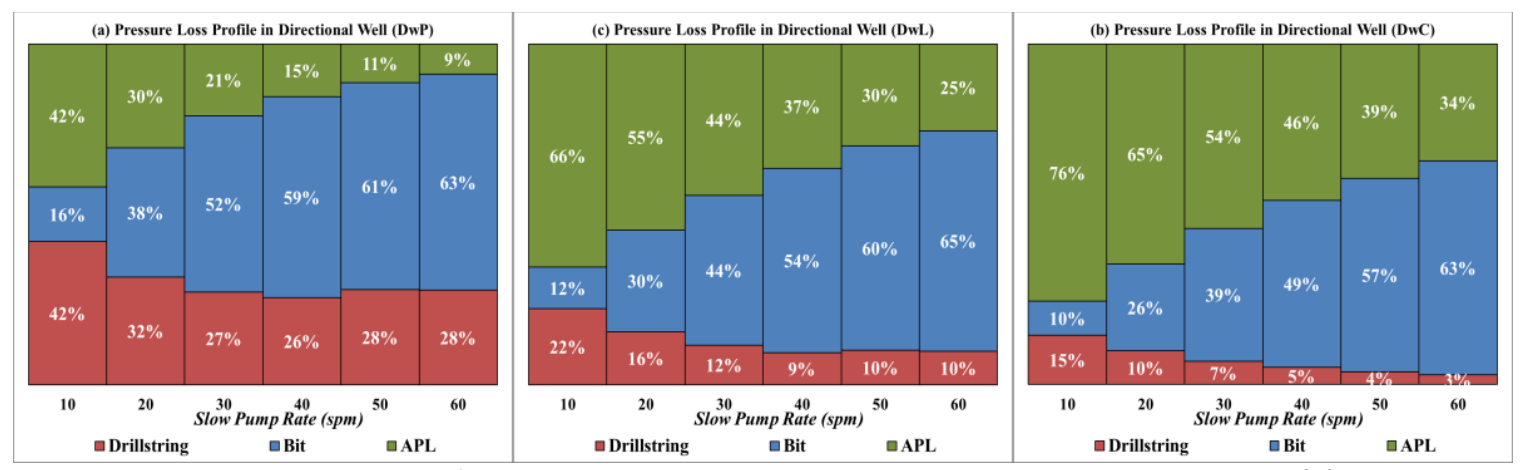

Figure 4.8: Pressure loss profiles inside the string, at bit and APL in a directional well (a) drilled with pipes, (b) drilled with liner and (c) drilled with casing.
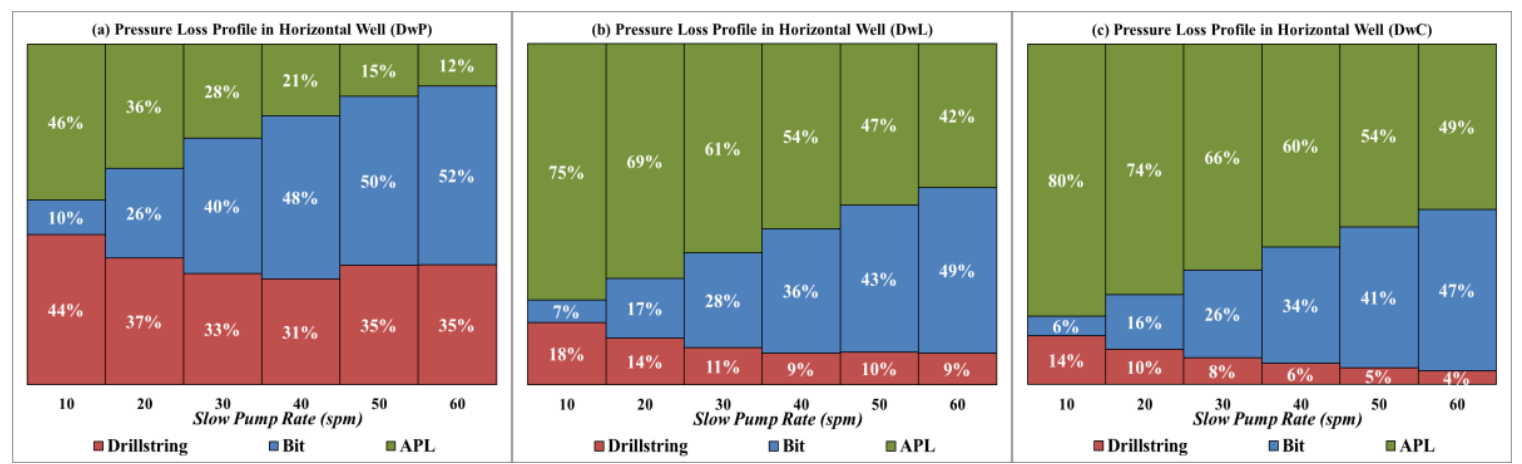

Figure 4.9: Pressure loss profiles inside the string, at bit and APL in a horizontal well (a) drilled with pipes, (b) drilled with liner and (c) drilled with casing. 
Figure 4.10 through Figure 4.12 compare ECD profile and pressure loss ratio (R) studied at slow (kill) pump rates (up to $250 \mathrm{gpm}$ ). Results are given for vertical, directional, and horizontal wells drilled with drillpipe, liner and casing strings. $R$ is the ratio of APL and pressure losses inside the drillstring excluding the drill bit losses. In conventional drillstring configuration, $\mathrm{R}$ is less than or equal to one; however, in DwC/DwL, R surges up to 12 . Obviously, the higher the well deviation with a smaller annulus, the higher the ECD and R values. As an example, in a vertical well drilled with pipe at a slow pump rate of $60 \mathrm{spm}$ (Figure 4.10), ECD is $12.2 \mathrm{ppg}$ and $\mathrm{R}$ is 0.3 . In a horizontal well drilled with casing at $60 \mathrm{spm}$ (Figure 4.12), ECD is $13.8 \mathrm{ppg}$ and $R$ is 12. Even at slow pump rates, $D w C / D w L$ are subjected to an inverse friction loss profile. Consequently, with $\mathrm{DwC} / \mathrm{DwL}$, high ECD and APL values necessitate adjustments to the pumping schedule (Elshehabi and Bilgesu, 2016).

(a) Vertical Well WBM Hydrualics

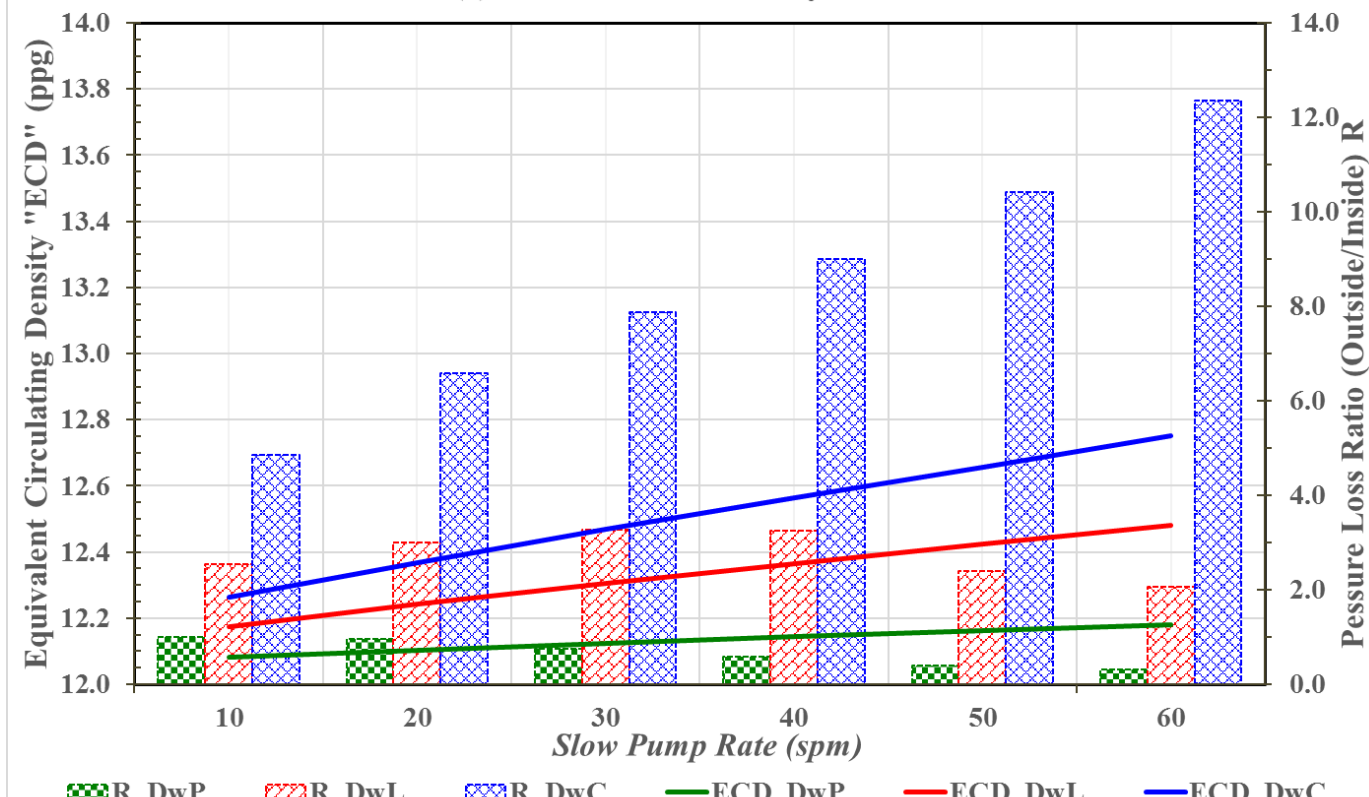

Figure 4.10: ECD profile and pressure loss ratio $(R)$ at slow pump rates in a vertical well drilled with DwP, DwL, and DwC. 


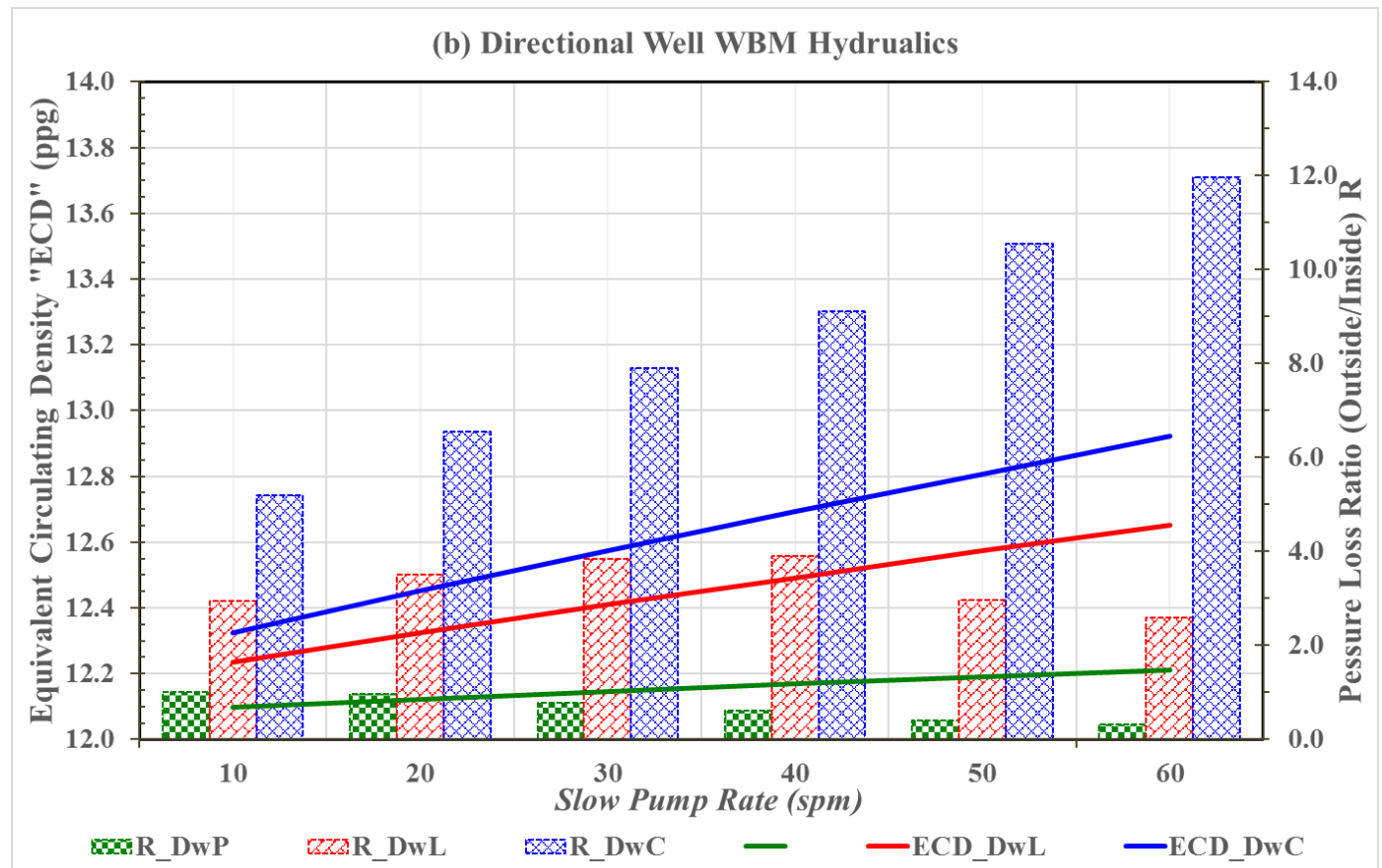

Figure 4.11: ECD profile and pressure loss ratio $(R)$ at slow pump rates in a directional well drilled with DwP, DwL, and DwC.

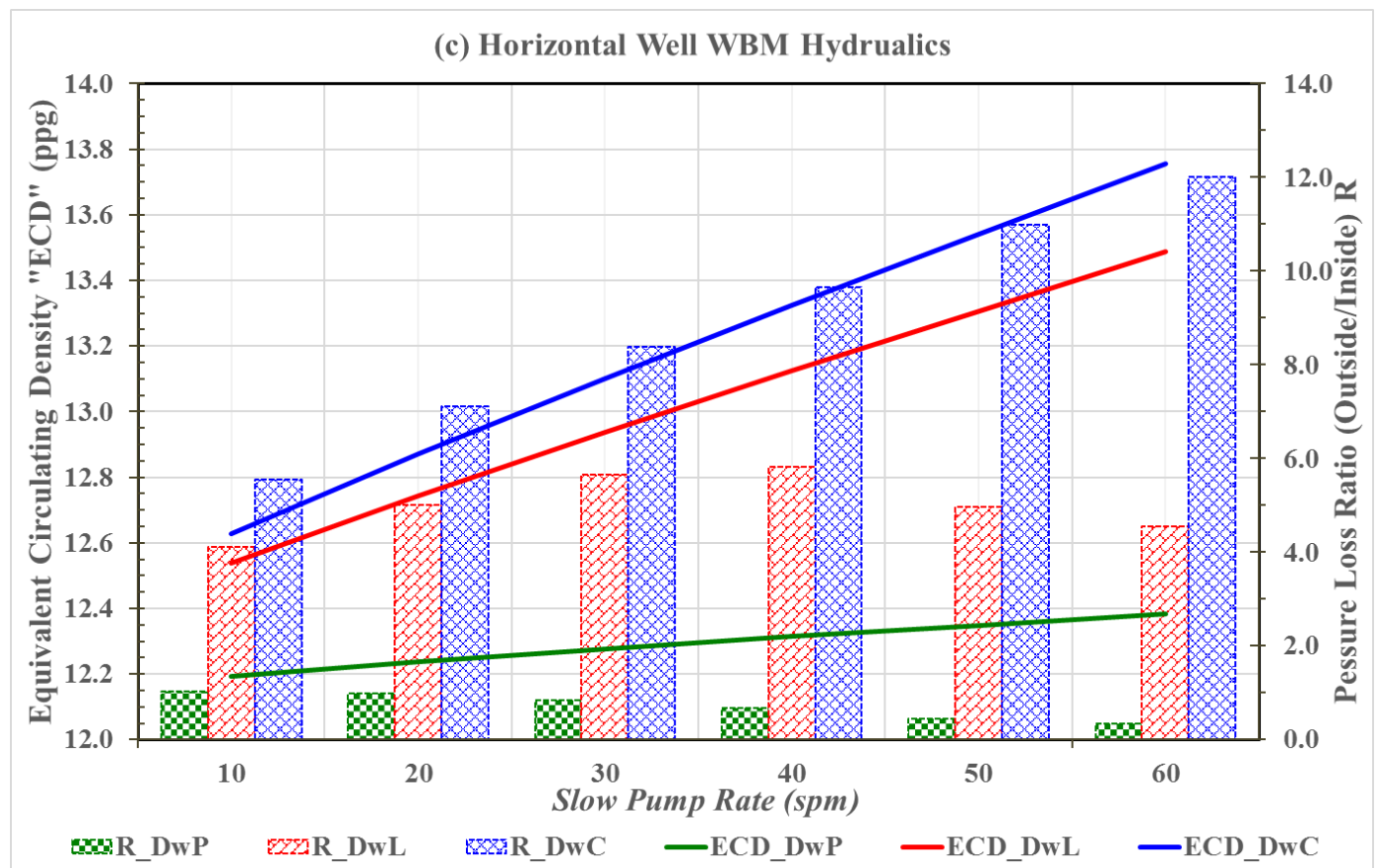

Figure 4.12: ECD profile and pressure loss ratio $(R)$ at slow pump rates in a horizontal well drilled with DwP, DwL, and DwC. 


\subsubsection{Drilling with Casing/Liner in Oil Based Mud}

Figure 4.13 show the pressure loss profile in a horizontal well drilled with pipe, casing, and liner using oil based mud. At $60 \mathrm{spm}$, the APL accounts for $17 \%$ of the system friction in DwP (Figure 4.13a). However, the APL represents 54\% in DwC as shown in Figure $4.13 \mathrm{c}$ and increases to $81 \%$ at $10 \mathrm{spm}$. In comparison to WBM shown in Figure 4.9, OBM represents higher APL at all flow rates because of the higher viscosity. Therefore, APL should not be neglected at slow pump rates.
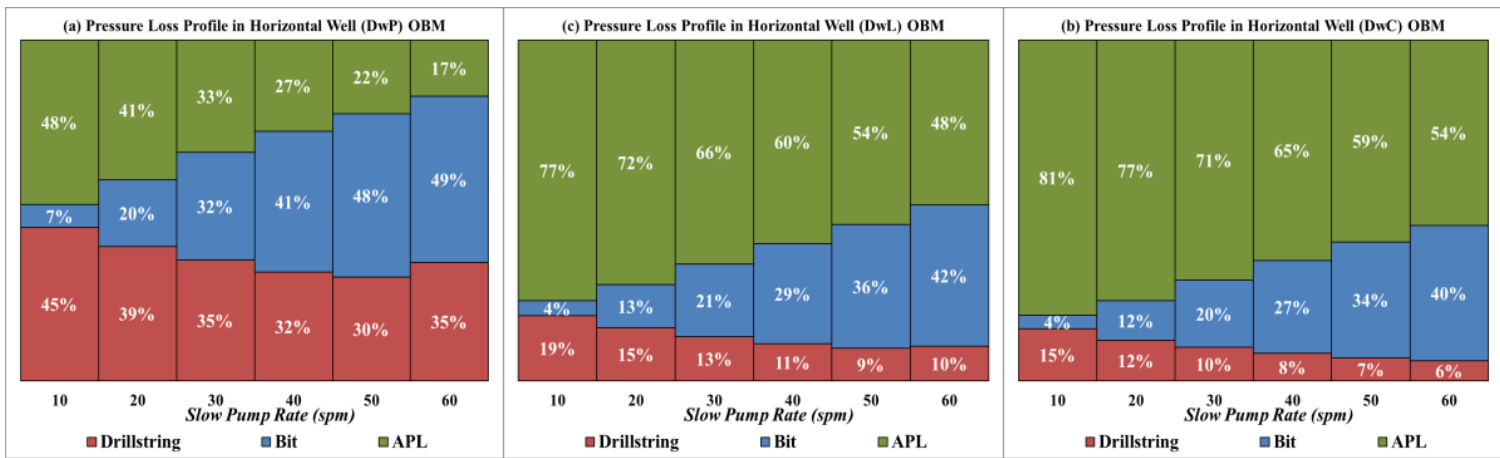

Figure 4.13: Pressure loss profiles inside the string, at bit and APL in horizontal well (a) drilled with pipes, (b) drilled with liner and (c) drilled with casing in OBM.

Figure 4.14 compares the ECD profile and pressure loss ratio $(R)$ at different slow pump rates. It is obvious that in DwC, the ECD progressively increases to 14.5 ppg at $60 \mathrm{spm}$ and applies an additional $2.5 \mathrm{ppg}$ equivalent friction to the bottomhole. In contrast, the ECD increases slightly to $12.6 \mathrm{ppg}$ in DwP at the same flow rate. Likewise, $\mathrm{R}$ increases to 9.4 in DwC at $60 \mathrm{spm}$ while it is only 0.5 in DwP. Therefore, in DwC/DwL, hydraulics profile is inverted and APL is high and well control stepdown chart should consider the high APL. Based on this hydraulic result, pressure loss inside the drill string including bit pressure losses can be approximated as $\left(133 \% \times \Delta \mathrm{P}_{\text {Bit }}\right)$ in $\mathrm{DwL}$, or as $\left(150 \% \times \Delta \mathrm{P}_{\text {Bit }}\right)$ in $\mathrm{DwC}$. The approximated values can be used to calculate the R2SD model parameters in equations 3.13 and 3.15. 


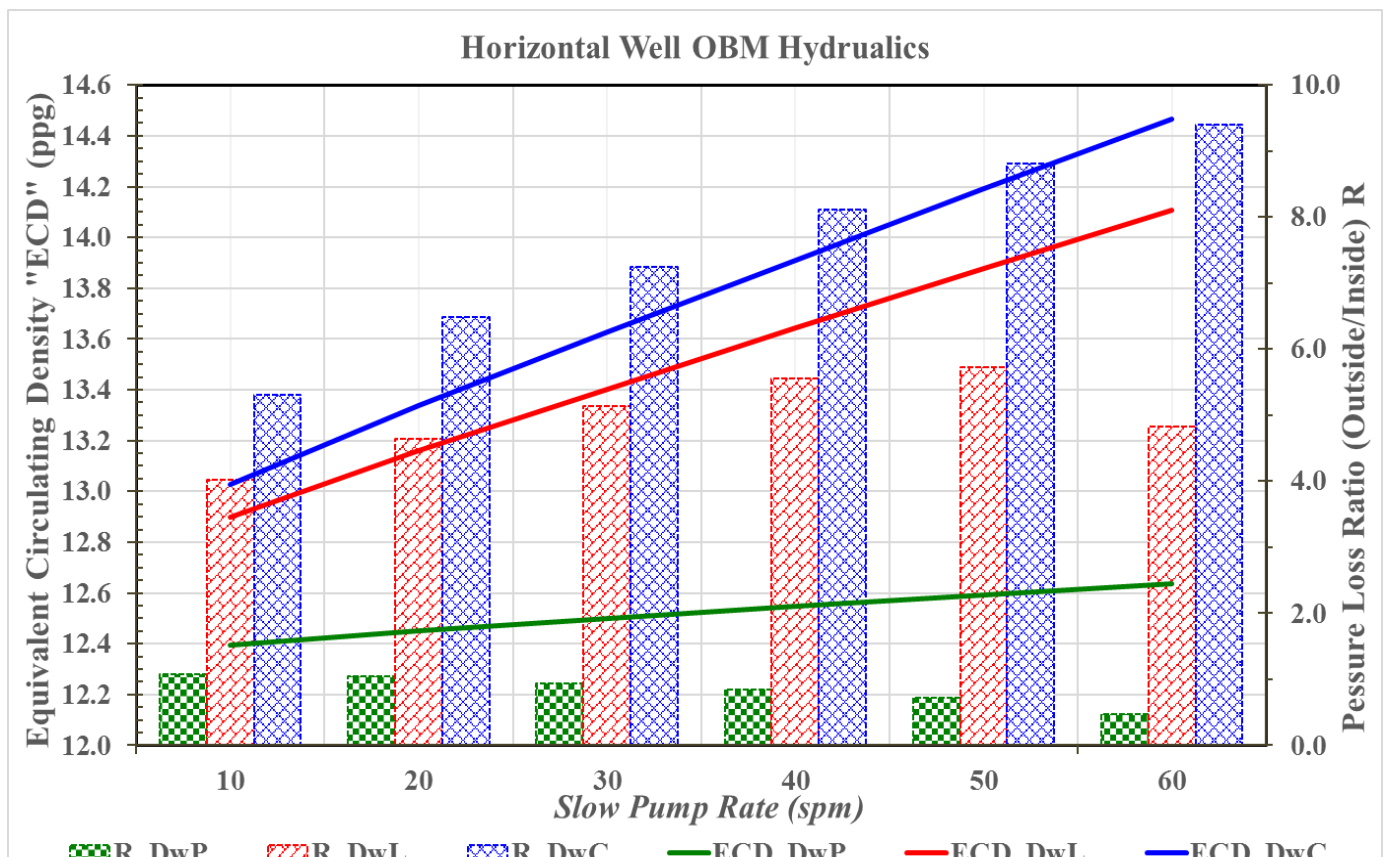

Figure 4.14: ECD profile and pressure loss ratio $(R)$ at slow pump rates in horizontal wells.

\subsection{Hydraulics Results for Inclined Upward and Downward Laterals}

\subsubsection{Pressure and ECD Profiles in Inclined Downward Lateral}

Figure 4.15 shows the impact of changing the pump flow rate on circulating pressure and ECD profiles in an inclined downward lateral. Obviously, reducing the pump rate significantly decreases the standpipe pressure, APL and ECD. For instance, standpipe pressure decreases form $4,377 \mathrm{psi}$ at $500 \mathrm{gpm}$ to $692 \mathrm{psi}$ at 100 gpm. Consequently, the APL reduces from 520 psi to 315 psi and the ECD decreases from $13.64 \mathrm{ppg}$ to $13.15 \mathrm{ppg}$. Figure 4.16 illustrates the impact of flow rate on standpipe pressure and APL at $100 \%$ cutting transport ratio for the perfect hole cleaning condition. At $500 \mathrm{gpm}$, the APL represents $11.9 \%$ of the pump pressure; while at a very slow pump rate $(100 \mathrm{gpm})$, the APL is $45.5 \%$ of the system friction losses. Therefore, at slow pump rates, the APL represents a significant ratio of system pressure losses and this should be considered in well control practices. 

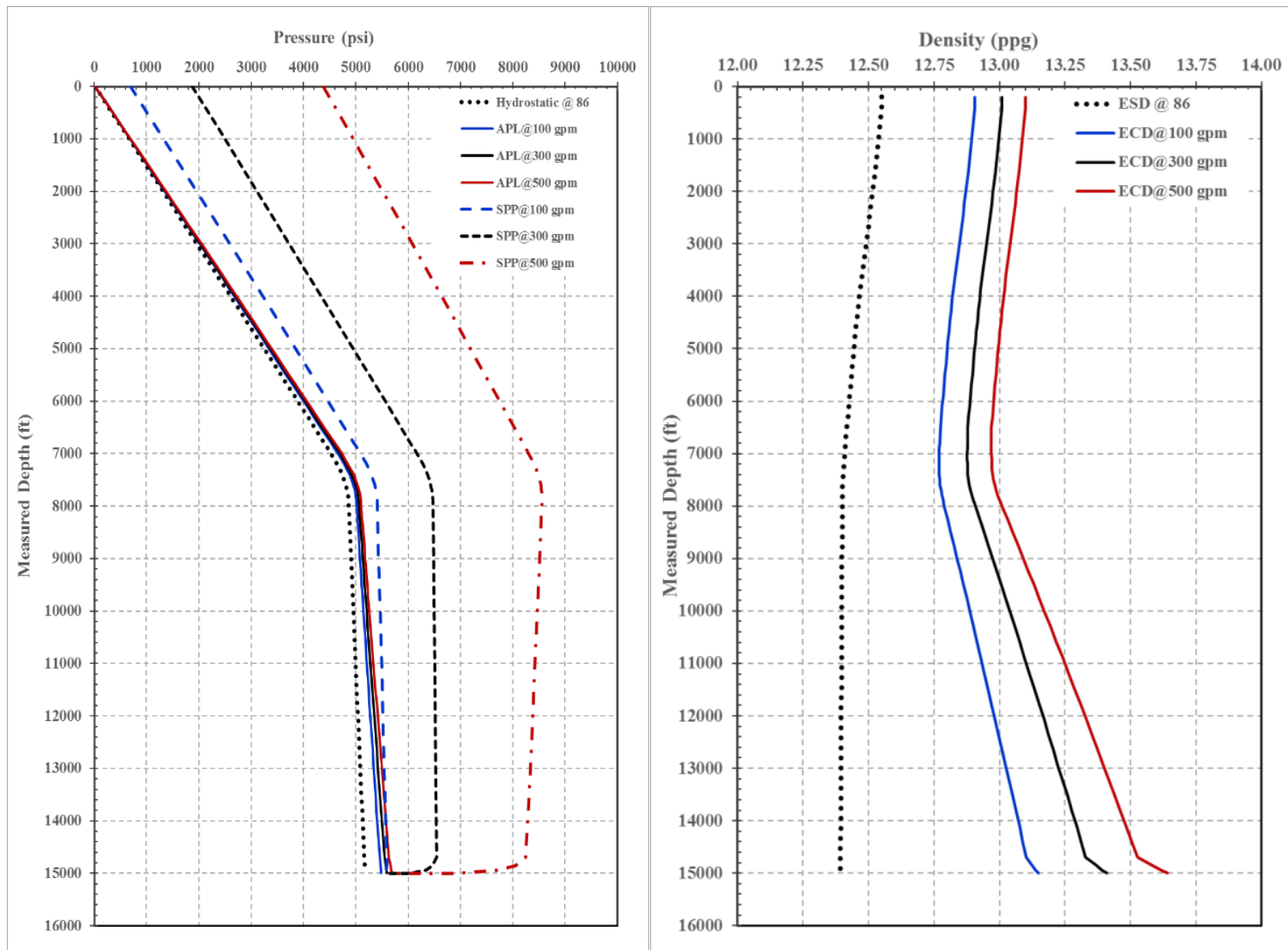

Figure 4.15: Pressure and ECD profiles in an inclined downward at 100, 300, and $500 \mathrm{gpm}$ flow rates.

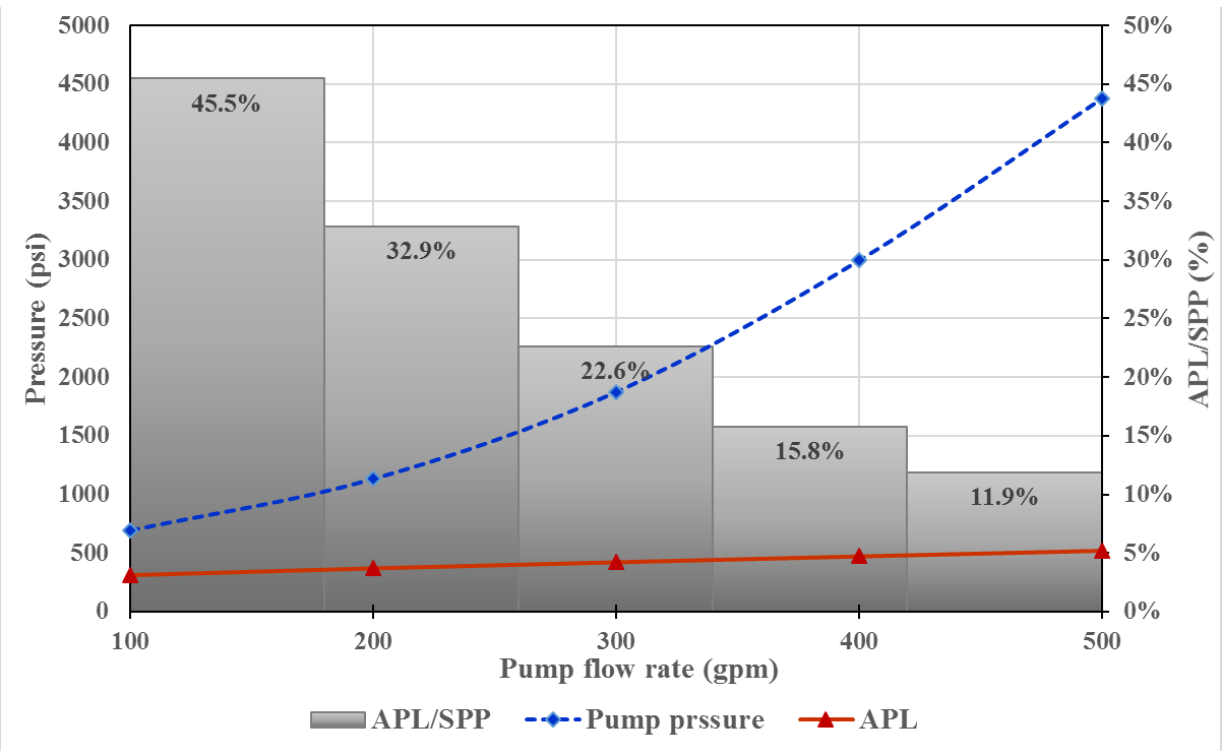

Figure 4.16: Standpipe pressure and annular pressure loss at slow pump rates in an inclined downward well. 


\subsubsection{Pressure and ECD Profiles in Inclined Upward Lateral}

Figure 4.17 demonstrates the impact of flow rate on circulating pressure and ECD in inclined upward laterals. Standpipe pressure decreases form 4,381 psi at $500 \mathrm{gpm}$ to $692 \mathrm{psi}$ at $100 \mathrm{gpm}$. As a result, the APL decreases from $469 \mathrm{psi}$ to 283 psi and the ECD reduces from $13.83 \mathrm{ppg}$ to $13.27 \mathrm{ppg}$ when flow rate is reduced from $500 \mathrm{gpm}$ to $100 \mathrm{pgm}$.
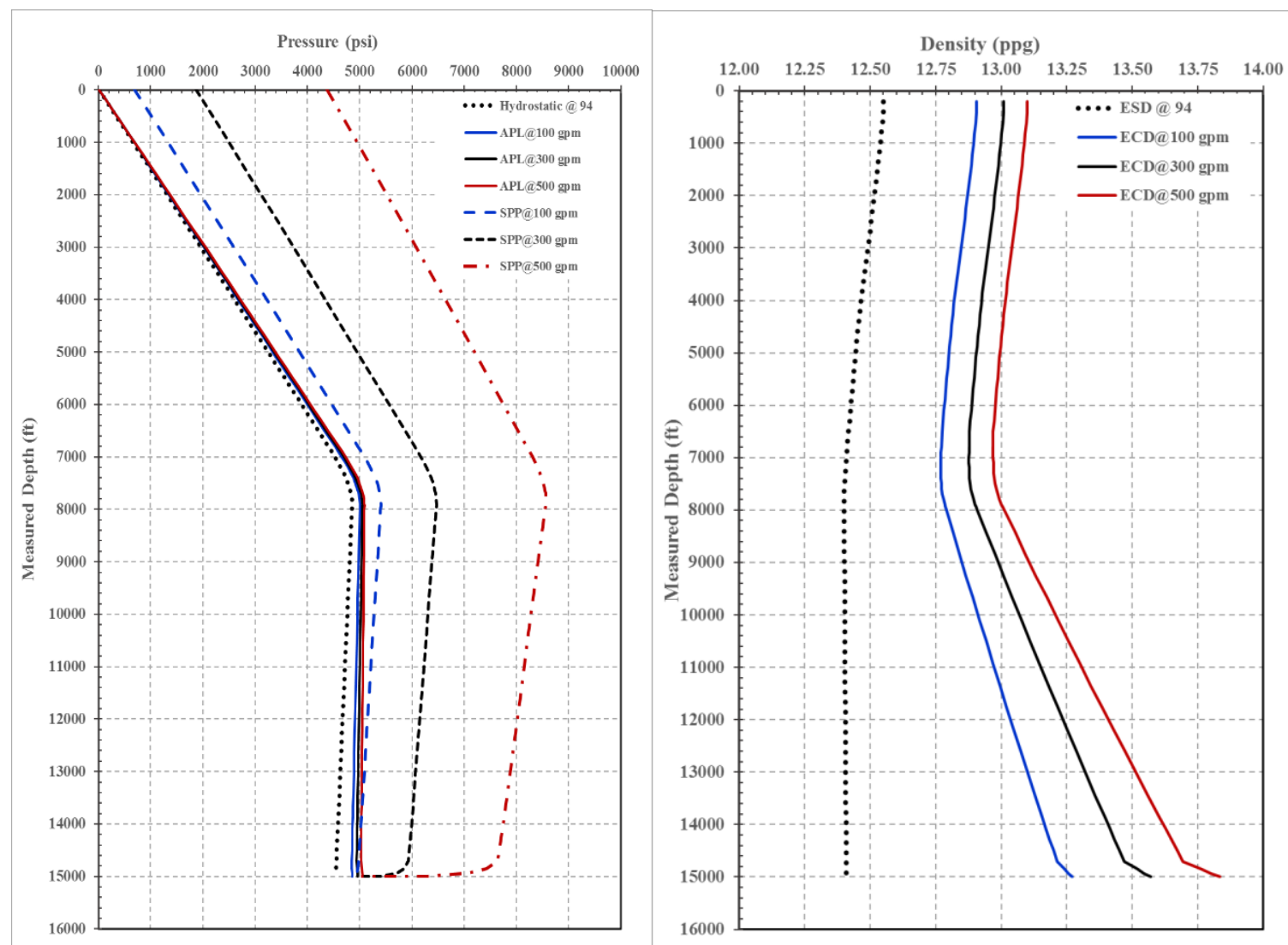

Figure 4.17: Pressure and ECD profiles in inclined upward at 100, 300, and $500 \mathrm{gpm}$ flow rates.

Figure 4.18 shows the impact of flow rate on standpipe pressure and APL considering perfect hole cleaning conditions. The APL constitutes $10.7 \%$ of the pump pressure at $500 \mathrm{gpm}$. However, at a very slow pump rate (100 gpm), the APL ratio significantly increases to $40.9 \%$ of the system friction loss. This observation is consistent with the results of an inclined downward lateral (Figure 4.16). Therefore, well control operations should take APL into consideration to avoid fracturing the casing shoe during the kick circulation. 


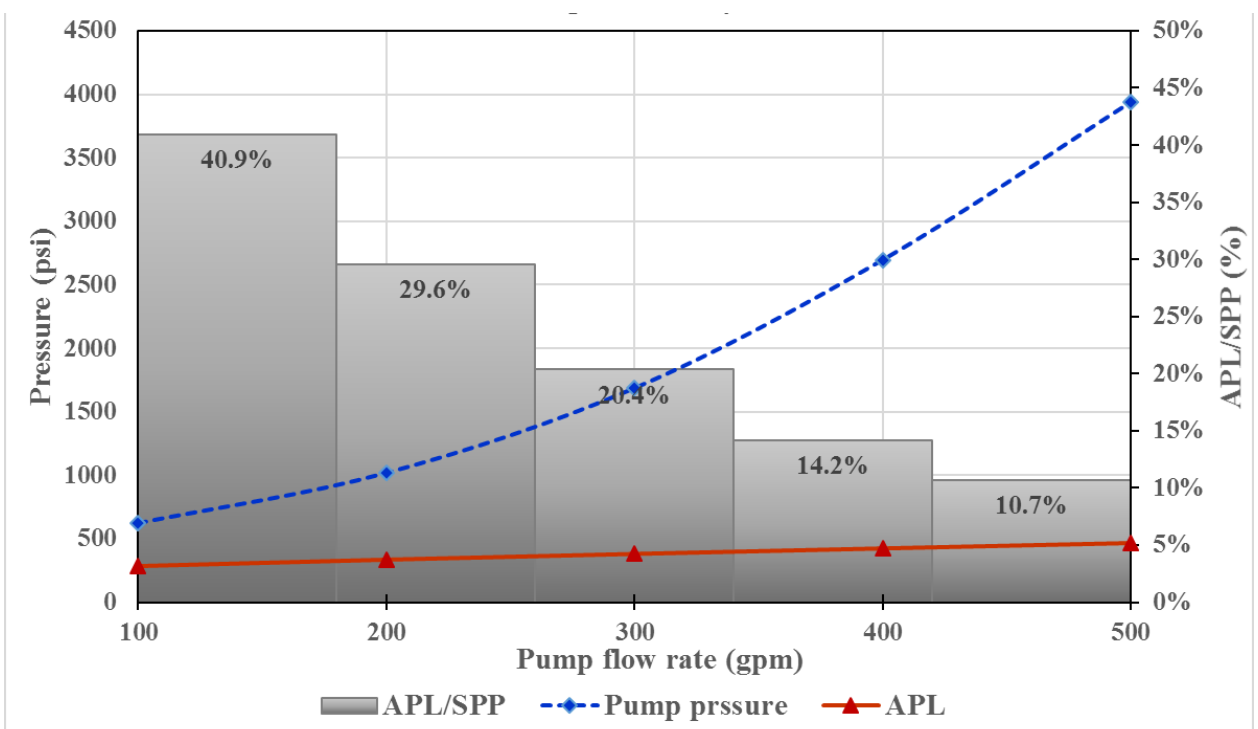

Figure 4.18: Standpipe pressure and annular pressure loss at slow pump rates in an inclined upward well.

\subsubsection{Comparison between Inclined Upward and Downward Laterals}

ECD and pressure profiles for $86^{\circ}$ inclined downward, $90^{\circ}$ flat horizontal, and $94^{\circ}$ inclined upward laterals are compared in Figure 4.19 at the flow rate of $460 \mathrm{gpm}$. In inclined downward lateral, the maximum TVD is at the toe. Therefore, the circulating pressure increases inside the lateral section until it reaches the maximum at the bit depth (Figure 4.19). ECD is higher in inclined upward lateral compared to the flat horizontal well, as the TVD at the toe is less than the TVD at the heel. In flat horizontal and upward laterals, APL value is 520 psi, but ECD is 13.73 ppg and $13.84 \mathrm{ppg}$, respectively. Furthermore, Figure 4.19 shows that in a flat horizontal well the hydrostatic pressure is constant at the value of 4845 psi inside the lateral section. At the normal drilling flow rate $460 \mathrm{gpm}$, the standpipe pressure is $3811 \mathrm{psi}$. In inclined downward laterals, TVD is higher at the toe and hydrostatic pressure increases by $6.5 \%$ and standpipe pressure rises by $3.2 \%$ from toe to shoe. In addition, APL significantly increases by $21.9 \%$ while ECD increase $1.5 \%$ only. However, in inclined upward where the TVD is less than flat horizontal, hydrostatic pressure decreases by $6.5 \%$ and standpipe slightly changes by $0.1 \%$ from toe to shoe. Also, APL insignificantly changes by $0.4 \%$ while ECD increases by $0.7 \%$. This is because cutting transport ratio (CTR) is $73.8 \%$ in inclined downward compared to $83.9 \%$ in inclined upward at flow rate of $460 \mathrm{gpm}$ (Figure 4.20 ). 

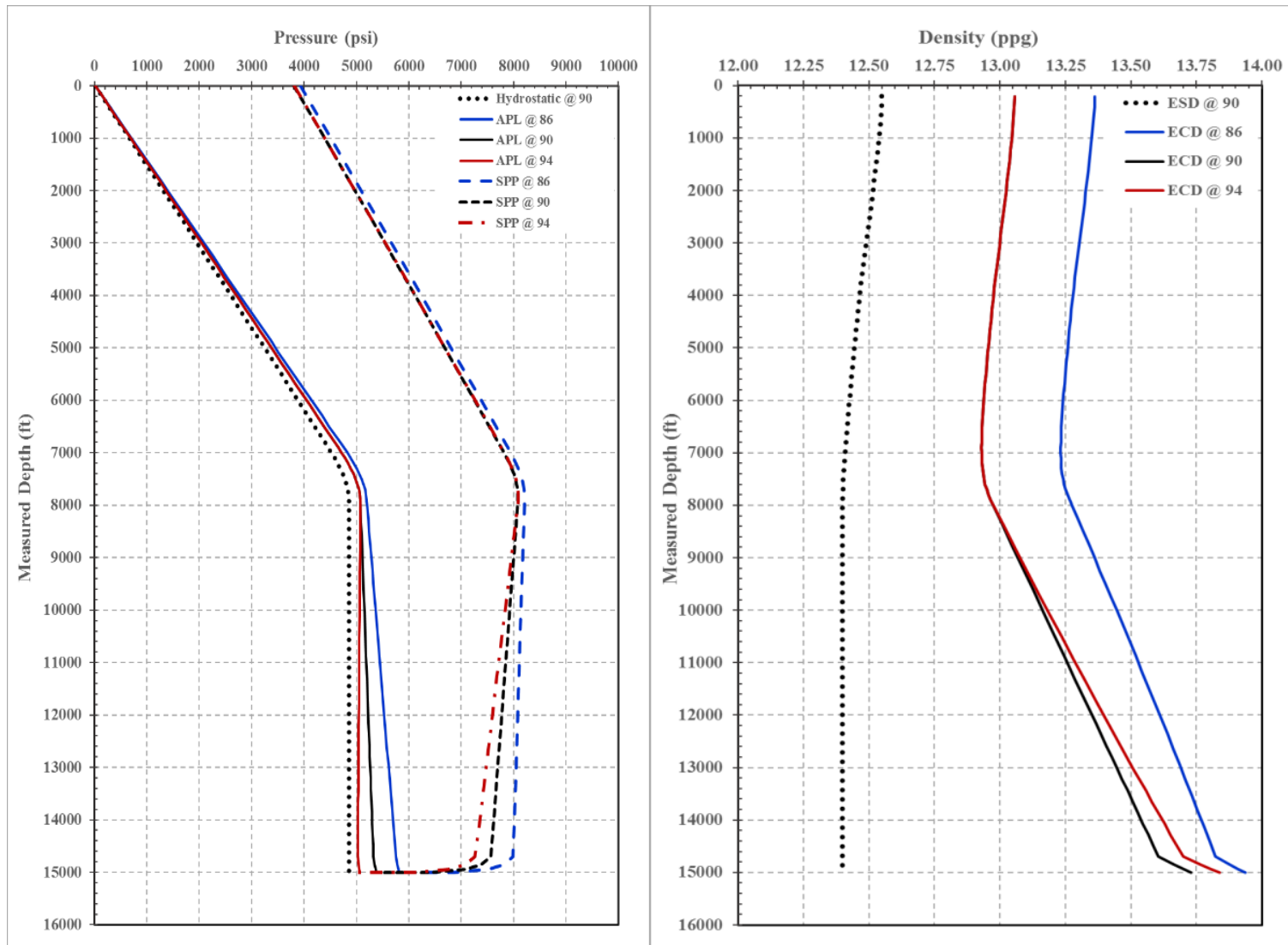

Figure 4.19: ECD, hydrostatic and circulating pressure profiles in $86^{\circ}$ inclined downward, $90^{\circ}$ flat and $94^{\circ}$ inclined upward laterals.

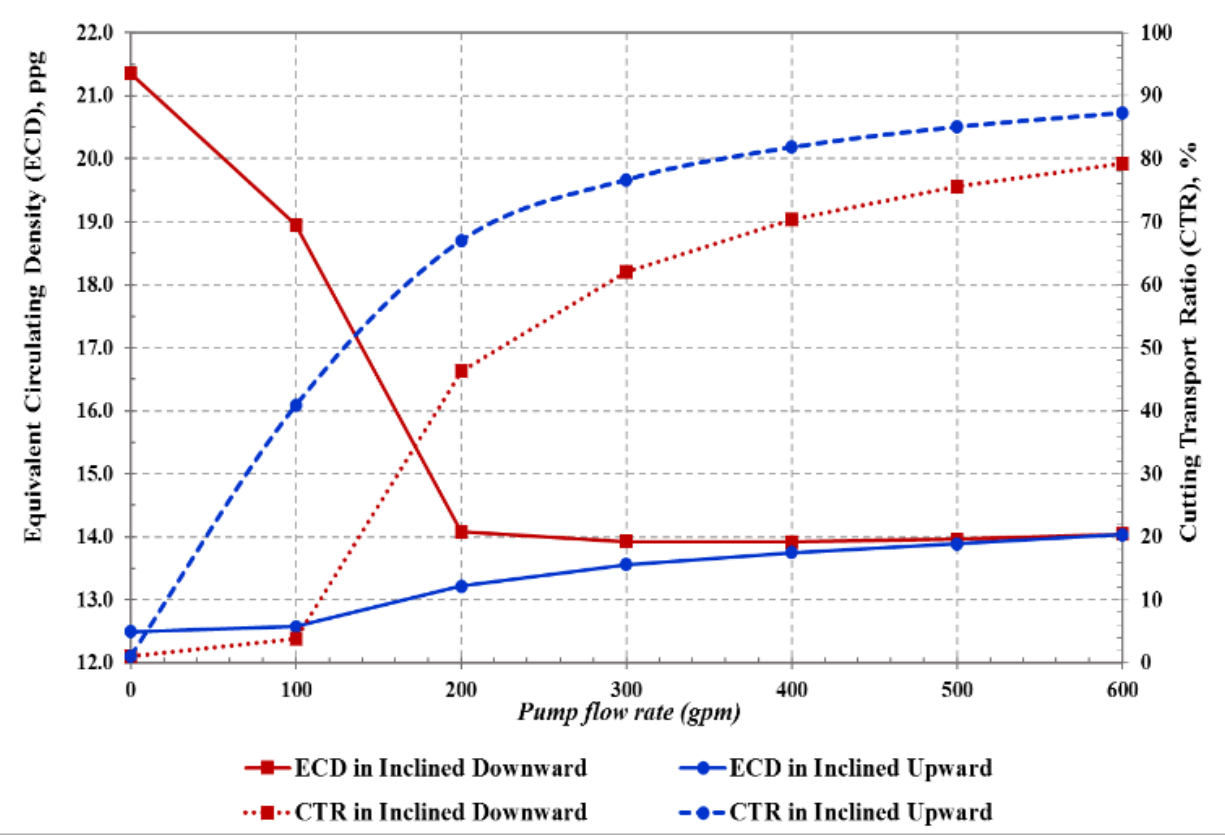

Figure 4.20: Impact of flow rate on ECD and cutting transport ratio in inclined upward and downward laterals. 
Figure 4.20 compares Equivalent Circulating Density (ECD) and Cutting Transport Ratio (CTR) in inclined upward with inclined downward laterals at flow rates up to $600 \mathrm{gpm}$. APL and associated ECD are higher in inclined downward lateral as a result of lower CTR compared to inclined upward laterals. This is mainly because of gravity associated cuttings accumulation on the bottomhole side at the toe. Obviously, higher the flow rate, higher the cutting transport ratio and lower the ECD in inclined downward. However, upon achieving the optimum hole cleaning, higher flow rates create excessive friction losses, and increase ECD.

For instance, at no circulation and due to cuttings loading, the ECD at the bottomhole can reach a dangerous value of $21.3 \mathrm{ppg}$ in inclined downward lateral since cutting settling velocity is $33.5 \mathrm{ft} / \mathrm{min}$. In contrast, ECD is $12.5 \mathrm{ppg}$ only in inclined upward lateral where cuttings settling velocity is $16 \mathrm{ft} / \mathrm{min}$ and cuttings accumulate at the heel. Further, in inclined upward lateral at a flow rate of $200 \mathrm{gpm}$, CTR is $67 \%$ and ECD is $13.22 \mathrm{ppg}$. In inclined downward lateral, CTR drops to $46.3 \%$ therefore, ECD increases to $14.08 \mathrm{ppg}$. At the high flow rate of $500 \mathrm{gpm}$, CTR is more than $50 \%$ ( $85 \%$ in inclined upward and $75 \%$ in inclined downward), and ECD is around $13.9 \mathrm{ppg}$ for both cases. Therefore, APL, associated ECD, and critical flow rate for proper hole cleaning are higher in inclined downward laterals compared to inclined upward laterals. 


\section{Part 2: Well Control Results}

\subsection{Well Control Study in Marcellus Shale Lateral}

\subsubsection{Impact of Well Type on Typical Surface Measurements}

Figure 4.21 compares the typical surface pressure measurements in a horizontal well with a vertical well with the same TVD using a kick size of 20 bbls circulated at a rate of $150 \mathrm{gpm}$. The vertical well ICP and FCP values were 836 and $397 \mathrm{psi}$, respectively. In the horizontal well, because of the higher friction, the ICP is $1,114 \mathrm{psi}$ and the FCP is 525 psi. The kick circulation needs 8.2 hours in the horizontal well compared to 4.1 hours in the vertical well. In contrast, in a horizontal well, the choke experiences $16.5 \%$ less pressure than in a vertical well. Further, the maximum pit gain and gas flow rate are reduced significantly in the horizontal well by $27.9 \%$ and $44 \%$, respectively. Meanwhile, in the horizontal well, gas bubbles trapped in the lateral section and the free gas expands only after it reaches the vertical section.
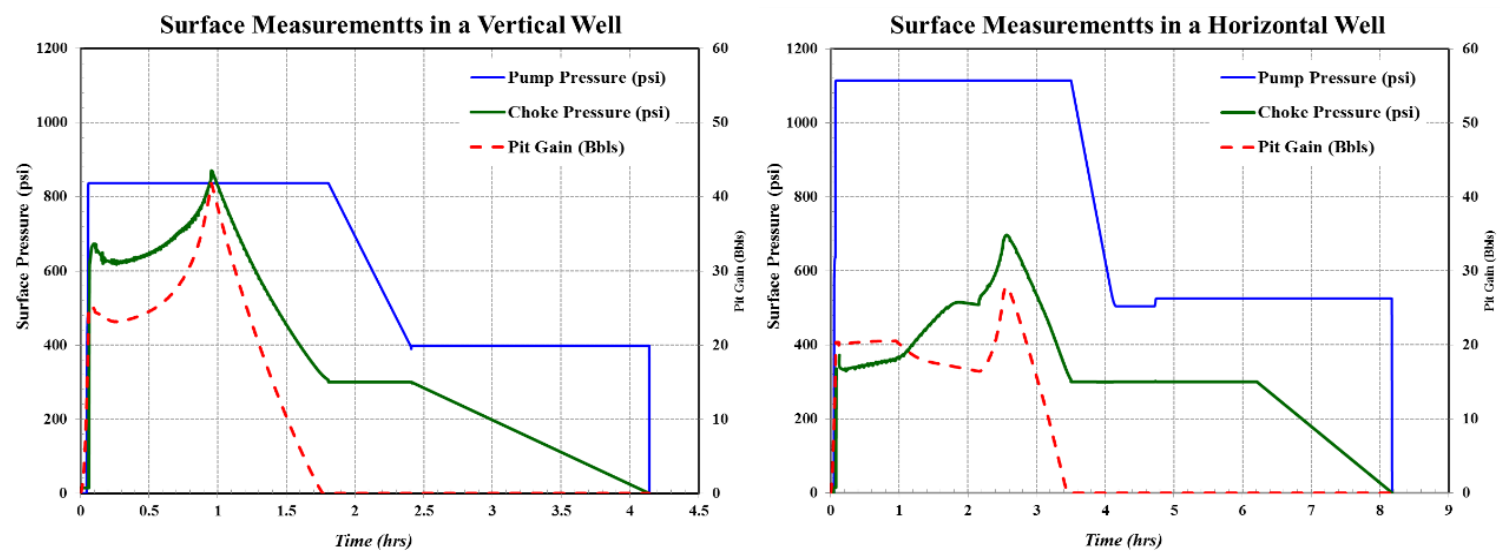

Figure 4.21: Pump pressure, choke pressure and pit gain in a horizontal well and a vertical well with the same TVD with a 20 bbls gas kick circulated at $150 \mathrm{gpm}$.

Choke pressure and pit gain are presented in Figure 4.22 for a horizontal well, a vertical well with the same TVD, and a vertical well with the same TD. Clearly, gas constantly expands in vertical well after it breaks out of solution at the bubble point. The maximum choke pressure increase is $166 \%$ greater in the long vertical well compared to the horizontal well due to the higher difference between bottomhole and surface conditions in the deeper well and with higher influx expansion rates greater by $169 \%$ compared to $137 \%$ in the horizontal well. 
Gas discharge flow rate is 2.5 MMSCFD in the short vertical well compared to 1.4 MMSCFD in the horizontal well. In horizontal well, the change in choke and casing shoe pressure doesn't start until the gas reaches the curve section and starts expanding. Therefore, the surface pressures and gas expansion rates are less in horizontal wells compared to vertical wells with the same TVD or TD as a result of gas dispersion and entrapment in lateral section compared to single slug expansion in vertical wells.
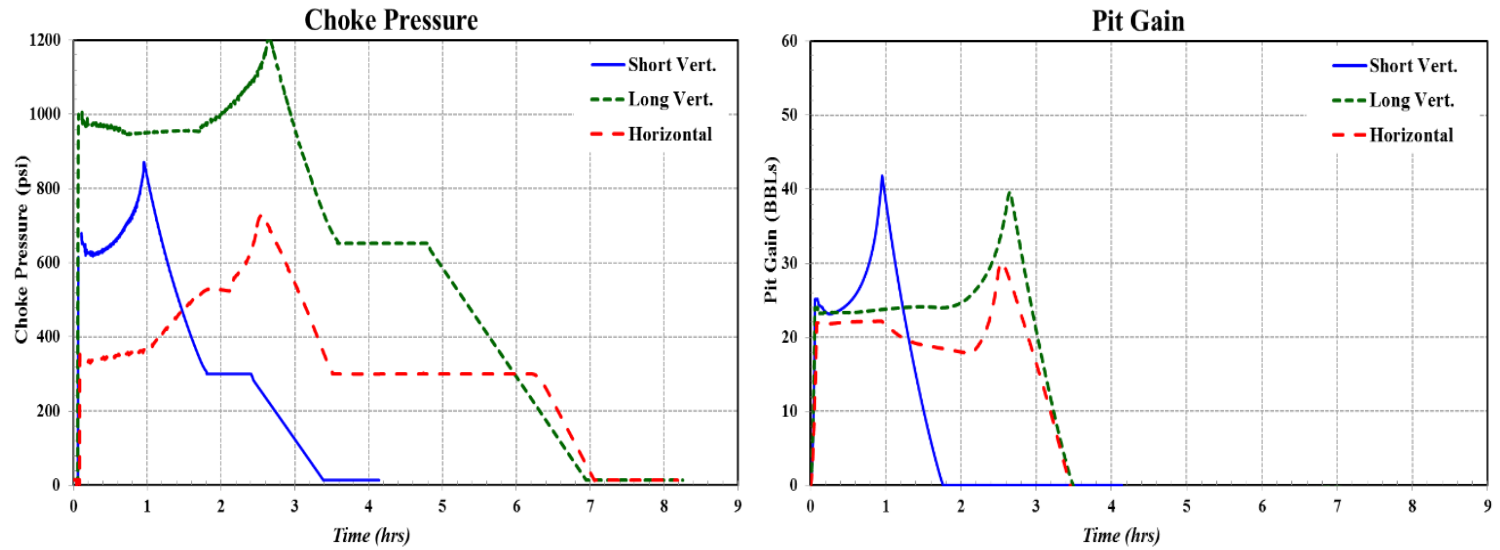

Figure 4.22: Choke pressure and pit gain in a horizontal well, a vertical well with the same TVD, and a vertical well with the same TD with a 20 bbls gas kick circulated at $150 \mathrm{gpm}$.

\subsubsection{Impact of Well Type on Slow Pump Rate and Shut-in Pressure Profile}

The results shown in Figure 4.23 illustrates the typical static and dynamic pressure profiles experienced in a vertical well at a normal drilling flow rate of 460 $\mathrm{gpm}$. Also, it shows pressure profile at a slow pump rate of $150 \mathrm{gpm}$ and shut-in conditions when a 20 bbls gas kick is received. The dynamic pressure profile consists of two components. First, the hydrostatic pressure component which increases linearly with the TVD. Second, the dynamic friction losses that depend on the tubular/wellbore configurations, mud properties, flow rate, and measured depth. Therefore, the dynamic downhole pressure profile inside the drillstring increases with depth until it reaches the BHA. Then, it decreases due to the high friction losses inside the BHA and at the bit. Moving forward in the annulus side, the pressure profile decreases until it reaches the surface with the atmospheric pressure (Bourgoyne et al., 1991). The slower pump rate results in lower pump and annular pressures. 

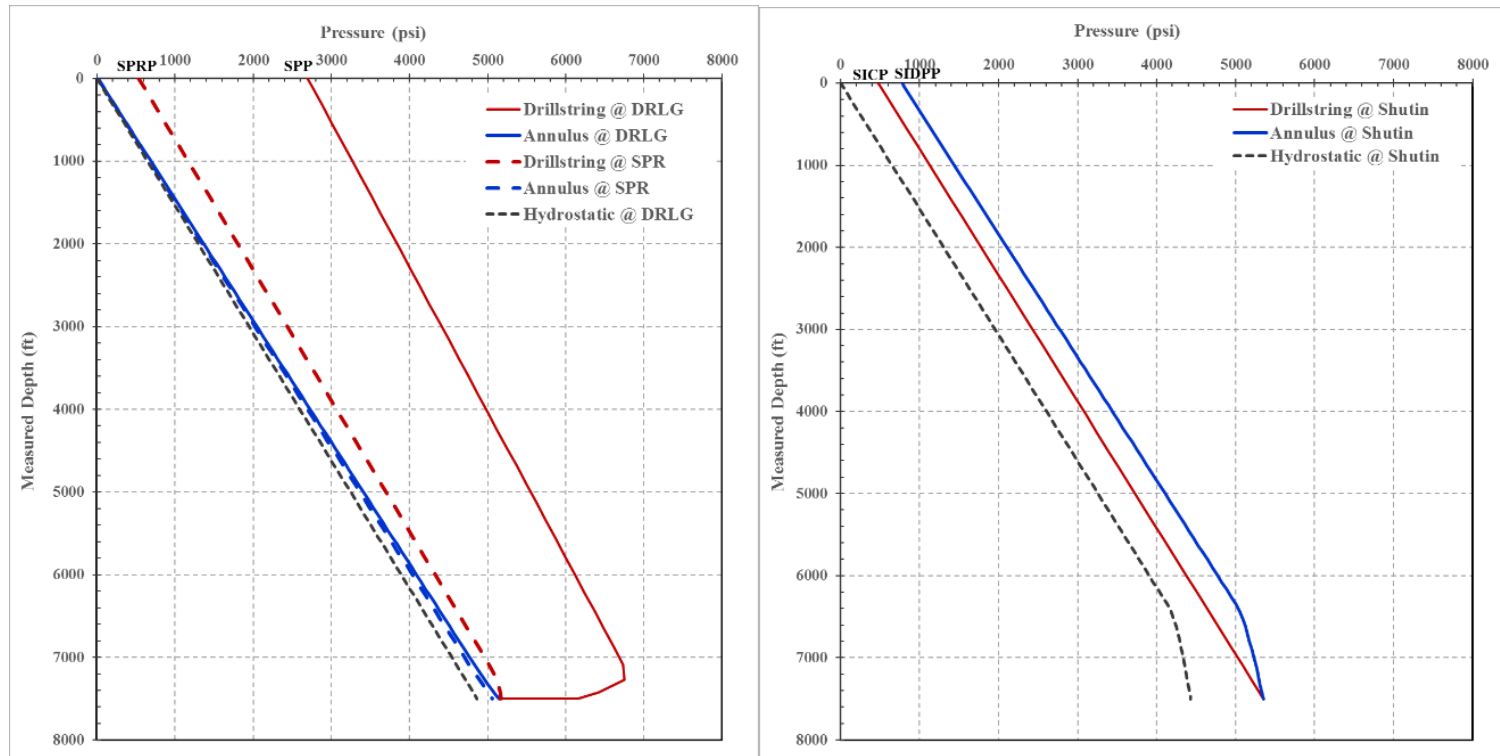

Figure 4.23: Pressure profiles at drilling (460 gpm), slow pump rate (150 spm), and shut-in conditions in a vertical well with a 20 bbls gas kick.

For instance, in the vertical well at $150 \mathrm{gpm}$, the pump pressure is $536 \mathrm{psi}$ and APL is 194 psi compared to 2699 psi and 281 psi at the drilling flow rate of 460 gpm. In addition, upon receiving a 20 bbls gas kick and closing the BOP, the corresponding SIDPP and SICP are 473 psi and 778 psi, respectively. According to Watson et al. (2003), the SICP is higher than SIDPP because of the occupied length of the less density gas influx in the annulus that results in less hydrostatic pressure.

Figure 4.24 shows pressure profiles for MRC X1 horizontal well at a normal circulation rate of $460 \mathrm{gpm}$, slow pump rate of $150 \mathrm{gpm}$, and shut-in conditions. Along the downhole, the dynamic pressure profile shows the same behavior as in a vertical well (Figure 4.23) until it reaches the lateral section. Whereas, there is no significant change in TVD in the lateral section, the hydrostatic pressure is constant (Figure 4.24). Pump pressure decreases to $657 \mathrm{psi}$ at $150 \mathrm{gpm}$ compared to 3373 psi at $460 \mathrm{gpm}$ and the APL decreases from 520 psi to $333 \mathrm{psi}$. APL accounts for $50 \%$ of the pump pressure at $150 \mathrm{gpm}$ and this observation is consistent with the results shown in Figure 4.5. Unlike the vertical well, there is no difference between SICP and SIDPP of 650 psi for the horizontal well since the gas influx has insignificant vertical height inside the lateral section (Choe et al., 2005). 

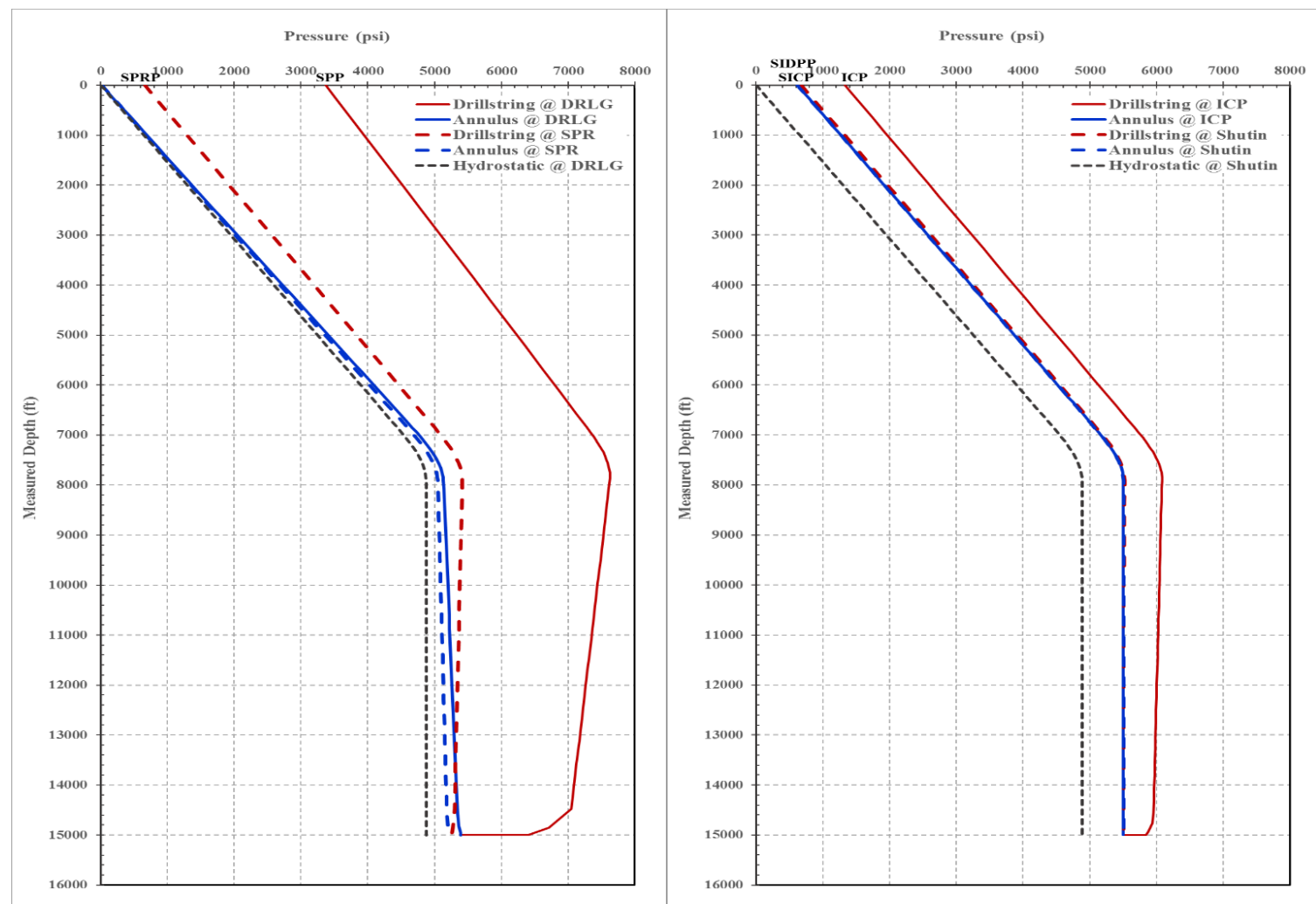

Figure 4.24: Pressure profiles at drilling (460 gpm), slow pump rate (150 spm), and shut-in conditions in MRC X1 horizontal well with a 20 bbls gas kick.

Regardless of the influx characteristics, SICP in horizontal wells is impacted only by the degree of underbalance between reservoir and hydrostatic pressures. Initially the dynamic bottomhole pressure overbalances the formation pressure until the kick is started. Then the reservoir pressure dominates the bottomhole conditions. After the well is shut-in and prior to kick circulation, the ICP and FCP are estimated to maintain the dynamic BHP by balancing the reservoir pressure at 5500 psi thru kick circulation. ICP and FCP are estimated as following:

$$
\begin{aligned}
& I C P=S I D P P+S P R P=650+680=1330 p s i \\
& F C P=S P R P \times \frac{K M W}{O M D}=680 x \frac{13.25}{12.5}=720 p s i
\end{aligned}
$$




\subsection{Well Control Results in an Oil Based Mud}

The horizontal wellbore configuration shown in Figure 3.2 and Table 3.2 was used to investigate the impact of gas solubility in an oil based mud on well control operations. In this part of the study, an interactive real-time drilling and well control simulator is used for more than 500 hours. Figure 4.25 compares pressure values for circulating a 20 bbls gas kick with the Wait-and-Weight method at 40 spm using two different step-down approaches. A vertical well step-down (solid line \#1) schedule is compared to an approximated horizontal well step-down (dotted line \#2) schedule. The recorded SIDPP is $355 \mathrm{psi}$ and the slow pump rate pressure is 565 psi at $40 \mathrm{spm}$. For vertical step-down, FCP is reached when the heavy mud filled the entire drillstring and exit the bit after 2,614 strokes. However, in the approximated horizontal step-down, FCP is reached once the heavy mud reaches the kick-off point for the rest of the circulation times. Results in Figure 4.25 show that the assumption of using vertical well step-down schedule in horizontal wells is invalid.

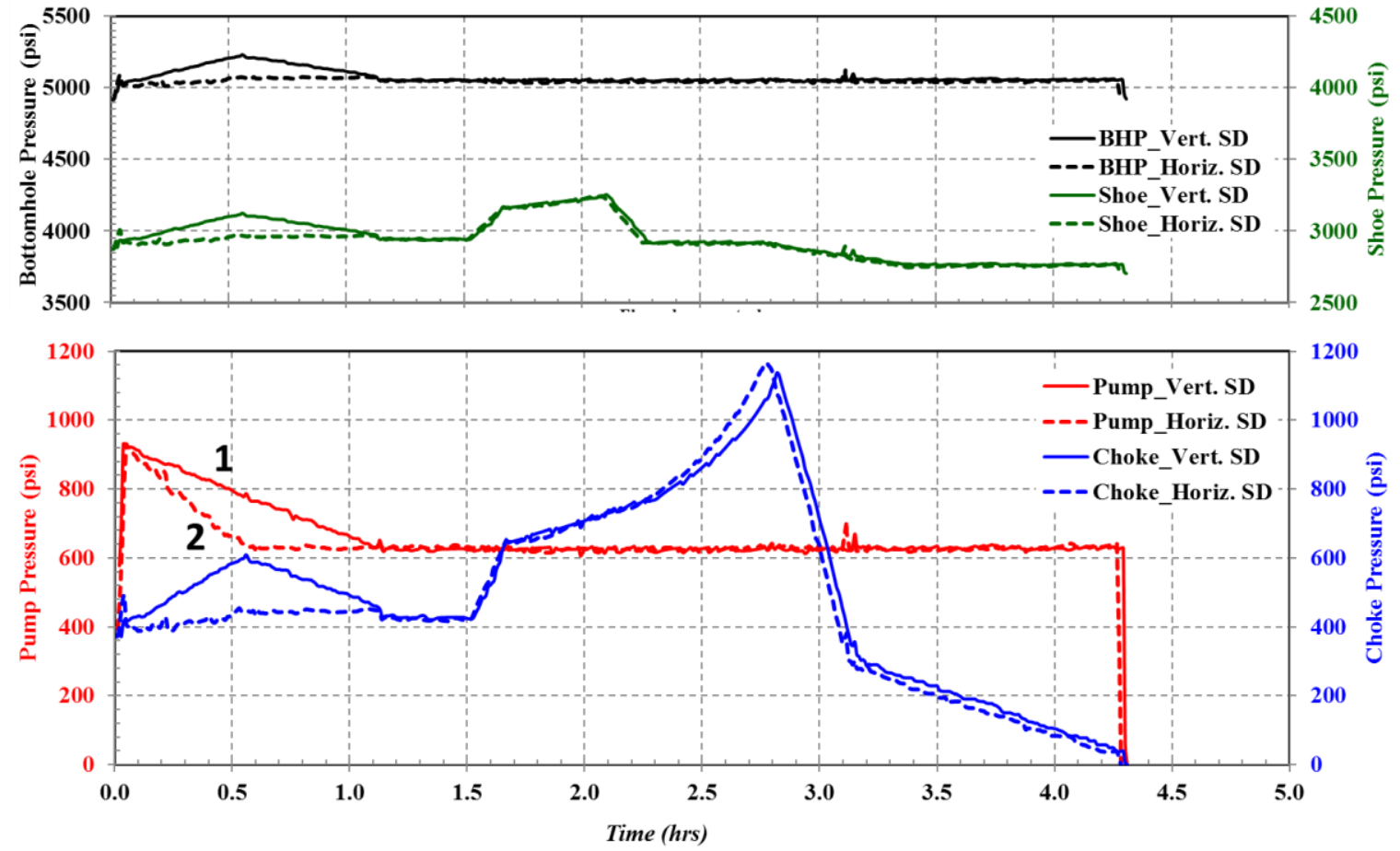

Figure 4.25: Impact of pressure step-down (SD) schedule on a 20 bbls gas kick circulated at 40 spm using Wait-and-Weights method. 
The bottomhole pressure increases and reaches the maximum of 5,250 psi when the heavy mud is at the KOP and generates 180 psi extra backpressure. Basically, the pump pressure consists of two components: static-head and dynamicfrictional pressures. The static-head provides hydrostatic balance with formation pressure which is a linear correlation with TVD. The dynamic-frictional pressure linearly increases with measured depth as the heavy mud weight creates higher friction losses (Grace, 2003). In vertical wells, TVD and measured depths are equal but in horizontal wells measured depth is greater than the vertical depth resulting in higher frictional pressures. In horizontal wells, the step-down schedule is dependent on the wellbore geometry (Santos, 1991b; Gjorv, 2003; Choe et al., 2005). Therefore, this study utilizes the approximated horizontal step-down to maintain the bottomhole pressure constant while the heavy mud is displacing the old mud.

\subsubsection{Impact of Well Control Method}

In comparing Driller's and Wait-and-Weight methods in Figure 4.26 and Figure 4.27, it is obvious that surface and downhole pressures are slightly different. For Driller's method with WBM, ICP of 945 psi was maintained for 3.15 hours, then pressure was stepped-down to FCP of 630 psi after 3.7 hours. The FCP was kept constant throughout the circulation time of 7.4 hours. However, in Wait-and-Weight method less circulation time of 4.3 hours is needed and pressure step-down starts immediately. Likewise, Figure 4.27 compares the two well control methods in horizontal well drilled using OBM. Obviously, released gas at the bubble point after 2.67 hours results in a higher choke pressure of 1,372 psi compared to 1,095 psi in WBM. The main advantage of applying the W\&W method in vertical wells is to reduce downhole pressures by introducing the heavy mud to the wellbore before the influx is circulated out (Adams and Kuhlman, 1994; Grace, 2003; Watson et al., 2003). However, unlike vertical wells, the merely advantage of applying W\&W method in horizontal wells is to save the operation time. Therefore, the Driller's method is preferred to limit the risk associated with gas migration during waiting times (Elshehabi and Bilgesu, 2015b; Guner et al., 2016). 


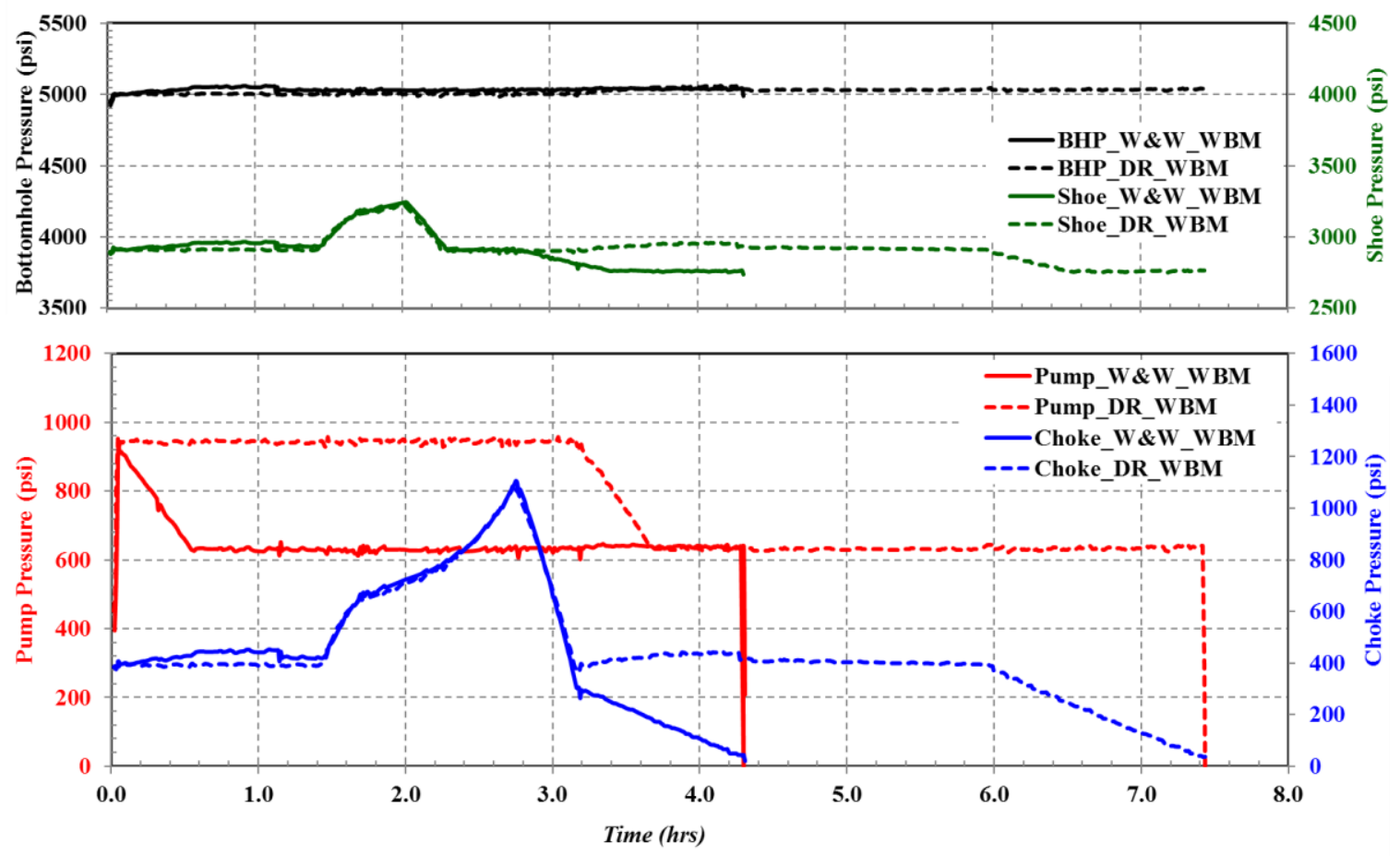

Figure 4.26: A comparison between Driller's and Wait-and-Weight for 20 bbls kick circulated at 40 spm in WBM.

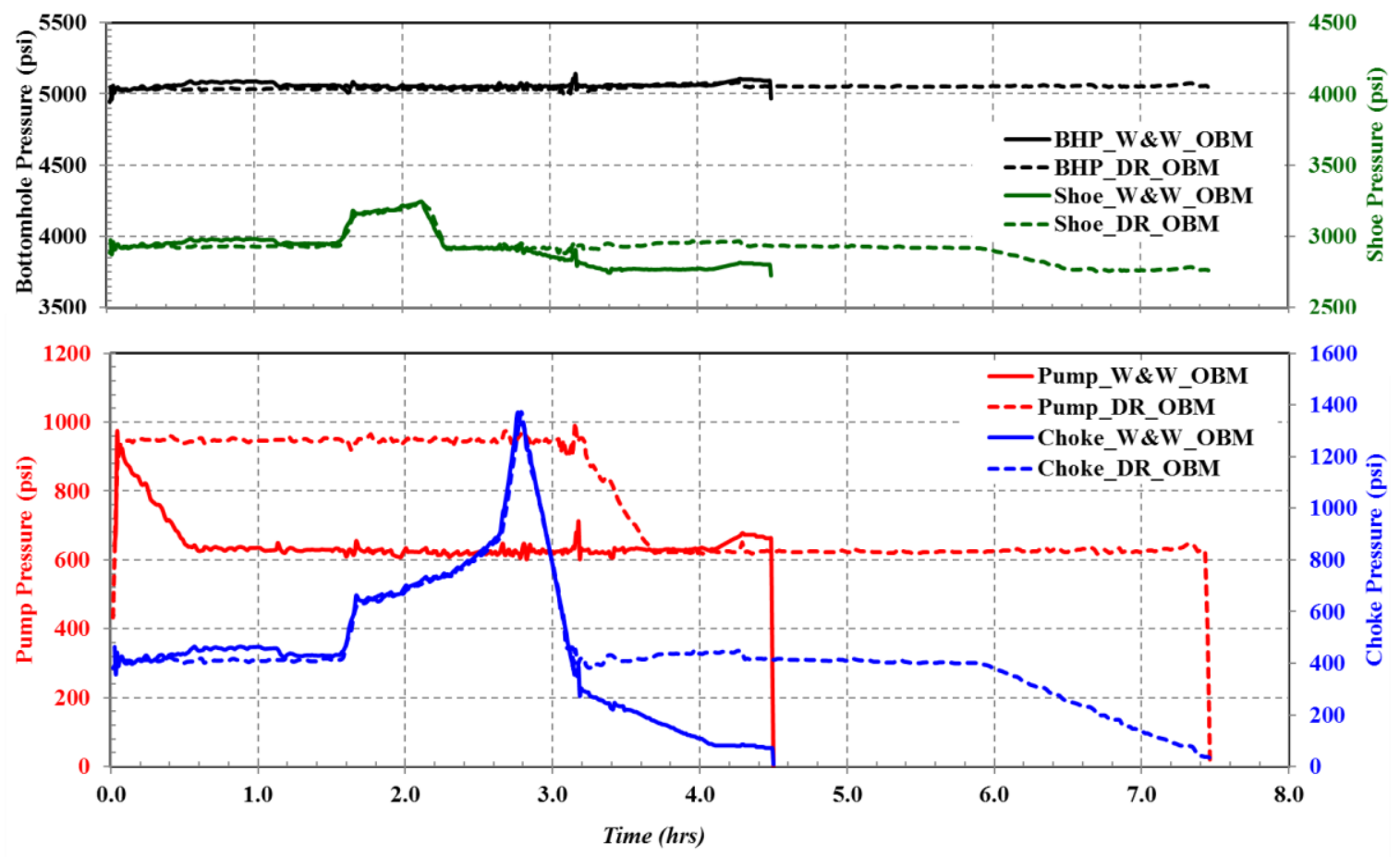

Figure 4.27: A comparison between Driller's and Wait-and-Weight for 20 bbls kick circulated at 40 spm in OBM. 


\subsubsection{Impact of Kick Circulation Rate}

Figure 4.28 and Figure 4.29 show the impact of circulating the influx at slow pump rates of 20, 40 and $60 \mathrm{spm}$. Results illustrate that for the slowest pump rate of $20 \mathrm{spm}$, the pressures experienced at the pump, choke, and bottomhole are lower in comparison to the pump rate of $60 \mathrm{spm}$. In contrast, $60 \mathrm{spm}$ requires less circulation time of $5.0 \mathrm{hrs}$ versus $15.0 \mathrm{hrs}$ at $20 \mathrm{spm}$. Bottomhole would experience slightly higher pressure of $5,137 \mathrm{psi}$ at $60 \mathrm{spm}$ versus $5,011 \mathrm{psi}$ at $20 \mathrm{spm}$. Figure 4.28 shows at $60 \mathrm{spm}$, even though the choke was fully open at the end, while the heavy mud was filling the annulus, the choke line friction was high enough to create back pressure on the wellbore. It is conduced that the pump rate of $40 \mathrm{spm}$ (167 $\mathrm{gal} / \mathrm{min}$ ) which is around $1 / 3$ of some reported field rates of $500 \mathrm{gpm}$ for horizontal sections is suitable to investigate gas kick behavior in oil based mud.

Although the surface choke pressure change was insignificant, higher pump rates resulted in slightly higher ECDs, and casing shoe pressures. However, in slow pump rates, the slope of wellbore pressure increase due to gas liberation and expansion is lower than the slope observed for high pump rates (Figure 4.29). Choke operator can interact effectively at slow pump rate taking into account the choke delay time of 2 seconds per 1,000 ft. However, at very slow pump rates there is a risk of choke plugging or washout as a result of the extensive usage.

Figure 4.30 and Table 4.1 summarize the surface and downhole pressure measurements at different pump rates such as the maximum ECD, BHP, choke,

and casing shoe pressures. Obviously, higher the pump rate higher the surface and downhole pressures and shorter the circulation time. For instance, Table 4.1 shows that increasing the pump rate from $20 \mathrm{spm}$ to $40 \mathrm{spm}$ decreases the circulation time to $50 \%$ while increasing the SPRP from 205 psi to 565 psi. 

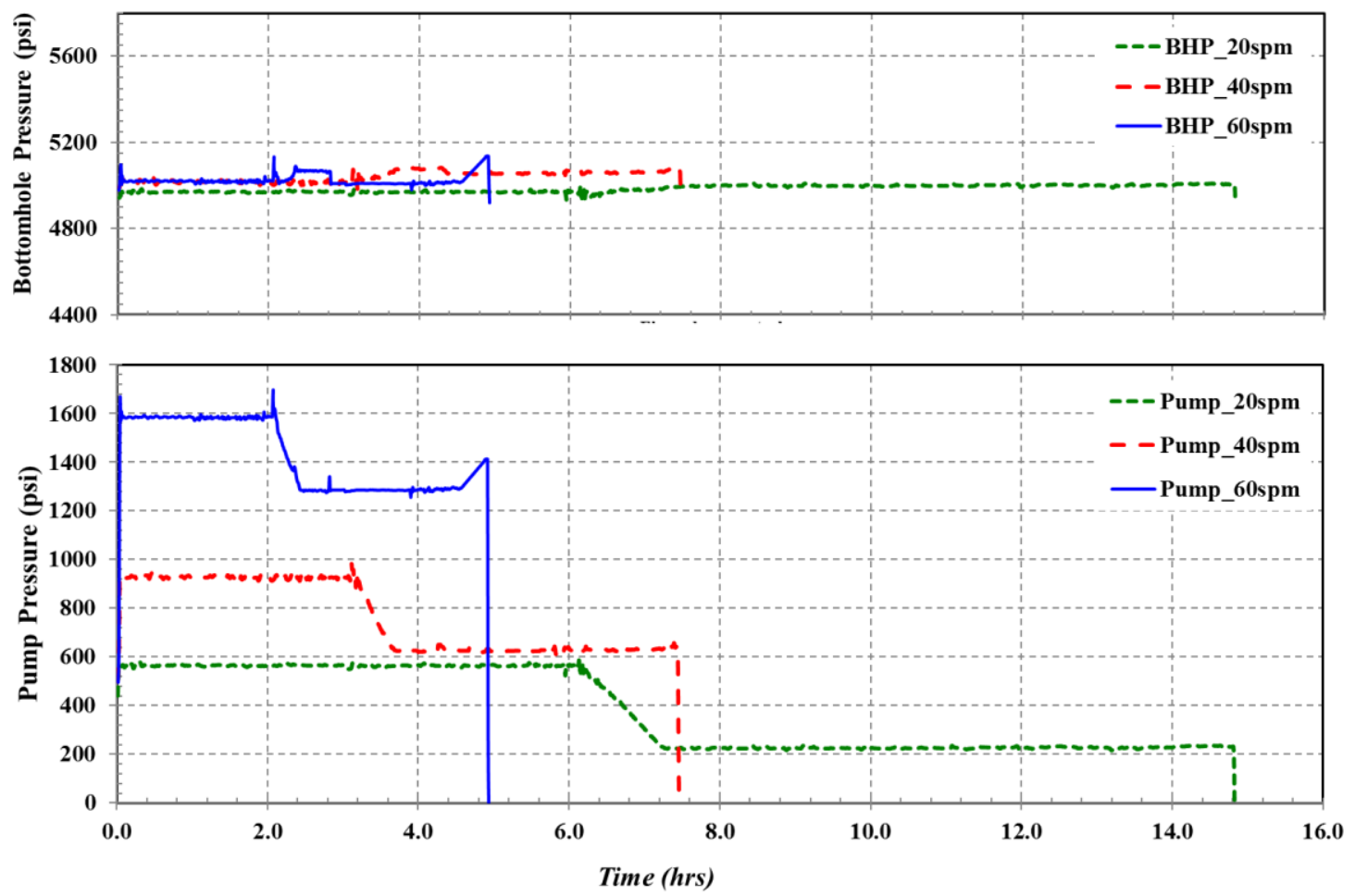

Figure 4.28: Impact of circulation rates of 20,40 , and $60 \mathrm{spm}$ on pump and bottomhole pressures.
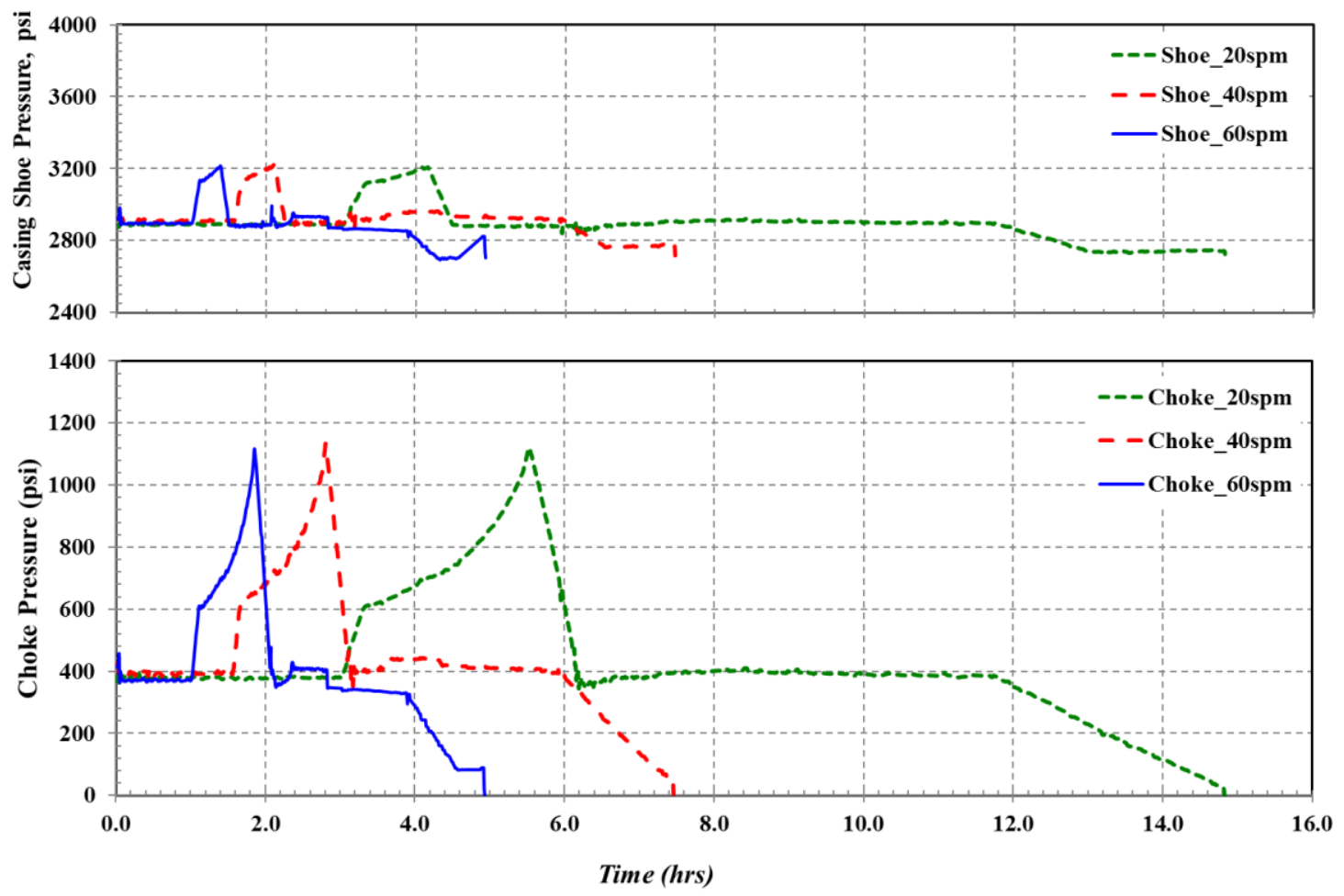

Figure 4.29: Impact of circulation rates of 20,40 , and $60 \mathrm{spm}$ on choke and casing shoe pressures. 


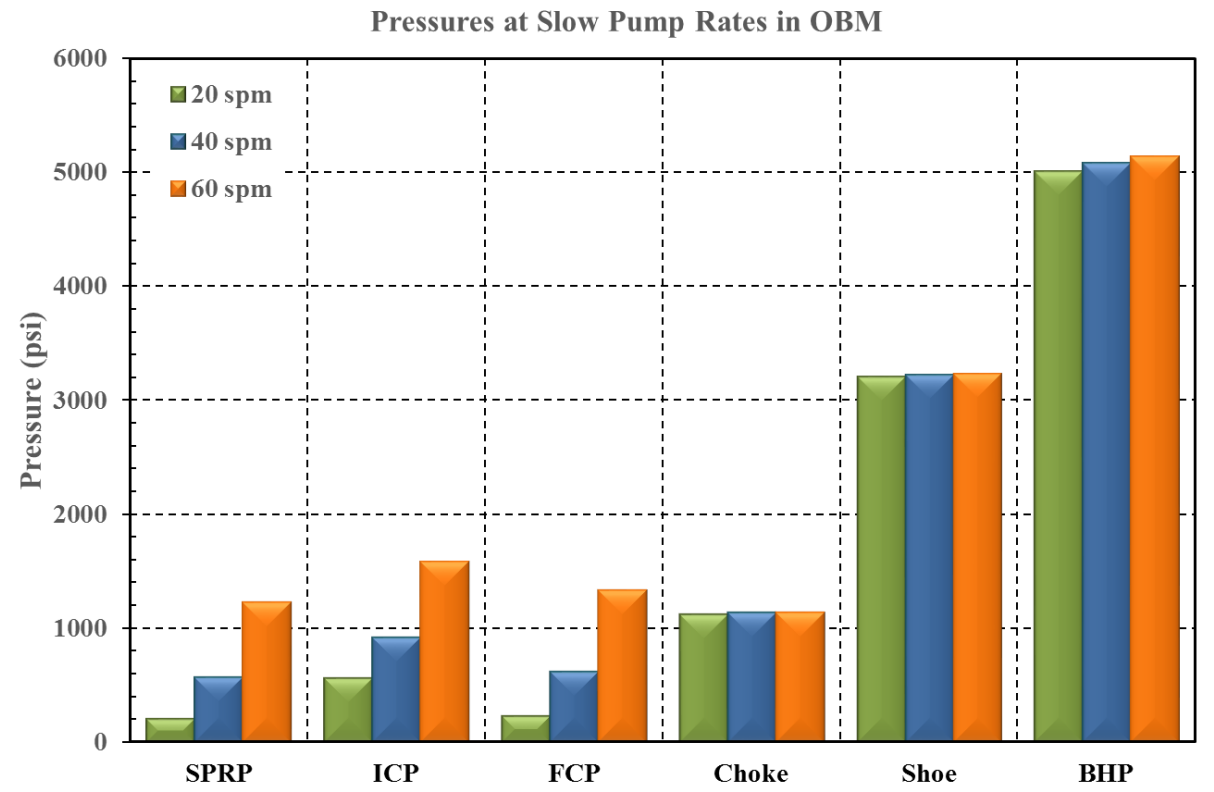

Figure 4.30: Surface and downhole pressures comparison at 20, 40, and $60 \mathrm{spm}$ for 20 bbls gas kick in OBM.

Table 4.1: Recorded surface and downhole parameters at 20, 40, and $60 \mathrm{spm}$ for 20 bbls gas kick in OBM

\begin{tabular}{|l|c|c|c|c|c|c|c|c|}
\hline $\begin{array}{l}\text { Pump } \\
\text { circulation } \\
\text { rate }\end{array}$ & $\begin{array}{c}\text { Slow pump } \\
\text { rate } \\
\text { pressure } \\
\text { (SPRP), psi }\end{array}$ & $\begin{array}{c}\text { Initial } \\
\text { circuiting } \\
\text { pressure } \\
\text { (ICP), psi }\end{array}$ & $\begin{array}{c}\text { Final } \\
\text { circulating } \\
\text { pressure } \\
\text { (FCP), psi }\end{array}$ & $\begin{array}{c}\text { Total } \\
\text { circulation } \\
\text { time, hrs. }\end{array}$ & $\begin{array}{c}\text { Max } \\
\text { bottomhole } \\
\text { pressure, psi }\end{array}$ & $\begin{array}{c}\text { Max choke } \\
\text { pressure, } \\
\text { psi }\end{array}$ & $\begin{array}{c}\text { Max casing } \\
\text { shoe } \\
\text { pressure, } \\
\text { psi }\end{array}$ & $\begin{array}{c}\text { Max } \\
\text { equivalent } \\
\text { circulating } \\
\text { density } \\
\text { (ECD), ppg }\end{array}$ \\
\hline 20 & 205 & 560 & 223 & 15.0 & 5,011 & 1,121 & 3,207 & 13.24 \\
\hline 40 & 565 & 920 & 613 & 7.5 & 5,084 & 1,133 & 3,221 & 13.43 \\
\hline 60 & 1,225 & 1,580 & 1,328 & 5.0 & 5,137 & 1,137 & 3,234 & 13.57 \\
\hline
\end{tabular}

\subsubsection{Impact of Drilling Fluid Type}

In this part, gas kicks in WBM and OBM were compared. As a result of gas solubility in OBM, a gas kick with 2.5 times larger in size at downhole than the kick in WBM is studied using Driller's and Wait-and-Weight methods. Figure 4.31 shows the observed pressures for the Driller's method. In both cases with WBM and OBM, pumping schedule is the same and the bottomhole pressure is constant throughout the 7.5 hours of operation. The choke and casing pressures in WBM follows the typical kick behaviors in horizontal wells. In OBM, the casing shoe pressure change was insignificant as gas comes out of solution near the surface. The casing shoe pressure increases to its maximum value once the gas influx top reaches the shoe. 
While the gas influx rises above shoe depth, the shoe pressure decreases. Once the influx is inside the casing, the casing shoe pressure will not change unless a heavier mud is circulated around the shoe. Furthermore, in OBM, choke pressure is less than in WBM case until the bubble point pressure is reached. Then, at the bubble point, the gas in solution is released and expansion rate is higher and choke pressure sharply increases to a higher value of 1,441 psi in OBM compared to 1,094 psi in WBM.

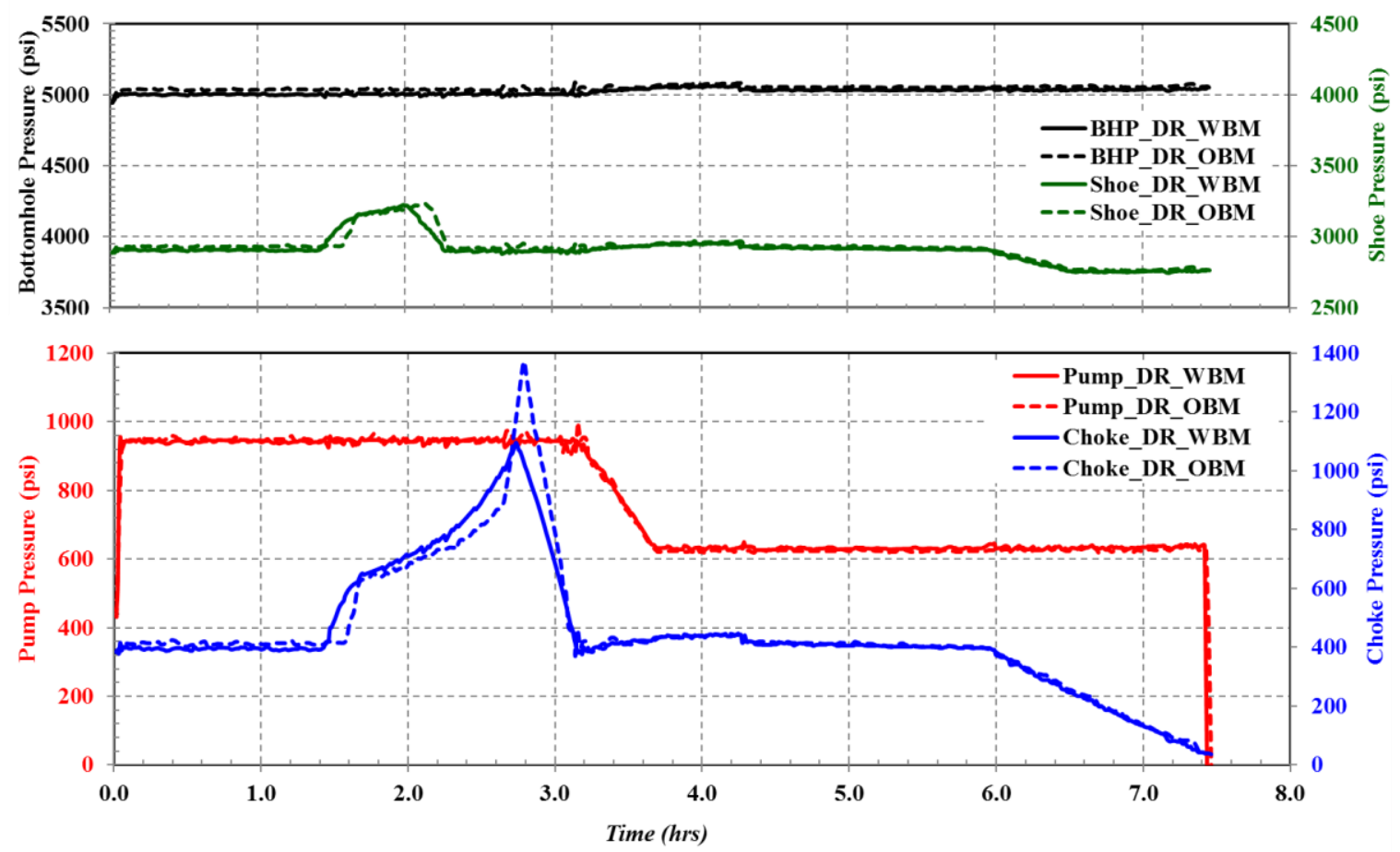

Figure 4.31: A comparison between gas kick in oil based and water based muds using Driller's method at $40 \mathrm{spm}$.

The Wait-and-Weight method was also investigated and the results are shown in Figure 4.32. This method needs only 4.5 hours of operation which saves $40 \%$ time when compared to Driller's method. The bottomhole pressure was kept constant by following the same modified step-down schedule. Moreover, the maximum choke pressure in OBM is 1,370 psi compared to 1,107 psi in WBM due to gas solubility. Therefore, Wait-and-Weight method is only effective in controlling gas kicks in WBM or OBM in horizontal wells when the heavy mud displaced the vertical annular section before gas influx reaches the choke. 


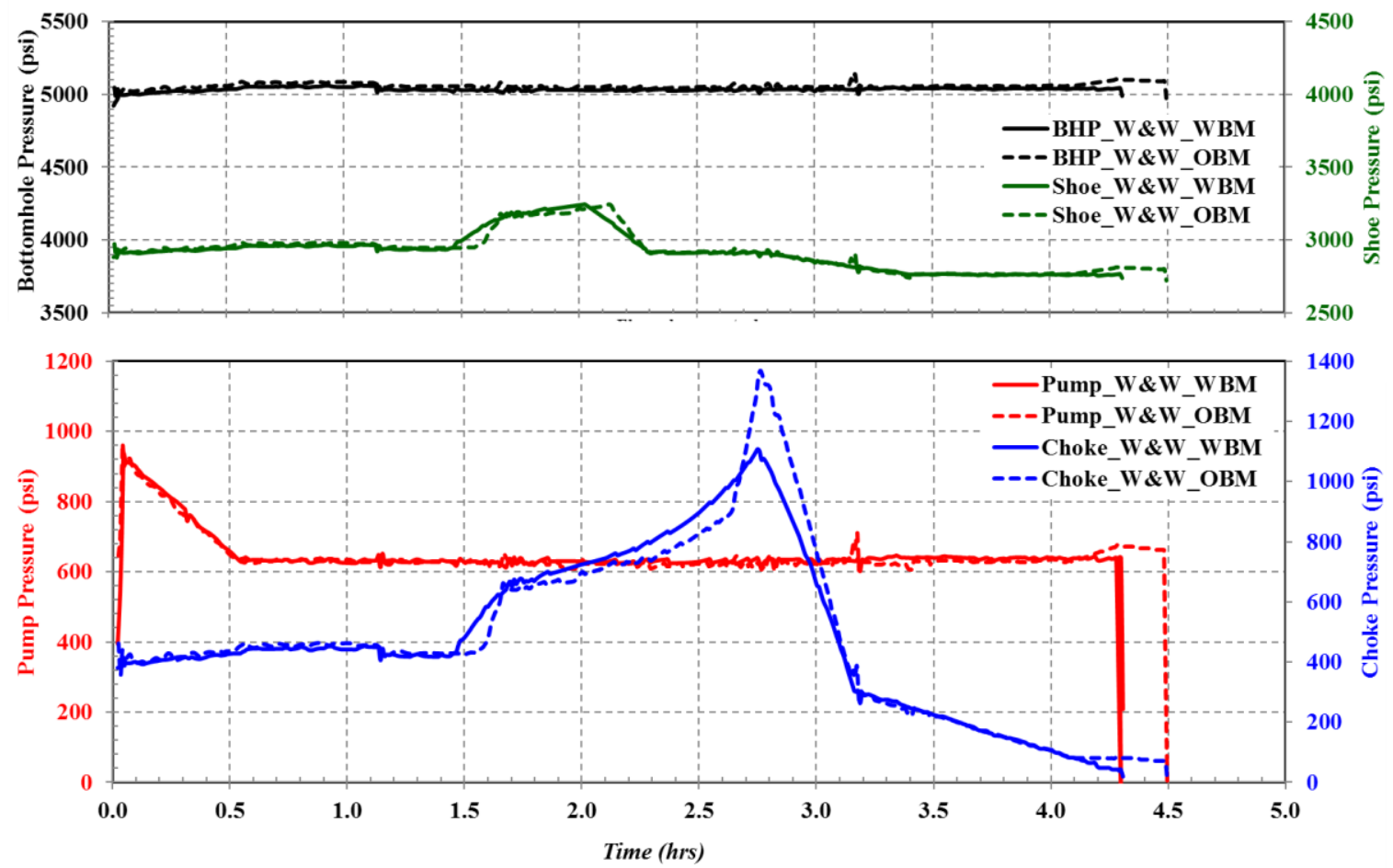

Figure 4.32: A comparison between gas kick in oil based and water based muds using Wait-andWeight method at $40 \mathrm{spm}$.

\subsubsection{Impact of the Degree of Gas Solubility in Oil Based Mud}

Several degrees of gas solubility in OBM and their impact on influx behavior were studied. Typically, it is hard to define the exact solubility value as many factors are affecting gas solubility in OBM such as pressure, temperature, gas gravity, solid content, and water/oil ratio (Silva et al., 2004; Ribeiro et al., 2006; Monteiro et al., 2010). In all cases, the surface pit gain was kept constant at 20 bbls, while the downhole volume changed according to the degree of solubility. The ratio between OBM/WBM kick volumes at downhole conditions was defined as $\mathrm{R}$ and considered as an indicator of the solubility. In WBM gas kick reservoir volume was 14 bbls under downhole pressure and temperature conditions. Higher the ratio $(R)$, higher the solubility of gas in the OBM. In contrast, higher the solubility lower the bubble point pressure with gas release closer to the surface. Table 4.2 and Figure 4.33 show kicks circulated out of the hole using Driller's method at $40 \mathrm{spm}$ keeping the bottomhole pressure constant around 5,080 psi. 
Table 4.2: Surface and downhole recorded data at different gas solubility values in OBM.

\begin{tabular}{|c|c|c|c|c|c|}
\hline $\begin{array}{c}\text { OBM/WBM kick } \\
\text { size ratio (R) }\end{array}$ & $\begin{array}{c}\text { Max. } \\
\text { bottomhole } \\
\text { pressure, psi }\end{array}$ & $\begin{array}{c}\text { Max. choke } \\
\text { pressure, psi }\end{array}$ & $\begin{array}{c}\text { Max. casing } \\
\text { shoe pressure, } \\
\text { psi }\end{array}$ & $\begin{array}{c}\text { Max. } \\
\text { ECD, } \\
\text { ppg }\end{array}$ & $\begin{array}{c}\text { Max. pit } \\
\text { gain, } \\
\text { bbls }\end{array}$ \\
\hline WBM & 5,061 & 1,094 & 3,227 & 13.37 & 60.9 \\
\hline 1.0 & 5,079 & 1,133 & 3,235 & 13.42 & 65.5 \\
\hline 1.1 & 5,080 & 1,134 & 3,227 & 13.42 & 65.1 \\
\hline 1.2 & 5,080 & 1,136 & 3,222 & 13.42 & 65.3 \\
\hline 1.6 & 5,076 & 1,188 & 3,218 & 13.41 & 69.7 \\
\hline 2.5 & 5,089 & 1,372 & 3,233 & 13.44 & 82.7 \\
\hline 5.0 & 5,080 & 1,784 & 3,174 & 13.42 & 122.1 \\
\hline
\end{tabular}
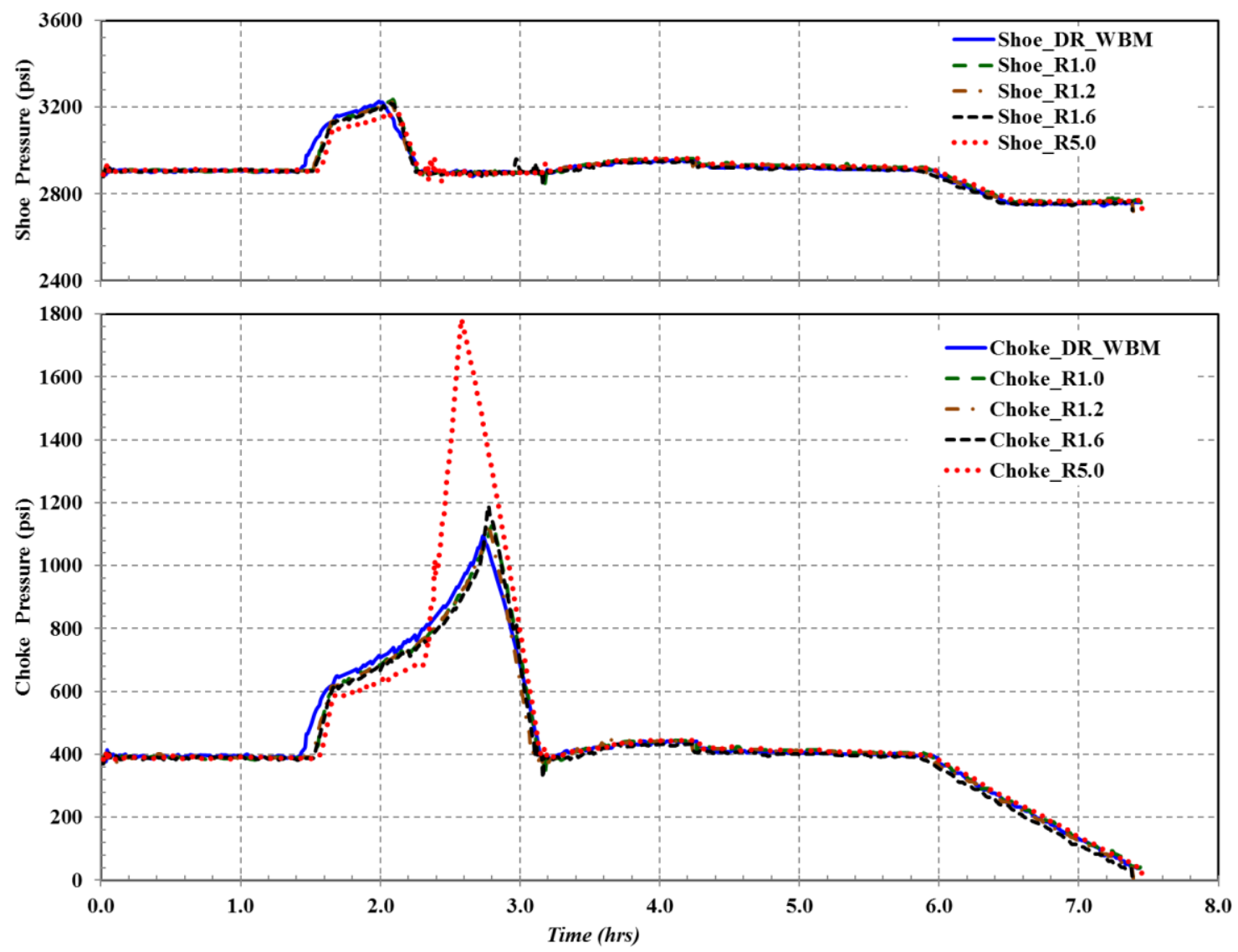

Figure 4.33: Impact of gas solubility in OBM on the choke and casing shoe pressures.

Gas solubility had a major impact on the choke pressure and pit gain particularly when the gas reached the surface. At the highest solubility value selected $(R=5)$, the choke pressure elevated up to $163 \%$ and pit gain expanded up to $200 \%$ of WBM conditions. 
Therefore, the choke might experience operational problems and mud gas separator should be sized properly to handle this increase in the gas volume. Figure 4.34 show the previous graph (Figure 4.33) in a time expanded scale between one and four hours. The location "A" represents the gas entering the vertical section. Obviously, in WBM, the choke pressure started to rise earlier as the gas is in free phase. In contrast, in OBM at high solubility rates, the two phase flow acts more like liquid kicks and observed choke pressure values are lower. However, once the gas reaches the bubble point as shown as "B", the choke pressure rapidly increases as gas is liberated. Once the top of gas is at the surface, the choke experiences its peak pressure. Then, the pressure will start decreasing as the gas is circulated out of the wellbore. The slope of the line defines how rapid the choke pressure is increasing or decreasing based on the gas size at the surface conditions.

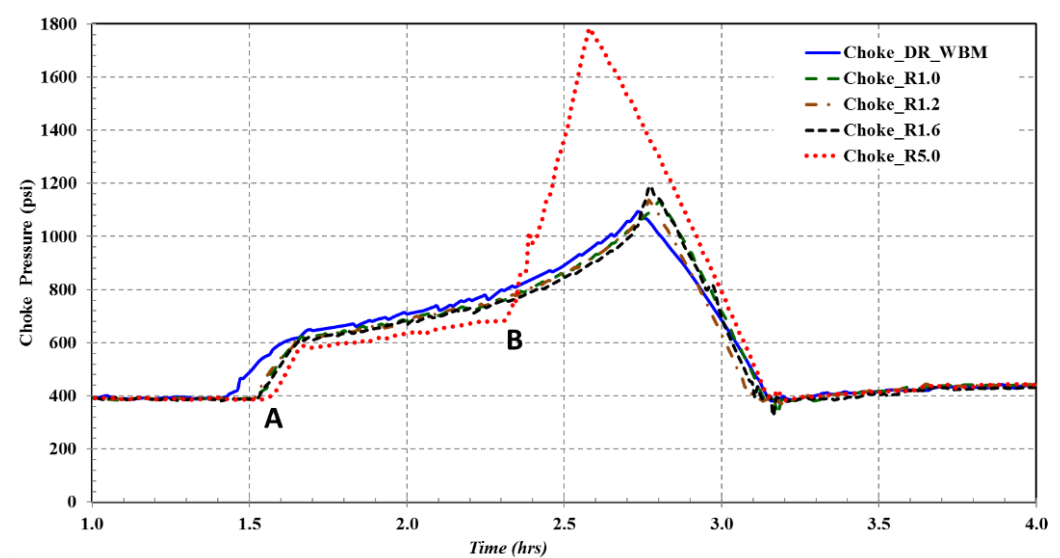

Figure 4.34: Impact of gas solubility in OBM on choke pressure when gas reaches the surface.

\subsubsection{Impact of Influx Fluid Type}

The behavior of water kick was compared to gas kick during drilling a horizontal well using OBM as shown in Figure 4.35 and Figure 4.36. Controlling the pump pressure is much harder while having a gas in the hole compared to water kick. For gas kick, casing shoe pressure is 3,233 psi and choke pressure is 1,372 psi. These pressures are much higher compared to water kick where shoe pressure is 3,041 psi and choke pressure is 532 psi only. Furthermore, the pit gain when the gas kick reaches the choke is 82.7 bbls compared to 20 bbls when water kick reaches the choke since water is incompressible. 


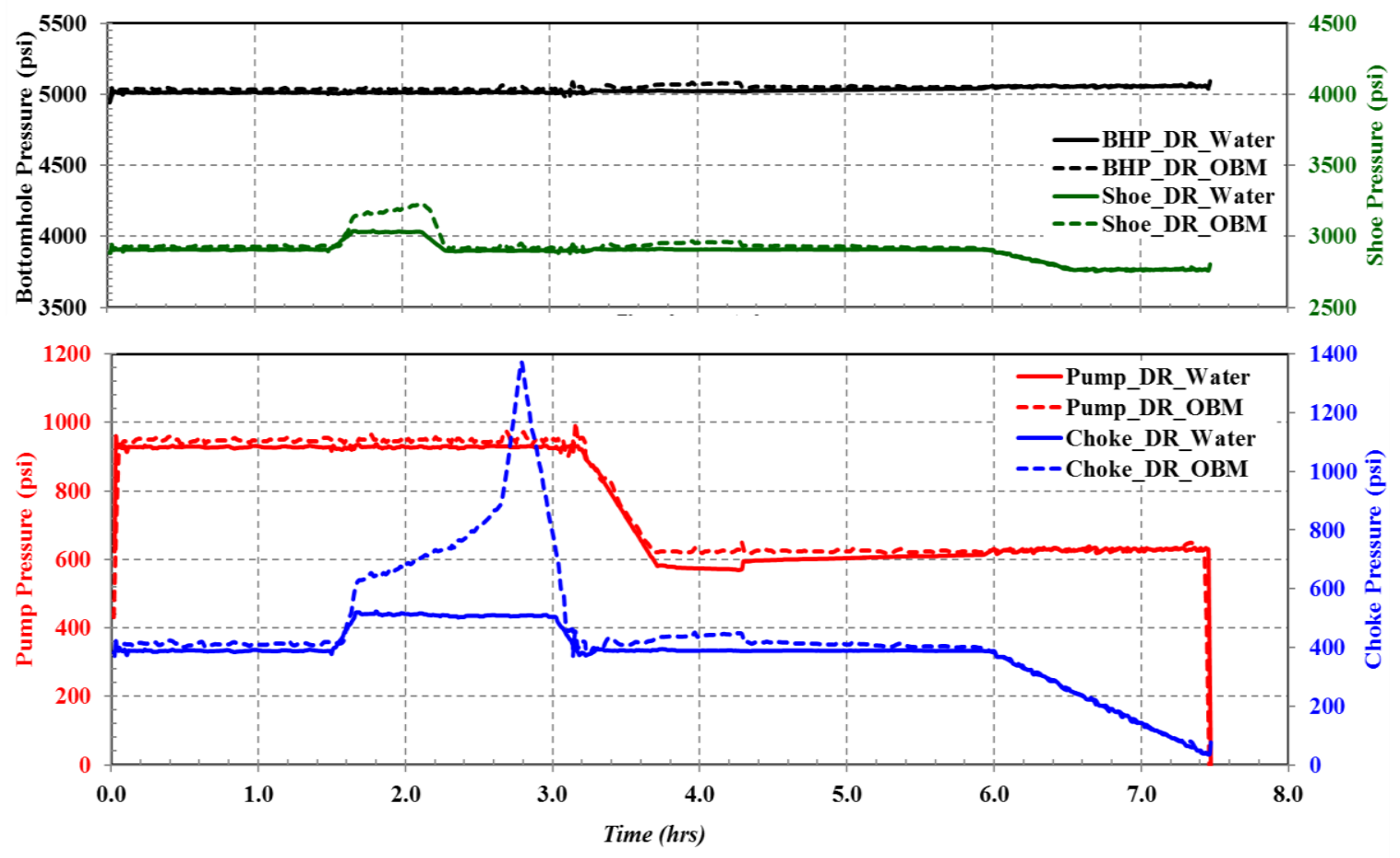

Figure 4.35: A comparison between water and gas kicks in an OBM using Driller's method at 40 spm.

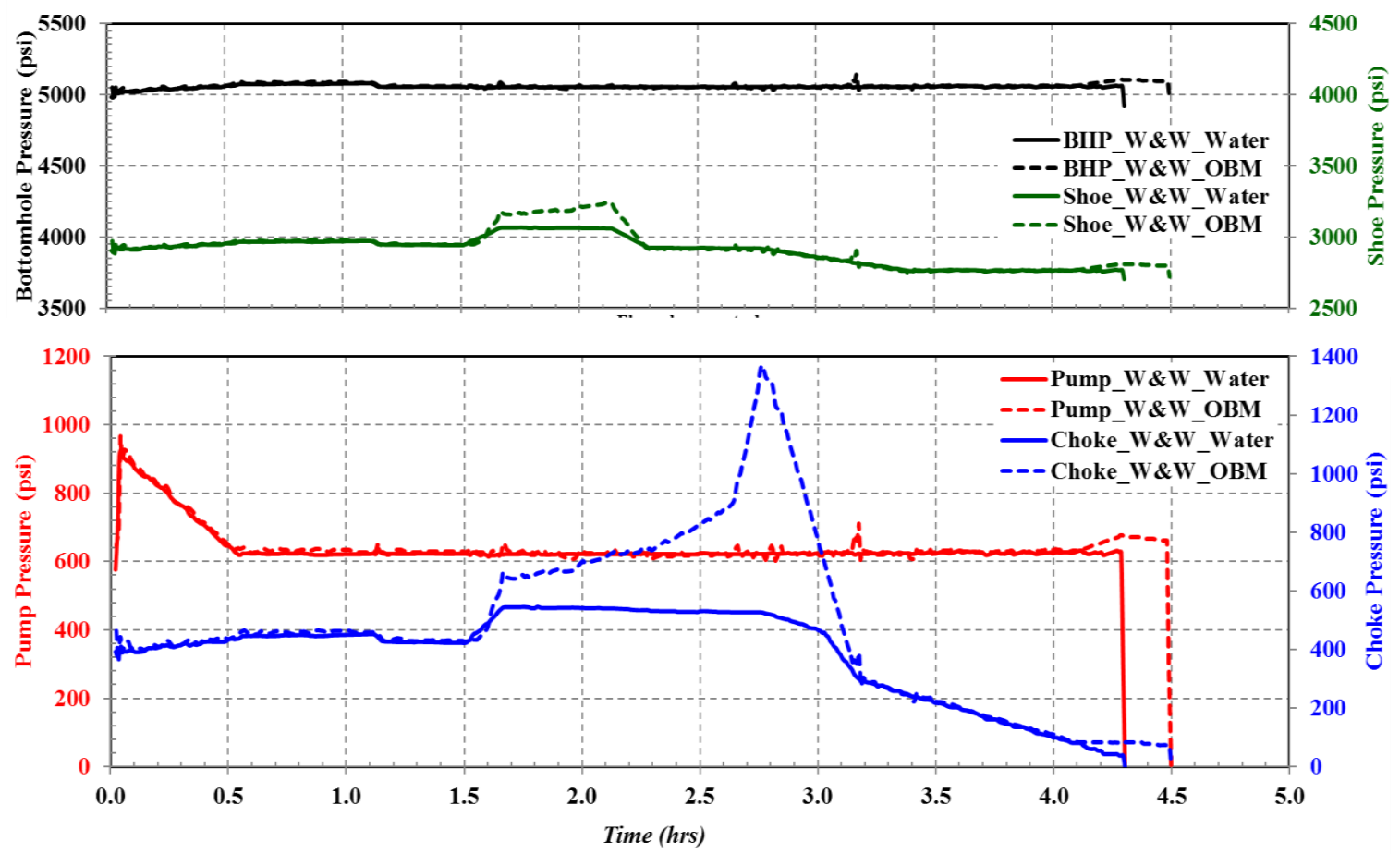

Figure 4.36: A comparison between water and gas kicks in an OBM using Wait-and-Weight method at $40 \mathrm{spm}$. 
Wait-and-Weight method was conducted with water kick and results are shown in Figure 4.36. The influx type can be identified from the choke pressure as the water is incompressible and the choke pressure increases once the kick is in the vertical section then it levels up contrary to continuous increase in gas kicks. Then, choke pressure decreases while the kick is circulated out. Furthermore, it drops to zero once the kill mud reaches the surface. However, gas kick behavior in OBM is complicated due to gas solubility which is controlled by many parameters. Additionally, gas density is lower and it accumulates at the high side of horizontal section in particular inside caved and enlarged pockets. In inclined upward horizontal sections, gas has the tendency to migrate towards the end of well rather than to the vertical hole. Therefore, high annular velocity is required to flush these gas pockets (Elshehabi and Bilgesu, 2017).

\subsection{Well Control Results for Drilling with Casing and Liner}

\subsubsection{Vertical Well Drilled with Casing/Liner}

In this part of the study, a gas influx size was kept constant at a surface volume of 20 bbls and the kill rate was selected as $40 \mathrm{spm}$. Table 4.3 lists SIDPP and shows that SICP is usually higher and depends on gas column height and the difference in mud and gas densities. For instance, in DwC, the gas kick occupies longer interval therefore, the SICP is 703 psi compared to 653 psi in DwP. Figure 4.37 and Figure 4.38 show the vertical well step-down applied assuming that APL is neglected. Since APL is higher in DwC compared to DwP as discussed in the hydraulics results, BHP is higher in DwC even though ICP and FCP are lower. The small annular clearance requires less volume of mud to displace therefore, the circulation time for DwC is $2.78 \mathrm{hrs}$ compared to $3.42 \mathrm{hrs}$ in DwP (Table 4.3).

Table 4.3: Surface and downhole measurements for DwP, DwL, and DwC in a vertical well controlled with Driller's method at $40 \mathrm{spm}$.

\begin{tabular}{|l|l|l|l|l|l|l|l|l|l|l|}
\hline $\begin{array}{l}\text { Verticall } \\
\text { Well }\end{array}$ & $\begin{array}{l}\text { SPRP, } \\
\text { psi }\end{array}$ & $\begin{array}{l}\text { SIDPP, } \\
\text { psi }\end{array}$ & $\begin{array}{l}\text { SICP, } \\
\text { psi }\end{array}$ & $\begin{array}{l}\text { ICP, } \\
\text { psi }\end{array}$ & $\begin{array}{l}\text { FCP, } \\
\text { psi }\end{array}$ & $\begin{array}{l}\text { Time, } \\
\text { hrs. }\end{array}$ & $\begin{array}{l}\text { Max } \\
\text { BHP, } \\
\text { psi }\end{array}$ & $\begin{array}{l}\text { Max } \\
\text { Choke, } \\
\text { psi }\end{array}$ & $\begin{array}{l}\text { Max } \\
\text { Shoe, } \\
\text { psi }\end{array}$ & $\begin{array}{l}\text { Max } \\
\text { ECD, } \\
\text { ppg }\end{array}$ \\
\hline DwP & 466 & 350 & 653 & 815 & 490 & 3.42 & 4,830 & 1,088 & 3,250 & 13.27 \\
\hline DwL & 443 & 345 & 695 & 780 & 440 & 3.15 & 4,866 & 1,087 & 3,448 & 13.37 \\
\hline DwC & 424 & 348 & 703 & 775 & 460 & 2.78 & 4,907 & 1,389 & 3,455 & 13.48 \\
\hline
\end{tabular}




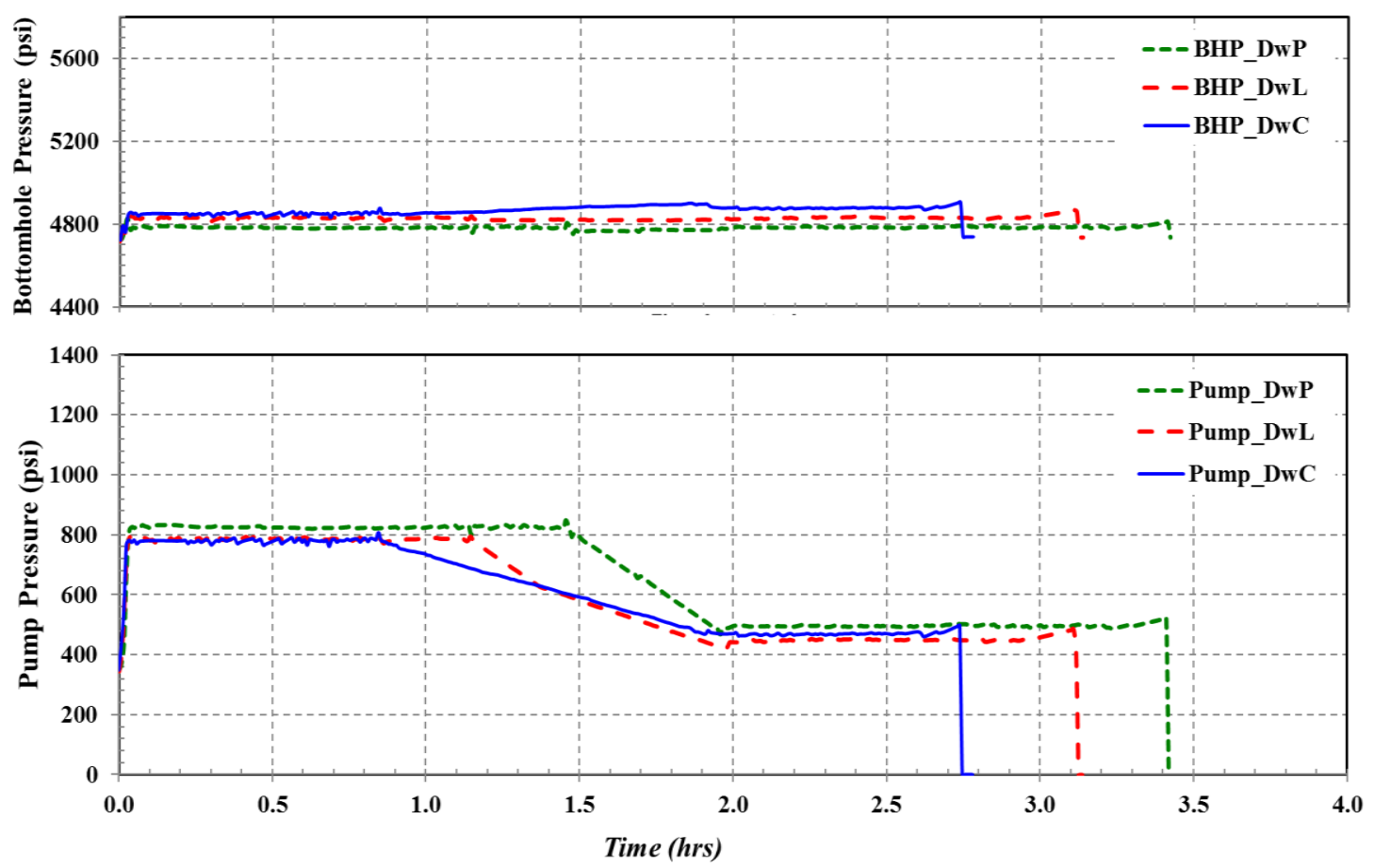

Figure 4.37: Pump and bottomhole pressures for a vertical well controlled with Driller's method at 40 spm.
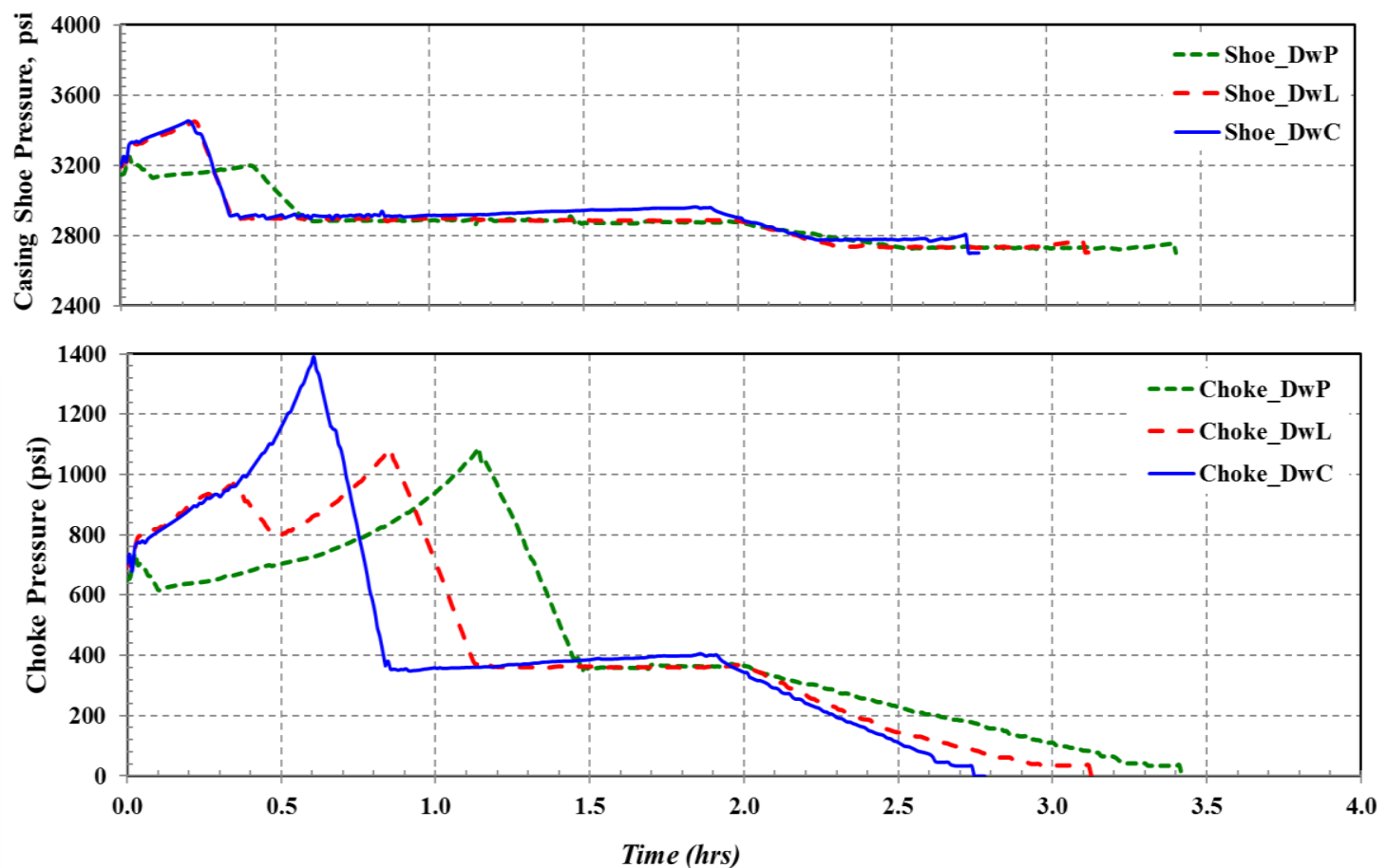

Figure 4.38: Choke and casing shoe pressures for a vertical well controlled with Driller's method at $40 \mathrm{spm}$. 
At $40 \mathrm{spm}$, in DwP, filling the drillpipe with the heavy mud requires $0.5 \mathrm{hrs}$ and displacing the entire annulus needs $1.46 \mathrm{hrs}$ (Figure 4.37). However, due to the enlarged pipe diameter in DwC, 1.05 hrs are required to fill the drillpipe with the heavy mud. Also, it requires $0.83 \mathrm{hrs}$ to displace the annular volume compared to $1.46 \mathrm{hrs}$ in DwP. This results in a complete displacement of gas influx from the wellbore before the drillstring is filled with heavy mud in DwC. Therefore, casing shoe pressure will not be minimized if the Wait-and-Weight method is applied. Driller's method is preferred since a proper pressure step-down schedule can be verified with a constant casing pressure while filling the drillstring with heavy mud.

Figure 4.38 indicates gas influx is twice in length in the tight annulus of DwC and reaches surface earlier. This results in higher surface choke and casing shoe pressures. In DwL, as a result of the string/hole configuration, the step-down slope changes at the liner hanger depth. Therefore, instead of applying the straight line step-down, the casing pressure was kept constant. Drilling with liner can be considered as an inverted tapered string where friction loss is not linearly distributed. Also, as gas moves from tight liner annulus to wider annular pipe section at the top of the liner, a sharp decrease in choke pressure is experienced as gas height decreases. This change in the influx high did not impact the casing shoe since the influx was already above the casing shoe (Figure 4.38).

\subsubsection{Directional Well Drilled with Casing/Liner}

An approximated step-down was tested in a directional well as shown in Figure 4.39 and Figure 4.40. This approximated step-down assumes the FCP can be reached at the TVD instead of the total depth. This assumption is based on the fact that BHP is highly impacted with the heavy mud back pressure that is a function of TVD. Nevertheless, the BHP increases slightly as the heavy mud introduces higher friction losses. ICP and FCP values are 815 psi and 490 psi, respectively and surface-to-surface strokes are 5,600 (2.33 hours). However, when same ICP and FCP values were used for the three wellbore assemblies, bottomhole pressure was higher in DwC as shown in Figure 4.39 and Table 4.4. 


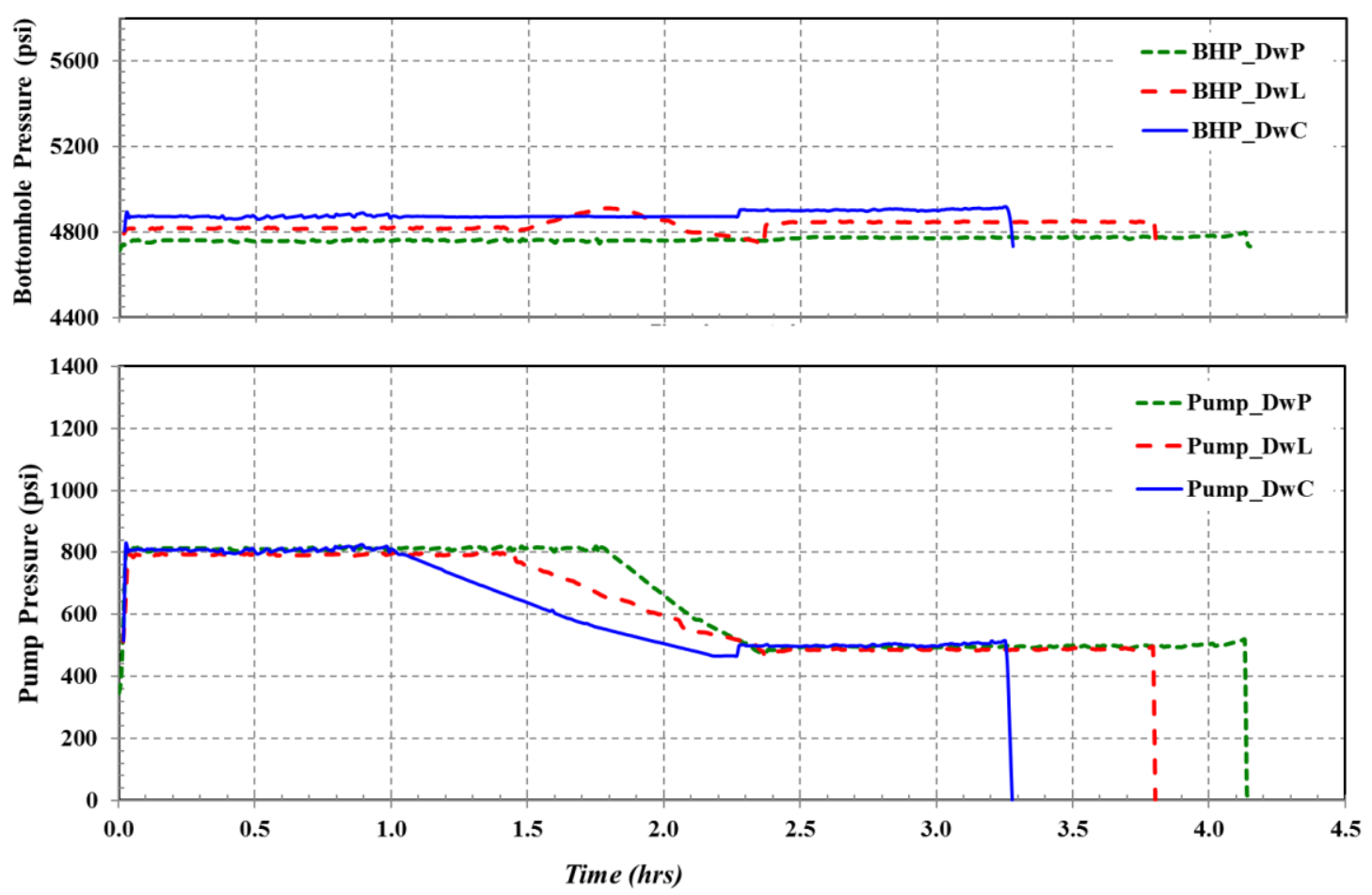

Figure 4.39: Pump and bottomhole pressures for a directional well controlled with Driller's method at $40 \mathrm{spm}$.
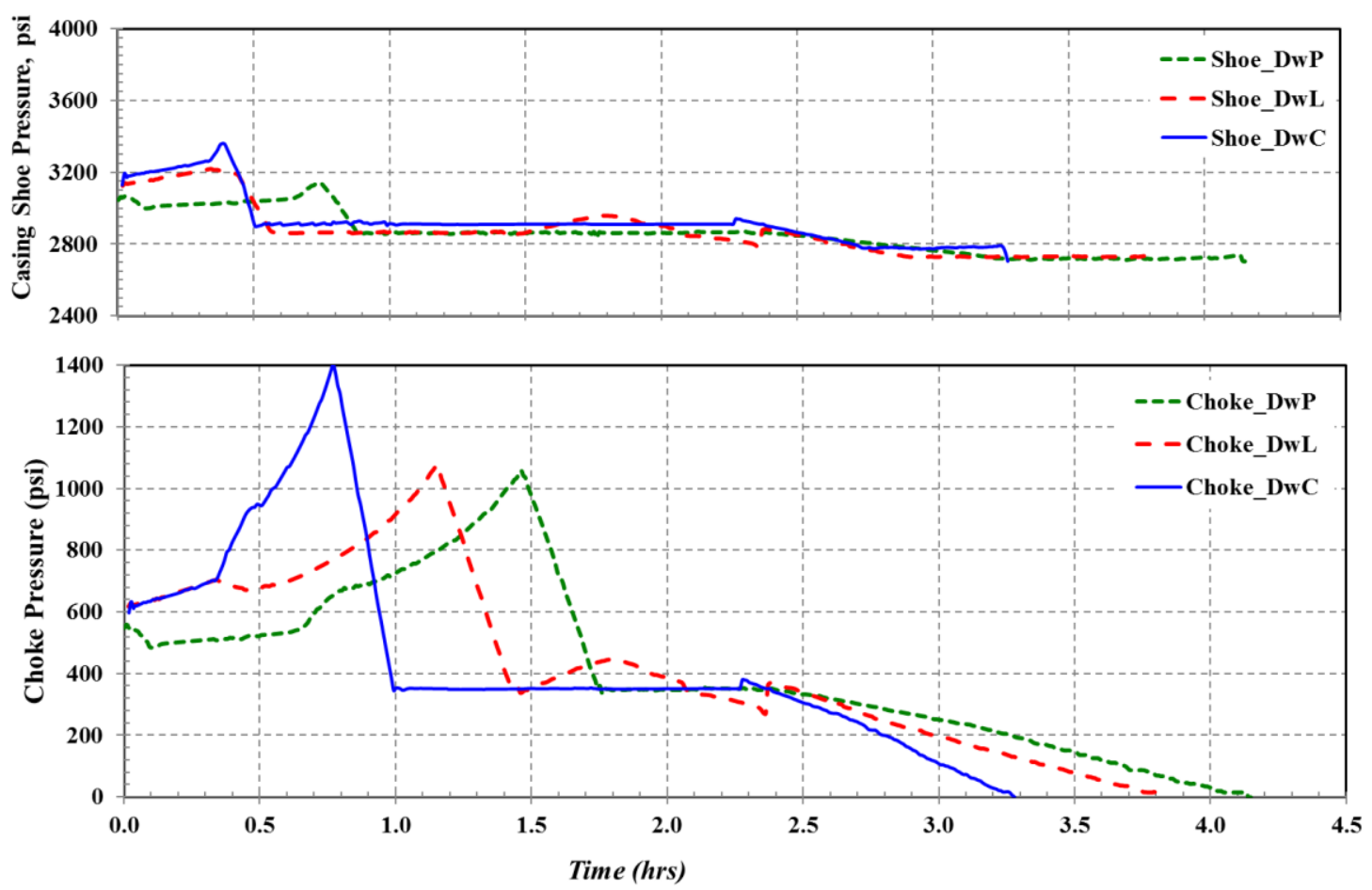

Figure 4.40: Choke and casing shoe pressures for a directional well controlled with Driller's method at $40 \mathrm{spm}$. 
This is contributed to the high APL that was assumed neglected in the stepdown schedule, however, it is added to the BHP. In DwP, the approximated stepdown was successful in keeping constant BHP as verified by a constant casing pressure. In case of drilling with liner, a step-down with a two-slope line was predicted but a vertical well straight-line step-down was assumed for easiness. In DwL, results show that bottomhole was subjected to over-pressure with increased choke and casing shoe pressures while the heavy mud is circulated. This overpressure is followed with gradual pressure decrease. Choke and casing shoe pressures increased at higher rate after gas kick is circulated to the vertical section in the annulus.

Table 4.4: Surface and downhole measurements for DwP, DwL, and DwC in a directional well controlled with Driller's method at $40 \mathrm{spm}$.

\begin{tabular}{|l|c|c|c|c|c|c|c|c|c|c|}
\hline $\begin{array}{l}\text { Directional } \\
\text { Well }\end{array}$ & $\begin{array}{c}\text { SPRP, } \\
\text { psi }\end{array}$ & $\begin{array}{c}\text { SIDPP, } \\
\text { psi }\end{array}$ & $\begin{array}{c}\text { SICP, } \\
\text { psi }\end{array}$ & $\begin{array}{c}\text { ICP, } \\
\text { psi }\end{array}$ & $\begin{array}{c}\text { FCP, } \\
\text { psi }\end{array}$ & $\begin{array}{c}\text { Time, } \\
\text { hrs. }\end{array}$ & $\begin{array}{c}\text { Max } \\
\text { BHP, } \\
\text { psi }\end{array}$ & $\begin{array}{c}\text { Max } \\
\text { Choke, } \\
\text { psi }\end{array}$ & $\begin{array}{c}\text { Max } \\
\text { Shoe, } \\
\text { psi }\end{array}$ & $\begin{array}{c}\text { Max } \\
\text { ECD, } \\
\text { ppg }\end{array}$ \\
\hline DwP & 462 & 346 & 549 & 815 & 490 & 4.15 & 4,798 & 1,060 & 3,142 & 13.18 \\
\hline DwL & 439 & 347 & 582 & 790 & 480 & 3.8 & 4,911 & 1,080 & 3,218 & 13.49 \\
\hline DwC & 456 & 347 & 574 & 805 & 495 & 3.28 & 4,917 & 1,403 & 3,360 & 13.51 \\
\hline
\end{tabular}

\subsubsection{Horizontal Well Drilled with Casing/Liner using WBM}

Based on the results discussed earlier for vertical and directional wells, the reduced two-stage step-down (R2SD) model was developed and applied for horizontal wells drilled with casing/liner. Figure 4.41 and Table 4.5 compare the conventional Driller's method to the Driller's method with R2SD model. The estimated values required for the R2SD model are shown in Table 4.5 for DwL/DwC drilled with WBM. As concluded in the hydraulics results the APL is very high in DwC and should not be neglected in step-down calculations. The following equations were used to approximate the reduced ICP (ICP') and FCP (FCP').

$$
\begin{aligned}
& \text { DwC ICP' }(p s i) \approx S I D P P+1.5 \Delta P_{\text {Bit }} \\
& F C P^{\prime}(p s i) \approx 1.5 \Delta P_{B i t} \\
& \text { DwL } \\
& I C P^{\prime}(p s i) \approx S I D P P+1.33 \Delta P_{B i t} \\
& F C P^{\prime}(p s i) \approx 1.33 \Delta P_{B i t}
\end{aligned}
$$




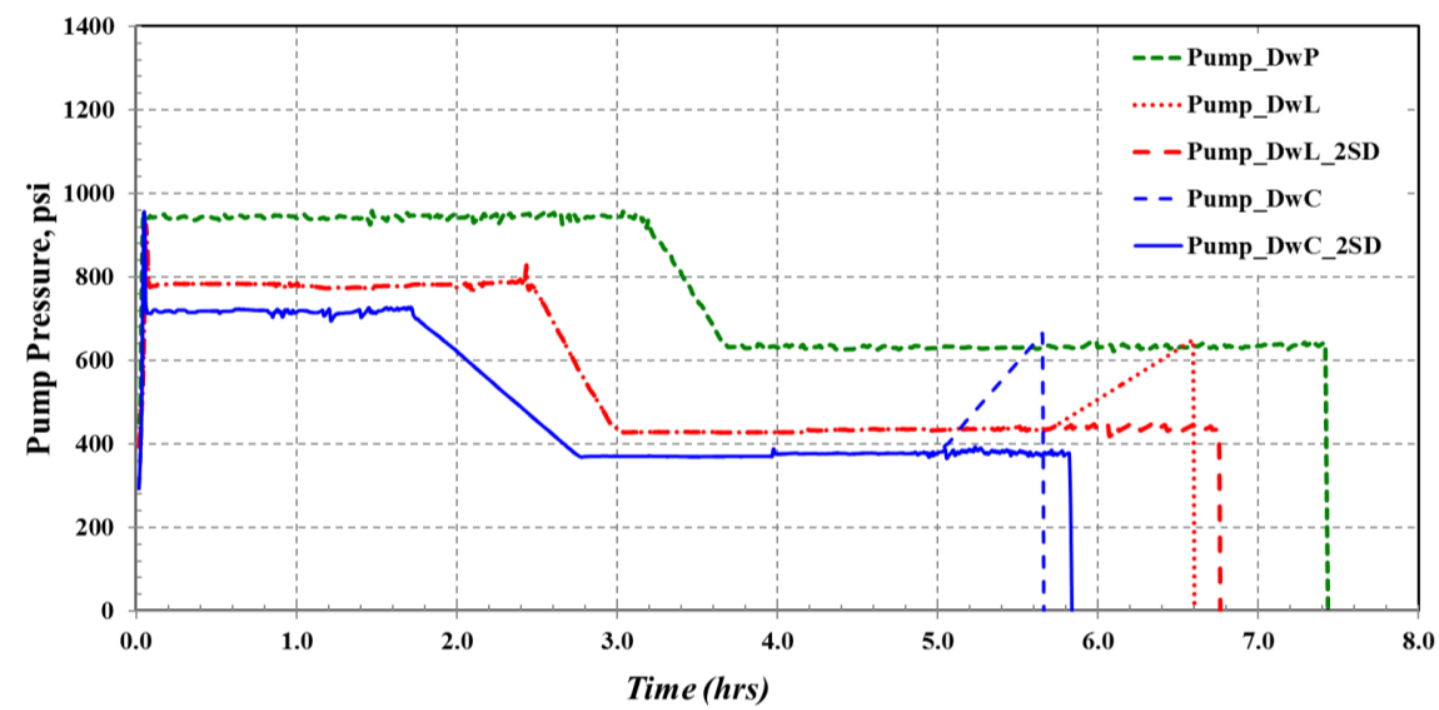

Figure 4.41: Pump pressure comparison for a horizontal well using Driller's method with conventional step-down and R2SD at 40 spm in WBM.

Table 4.5: R2SD Model calculations for DwL and DwC in a horizontal well using Driller's method at $40 \mathrm{spm}$.

\begin{tabular}{|c|c|c|c|c|c|c|c|c|c|c|c|c|}
\hline & $\begin{array}{c}\text { SPRP } \\
\text { psi }\end{array}$ & $\begin{array}{c}\text { SIDPP } \\
\text {, psi }\end{array}$ & $\begin{array}{c}\text { SICP, } \\
\text { psi }\end{array}$ & $\begin{array}{c}\text { ICP, } \\
\text { psi }\end{array}$ & $\begin{array}{c}\text { FCP, } \\
\text { psi }\end{array}$ & $\begin{array}{l}\text { ICP', } \\
\text { psi }\end{array}$ & $\begin{array}{c}\text { FCP', } \\
\text { psi }\end{array}$ & $\begin{array}{c}\Delta \mathrm{ICP} \\
\text { psi }\end{array}$ & $\begin{array}{c}\Delta \mathrm{FCP}, \\
\text { psi }\end{array}$ & $\begin{array}{c}\text { BHP, } \\
\text { psi }\end{array}$ & $\begin{array}{c}\text { BHP', } \\
\text { psi }\end{array}$ & $\begin{array}{c}\Delta \mathrm{BHP}, \\
\text { psi }\end{array}$ \\
\hline wL & 572 & 350 & 361 & 922 & 620 & 772 & 422 & 151 & 198 & 5,354 & 5,108 & 246 \\
\hline DwC & 606 & 350 & 362 & 956 & 657 & 724 & 374 & 232 & 283 & 5,511 & 5,136 & 375 \\
\hline
\end{tabular}

As shown in Figure 4.41, in DwC, the estimated ICP value was 956 psi; however, the R2SD model predicted ICP' to be 724 psi. Therefore, once the pump is brought to the kill rate, the remote choke was opened to achieve the reduced ICP. Likewise, FCP was reduced to 374 psi instead of the estimated value of 657 psi. Also, the estimated ICP was 922 psi for DwL and the reduced ICP' was 722 psi, and FCP was reduced to 422 psi instead of 620 psi. Obviously, R2SD model successfully reduced surface and downhole pressures. For instance, the values of ICP, FCP, and BHP were reduced by 232,283 , and 375 psi, respectively. When the kill mud reached the vertical section in the annulus, BHP experienced backpressure created by the choke line friction (Figure 4.41). To prevent over-pressurizing the wellbore, once the backpressure starts, the pump rate was slowly decreased until the heavy mud reached the surface. In DwC the pump rate was decreased from 40 to $23 \mathrm{spm}$ (Table 4.6). The reduction in downhole/surface pressures due to R2SD model is shown in Figure 4.42 and Figure 4.43. 


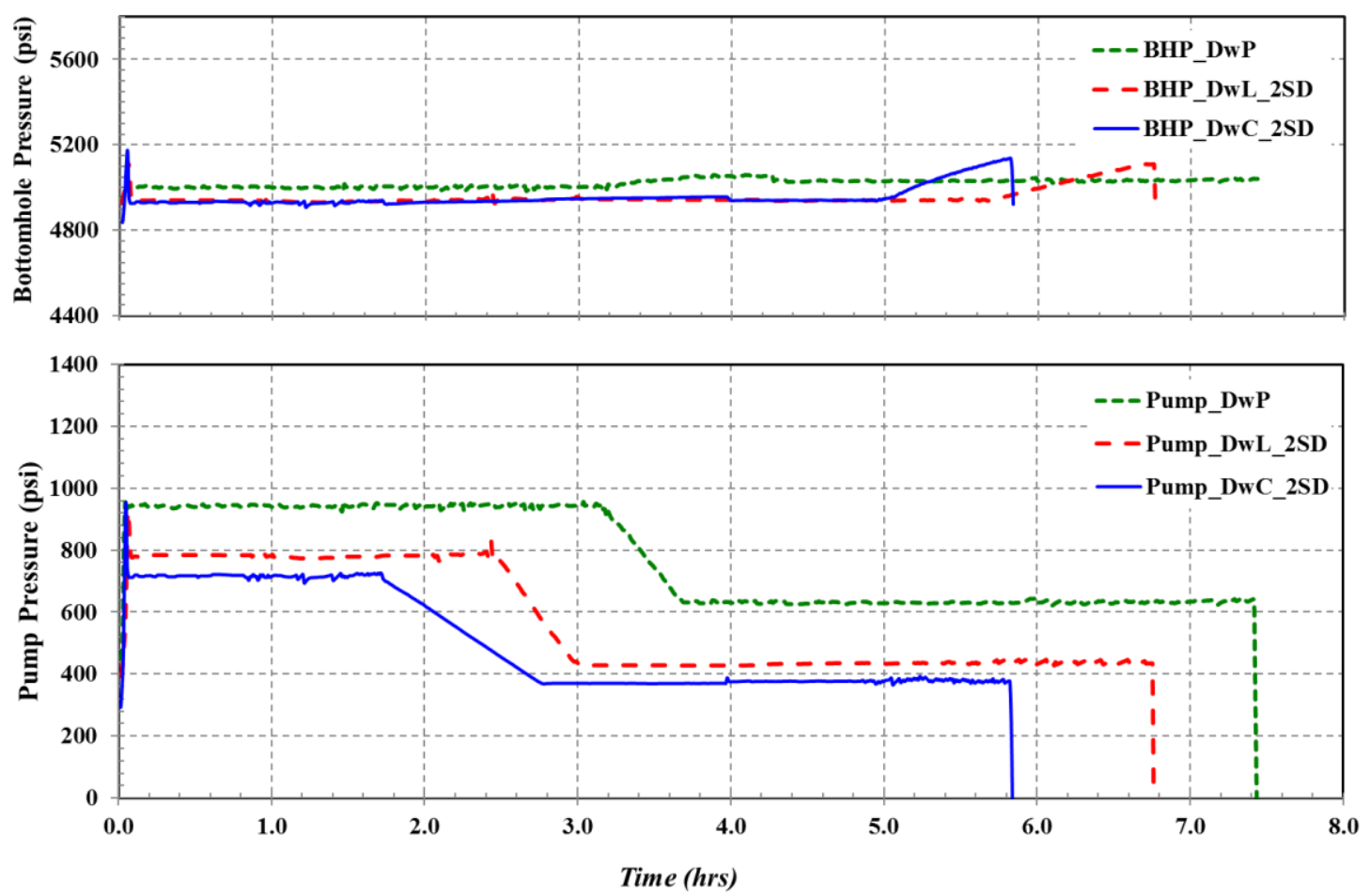

Figure 4.42: Pump and bottomhole pressures for a horizontal well controlled with Driller's method at $40 \mathrm{spm}$ in WBM.
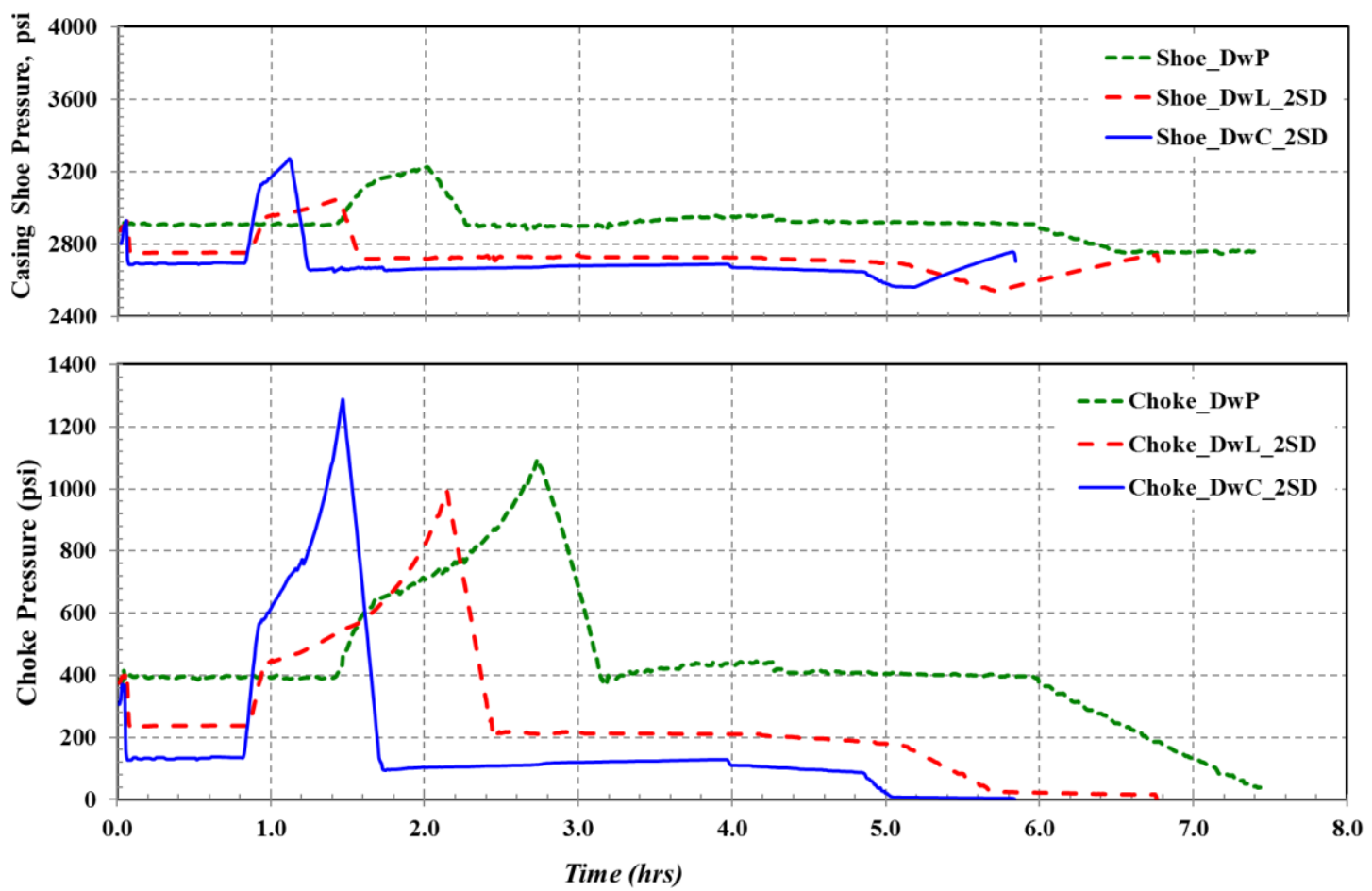

Figure 4.43: Choke and casing shoe pressures for a horizontal well controlled with Driller's method at $40 \mathrm{spm}$ in WBM. 
Table 4.6: Surface and downhole measurements for DwP, DwL, and DwC in a horizontal well drilled with WBM and controlled with Driller's method at $40 \mathrm{spm}$.

\begin{tabular}{|l|c|c|c|c|l|l|l|l|}
\hline $\begin{array}{l}\text { Horizontal } \\
\text { Well-WBM }\end{array}$ & ICP, psi & FCP, psi & $\begin{array}{l}\text { Time, } \\
\text { hrs. }\end{array}$ & $\begin{array}{l}\text { Max } \\
\text { BHP, psi }\end{array}$ & $\begin{array}{l}\text { Max } \\
\text { Choke, } \\
\text { psi }\end{array}$ & $\begin{array}{l}\text { Max } \\
\text { Shoe, } \\
\text { psi }\end{array}$ & $\begin{array}{l}\text { Max } \\
\text { ECD, } \\
\text { ppg }\end{array}$ & $\begin{array}{l}\text { Final } \\
\text { spm }\end{array}$ \\
\hline DwP & 940 & 630 & 7.44 & 5,061 & 1,095 & 3,227 & 13.37 & 40 \\
\hline DwL & 775 & 425 & 6.75 & 5,108 & 996 & 3,052 & 13.5 & 32 \\
\hline DwC & 710 & 370 & 5.84 & 5,136 & 1,289 & 3,272 & 13.65 & 23 \\
\hline
\end{tabular}

As shown in Figure 4.42, the ICP' was kept constant in the first circulation. Then, the first pressure step-down was applied by decreasing the pump pressure to FCP' when the heavy mud reached the TVD. This was verified by monitoring a constant casing pressure. Then, FCP' was kept constant while the heavy mud was displacing the lateral section. Once the backpressure started, the second pump rate step-down was applied by slowly decreasing the pump speed. Decreasing the pump rate while backpressure was experienced maintained FCP constant and consequently eliminated BHP from over-pressurizing. The benefit of R2SD model was verified by keeping constant BHP throughout the kick circulation. Figure 4.43 shows that casing shoe and choke pressures were constant while the gas influx was circulated out of the lateral section. Once the influx reaches the vertical section, a sharp pressure increase on choke and later on casing shoe were experienced.

\subsubsection{Horizontal Well Drilled with Casing/Liner using OBM}

The impact of gas solubility in oil based mud is studied in wells drilled with casing/liner and is compared to wells drilled with pipes. In the case of DwC, at the kill rate (40 spm), ICP was estimated to be 971 psi; however, R2SD model predicted ICP' to be 724 psi as shown in Figure 4.44 and Table 4.7. Also, the FCP was reduced from 673 psi to 374 psi that successfully reduced the values of ICP, FCP, and BHP by 247, 299, 403 psi, respectively. Furthermore, BHP, casing shoe, and choke pressures experienced a sharp backpressure increase once the influx reached the vertical section. BHP increased to 5,144 psi in the case of DwC, and 5,114 psi in DwL. To prevent over-pressurizing the wellbore, once the backpressure started, the pump rate is slowly decreased. For instance, in DwC the pump rate was decreased from 40 to $25 \mathrm{spm}$ and $32 \mathrm{spm}$ in DwL (Table 4.8). 


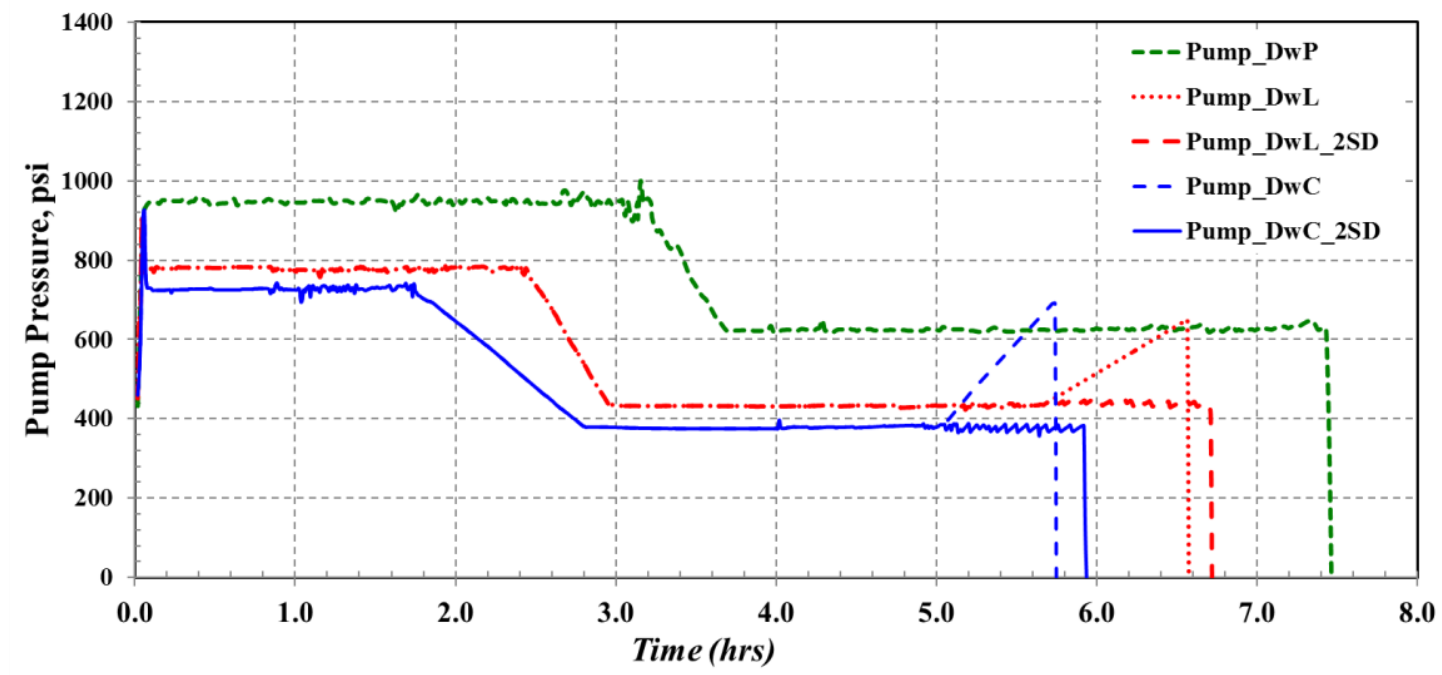

Figure 4.44: Pump pressure comparison for a horizontal well using Driller's method at 40 spm OBM.

Table 4.7: Model calculations for DwL, DwC in a horizontal well using Driller's method at $40 \mathrm{spm}$.

\begin{tabular}{|l|c|c|c|c|c|c|c|c|c|c|c|c|}
\cline { 2 - 12 } \multicolumn{1}{c|}{} & $\begin{array}{c}\text { SPRP, } \\
\text { psi }\end{array}$ & $\begin{array}{c}\text { SIDPP } \\
\text {, psi }\end{array}$ & $\begin{array}{c}\text { SICP, } \\
\text { psi }\end{array}$ & $\begin{array}{c}\text { ICP, } \\
\text { psi }\end{array}$ & $\begin{array}{c}\text { FCP, } \\
\text { psi }\end{array}$ & $\begin{array}{c}\text { ICP', } \\
\text { psi }\end{array}$ & $\begin{array}{c}\text { FCP', } \\
\text { psi }\end{array}$ & $\begin{array}{c}\Delta \text { ICP, } \\
\text { psi }\end{array}$ & $\begin{array}{c}\Delta \text { FCP, } \\
\text { psi }\end{array}$ & $\begin{array}{c}\text { BHP, } \\
\text { psi }\end{array}$ & $\begin{array}{c}\text { BHP', } \\
\text { psi }\end{array}$ & $\begin{array}{c}\Delta \text { BHP, } \\
\text { psi }\end{array}$ \\
\hline DwL & 574 & 350 & 362 & 924 & 622 & 772 & 422 & 153 & 200 & 5,365 & 5,114 & 251 \\
\hline DwC & 621 & 350 & 362 & 971 & 673 & 724 & 374 & 247 & 299 & 5,547 & 5,144 & 403 \\
\hline
\end{tabular}

The application of R2SD method in reducing downhole/surface pressures is shown in Figure 4.45 and Figure 4.46 for DwL and DwC. The ICP' was kept constant in the first circulation then, pump pressure was stepped-down to FCP' when the heavy mud reaches the TVD. This step-down chart was verified by monitoring a constant casing pressure since all the gas was circulated out of the hole. FCP' was kept constant while the heavy mud was displacing the lateral and vertical sections. Once the backpressure started in the vertical annulus, the second pump rate stepdown was applied by slowly decreasing the pump speed. The results show that the decreasing of pump rate while backpressure was experienced maintained FCP' constant and consequently eliminated BHP from over-pressurizing. R2SD method was verified by keeping constant BHP throughout the well control operation. Figure 4.46 shows that casing shoe and choke pressures were constant while the gas influx was circulated out of the lateral section. Once the influx reaches the bubble point pressure in the vertical annulus section, a sharp pressure increase on choke and later on casing shoe were experienced. 


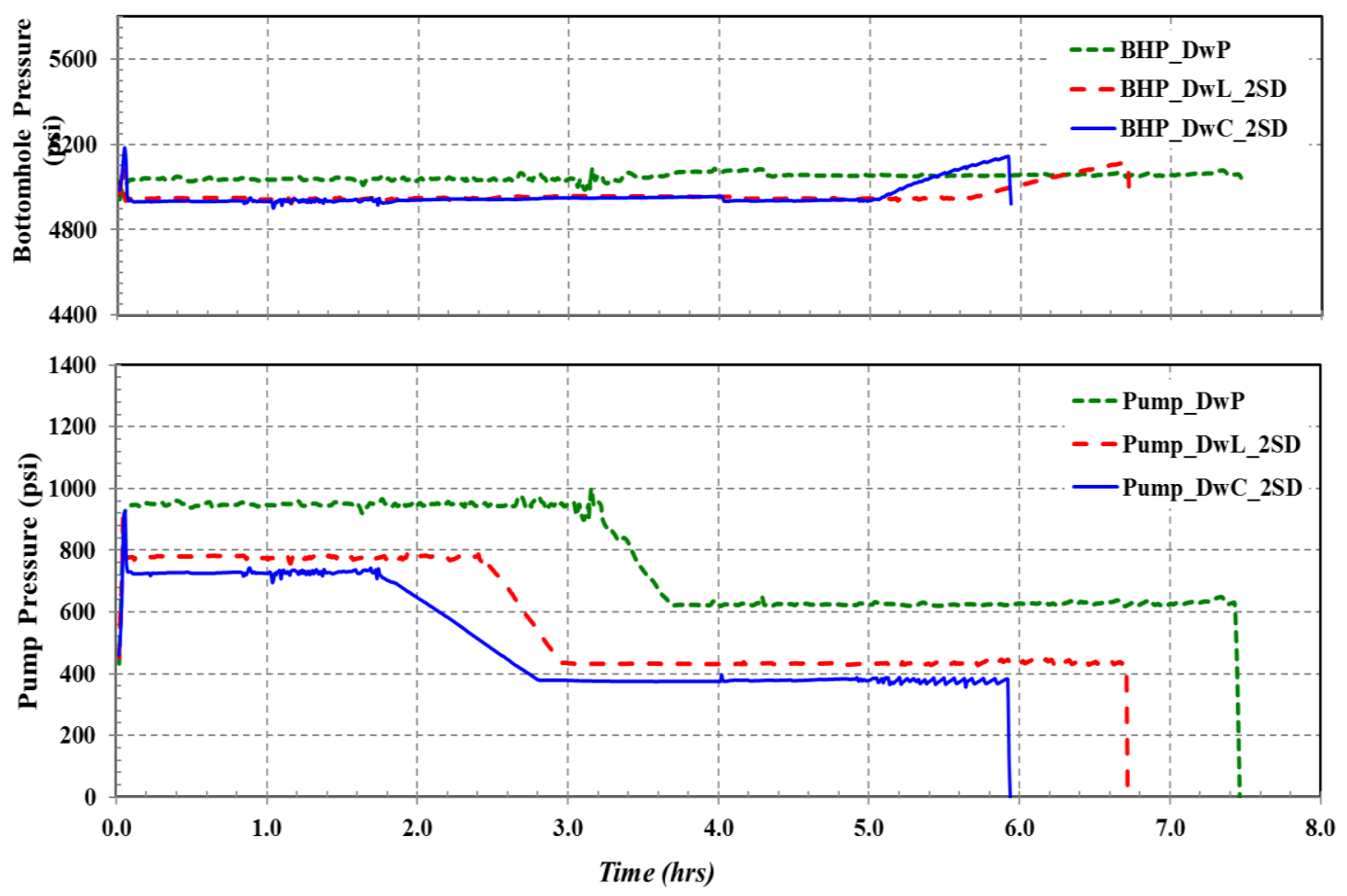

Figure 4.45: Pump and bottomhole pressures for a horizontal well drilled with DwP, DwL and DwC and controlled with R2SD model in OBM.
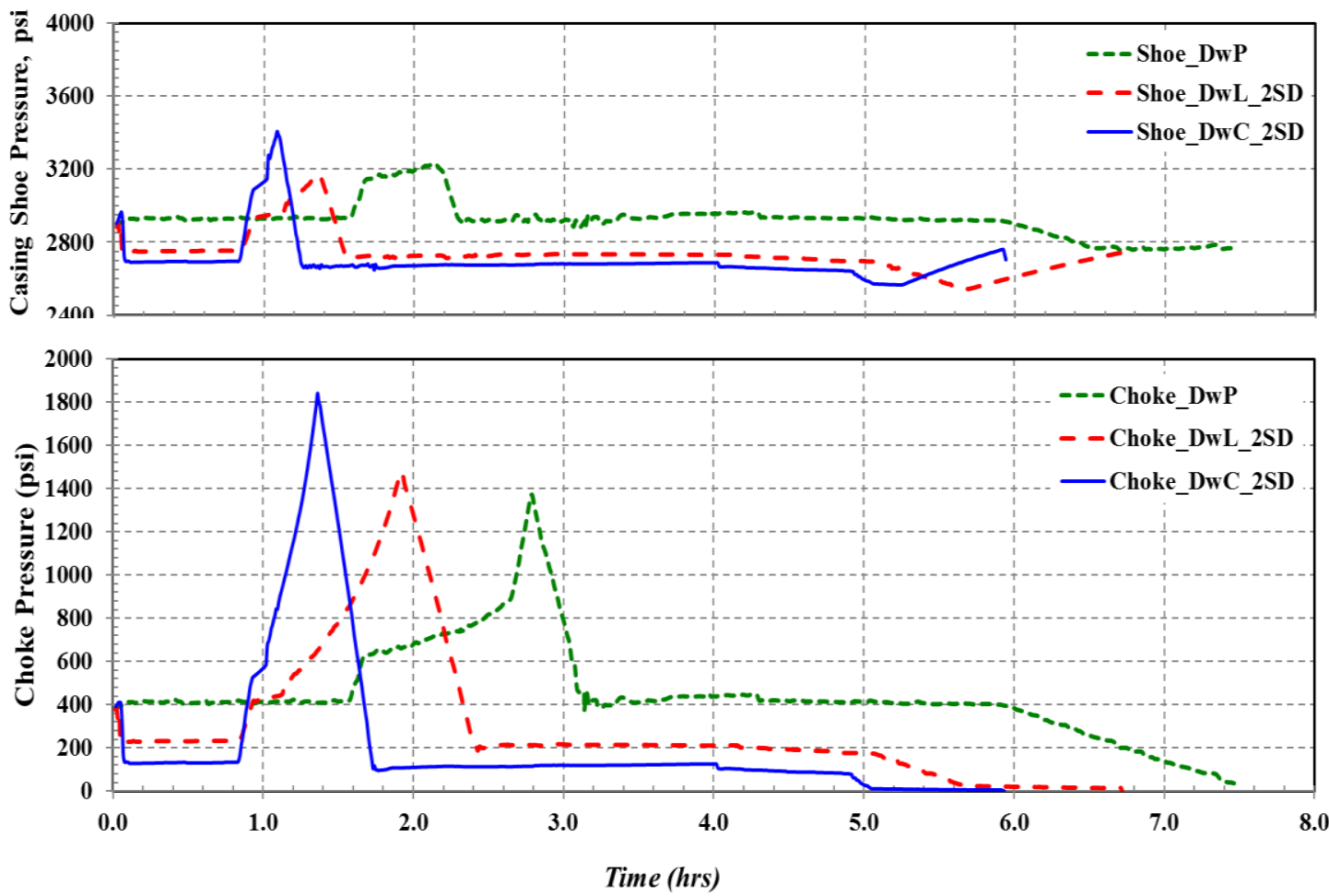

Figure 4.46: Choke and casing shoe pressures for a horizontal well drilled with DwP, DwL and DwC and controlled with R2SD model in OBM. 
Table 4.8 Surface and downhole measurements for DwP, DwL, and DwC in horizontal well drilled with OBM and controlled with Driller's method at $40 \mathrm{spm}$

\begin{tabular}{|l|c|c|c|c|c|c|c|c|}
\hline $\begin{array}{l}\text { Horizontal Well- } \\
\text { OBM }\end{array}$ & ICP, psi & FCP, psi & Time, hrs. & $\begin{array}{c}\text { Max BHP, } \\
\text { psi }\end{array}$ & $\begin{array}{c}\text { Max Choke, } \\
\text { psi }\end{array}$ & $\begin{array}{c}\text { Max Shoe, } \\
\text { psi }\end{array}$ & $\begin{array}{c}\text { Max ECD, } \\
\text { ppg }\end{array}$ & Final spm \\
\hline DwP & 940 & 620 & 7.50 & 5,088 & 1,372 & 3,233 & 13.44 & 40 \\
\hline DwL & 775 & 425 & 6.75 & 5,114 & 1,481 & 3,172 & 13.51 & 32 \\
\hline DwC & 725 & 375 & 5.92 & 5,144 & 1,840 & 3,405 & 13.7 & 25 \\
\hline
\end{tabular}

For the same kick size (20 bbls), the final gas volume was 112 bbls in OBM compared to 68 in WBM as show in Figure 4.47. In DwC/DwL, influx height can be several fold longer and kick reaches surface earlier and creates higher choke and casing shoe pressures. At bubble point, dissolved gas unexpectedly released from solution and resulted in higher pit deviation, and high surface choke and casing shoe pressures. Frequent choke adjustments are required to shield the casing shoe from intense changes in wellbore pressure when gas is liberated. For instance, Figure 4.47 shows that the choke pressure experienced additional 550 psi in OBM where the pressure is 1,840 psi in OBM compared to 1,290 psi in WBM.

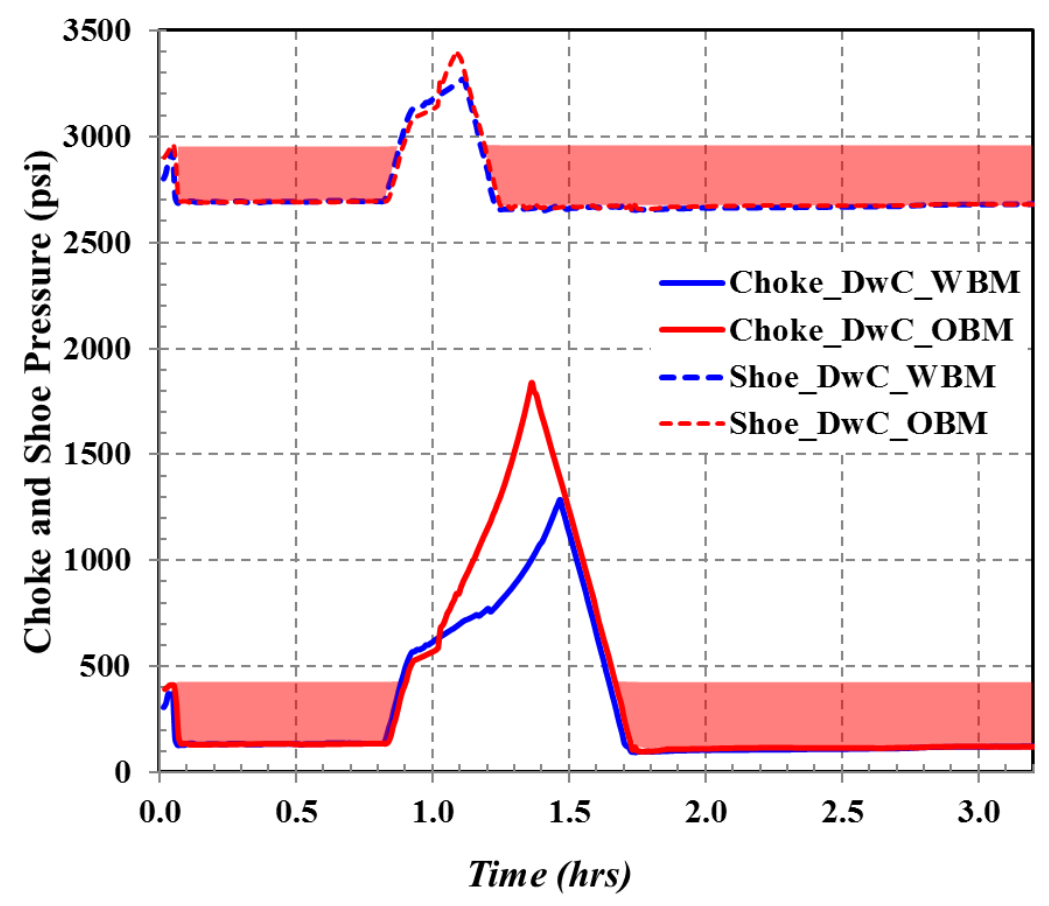

Figure 4.47: Comparison OBM and WBM in DwC 2SD Horizontal well. 
Figures A.1 through A.6 shown in the Appendix A represent the results of vertical, directional and horizontal wells drilled with pipes/casing/liner. Figures A.1 and A.2 compare vertical, directional, and horizontal wells drilled with pipes. Figures A.3 and A.4 shows results for DwL. Figures A.5 and A.6 show results for DwC. Horizontal wells required higher pumping pressures for longer times. In vertical wells, gas starts expansion immediately after passing the BHA section; however, in horizontal wells there is no change in choke pressure until gas reaches vertical section. In the case of DwC/DwL the R2SD model kept the BHP in horizontal wells in the same range as vertical wells and resulted in less choke and shoe pressures.

\subsection{Well Control in Inclined Upward/Downward Laterals}

\subsubsection{Impact of Kick Location}

Also, the study evaluated kick experienced at shallow, middle and deep zones in the lateral section in inclined upward/downward laterals utilizing a dynamic well control simulator. Figure 4.48 shows choke pressure and pit gain for an inclined downward lateral with the kick size of 20 bbls encountered at the entry point of the lateral section (heel), mid-way to the end, and at the total depth (toe). It is clear that longer times are needed to circulate deeper kicks. For instance, 8.1 hours are required to circulate the kick at the toe compared to 4.4 hours for the heel kick (Table 4.9). Table 4.9 illustrates that deeper the wellbore, higher the system friction losses, and higher the ICP, FCP and BHP.

Figure 4.48 shows that the choke pressure and consequently the casing shoe pressure are higher in heel kicks, due to the continuous gas expansion after passing the BHA. The gas influx expanded $174 \%$ in the heel kick compared to $136 \%$ only in the toe kick. This behavior is contributed to the dispersed gas bubbles that are trapped by mud yield properties. In deeper kicks, when gas reaches the vertical section, wellbore pressure increases and free gas dissolves in oil based mud therefore, the surface pit gain decreases. At the bubble point, gas breaks out of solution near the surface and expands continuously until it reaches the choke. Figure 4.49 shows the unique behavior of gas kick in inclined upward lateral when the same size kick encountered at the heel, mid-way, and at the toe. 

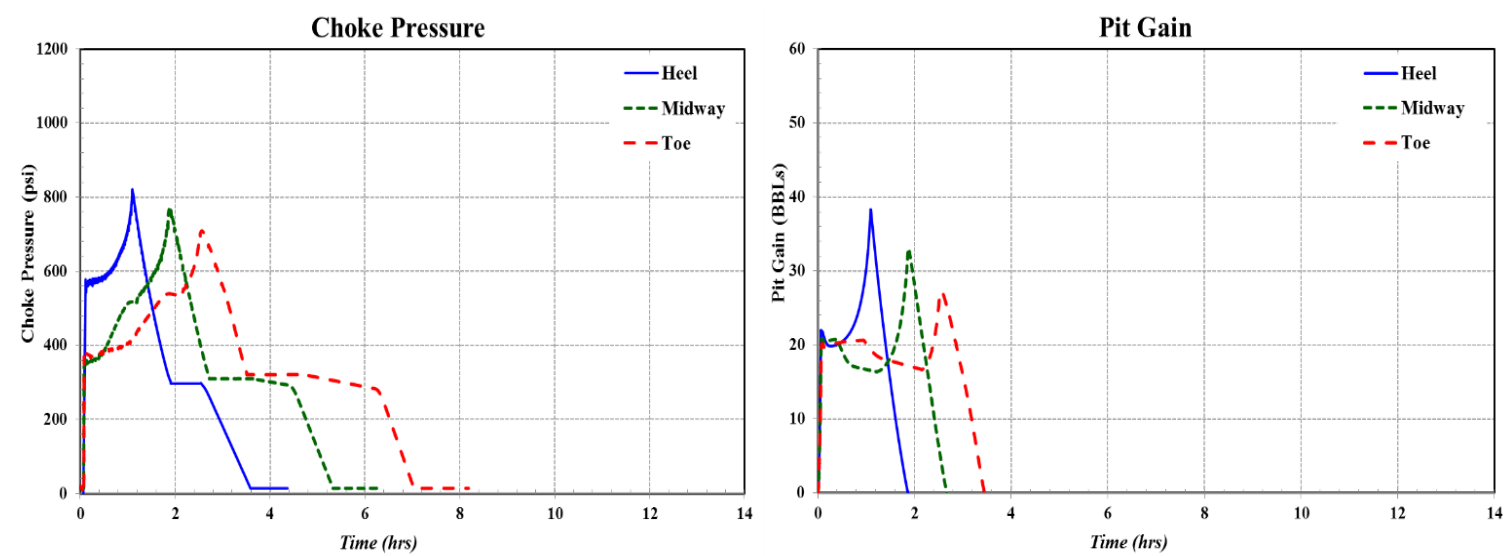

Figure 4.48: Choke pressure and pit gain at heel, midway, and toe in inclined downward lateral.
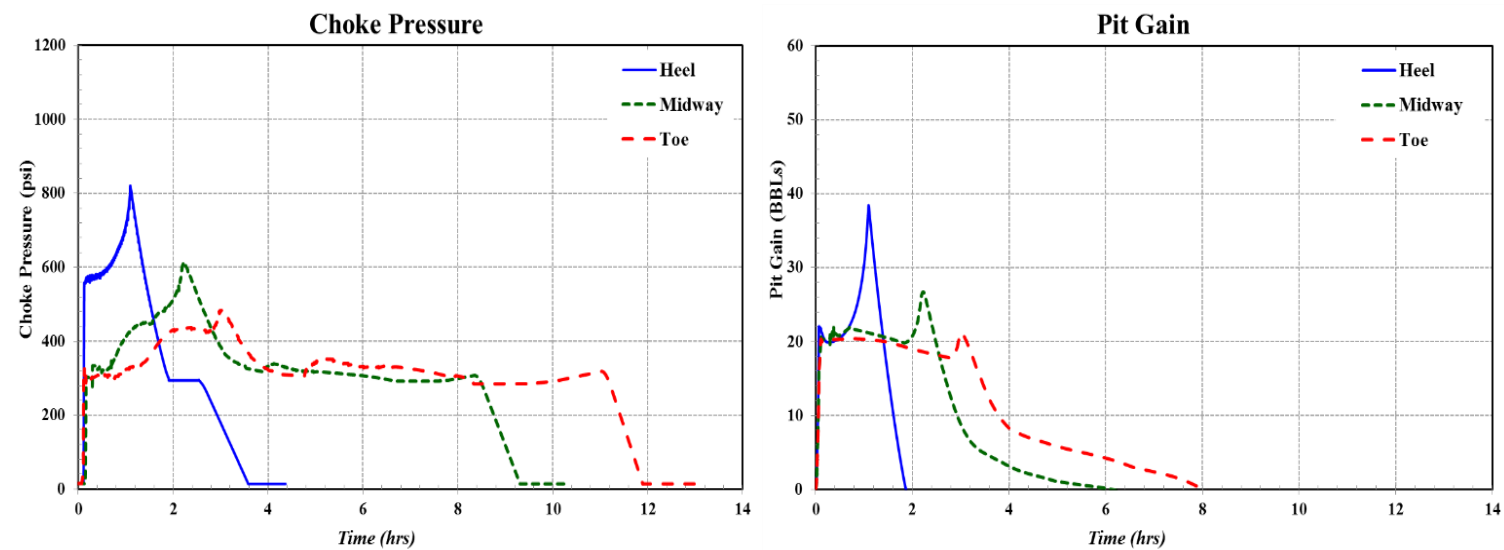

Figure 4.49: Choke pressure and pit gain at heel, midway, and toe in inclined upward lateral.

Table 4.9: Surface and down-hole recorded data for different kick locations in inclined downward, flat horizontal, and inclined upward wells.

\begin{tabular}{|c|c|c|c|c|c|c|c|c|}
\hline & $\begin{array}{c}\text { Kick } \\
\text { Location }\end{array}$ & $\begin{array}{l}\text { Time } \\
\text { (hrs) }\end{array}$ & $\begin{array}{l}\text { ICP } \\
\text { (psi) }\end{array}$ & $\begin{array}{l}\text { FCP } \\
\text { (psi) }\end{array}$ & $\begin{array}{l}\text { Max Gas Flow } \\
\text { Rate (MMSCFD) }\end{array}$ & $\begin{array}{c}\text { Bottomhole } \\
\text { Pressure } \\
\text { (psi) }\end{array}$ & $\begin{array}{c}\text { Max Casing } \\
\text { Shoe Pressure } \\
\text { (psi) }\end{array}$ & $\begin{array}{c}\text { Max Choke } \\
\text { Pressure } \\
\text { (psi) }\end{array}$ \\
\hline \multirow{3}{*}{$\begin{array}{l}\text { Inclined } \\
\text { Downwarc }\end{array}$} & Heel & 4.4 & 854 & 413 & 2.27 & 5,383 & 2,011 & 821 \\
\hline & Mid-way & 6.3 & 1,008 & 484 & 1.75 & 5,641 & 1,954 & 773 \\
\hline & Toe & 8.1 & 1,134 & 524 & 1.29 & 5,889 & 1,889 & 708 \\
\hline \multirow{3}{*}{$\begin{array}{c}\text { Flat } \\
\text { Horizontal }\end{array}$} & Heel & 4.3 & 851 & 413 & 2.31 & 5,379 & 2,009 & 820 \\
\hline & Mid-way & 6.27 & 999 & 485 & 1.84 & 5,467 & 1,951 & 774 \\
\hline & Toe & 8.1 & 1,114 & 525 & 1.32 & 5,545 & 1,883 & 696 \\
\hline \multirow{3}{*}{$\begin{array}{l}\text { Inclined } \\
\text { Upward }\end{array}$} & Heel & 4.36 & 851 & 413 & 2.27 & 5,379 & 2,010 & 820 \\
\hline & Mid-way & 10.26 & 963 & 455 & 0.98 & 5,319 & 1,838 & 611 \\
\hline & Toe & 13 & 1,099 & 525 & 0.65 & 5,265 & 1,789 & 483 \\
\hline
\end{tabular}

When the results shown in Figure 4.48 and Figure 4.49 are compared, it is seen that longer times are needed to circulate the same size of the kick in inclined upward laterals. For instance, a 20 barrels kick encountered at the toe required 13 hours in upward lateral compared to 8.1 hours for toe-down lateral (Table 4.9). 
Figure 4.49 shows that the choke pressure and consequently the casing shoe pressure are much higher in the heel kick due to continuous gas expansion. The gas expanded $174 \%$ in the heel kick compared to $104 \%$ in the toe kick due to gas tendency to migrate to the toe in the opposite direction of the mud flow. Dispersed and entrapped gas bubbles by mud yield point contribute to this behavior in comparison to slug flow in inclined downward laterals. Thus, inclined upward lateral experienced less surface pressures and volumes compared to downward lateral. However, kicks in toe-up laterals required longer circulation times to flush out all the trapped gas bubbles.

Figure 4.50 compares surface and downhole pressures for inclined upward, inclined downward, and flat horizontal laterals. Closer the kick to the vertical section, less the circulation time, but higher the expansion rate, choke, and casing shoe pressures. Although, inclined upward experienced less wellbore and surface pressures for the same size kick, it needed extended circulation times. For example, compared to inclined downward, choke pressure was 32\% less, shoe pressure was $5 \%$ less, bottomhole pressure was $11 \%$ less, and gas expansion was $23 \%$ less, however, the circulation time was $60 \%$ higher. Therefore, higher the TVD difference, higher the deviation in behavior between heel and toe kicks in toe-up/toe-down laterals.

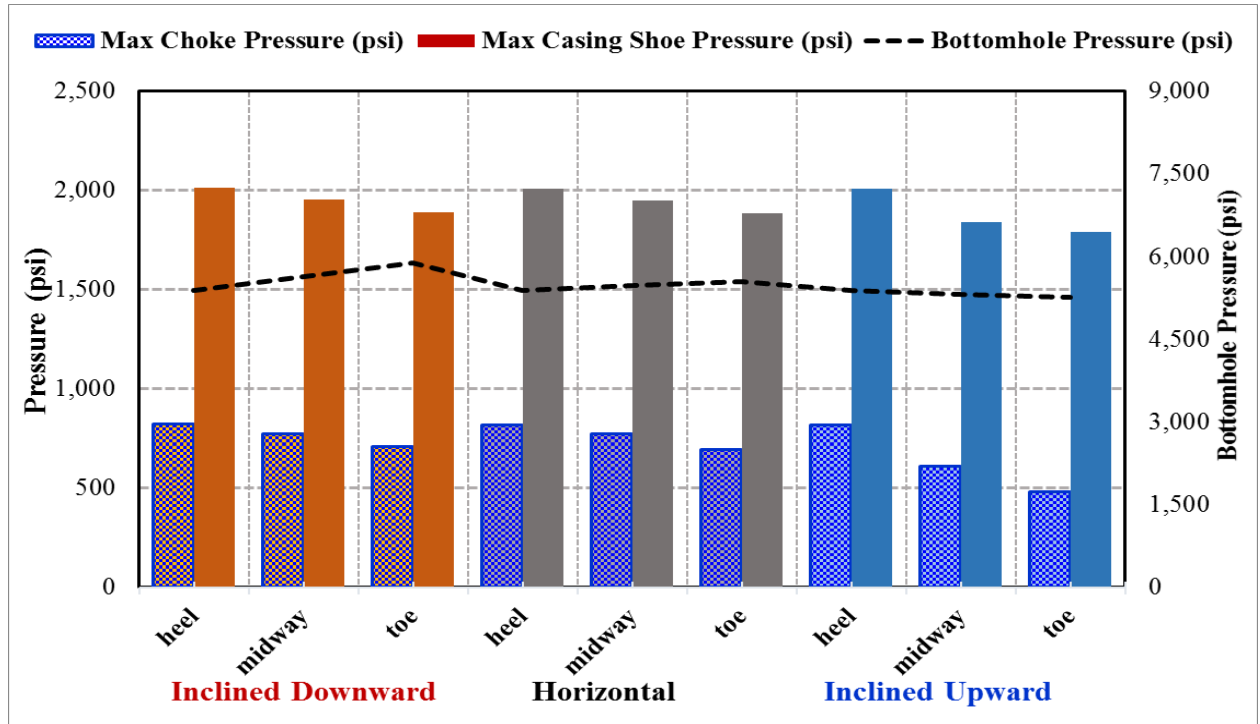

Figure 4.50: Surface and bottomhole pressures at heel, midway, and toe in inclined upward/downward laterals. 


\subsubsection{Impact of Influx Size}

Five kick sizes are examined to investigate the impact of early kick detection. The slower the crew in detecting a kick and closing the BOP, higher the pit gain. Figure 4.51 shows choke pressure and pit gain for an inclined downward lateral with influx size for the range of 10 to 80 bbls. Clearly, higher the kick size, higher the gas flow rate, pit gain, choke, and shoe pressures as shown in Table 4.10. For instance, choke pressure increases to 1,529 psi at 80 bbls in comparison to 511 psi at 10 bbls. The highest gas discharge rate was 3.61 MMSCFD at 80 bbls. All gas kick sizes were circulated out in 3.5 hours, while the total circulation time was 8.2 hours. Even though the same ICP and FCP pressures were used to keep the BHP constant, higher kick sizes resulted in higher pit gain and surface pressure. It is interesting to note that, in inclined upward lateral shown in Figure 4.52, 80 bbls kick required 15.7 hours in comparison to 3.5 hours in inclined downward (Figure 4.51).
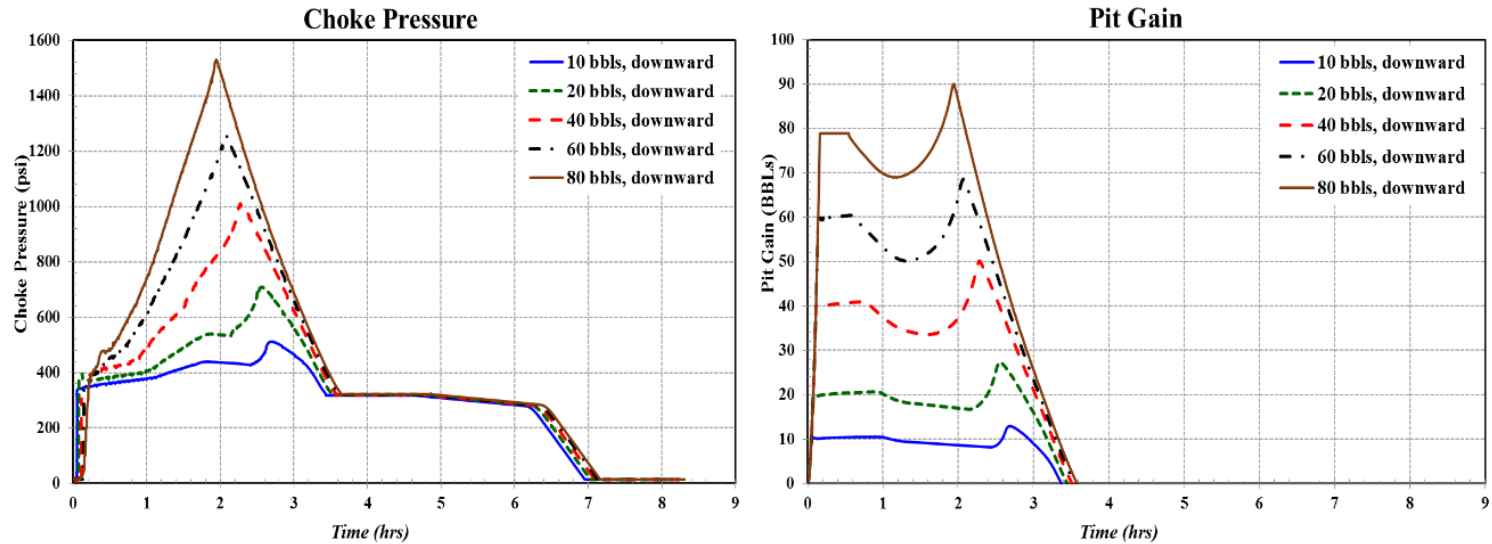

Figure 4.51: Choke pressure and pit gain comparison in an inclined downward at different kick sizes.
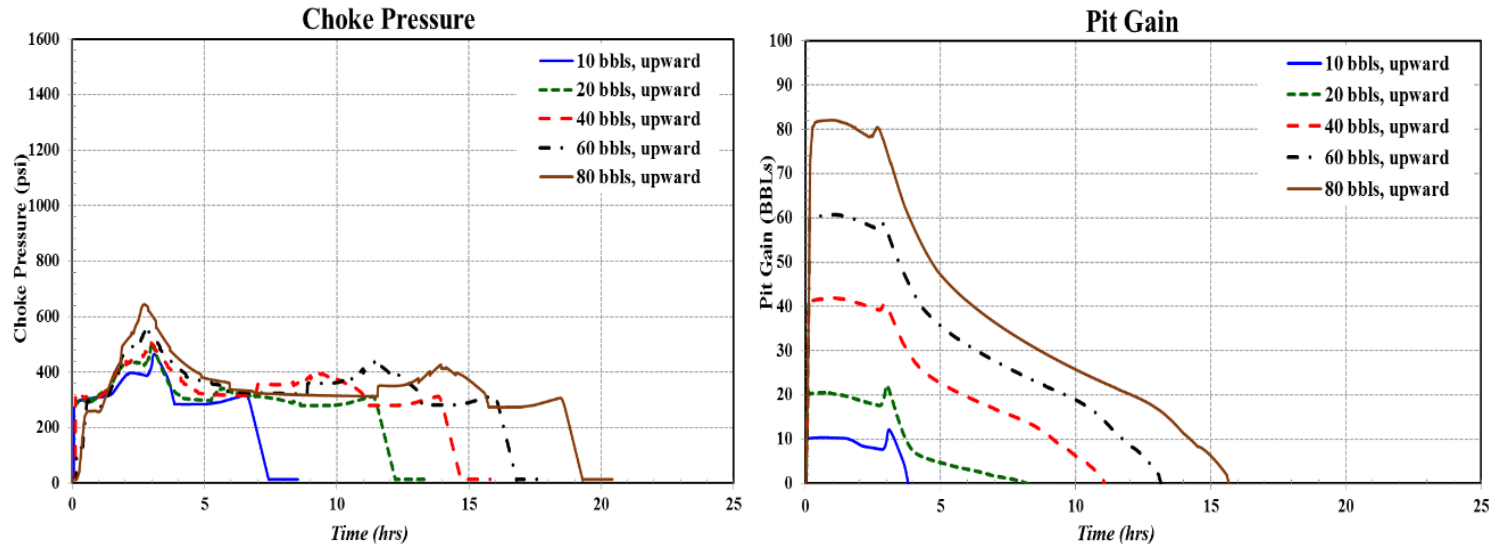

Figure 4.52: Choke pressure and pit gain comparison in an inclined upward at different kick sizes. 
Table 4.10: Surface and down-hole recorded data for different kick sizes in inclined downward, flat horizontal, and inclined upward wells.

\begin{tabular}{|c|c|c|c|c|c|c|c|}
\hline & $\begin{array}{c}\text { Influx Size } \\
\text { (BBLs) }\end{array}$ & $\begin{array}{l}\text { Time } \\
\text { (hrs) }\end{array}$ & $\begin{array}{cc}\text { ICP } & \text { FCP } \\
\text { (psi) } & \text { (psi) } \\
\end{array}$ & $\begin{array}{c}\text { Gas Flow Rate } \\
\text { (MMSCFD) }\end{array}$ & $\begin{array}{c}\text { Bottomhole } \\
\text { Pressure (psi) }\end{array}$ & $\begin{array}{c}\text { Max Shoe } \\
\text { Pressure (psi) }\end{array}$ & $\begin{array}{c}\text { Max Choke } \\
\text { Pressure (psi) }\end{array}$ \\
\hline \multirow{5}{*}{$\begin{array}{l}\text { Inclined } \\
\text { Downward }\end{array}$} & 10 bbls & 8.1 & 1,130524 & 0.77 & 5,886 & 1,794 & 511 \\
\hline & 20 bbls & 8.2 & 1,134524 & 1.28 & 5,889 & 1,901 & 708 \\
\hline & 40 bbls & 8.2 & 1,132525 & 2.06 & 5,888 & 2,176 & 1,009 \\
\hline & 60 bbls & 8.3 & 1,133525 & 2.62 & 5,889 & 2,382 & 1,256 \\
\hline & $80 \mathrm{bbls}$ & 8.3 & 1,135525 & 3.61 & 5,891 & 2,617 & 1,529 \\
\hline \multirow{5}{*}{$\begin{array}{l}\text { Flat } \\
\text { Horizontal }\end{array}$} & 10 bbls & 8.1 & 1,114524 & 0.75 & 5,545 & 1,172 & 489 \\
\hline & 20 bbls & 8.2 & 1,114525 & 1.32 & 5,545 & 1,883 & 696 \\
\hline & 40 bbls & 8.2 & 1,114525 & 2.35 & 5,545 & 2,187 & 1,018 \\
\hline & 60 bbls & 8.3 & 1,114526 & 3.26 & 5,546 & 2,444 & 1,278 \\
\hline & 80 bbls & 8.3 & 1,114526 & 4.02 & 5,546 & 2,655 & 1,139 \\
\hline \multirow{5}{*}{$\begin{array}{l}\text { Inclined } \\
\text { Upward }\end{array}$} & 10 bbls & 8.5 & 1,099524 & 0.69 & 5,265 & 1,752 & 464 \\
\hline & 20 bbls & 13.3 & 1,094525 & 0.74 & 5,260 & 1,791 & 501 \\
\hline & 40 bbls & 15.7 & 1,021445 & 0.59 & 5,261 & 1,807 & 506 \\
\hline & 60 bbls & 17.9 & 1,024444 & 0.67 & 5,263 & 1,850 & 563 \\
\hline & 80 bbls & 20.4 & 1,015436 & 0.84 & 5,254 & 1,900 & 644 \\
\hline
\end{tabular}

In contrast to inclined downward lateral, in inclined upward lateral, higher was the kick size, longer the circulation times. The associated pressures are shown in Table 4.10 for both laterals. For instance, choke pressure increases to $644 \mathrm{psi}$ at 80 bbls compared to $464 \mathrm{psi}$ at $10 \mathrm{bbls}$ for inclined upward lateral. Figure 4.53 compares pump and choke pressures for 20 and 40 bbls kick in inclined downward and upward laterals. The first circulation of the Driller's method required 3.6 hours in inclined downward, while it needed 11.13 hours in inclined upward with 40 bbls kick. Noticeably, larger kick sizes resulted in higher pit gain, flow rate, choke and shoe pressures in inclined downward. In inclined upward higher kick size needed longer times to be flushed with less surface impact. For instance, 40 bbls kick expanded $124 \%$ in inclined downward, but it expanded only by $104 \%$ in inclined upward as shown in Figure 4.54.

Choke pressure increased by $143 \%$ in inclined downward lateral, however it insignificantly changed in upward lateral to $101 \%$ (Figure 4.53). Gas flushed as a single slug in inclined downward. However, in toe-up laterals, dispersed gas bubbles reached the surface in two major waves. The first wave was high in magnitude than a second wave of gas that flushed out all the remaining dispersed bubbles towards the end of circulation. 
For instance, in toe-down, when a 40 bbls gas reached the surface, the maximum flow rate was 2.4 MMSCFD and discharge time was 1.4 hours. However, in inclined upward first gas wave reached the surface with 0.6 MMSCFD rate. Then, after 8.4 hours of gas discharge, the second wave approached the choke with a flow rate of 0.4 MMSCFD (Figure 4.54).
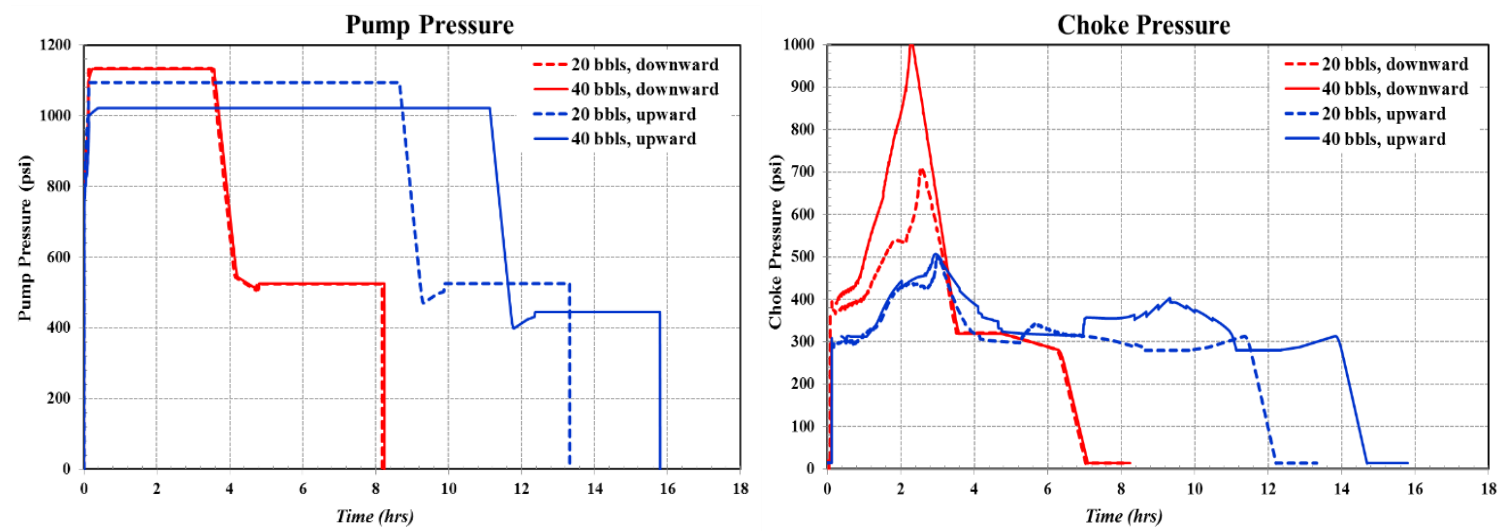

Figure 4.53: Pump and choke pressure or 20 and 40 bbls in upward/downward lateral.
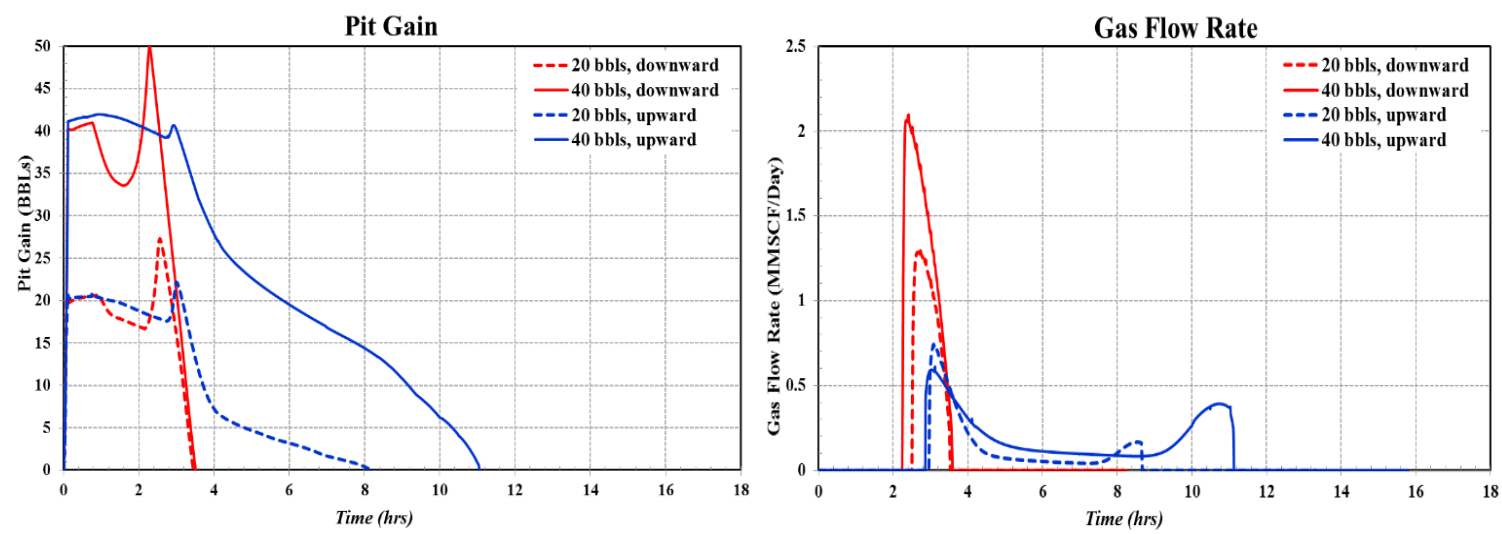

Figure 4.54: Pit gain and flow rate for 20 and 40 bbls in upward/downward lateral.

Figure 4.55 compares five kick sizes of 10, 20, 40,60, and 80 bbls in inclined downward, flat horizontal, and upward laterals. To keep constant bottomhole pressure, initial and final circulating pressures were kept at the same value. However, in inclined downward and inclined upward laterals, when the influx size increased to 80 bbls, maximum choke pressure increased by $299 \%$ and $139 \%$, at the same time, casing shoe pressure increased to $146 \%$ and $108 \%$, respectively. Even though, all influx sizes required 8.2 hours in toe-down lateral, the circulation time for 80 bbls increased by $240 \%$ in inclined upward. Gas flow rate increased by $369 \%$ in downward compared to $22 \%$ in upward lateral. 


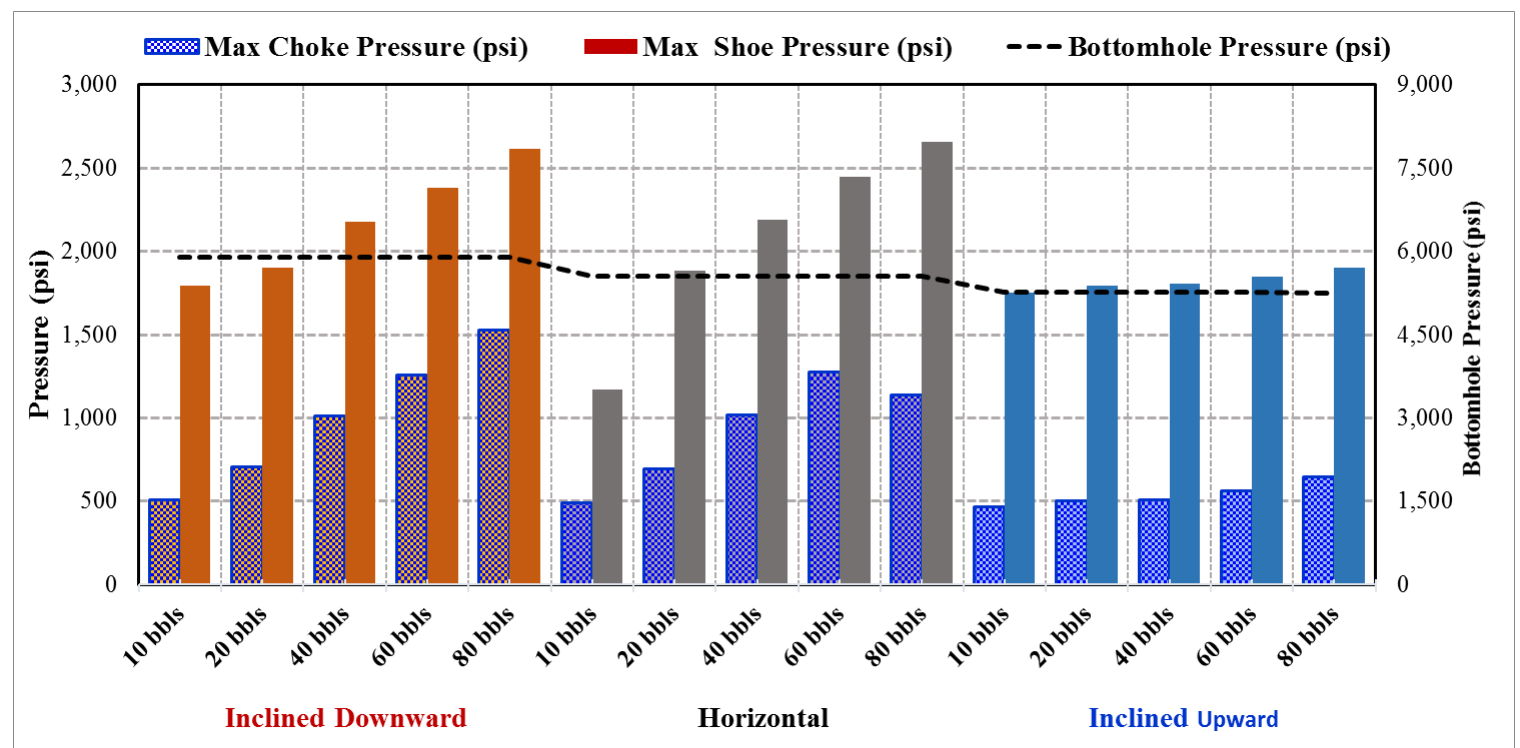

Figure 4.55: Surface and bottomhole pressures comparison at different kick sizes in inclined upward/downward laterals.

The results of kick size study highlights the importance of crew awareness of early kick detection techniques to avoid exceeding of kick tolerance and maximum allowable annular surface pressure (MAASP) and risking well integrity. Therefore, kick size highly influences surface pressures and volumes in inclined downward, but only impacts circulation time in inclined upward.

\subsubsection{Impact of Kick Circulation Rate}

The impact of kick circulation rate on surface and bottomhole pressures and volumes was studied and the results are presented in this section. Figure 4.56 and Figure 4.57 show that for the slowest pump rate of $50 \mathrm{gpm}$ the pressure experienced at the pump, choke and bottomhole were less. Longer circulation times were required for the highest circulation rate of $250 \mathrm{gpm}$. Table 4.11 shows that for inclined downward lateral, $250 \mathrm{gpm}$ flow rate required 5.0 hours in comparison to 24.3 hours at $50 \mathrm{gpm}$. This resulted in increase of ICP from 852 to 1,540 psi. Also, FCP increased from 290 to 922 psi. Even though, in inclined upward, $250 \mathrm{gpm}$ required 5.2 hours, $50 \mathrm{gpm}$ needed an extended circulation time of 32.9 hours. Likewise, ICP increased from 821 to 1,509 psi, and FCP increased from 288 to 928 psi. 

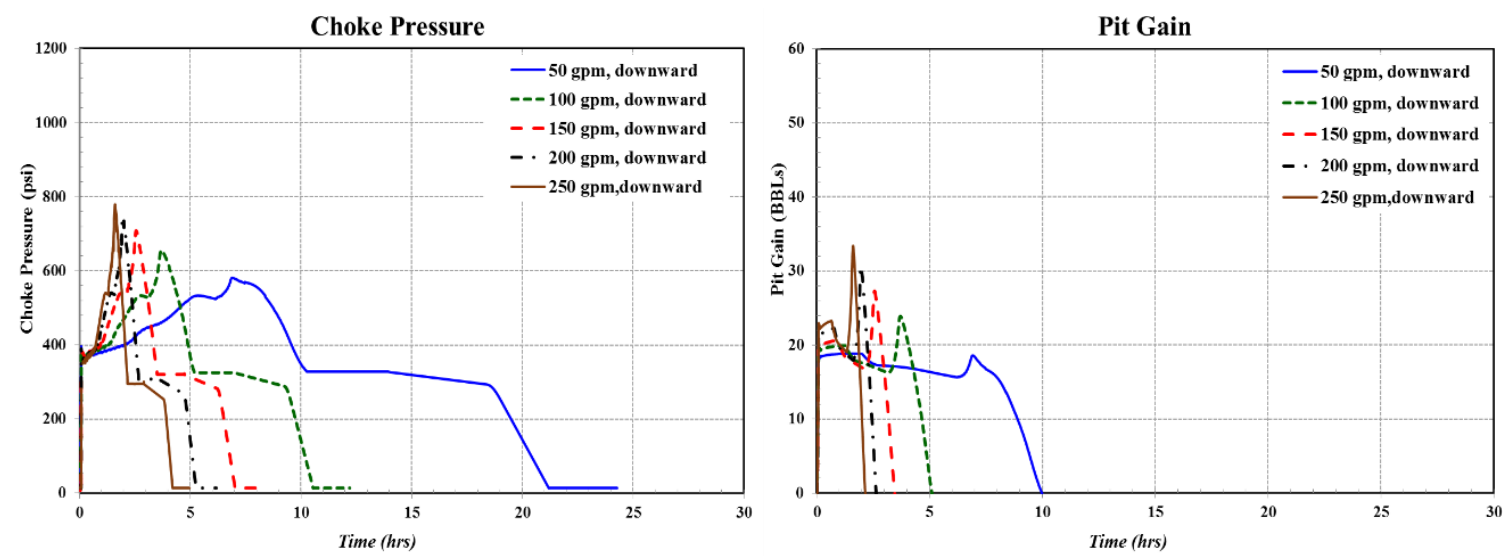

Figure 4.56: Effect of flow rate on choke pressure and pit gain in an inclined downward lateral.
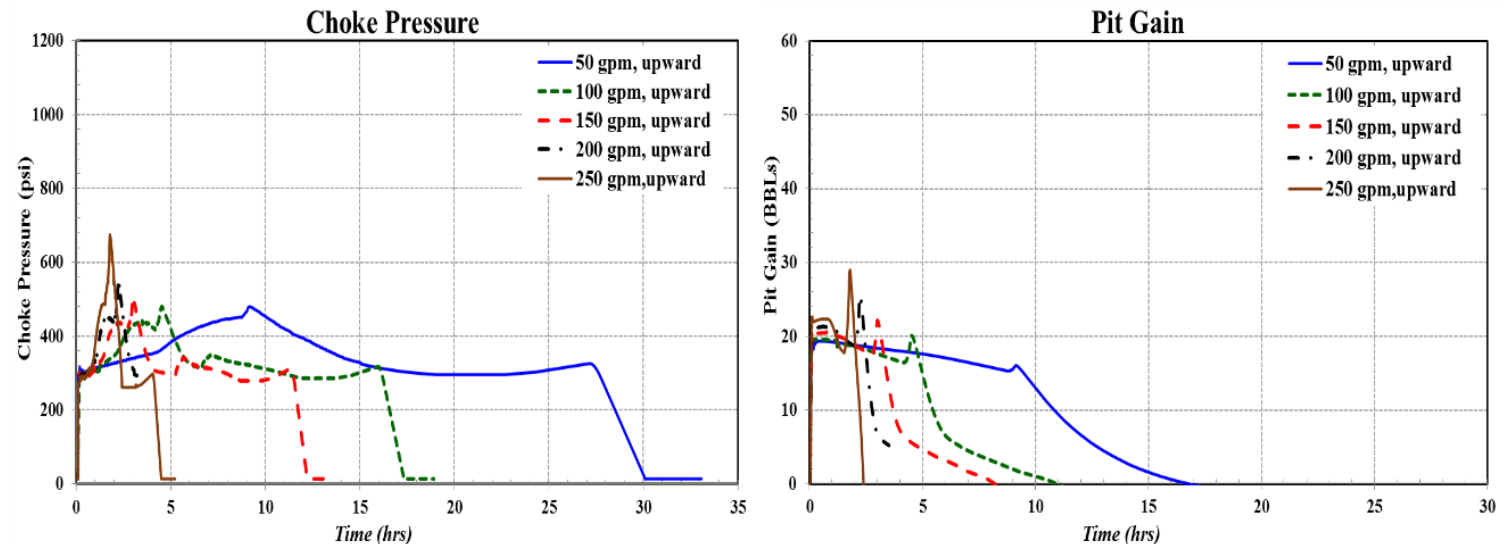

Figure 4.57: Effect of flow rate on choke pressure and pit gain in inclined upward lateral.

Table 4.11: Surface and down-hole recorded data for different circulation rates in inclined downward, flat horizontal, and inclined upward wells.

\begin{tabular}{|c|c|c|c|c|c|c|c|c|}
\hline & $\begin{array}{l}\text { Circulation } \\
\text { Rate (gpm) }\end{array}$ & $\begin{array}{l}\text { Time } \\
\text { (hrs) }\end{array}$ & $\begin{array}{l}\text { ICP } \\
\text { (psi) }\end{array}$ & $\begin{array}{l}\text { FCP } \\
\text { (psi) }\end{array}$ & $\begin{array}{c}\text { Gas Flow Rate } \\
\text { (MMSCFD) }\end{array}$ & $\begin{array}{c}\text { Bottomhole } \\
\text { Pressure (psi) }\end{array}$ & $\begin{array}{c}\text { Max Shoe } \\
\text { Pressure (psi) }\end{array}$ & $\begin{array}{c}\text { Max Choke } \\
\text { Pressure (psi) }\end{array}$ \\
\hline \multirow{5}{*}{$\begin{array}{l}\text { Inclined } \\
\text { Downward }\end{array}$} & 50 gpm & 24.3 & 852 & 290 & 0.33 & 5,822 & 1,874 & 581 \\
\hline & 100 gpm & 12.2 & 974 & 385 & 0.75 & 5,856 & 1,878 & 655 \\
\hline & 150 gpm & 8.2 & 1,134 & 524 & 1.28 & 5,889 & 1,902 & 708 \\
\hline & 200 gpm & 6.2 & 1,320 & 701 & 1.88 & 5,915 & 1,944 & 748 \\
\hline & $250 \mathrm{gpm}$ & 5.0 & 1,540 & 922 & 2.55 & 5,941 & 1,973 & 779 \\
\hline \multirow{5}{*}{$\begin{array}{l}\text { Flat } \\
\text { Horizontal }\end{array}$} & 50 gpm & 24.1 & 834 & 289 & 0.33 & 5,480 & 1,838 & 578 \\
\hline & 100 gpm & 12.1 & 957 & 386 & 0.79 & 5,515 & 1,858 & 637 \\
\hline & 150 gpm & 8.1 & 1,114 & 525 & 1.31 & 5,545 & 1,883 & 696 \\
\hline & 200 gpm & 6.1 & 1,302 & 703 & 1.92 & 5,573 & 1,916 & 732 \\
\hline & $250 \mathrm{gpm}$ & 4.9 & 1,523 & 925 & 2.28 & 5,600 & 1,901 & 694 \\
\hline \multirow{5}{*}{$\begin{array}{l}\text { Inclined } \\
\text { Upward }\end{array}$} & 50 gpm & 32.9 & 821 & 288 & 0.17 & 5,203 & 1,785 & 479 \\
\hline & 100 gpm & 18.9 & 936 & 386 & 0.45 & 5,229 & 1,782 & 475 \\
\hline & 150 gpm & 13.3 & 1,094 & 525 & 0.72 & 5,260 & 1,791 & 499 \\
\hline & 200 gpm & 10.2 & 1,288 & 704 & 1.18 & 5,294 & 1,820 & 546 \\
\hline & $250 \mathrm{gpm}$ & 5.2 & 1,509 & 928 & 2.07 & 5,320 & 1,892 & 670 \\
\hline
\end{tabular}


Figure 4.58 and Figure 4.59 compare inclined upward/downward laterals at 50 and $100 \mathrm{gpm}$ kick circulation rates. Clearly, higher the circulation rate, higher the wellbore frictional losses and lower the circulation time. For inclined downward lateral, $100 \mathrm{gpm}$ circulation rate needed $50 \%$ less time (from 24.3 to 12.2 hours) in comparison to $50 \mathrm{gpm}$. This rate change resulted in 14\% increase in ICP (from 852 to $974 \mathrm{psi}$ ) and $33 \%$ increase in FCP (from 290 to $385 \mathrm{psi}$ ) with an average BHP of $5,840 \mathrm{psi}$. In the case of inclined upward lateral, $100 \mathrm{gpm}$ required $115 \%$ less time (from 32.9 to 18.9 hours). This rate change resulted in 12\% increase in ICP (from 821 to $936 \mathrm{psi}$ ), $25 \%$ increase in FCP (from 288 to $386 \mathrm{psi}$ ) with an average BHP of $5,216 \mathrm{psi}$. In inclined downward lateral at $100 \mathrm{gpm}$, choke pressure increased from 581 to 655 psi. In inclined upward lateral, gas flow rate increased from 0.17 to 0.45 MMDCFD, while in inclined downward lateral it increased from 0.33 MMSCFD to 0.75 MMSCFD as shown in Figure 4.59.
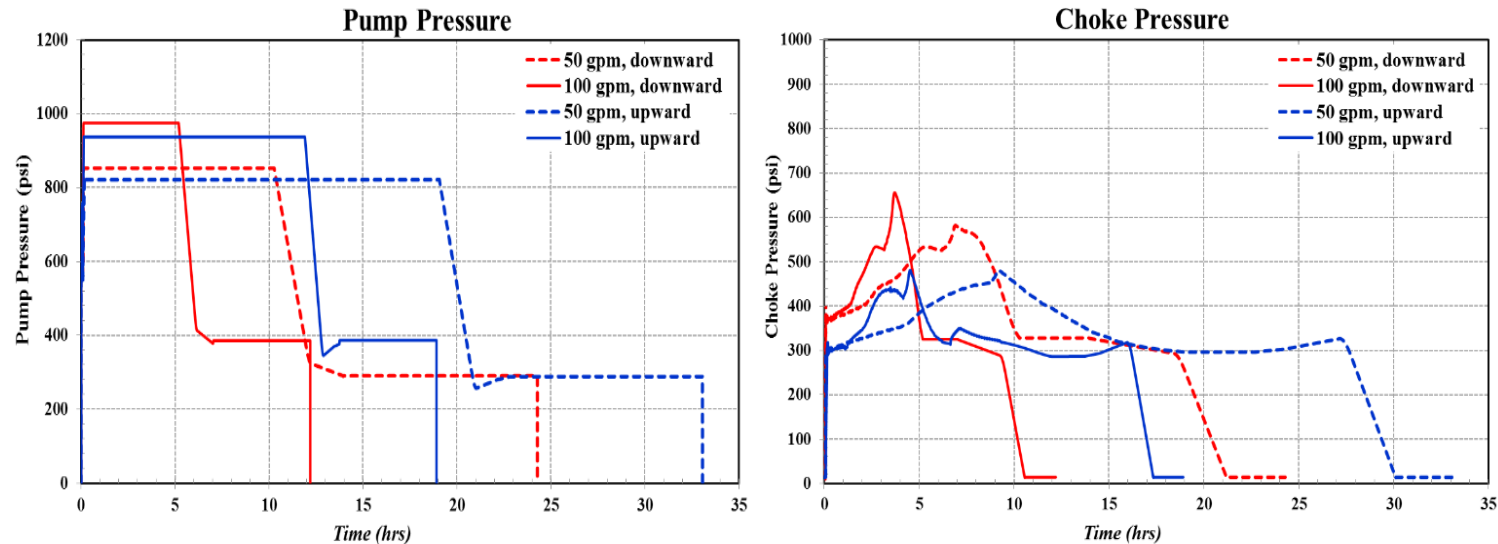

Figure 4.58: Pump and choke pressures at 50 and $100 \mathrm{gpm}$ flow rate in upward/downward lateral.
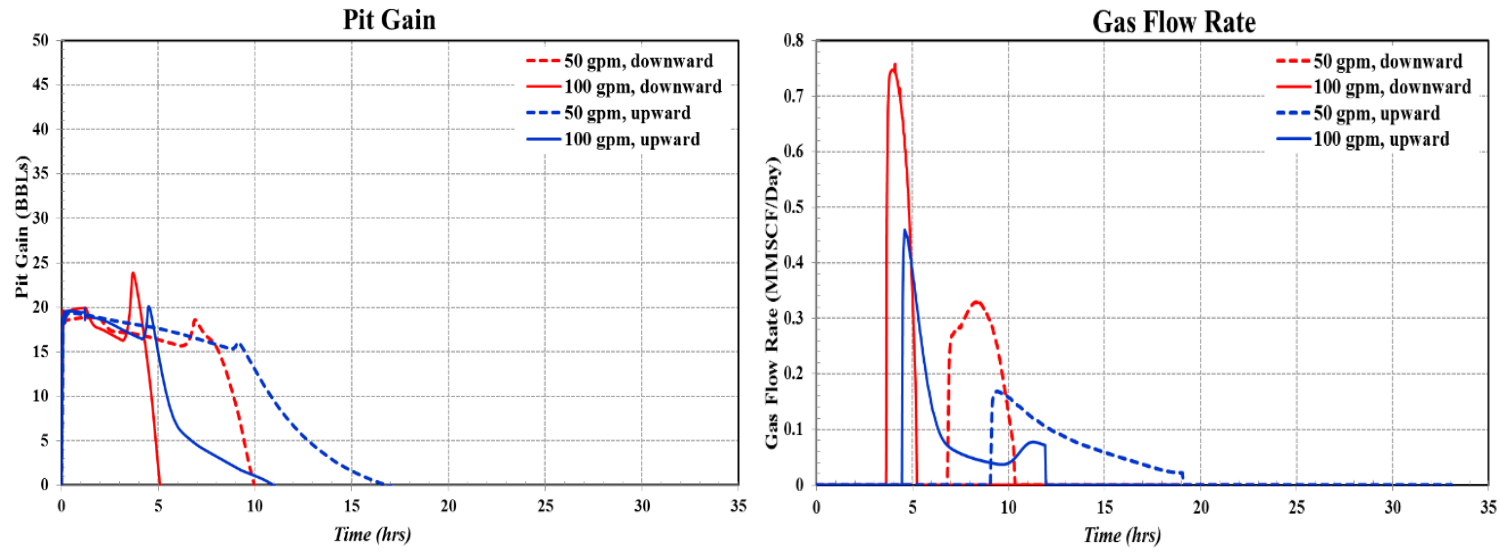

Figure 4.59: Pit gain and flow rate at 50 and $100 \mathrm{gpm}$ flow rate in upward/downward lateral. 
Figure 4.60 compares five kick circulation rates for a range of 50 to $250 \mathrm{gpm}$ in inclined upward, inclined downward and flat horizontal laterals. Circulating a kick at a flow rate of $250 \mathrm{gpm}$ instead of $50 \mathrm{gpm}$ required $84 \%$ less time (5.5 hours compared to 32.9 hours) in an inclined upward lateral. Despite keeping BHP constant, ICP and FCP progressively increased at ahigher rate due to larger friction losses. For example, ICP was $1,540 \mathrm{psi}$ at $250 \mathrm{gpm}$ compared to $852 \mathrm{psi}$ at $50 \mathrm{gpm}$ in the inclined downward lateral. Likewise, ICP increased to 1,509 psi compared to $852 \mathrm{psi}$ in the inclined upward lateral. However, higher impact was noticed on FCP as it increased from 290 to 922 psi in the inclined downward lateral and from 288 to 928 psi in theinclined upward lateral.

At slow pump rates, the slope of choke pressure ascent was lower as a result of less gas liberation and expansion when compared to the slope observed at high pump rates. Slug flow pattern dominated at high pump rates (250 gpm) enabling efficient gas circulation with less time. Nonetheless, gas expanded at a higher rate at the surface and resulted in higher choke and casing shoe pressures. The extended circulation time needed in upward laterals dispute the earlier claims of Santos (1991a), Choe (2001), and Watson et al. (2003) that circulation time is a function of pump rate only. For example, if the pump rate is decreased from 100 to $50 \mathrm{gpm}$, the circulation time needed at $50 \mathrm{gpm}$ would be twice the value at $100 \mathrm{gpm}$.

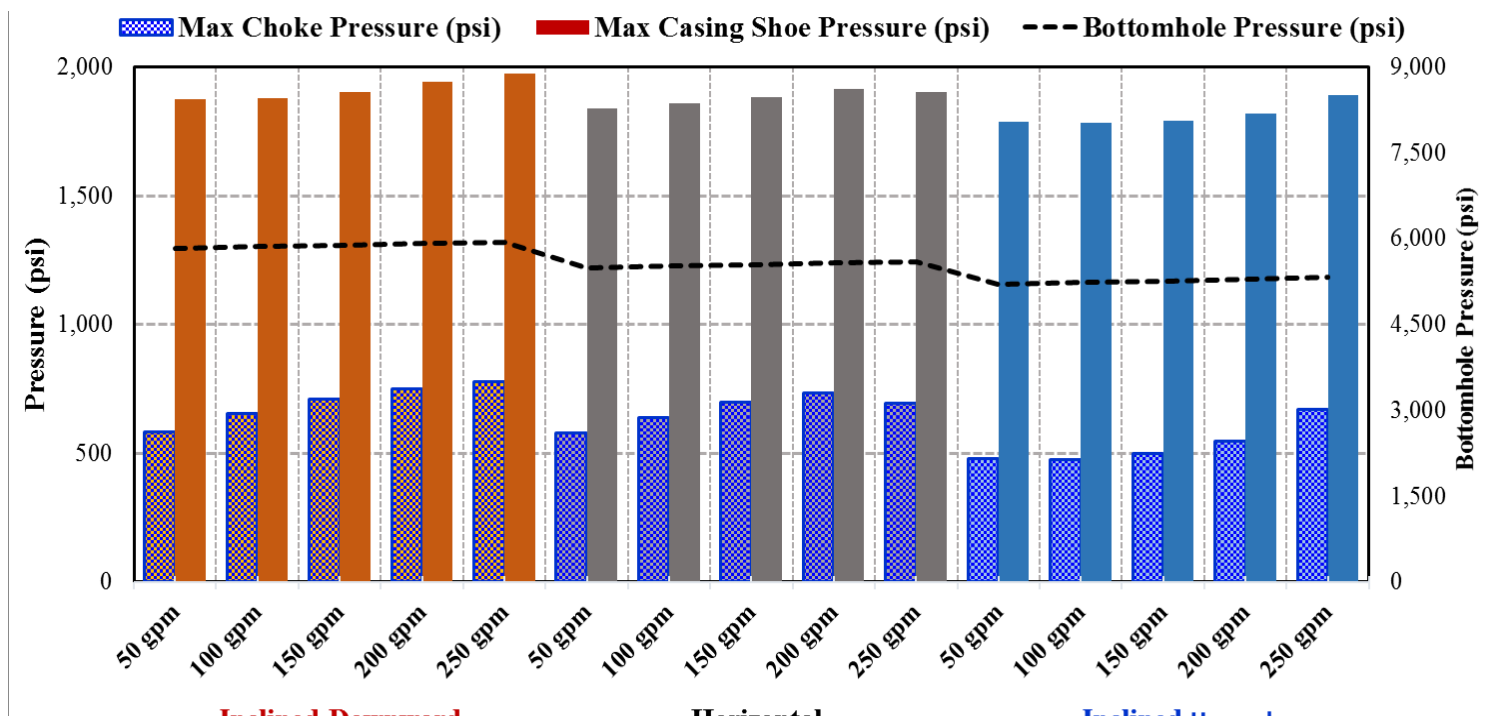

Figure 4.60: Surface and bottomhole pressures at different flow rates in inclined upward/downward laterals. 


\subsection{Marcellus and Utica shales Comparative Study and Sensitivity Analysis}

\subsubsection{Impact of Wellbore Profile}

The impact of inclination angle of lateral section was investigated in Marcellus (MRC) and compared to Utica (UTC) shale drilled with WBM. This study considered an influx volume of 20 bbls and a circulation rate of $200 \mathrm{gpm}$. As shown in Figure 4.61 and Table 4.12, in inclined upward lateral, higher circulation rates and longer time were required to flush out the dispersed gas bubbles completely. Upon circulating the gas, the surface pit gain was less due to the dispersed gas bubbles trapped in mud by yield stress that increased mud compressibility. Figure 4.61 also shows that in Utica shale with higher reservoir pressure and temperature, kick circulations resulted with higher wellbore and surface pressures. For inclined downward laterals (inclination angle $8^{\circ}$ ) gas migrated in slug flow pattern and continuously expanded and reached the surface faster. This resulted in higher pit gain and discharge rates. Conversely, in inclined upward profiles (inclination angle $92^{\circ}$ ), gas tended to migrate towards the end of the well (toe) and accumulated in high side pockets.
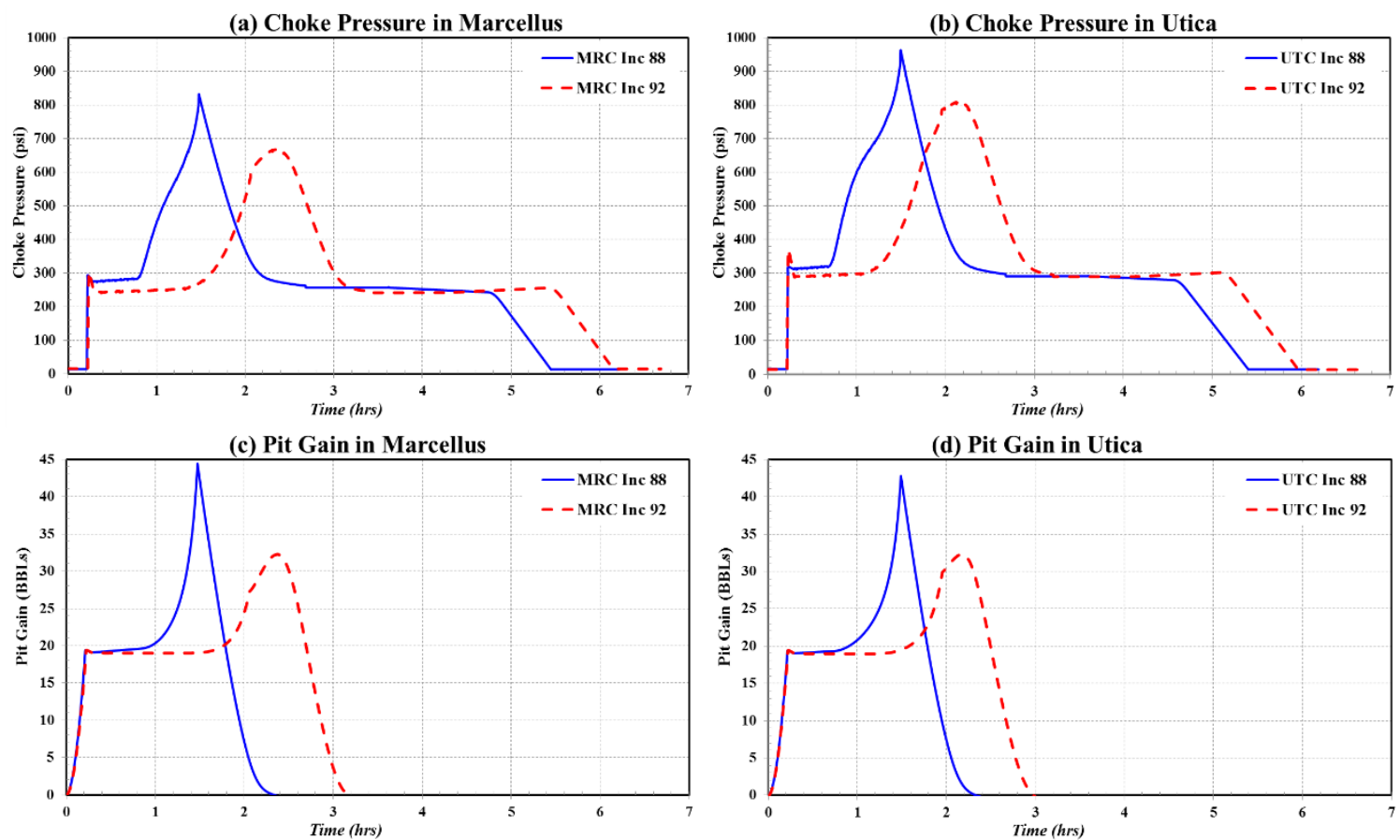

Figure 4.61: Impact of wellbore profile on choke pressure and pit gain in MRC and UTC drilled with WBM. 
Table 4.12: Surface and down-hole recorded data for inclined upward and downward in Marcellus and Utica Shales.

\begin{tabular}{|c|c|c|c|c|c|c|}
\hline & $\begin{array}{c}\text { Inclinatio } \\
\text { n Angle }\end{array}$ & $\begin{array}{c}\text { Time } \\
\text { (hrs) }\end{array}$ & $\begin{array}{c}\text { Max Gas } \\
\text { Flow Rate } \\
\text { (MMSCFD) }\end{array}$ & $\begin{array}{c}\text { Bottomhole } \\
\text { Pressure } \\
\text { (psi) }\end{array}$ & $\begin{array}{c}\text { Max Casing } \\
\text { Shoe Pressure } \\
\text { (psi) }\end{array}$ & $\begin{array}{c}\text { Max Choke } \\
\text { Pressure } \\
\text { (psi) }\end{array}$ \\
\hline \multirow{2}{*}{$\begin{array}{c}\text { Marcellus } \\
\text { WBM }\end{array}$} & Inc. 88 & 6.2 & 2.59 & 5,509 & 1,999 & 830 \\
\cline { 2 - 7 } & Inc. 92 & 6.9 & 1.32 & 5,171 & 1,865 & 650 \\
\hline \multirow{2}{*}{$\begin{array}{c}\text { Marcellus } \\
\text { OBM }\end{array}$} & Inc. 88 & 6.4 & 2.31 & 5,685 & 1,802 & 642 \\
\cline { 2 - 7 } & Inc. 92 & 6.6 & 1.76 & 5,346 & 1,804 & 617 \\
\hline \multirow{2}{*}{ Utica WBM } & Inc. 88 & 6.2 & 2.68 & 7,277 & 2,375 & 963 \\
\cline { 2 - 7 } & Inc. 92 & 6.7 & 1.53 & 6,947 & 2,273 & 807 \\
\hline \multirow{2}{*}{ Utica OBM } & Inc. 88 & 6.4 & 2.08 & 7,474 & 2,198 & 772 \\
\cline { 2 - 7 } & Inc. 92 & 6.5 & 2.00 & 7,125 & 2,174 & 743 \\
\hline
\end{tabular}

Figure 4.62 compares pressure responses for Marcellus and Utica wells drilled with WBM and OBM. Choke and casing shoe pressures were higher in Utica inclined downward laterals drilled with WBM when compared to Marcellus inclined upward laterals drilled with OBM. The maximum gas surface flow rate while gas was circulated out was 2.68 MMSCFD in Utica well due to gas solubility and dispersion and the surface/downhole kick volume ratio was 2.1. The inclined downward lateral experienced higher surface and downhole pressures as well as higher gas expansion rates.

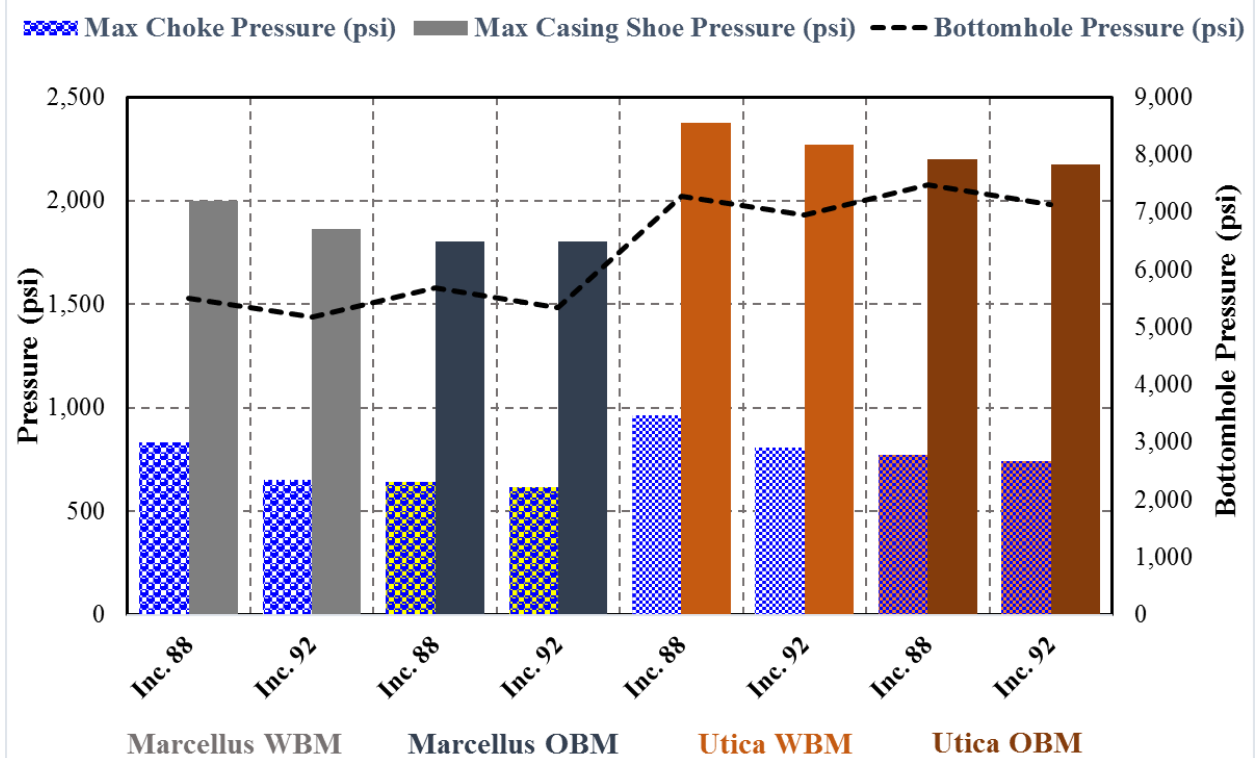

Figure 4.62: Comparison of pressures for Marcellus and Utica wellbore profiles drilled with WBM and OBM. 


\subsubsection{Impact of Well Control Method}

The results of Wait-and-Weight method (W\&W) are compared to the Driller's method as shown in Figure 4.63 and Table 4.13. While W\&W method saved 60\% of operation time, the maximum surface and downhole pressures were slightly less than Driller's method. W\&W was effective only when heavy mud reached the annulus vertical section and perhaps in horizontal wells the influx was already circulated out. In Utica lateral drilled with WBM, W\&W method resulted in a choke pressure of 1,144 psi compared to 1,166 psi using Driller's method. In OBM, choke pressure was higher in W\&W method due to higher bottomhole pressure. During new mud preparation time, gas migration will increase wellbore and surface pressures with a risk of exceeding shoe strength (Elshehabi and Bilgesu, 2015b).
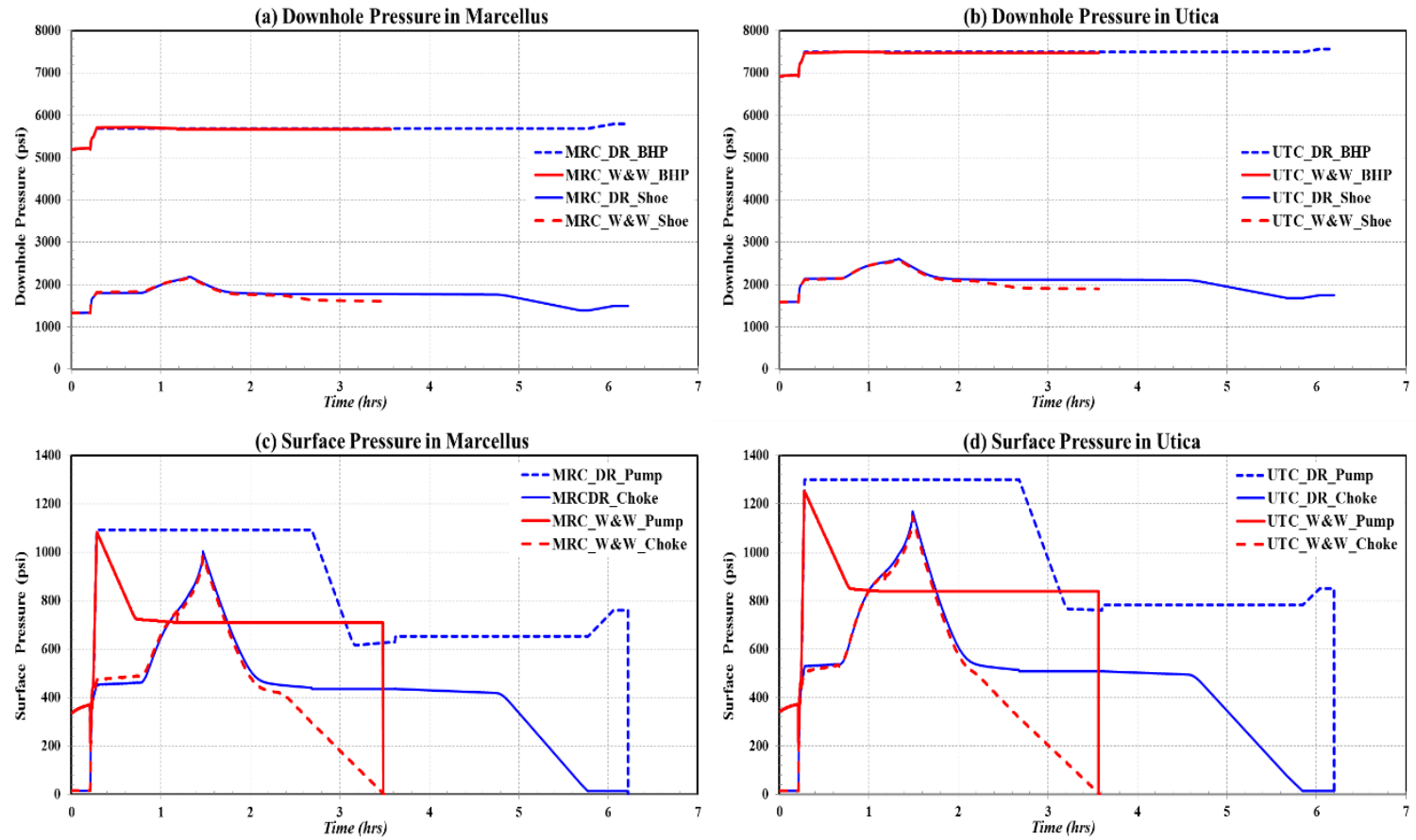

Figure 4.63: Impact of well control method on downhole and surface pressures in MRC and UTC.

Figure 4.64 shows that when WBM was used, the influx was circulated with slightly different surface and downhole pressures. However, in OBM with gas solubility and higher bottomhole pressure, the choke and casing shoe pressures were higher in W\&W method. The maximum gas discharge rate was 2.4 MMSCFD in Utica well drilled with OBM and circulated using W\&W and volume ratio was 1.1. 
Table 4.13: Surface and down-hole recorded data for Driller's and Wait-and-Weight methods in Marcellus and Utica Shales.

\begin{tabular}{|l|c|c|c|c|c|c|}
\hline & $\begin{array}{c}\text { Well } \\
\text { Control } \\
\text { Method }\end{array}$ & $\begin{array}{c}\text { Time } \\
\text { (hrs) }\end{array}$ & $\begin{array}{c}\text { Max Gas } \\
\text { Flow Rate } \\
\text { (MMSCFD) }\end{array}$ & $\begin{array}{c}\text { Bottomhole } \\
\text { Pressure } \\
\text { (psi) }\end{array}$ & $\begin{array}{c}\text { Max Casing } \\
\text { Shoe } \\
\text { Pressure } \\
\text { (psi) }\end{array}$ & $\begin{array}{c}\text { Max } \\
\text { Choke } \\
\text { Pressure } \\
\text { (psi) }\end{array}$ \\
\hline Marcellus WBM & Driller's & 6.2 & 2.95 & 5,687 & 2,185 & 1,002 \\
\cline { 2 - 7 } & W\&W & 2.7 & 2.92 & 5,670 & 2,165 & 985 \\
\hline Marcellus OBM & Driller's & 6.4 & 1.97 & 5,685 & 1,800 & 647 \\
\cline { 2 - 7 } & W\&W & 2.8 & 1.95 & 6,134 & 2,240 & 992 \\
\hline Utica WBM & Driller's & 6.2 & 3.14 & 7,497 & 2,604 & 1,166 \\
\cline { 2 - 7 } & W\&W & 2.7 & 3.11 & 7,472 & 2,580 & 1,144 \\
\hline \multirow{2}{*}{ Utica OBM } & Driller's & 6.4 & 2.08 & 7,474 & 2,200 & 771 \\
\cline { 2 - 7 } & W\&W & 2.8 & 2.37 & 7,905 & 2,600 & 1,092 \\
\hline
\end{tabular}

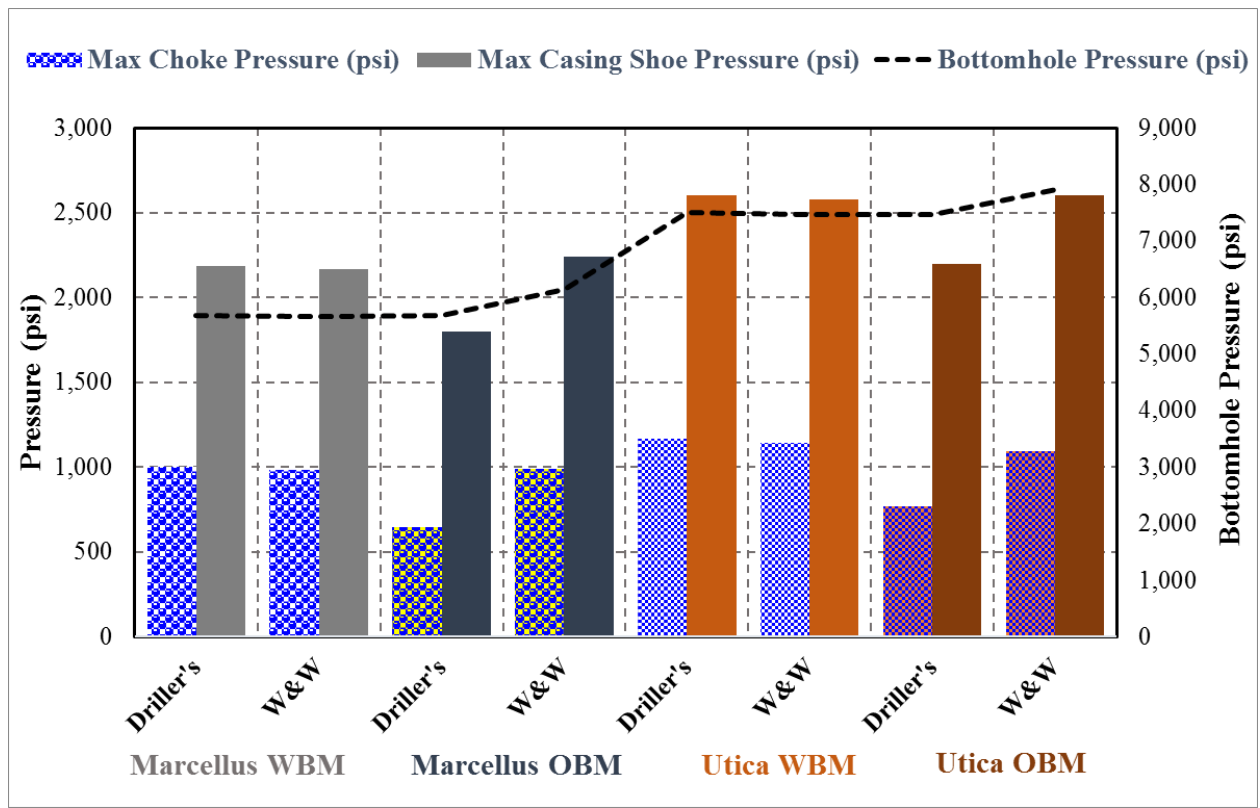

Figure 4.64: Comparison of pressures for Marcellus and Utica wells circulated with Driller's and W\&W methods.

\subsubsection{Impact of Drilling Fluid Type}

In WBM, slug flow pattern dominated and gas continuously expanded in vertical section and it reached surface faster in Marcellus well. This resulted in a higher surface/downhole volume ratio of 2.1 and a higher influx discharge rate of 2.6 MMSCFD as shown in Figure 4.65 and Table 4.14. In OBM gas dissolved in solution and dispersed bubble flow was dominant. However, the free gas kicks in WBM significantly reduced mud density compared to dissolved gas kicks in OBM. While gas was circulated towards the curve section, the pressure increased and more gas dissolved, and choke and pit gain decreased. 
Once free gas moved into the vertical section it expanded and choke pressure increased, and at the bubble point the gas in solution was released and expanded quickly. In contrast to conservative single flow results previously published (Elshehabi and Bilgesu, 2015a), gas kick in OBM resulted in lower circulating pressures compared to WBM.
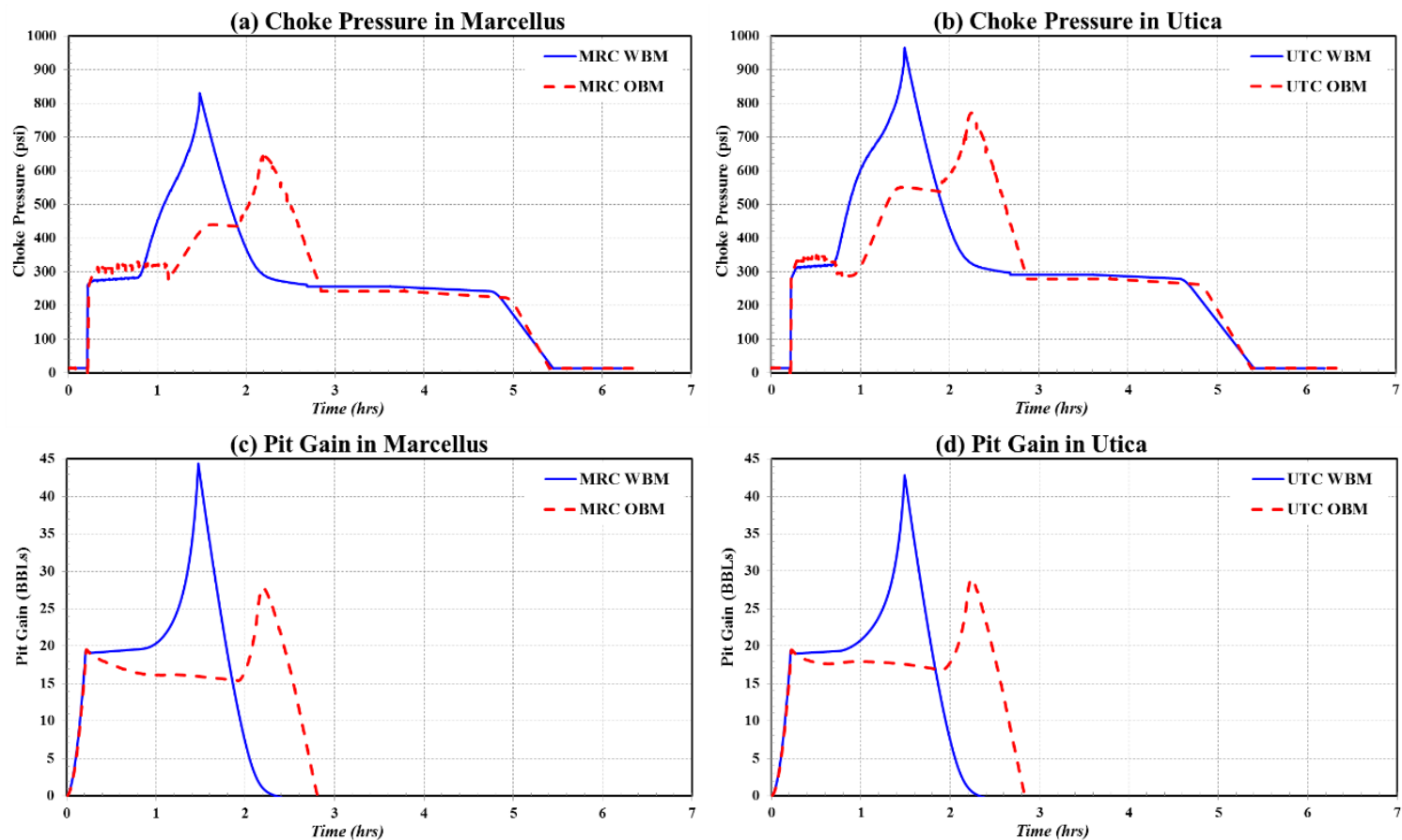

Figure 4.65: Impact of drilling fluid type on choke pressure and pit gain in MRC and UTC.

Table 4.14: Surface and down-hole recorded data for WBM and OBM in Marcellus and Utica Shales.

\begin{tabular}{|l|c|c|c|c|c|c|}
\hline & $\begin{array}{c}\text { Mud } \\
\text { Type }\end{array}$ & $\begin{array}{c}\text { Time } \\
\text { (hrs) }\end{array}$ & $\begin{array}{c}\text { Max Gas } \\
\text { Flow Rate } \\
\text { (MMSCFD) }\end{array}$ & $\begin{array}{c}\text { Bottomhole } \\
\text { pressure } \\
\text { (psi) }\end{array}$ & $\begin{array}{c}\text { Casing shoe } \\
\text { pressure } \\
\text { (psi) }\end{array}$ & $\begin{array}{c}\text { Choke } \\
\text { pressure } \\
\text { (psi) }\end{array}$ \\
\hline Marcellus WBM & WBM & 6.2 & 2.59 & 5,506 & 2,000 & 830 \\
\hline Marcellus OBM & OBM & 6.4 & 1.83 & 5,684 & 1,803 & 643 \\
\hline Utica WBM & WBM & 6.2 & 2.80 & 7,276 & 2,379 & 963 \\
\hline Utica OBM & OBM & 6.4 & 2.08 & 7,474 & 2,198 & 771 \\
\hline
\end{tabular}

Figure 4.66 compares pressure responses for Marcellus and Utica wells drilled with WBM and OBM. Choke and casing shoe pressures were higher in WBM compared to OBM. Since slug flow dominated in WBM, gas discharge rate was higher but gas circulation time was shorter. This observation was consistent with results of inclined upward/downward laterals. 


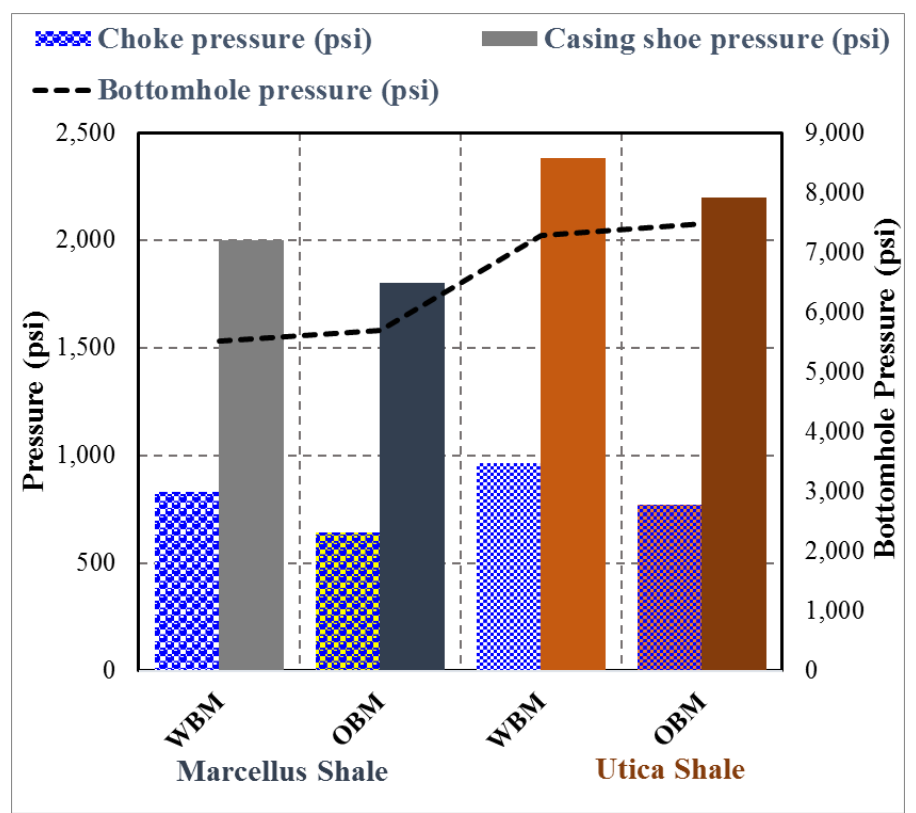

Figure 4.66: Comparison of pressures for Marcellus and Utica wells drilled with WBM and OBM.

\subsubsection{Impact of Kick Circulation Rate}

The impact of influx circulation rate was studied in Marcellus shale well and compared to Utica shale in inclined upward wells drilled with WBM. The study used an influx volume of $20 \mathrm{bbls}$ and circulation rates of 100,200 , and $300 \mathrm{gpm}$ as shown in Figure 4.67 and Table 4.14. Higher was the circulation rate, higher were the wellbore frictional losses and associated surface/downhole pressures. At a high flow rate of $60 \mathrm{spm}$, slug flow pattern governed and gas was circulated efficiently in less time. However, this resulted in higher gas expansion rates at the surface and higher choke and casing shoe pressures. At a slow pump rate of $20 \mathrm{spm}$, influx circulation needed 4.4 more time instead of the theoretical 3 times (from 60 to $20 \mathrm{spm}$ )due to the dispersed gas bubble tended to migrate towards the lateral high side. Gjorv (2003) suggested circulating the kick out at high rates, then reduced rates can be used to circulate the heavy mud in extended reach horizontal wells. In this study, 40 spm was used to circulate the influx then $20 \mathrm{spm}$ was used to displace the kill mud. This combination saved time with a slight increase in wellbore/surface pressures. The maximum influx discharge flow rate was 4.2 MMSCFD in Utica well drilled with WBM and circulated at $60 \mathrm{spm}$ with the surface expansion of influx by 2.5 times the downhole volume (Figure 4.68). 
(a) Choke Pressure in Marcellus

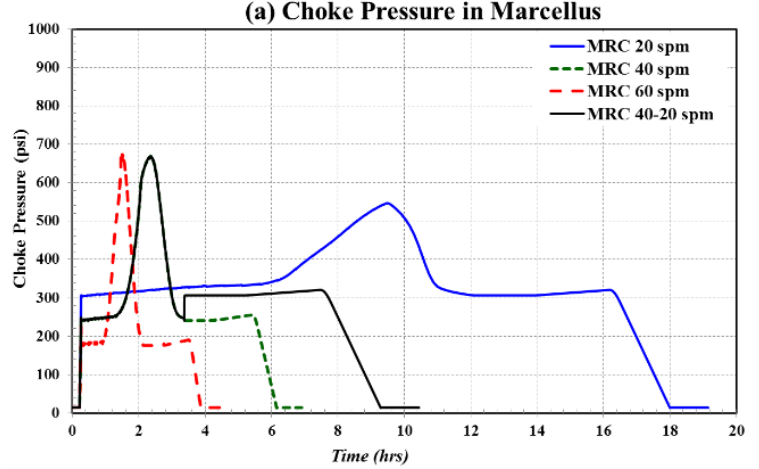

(c) Pit Gain in Marcellus

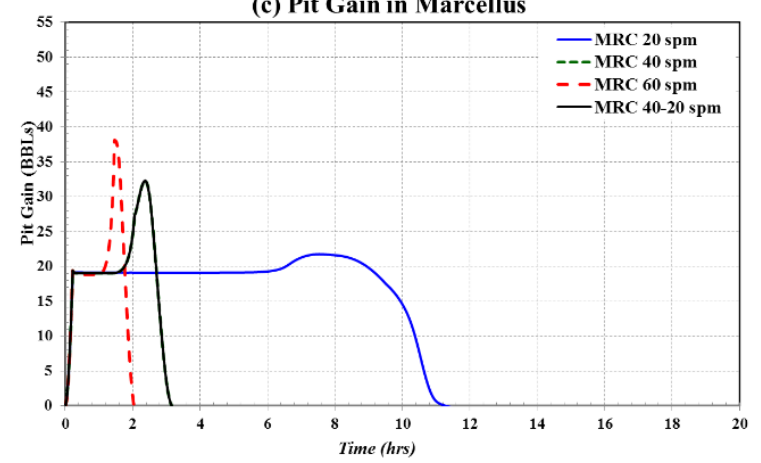

(b) Choke Pressure in Utica

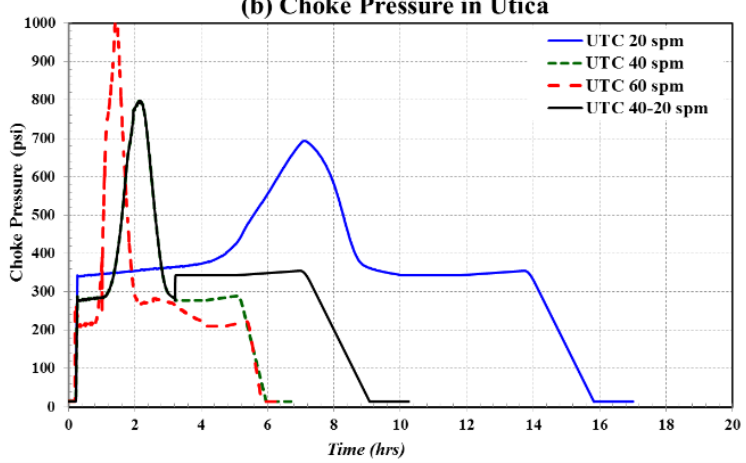

(d) Pit Gain in Utica

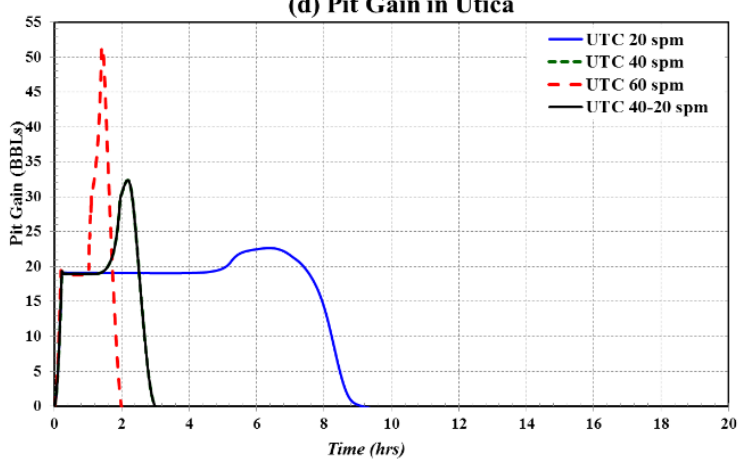

Figure 4.67: Impact of circulation rate on choke pressure and pit gain in WBM.

Table 4.15: Surface and down-hole recorded data for 20, 40, and $60 \mathrm{spm}$ in Marcellus and Utica Shales.

\begin{tabular}{|c|c|c|c|c|c|c|}
\hline & $\begin{array}{l}\text { Circulation } \\
\text { Rate (spm) }\end{array}$ & $\begin{array}{l}\text { Time } \\
\text { (hrs) }\end{array}$ & $\begin{array}{l}\text { Max Gas } \\
\text { Flow Rate } \\
\text { (MMSCFD) }\end{array}$ & $\begin{array}{l}\text { Bottomhole } \\
\text { Pressure } \\
\text { (psi) }\end{array}$ & $\begin{array}{l}\text { Max Casing } \\
\text { Shoe } \\
\text { Pressure } \\
\text { (psi) }\end{array}$ & $\begin{array}{c}\text { Max } \\
\text { Choke } \\
\text { Pressure } \\
\text { (psi) }\end{array}$ \\
\hline \multirow{3}{*}{ Marcellus WBM } & $20 \mathrm{spm}$ & 19.2 & 0.31 & 5,171 & 1,760 & 546 \\
\hline & $40 \mathrm{spm}$ & 6.9 & 1.32 & 5,171 & 1,870 & 668 \\
\hline & $60 \mathrm{spm}$ & 4.4 & 2.31 & 5,171 & 1,889 & 677 \\
\hline \multirow{3}{*}{ Marcellus OBM } & 20 spm & 13.7 & 0.49 & 5,346 & 1,825 & 534 \\
\hline & $40 \mathrm{spm}$ & 6.5 & 1.74 & 5,346 & 1,805 & 617 \\
\hline & $60 \mathrm{spm}$ & 4.5 & 2.40 & 5,346 & 1,754 & 535 \\
\hline \multirow{3}{*}{ Utica WBM } & $20 \mathrm{spm}$ & 16.9 & 0.42 & 6,934 & 2,148 & 693 \\
\hline & 40 spm & 6.7 & 1.53 & 6,934 & 2,261 & 796 \\
\hline & $60 \mathrm{spm}$ & 6.4 & 4.22 & 6,934 & 2,473 & 1,041 \\
\hline \multirow{3}{*}{ Utica OBM } & $20 \mathrm{spm}$ & 12.9 & 0.91 & 7,125 & 2,206 & 754 \\
\hline & $40 \mathrm{spm}$ & 6.5 & 2.00 & 7,125 & 2,175 & 743 \\
\hline & $60 \mathrm{spm}$ & 4.4 & 2.75 & 7,125 & 2,130 & 661 \\
\hline
\end{tabular}

Figure 4.68 compares Marcellus and Utica wells drilled with WBM and OBM at different flow rates. Higher was the flow rate, higher were the choke and casing shoe pressures in WBM. However, in OBM, higher flow rates resulted in lower surface pressure because of gas solubility and dispersed gas bubbles. 


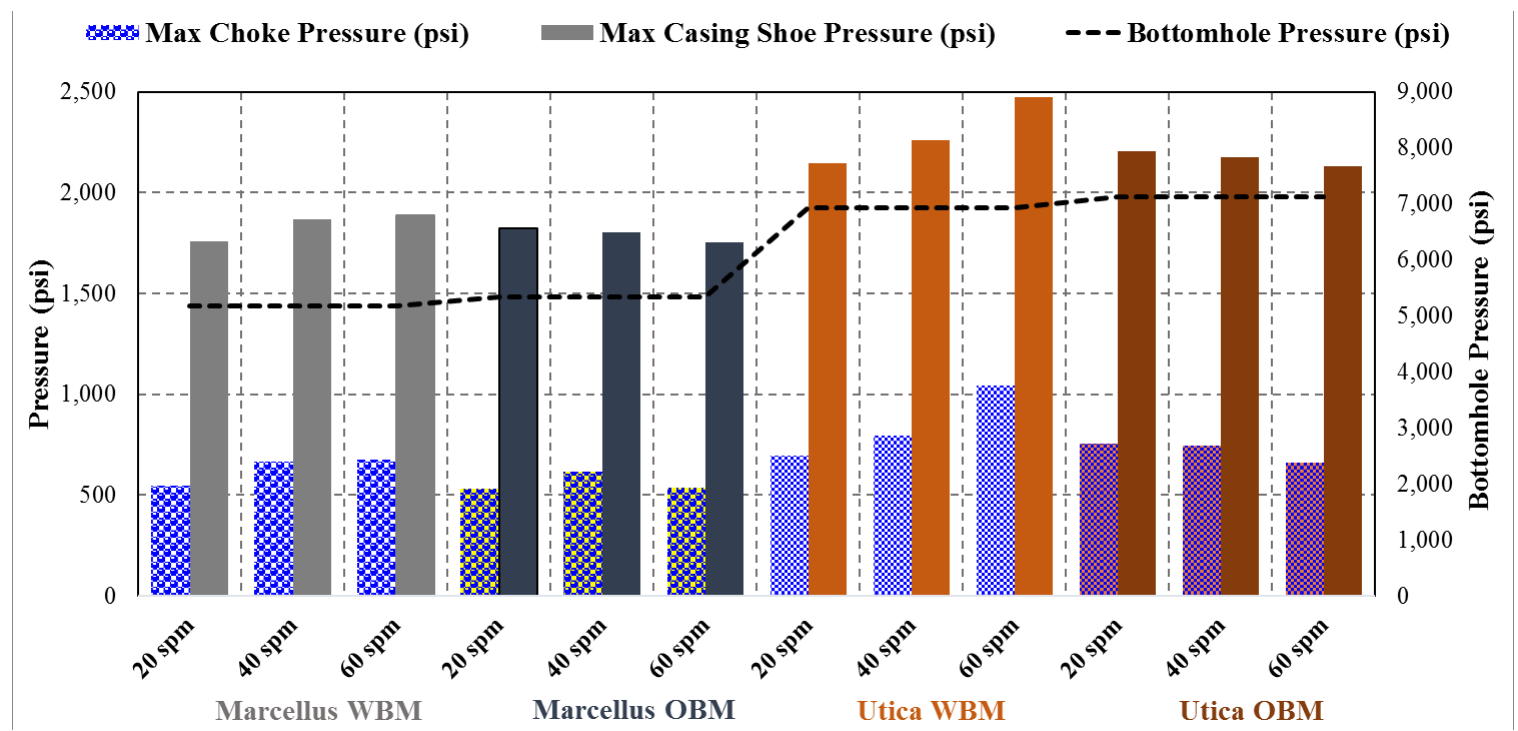

Figure 4.68: Comparison of pressures for Marcellus and Utica wells at 20, 40 and 60 spm.

\subsubsection{Impact of Influx Type}

Dry gas, rich condensate and black oil influx behaviors are studied in an inclined upward horizontal well drilled with OBM. As shown in Figure 4.69 and Table 4.16, the higher was the difference between the influx and mud densities with less degree of solubility, higher were the wellbore and surface pressures and volumes. In Utica shale, at higher reservoir pressure, solubility of dry gas in OBM and gas expansion in WBM were higher with higher surface volumes and pressures. While influx was circulated towards lateral heel, a back pressure was created and more gas dissolved in OBM increasing mud compressibility and decreasing mud density and pit deviation. In the vertical section the remaining free gas expanded, then at a bubble point between interval of 1000 and $2000 \mathrm{ft}$., dissolved gas liberated with a steep expansion rate. In black oil and condensate kicks, pit gain decreased slightly due to solution gas liberation. It was difficult to identify the influx while it was in the lateral section, therefore the worst-case scenario was to assume a gas kick. Low density influx unloaded the well at a much faster rate than liquid kicks. Figure 4.70 shows that in a Utica well drilled with WBM experiencing gas influx, the max choke pressure was $800 \mathrm{psi}$ and the gas discharge rate was 2.3 MMSCFD and the surface/downhole kick volume ratio was 1.6. Therefore, lower was the influx density, higher were the resultant surface and downhole pressures and associated volumes. 
(a) Choke Pressure in Marcellus

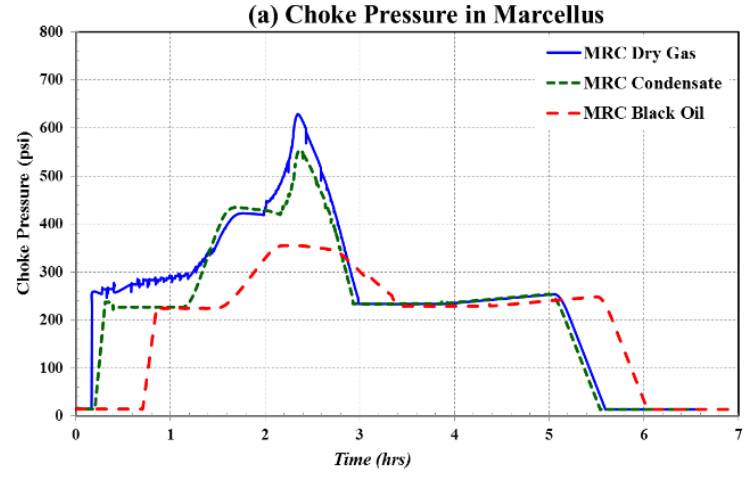

(c) Pit Gain in Marcellus

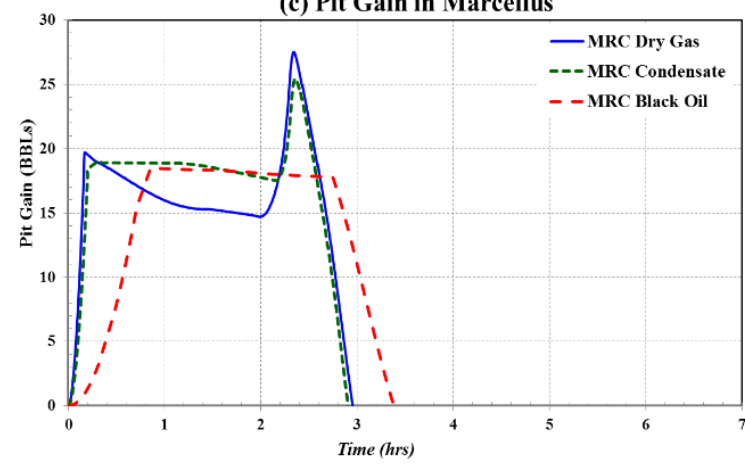

(b) Choke Pressure in Utica

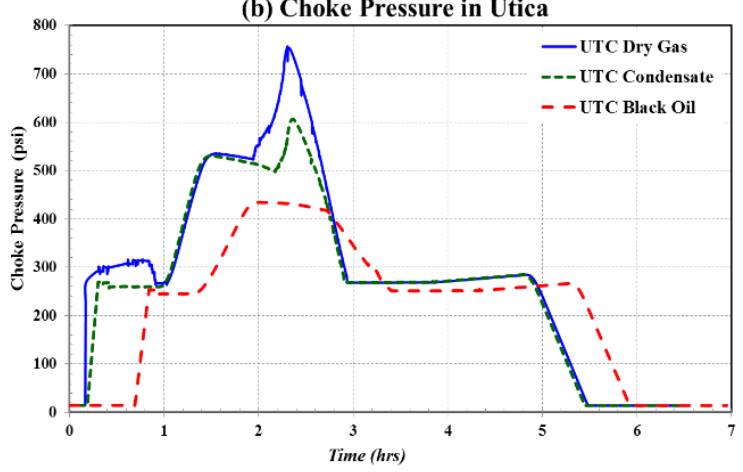

(d) Pit Gain in Utica

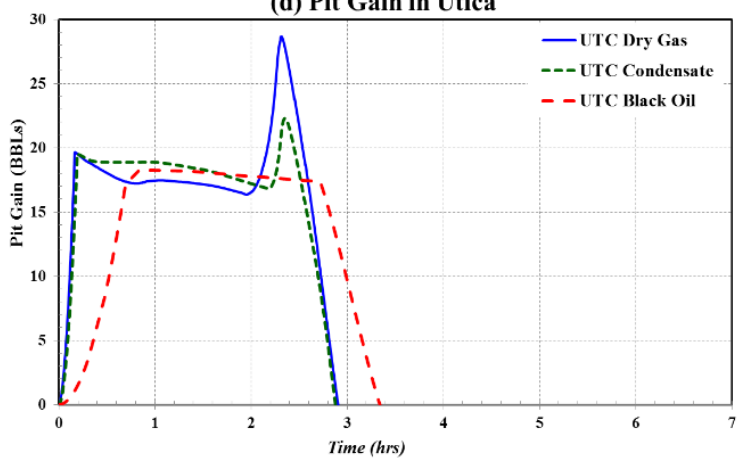

Figure 4.69: Impact of influx type on choke pressure and pit gain in OBM.

Table 4.16: Surface and down-hole recorded data for dry gas, condensate, and black oil kicks in Marcellus and Utica Shales.

\begin{tabular}{|l|c|c|c|c|c|c|}
\hline & Influx Type & Time (hrs) & $\begin{array}{c}\text { Max Gas } \\
\text { Flow Rate } \\
\text { (MMSCFD) }\end{array}$ & $\begin{array}{c}\text { Bottomhole } \\
\text { Pressure } \\
\text { (psi) }\end{array}$ & $\begin{array}{c}\text { Max Casing } \\
\text { Shoe } \\
\text { Pressure } \\
\text { (psi) }\end{array}$ & $\begin{array}{c}\text { Max } \\
\text { Choke } \\
\text { Pressure } \\
\text { (psi) }\end{array}$ \\
\hline \multirow{2}{*}{$\begin{array}{l}\text { Marcellus } \\
\text { WBM }\end{array}$} & Dry Gas & 6.9 & 2.53 & 5,178 & 1,880 & 676 \\
\cline { 2 - 7 } & Condensate & 6.5 & 1.52 & 5,174 & 1,792 & 660 \\
\cline { 2 - 7 } & Black Oil & 6.2 & 0.32 & 5,169 & 1,717 & 395 \\
\hline \multirow{3}{*}{$\begin{array}{l}\text { Marcellus } \\
\text { OBM }\end{array}$} & Dry Gas & 6.5 & 2.37 & 5,351 & 1,811 & 628 \\
\cline { 2 - 7 } & Condensate & 6.4 & 2.45 & 5,352 & 1,797 & 553 \\
\cline { 2 - 7 } & Black Oil & 6.1 & 0.36 & 5,346 & 1,717 & 354 \\
\hline \multirow{2}{*}{$\begin{array}{l}\text { Utica } \\
\text { WBM }\end{array}$} & Dry Gas & 6.7 & 2.32 & 6,936 & 2,266 & 800 \\
\cline { 2 - 7 } & Condensate & 6.5 & 2.39 & 6,939 & 2,157 & 743 \\
\cline { 2 - 7 } & Black Oil & 6.2 & 0.32 & 6,938 & 2,076 & 479 \\
\hline \multirow{3}{*}{ Utica OBM } & Dry Gas & 6.5 & 2.05 & 7,131 & 2,190 & 753 \\
\cline { 2 - 7 } & Condensate & 6.4 & 1.78 & 7,131 & 2,156 & 605 \\
\cline { 2 - 7 } & Black Oil & 6.2 & 0.35 & 7,113 & 2,059 & 432 \\
\hline
\end{tabular}




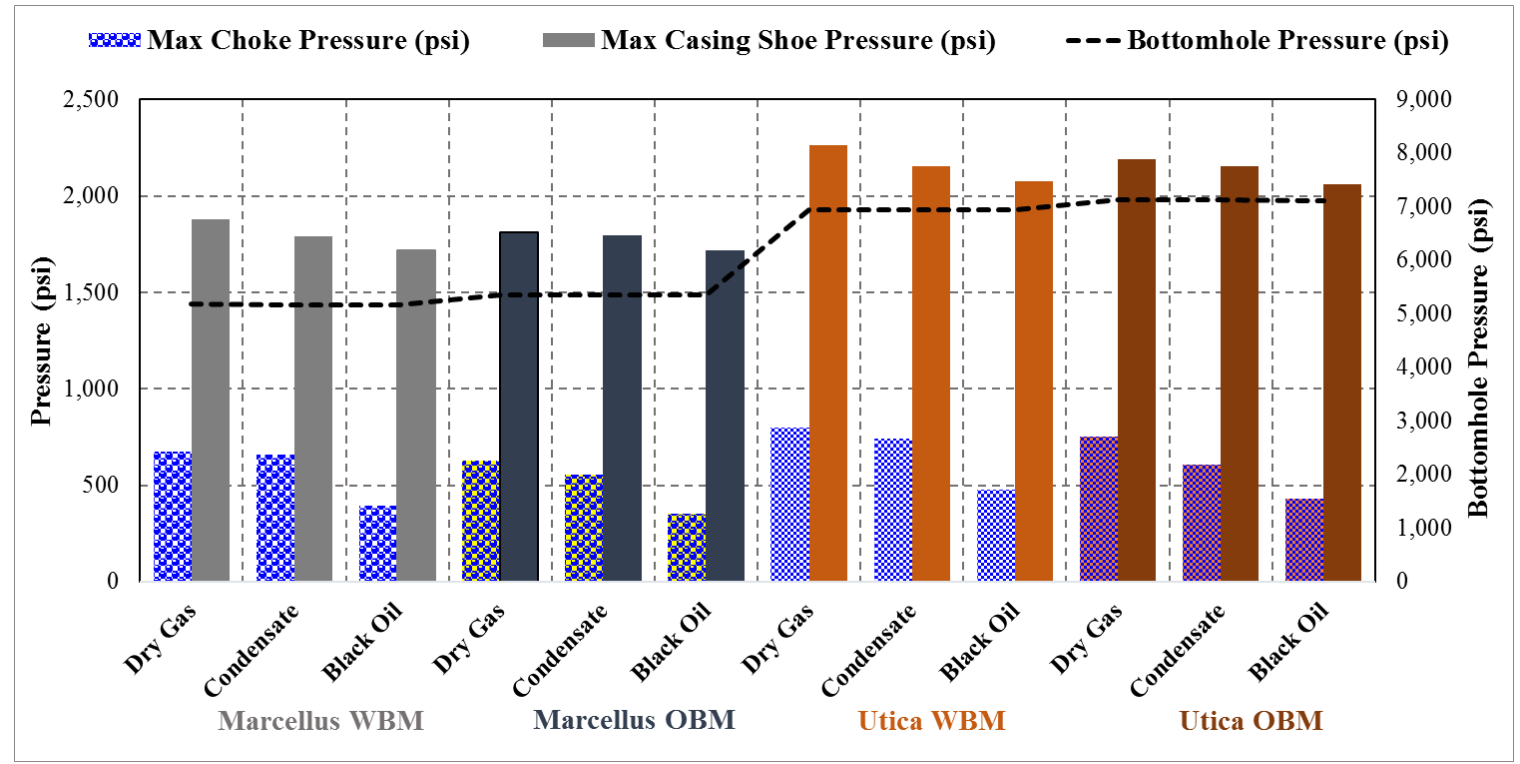

Figure 4.70: Comparison of pressure for Marcellus and Utica wells with different influx types.

\subsubsection{Impact of Influx Size}

Three kick sizes were examined to understand the impact of early kick detection and alertness of drilling crew. Figure 4.71 and Table 4.17 shows that larger influx sizes did not impact the drillpipe side of the U-tube model (pump and bottomhole pressures). Nevertheless, larger kicks highly impacted the annulus side of the U-tube model. The slower was the crew in detecting a kick and closing the BOP, higher were the choke and casing shoe pressures and pit gain. This highlights the importance of crew awareness of early kick detection techniques to avoid the exceeding of kick tolerance and maximum allowable annular surface pressure (MAASP) and risking well integrity. Surface and downhole pressures in OBM were less when predicted using a multiphase flow model in comparison to the conservative single slug flow model (Watson et al., 2003). Figure 4.72 shows that higher was the influx size higher were the surface and downhole pressures and volumes. Utica shale high reservoir pressure and temperature resulted with a higher impact on wellbore and surface pressures. The maximum gas flow rate was 3.93 MMSCFD in Utica well drilled with WBM and received 50 bbls kick. Also, the maximum choke pressure was 1,270 psi in comparison to 1,028 psi in Marcellus shale. 
(a) Choke Pressure in Marcellus

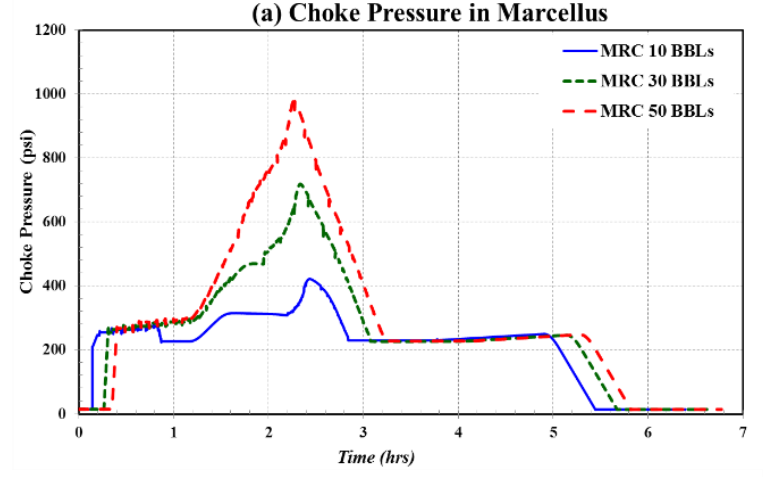

(c) Pit Gain in Marcellus

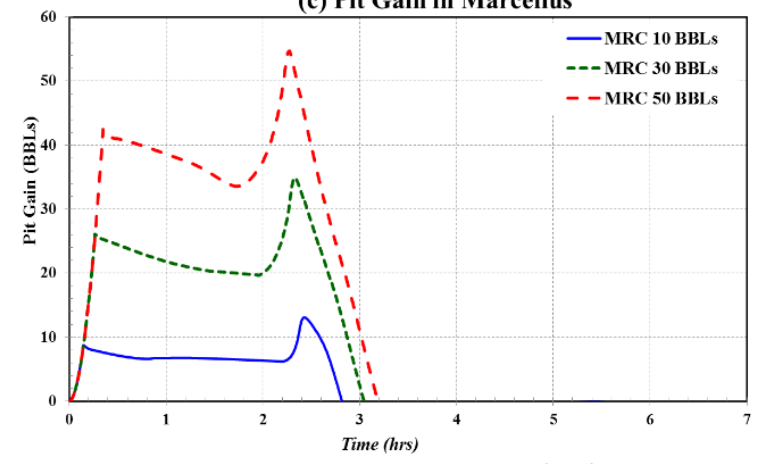

(b) Choke Pressure in Utica

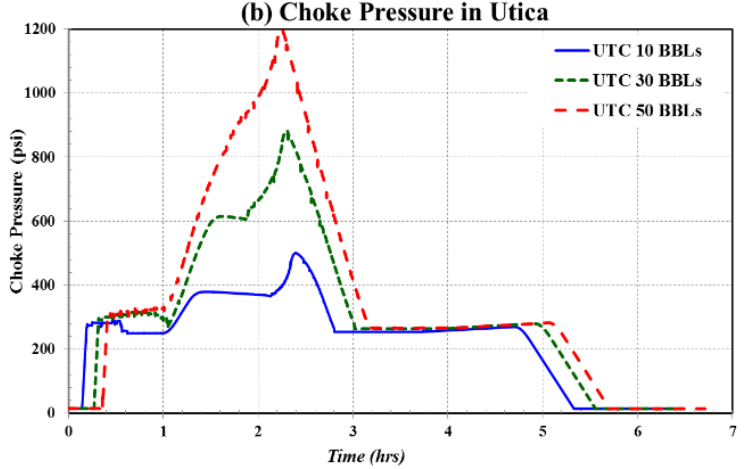

(d) Pit Gain in Utica

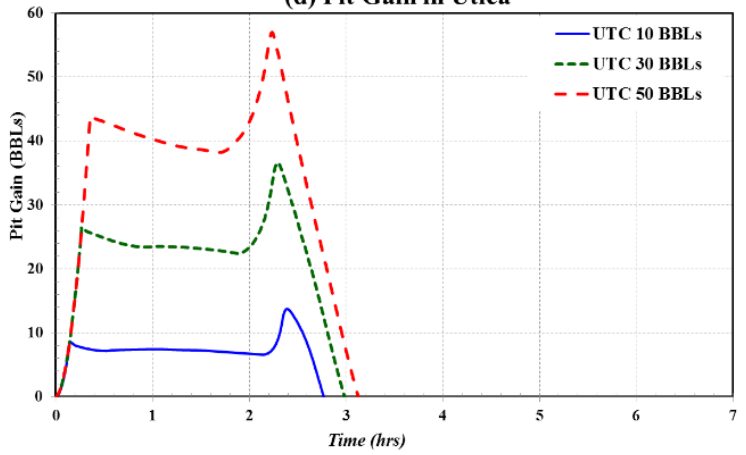

Figure 4.71: Impact of influx size on choke pressure and pit gain in OBM.

Table 4.17: Surface and down-hole recorded data for 10, 30, and 50 bbls influx size in Marcellus and Utica Shales.

\begin{tabular}{|l|c|c|c|c|c|c|}
\hline & $\begin{array}{c}\text { Influx Size } \\
\text { (BBLs) }\end{array}$ & Time (hrs) & $\begin{array}{c}\text { Max Gas } \\
\text { Flow Rate } \\
\text { (MMSCFD) }\end{array}$ & $\begin{array}{c}\text { Bottomhole } \\
\text { Pressure } \\
\text { (psi) }\end{array}$ & $\begin{array}{c}\text { Max Casing } \\
\text { Shoe } \\
\text { Pressure } \\
\text { (psi) }\end{array}$ & $\begin{array}{c}\text { Max } \\
\text { Choke } \\
\text { Pressure } \\
\text { (psi) }\end{array}$ \\
\hline \multirow{3}{*}{$\begin{array}{l}\text { Marcellus } \\
\text { WBM }\end{array}$} & $\mathbf{1 0}$ bbls & 6.8 & 0.71 & 5,170 & 1,753 & 509 \\
\cline { 2 - 7 } & $\mathbf{3 0}$ bbls & 6.9 & 1.91 & 5,170 & 1,977 & 802 \\
\cline { 2 - 7 } & $\mathbf{5 0}$ bbls & 7.1 & 2.94 & 5,170 & 2,072 & 1,028 \\
\hline \multirow{3}{*}{$\begin{array}{l}\text { Marcellus } \\
\text { OBM }\end{array}$} & $\mathbf{1 0}$ bbls & 6.4 & 1.05 & 5,347 & 1,677 & 421 \\
\cline { 2 - 7 } & $\mathbf{3 0}$ bbls & 6.6 & 2.13 & 5,344 & 1,891 & 718 \\
\cline { 2 - 7 } & $\mathbf{5 0}$ bbls & 6.8 & 3.21 & 5,346 & 2,127 & 971 \\
\hline \multirow{3}{*}{ Wtica } & $\mathbf{1 0}$ bbls & 6.7 & 0.74 & 6,932 & 2,092 & 580 \\
\cline { 2 - 7 } & $\mathbf{3 0}$ bbls & 6.8 & 2.24 & 6,935 & 2,403 & 963 \\
\cline { 2 - 7 } & $\mathbf{5 0}$ bbls & 6.9 & 3.93 & 6,935 & 2,673 & 1,270 \\
\hline \multirow{3}{*}{ Utica OBM } & $\mathbf{1 0}$ bbls & 6.3 & 1.21 & 7,116 & 2,004 & 499 \\
\cline { 2 - 7 } & $\mathbf{3 0}$ bbls & 6.5 & 2.46 & 7,126 & 2,293 & 874 \\
\cline { 2 - 7 } & $\mathbf{5 0}$ bbls & 6.7 & 3.64 & 7,129 & 2,601 & 1,200 \\
\hline
\end{tabular}




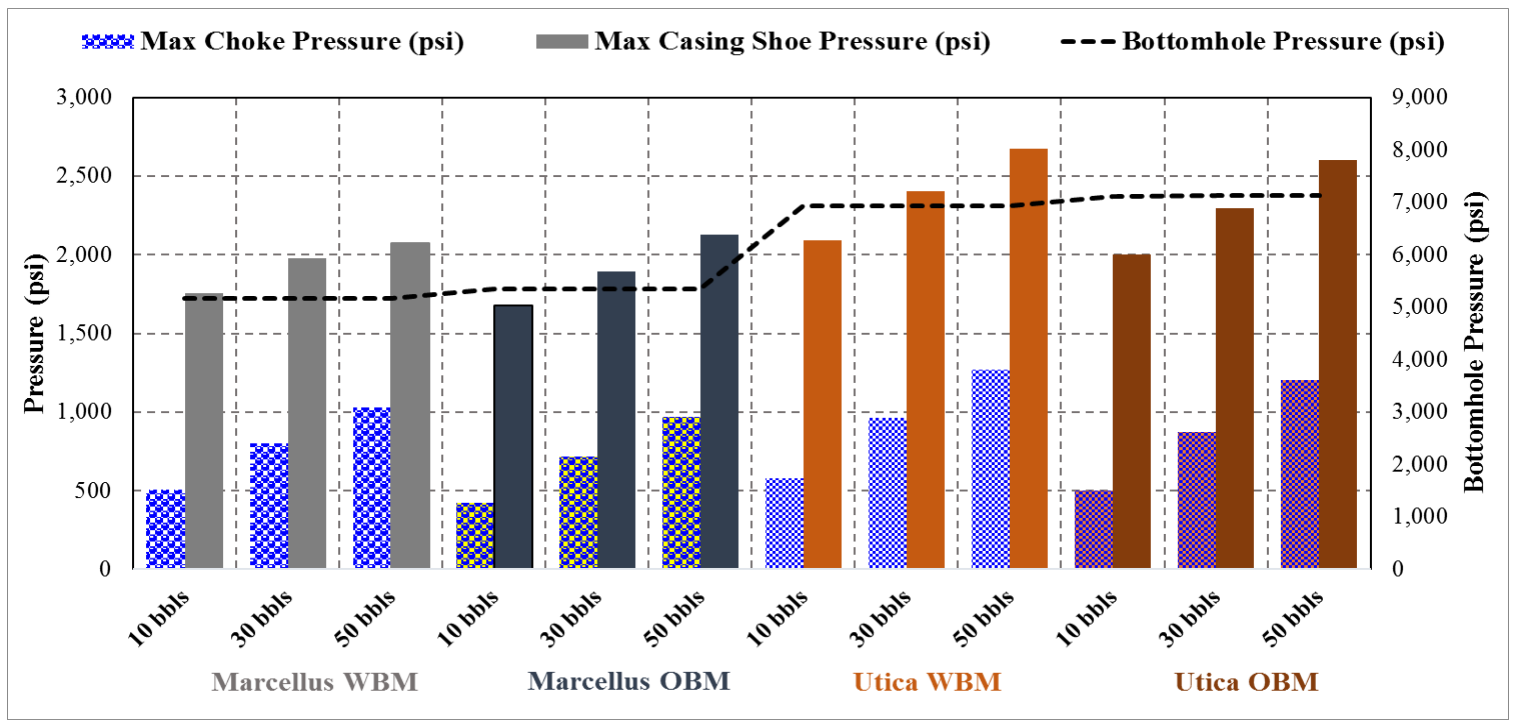

Figure 4.72: Comparison of pressures for Marcellus and Utica wells at different influx sizes.

\subsubsection{Impact of Kick Intensity}

Figure 4.73 and Table 4.18 show the impact of kick intensity and degree of underbalance during kick development in an inclined upward lateral. For the same kick size of 20 bbls and the flow rate of $200 \mathrm{gpm}$, higher kick intensity caused higher bottomhole/surface pressures and volumes and lowered the kick tolerance. Thus, heavier mud densities are required to balance higher intensity kicks. For instance, in Utica well drilled using WBM, when the kick intensity increased from 1 ppg to 2 ppg, an increase of $7 \%$ in bottomhole pressure, $19 \%$ in casing shoe pressure and $46 \%$ in choke pressure was observed. When a 3 ppg intensity kick received, an increase of $12 \%$ in BHP, $37 \%$ in shoe pressure and $91 \%$ in choke pressure were observed compared to $1 \mathrm{ppg}$. Figure 4.74 compares pressure values for Marcellus and Utica wells drilled with WBM and OBM. With higher kick intensities, higher surface pressure and flow rates were encountered. Consequently, wellbore pressures were higher at elevated kick intensities. For instance, in Utica well drilled with OBM, choke pressure was 1,600 psi at 3 ppg kick intensity in comparison to $837 \mathrm{psi}$ at $1 \mathrm{ppg}$. Likewise, the gas discharge rate was 2.29 MMSCFD at 3 ppg compared to 2.03 MMSCFD at $1 \mathrm{ppg}$. Kick intensity impacted kicks experienced in WBM with slightly higher choke pressures than in OBM. For example, in Marcellus well, choke pressure was 1,453 psi in WBM compared to 1,359 in OBM. 
(a) Choke Pressure in Marcellus

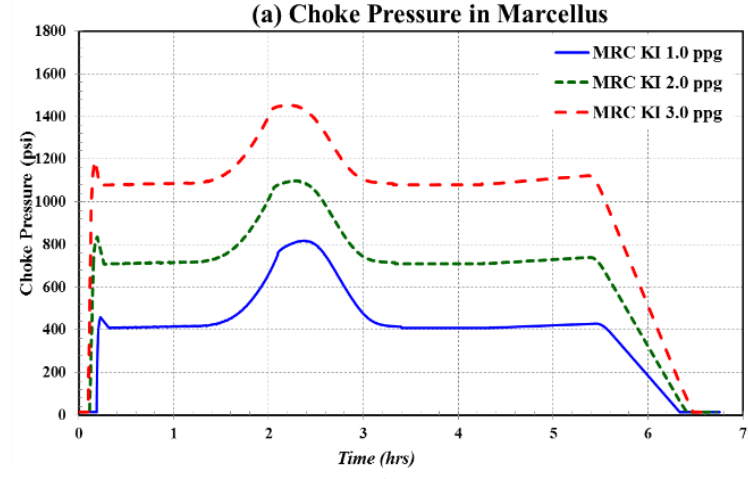

(c) Pit Gain in Marcellus

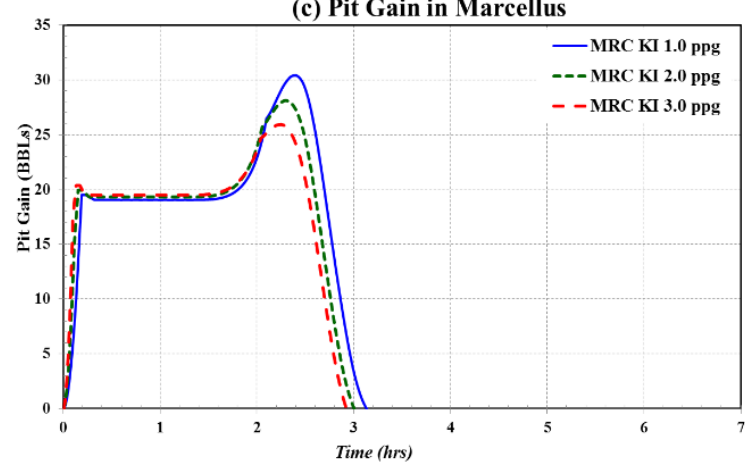

(b) Choke Pressure in Utica

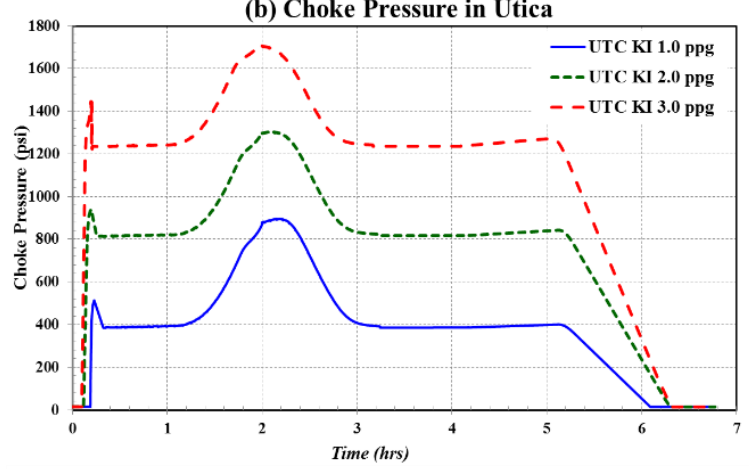

(d) Pit Gain in Utica

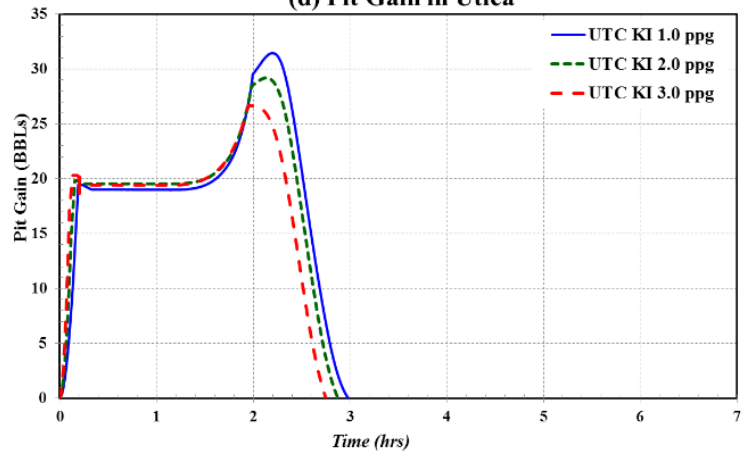

Figure 4.73: Impact of kick intensity on choke pressure and pit gain in WBM.

Table 4.18: Surface and down-hole recorded data for 1, 2, and 3 ppg kick intensity in Marcellus and Utica Shales.

\begin{tabular}{|c|c|c|c|c|c|c|}
\hline & $\begin{array}{c}\text { Kick } \\
\text { Intensity } \\
\text { (ppg) }\end{array}$ & Time (hrs) & $\begin{array}{l}\text { Max Gas } \\
\text { Flow Rate } \\
\text { (MMSCFD) }\end{array}$ & $\begin{array}{l}\text { Bottomhole } \\
\text { Pressure } \\
\text { (psi) }\end{array}$ & $\begin{array}{c}\text { Max Casing } \\
\text { Shoe } \\
\text { Pressure } \\
\text { (psi) }\end{array}$ & $\begin{array}{c}\text { Max } \\
\text { Choke } \\
\text { Pressure } \\
\text { (psi) }\end{array}$ \\
\hline \multirow{3}{*}{$\begin{array}{l}\text { Marcellus } \\
\text { WBM }\end{array}$} & 1 ppg & 6.9 & 1.37 & 5,340 & 2,039 & 817 \\
\hline & 2 ppg & 6.9 & 1.48 & 5,644 & 2,343 & 1,098 \\
\hline & 3 ppg & 6.9 & 1.61 & 6,019 & 2,719 & 1,453 \\
\hline \multirow{3}{*}{$\begin{array}{l}\text { Marcellus } \\
\text { OBM }\end{array}$} & $1 \mathrm{ppg}$ & 6.5 & 1.81 & 5,446 & 1,900 & 703 \\
\hline & 2 ppg & 6.5 & 1.91 & 5,821 & 2,265 & 1,017 \\
\hline & 3 ppg & 6.5 & 2.03 & 6,191 & 2,649 & 1,359 \\
\hline \multirow{3}{*}{$\begin{array}{l}\text { Utica } \\
\text { WBM }\end{array}$} & $1 \mathrm{ppg}$ & 6.7 & 1.59 & 7,044 & 2,369 & 895 \\
\hline & $2 \mathrm{ppg}$ & 6.7 & 1.77 & 7,512 & 2,810 & 1,303 \\
\hline & $3 \mathrm{ppg}$ & 6.7 & 1.79 & 7,906 & 3,242 & 1,706 \\
\hline \multirow{3}{*}{ Utica OBM } & $1 \mathrm{ppg}$ & 6.5 & 2.03 & 7,237 & 2,286 & 837 \\
\hline & $2 \mathrm{ppg}$ & 6.5 & 2.13 & 7,666 & 2,709 & 1,203 \\
\hline & $3 \mathrm{ppg}$ & 6.5 & 2.29 & 8,096 & 3,162 & 1,601 \\
\hline
\end{tabular}




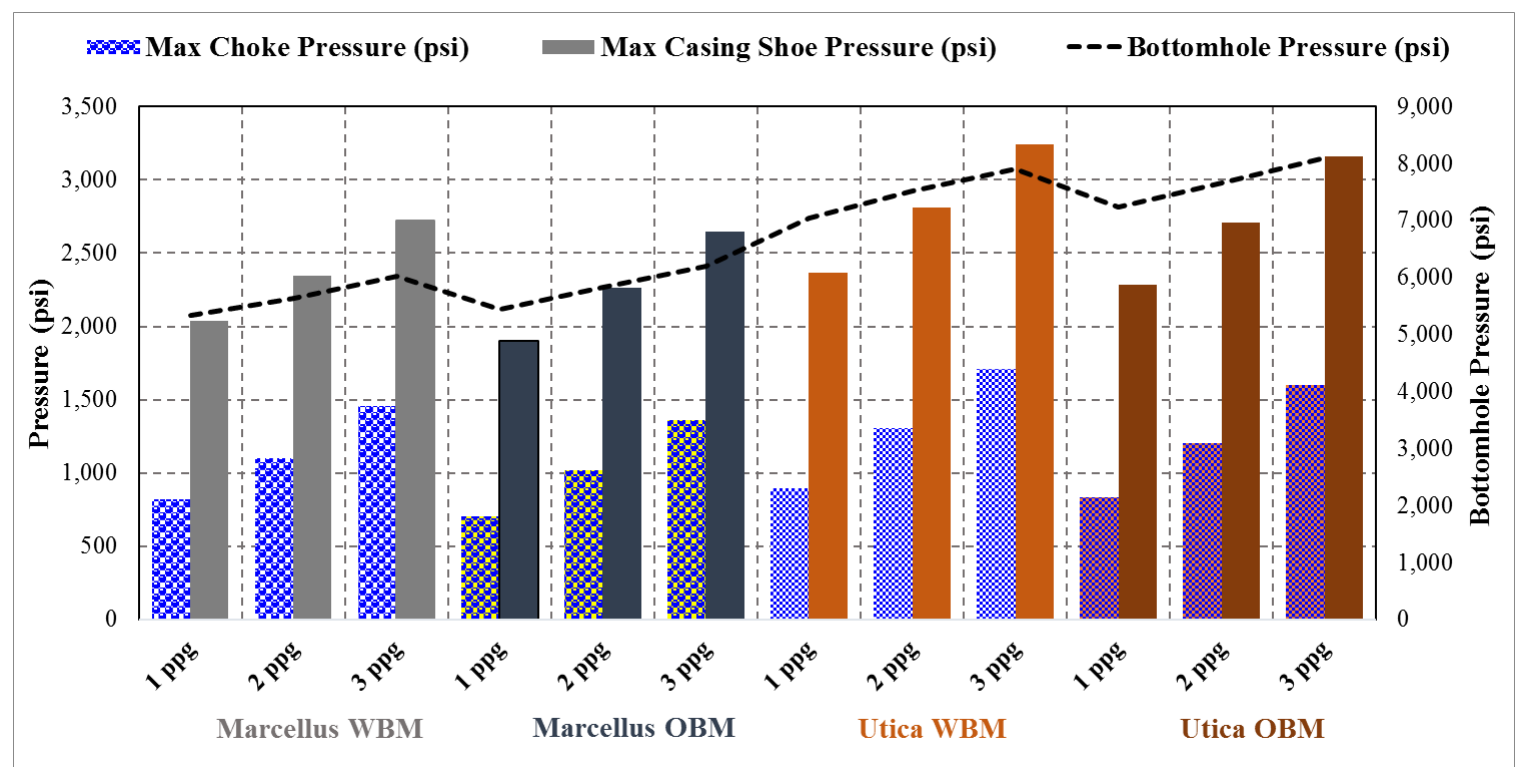

Figure 4.74: Comparison of pressures for Marcellus and Utica wells with different kick intensities (1,2 and $3 \mathrm{ppg})$. 


\section{CONCLUSION}

This research studied mud hydraulics and well control complications in inclined upward and downward laterals in unconventional shales. The study included the verification of the hydraulics base model with actual data from a Marcellus lateral. Hydraulics parameters and pressure profiles at normal drilling flow rates were compared to well control slow pump rates in different wellbore/string configurations. In addition, it investigated well control complications due to well type, gas solubility in oil based mud, and kicks received while running casing or liner strings. Furthermore, inclined downward lateral hydraulics and well control are studied and compared to inclined upward lateral configurations. Finally, this research performed a comparative well control study between Marcellus and Utica Shale laterals. The following conclusions are presented:

1. In the Marcellus Shale lateral, the hydraulics model successfully estimated the standpipe pressure with a regression coefficient $\left(R^{2}\right)$ of 0.974 . There were significant impacts of drilling rate of penetration, mud rheological properties, and drilled cuttings characteristics on hydraulics.

2. Drilling with casing and/or liner wellbore configurations are subjected to an inverted pressure loss profile compared to conventional drilling with drillpipes, since APL is higher than pressure loss inside the string and at the bit. Therefore, lower flow rates are recommended to achieve an effective annular velocity for proper hole cleaning without adding excessive frictional pressure losses.

3. Annular pressure loss, associated equivalent circulating density, and critical flow rate for proper hole cleaning are higher in inclined downward wellbore trajectories. This is a result of lower cutting transport ratio and accumulation of cuttings at the bottomhole compared to inclined upward laterals.

4. The Driller's method is preferred in horizontal wells because of the immediate influx circulation. However, the Wait-and-Weight method is beneficial if the heavy mud reaches the vertical section of annulus before the gas is circulated out of the hole.

5. Higher pump rate saves the operator time but results in higher choke and casing shoe pressures. Slower pump rate requires longer periods of time but enables safe kick handling and effective choke adjustments considering the 2 seconds/1000 ft choke pressure response delay time. 
6. Higher pit gains and choke pressures are expected with higher gas solubility values. Frequent choke adjustments are required to keep the bottomhole pressure constant and to shield the casing shoe from intense changes in pressure when gas is liberated at the bubble point pressure.

7. In drilling with a casing or liner, influx height is very long in the tight annulus. Therefore, the gas kick reaches the surface earlier and creates higher choke and casing shoe pressures.

8. The reduced two-stage step-down (R2SD) model was developed in this research to consider the high annular pressure loss. The use of model prevented over-pressurizing the downhole and maintained the well integrity.

9. While gas migration in water based mud creates additional pressures, gas solubility in synthetic oil based mud introduces uncertainty about influx size and type.

10. In inclined upward and downward laterals, the closer the kick location to the vertical section, the shorter the circulation time. However, the pit gain, gas discharge rate, choke pressure, and casing shoe pressure are higher.

11. In contrast to inclined downward, the inclined upward lateral experiences less surface and bottomhole pressures. However, it requires extended circulation times to flush out the dispersed and entrapped bubbles caused by the mud yield stress properties.

12. Larger kick sizes result in higher pit gain, gas flow rate, and choke and casing shoe pressures in inclined downward laterals. Yet, in inclined upward laterals, the higher the kick size, the longer the circulation times. However, larger kick sizes show an insignificant impact on choke and shoe pressures.

13. The deeper and over-pressurized Utica Shale well presents more well control challenges compared to the Marcellus Shale well. Over-pressurized formations can generate larger influx sizes and higher kick intensities resulting with higher pressures and volumes. The end result is the high risk of exceeding casing shoe strength and jeopardizing the Utica well integrity. 


\section{REFERENCES}

Aadnoy, B.S., Cooper, I., Miska, S.Z., Mitchell, R.F. and Payne, M.L. 2009. Advanced Drilling and Well Technology. Richarson, TX, USA: Society of Petroleum Engineers.

Adams, N. and Kuhlman, L. 1994. Kicks and Blowout Control, Second Edition. Tulsa, Oklahoma: Pennwell Publishing Company.

API RP13D 2010. Rheology and Hydraulics of Oil-well Drilling Fluids. API Recommended Practice Sixth Edition.

Arlanoglu, C. 2011. Casing Drilling and Modeling of Smear Effect. MS Thesis, University of Texas at Austin, TX, USA.

Belvalkar, R.A. and Oyewole, S. 2010. Development of Marcellus Shale in Pennsylvania. Presented at the SPE Annual Technical Conference and Exhibition, Florence, Italy, 19-22 September. http://dx.doi.org/10.2118/134852-MS.

Berthezene, N., de Hemptinne, J.-., Audibert, A. and Argillier, J.-. 1999. Methane solubility in synthetic oil-based drilling muds. Journal of Petroleum Science and Engineering 23 (2): 71-81. doi: http://dx.doi.org/10.1016/S0920-4105(99)00008-X.

Bidiwala, I. and Orr, B. 2014. What it Will Take to Sustain the Shale Boom. Energy Journal doi: http://www.oliverwyman.com/insights/publications/2014/nov/what-it-will-take-to-sustain-theshale-boom.html\#.V3LBL $\mathrm{kr}$ h/hF.

Bill, M. 1995. Advanced Oil Well Drilling Engineering Handbook and Computer Programs, 10th. Texas, USA: Society of Petroleum Engineers of the AIME.

Bourgoyne, A.T., Millheim, K.K., Chenevert, M.E. and Young Jr., F.S. 1991. Applied Drilling Engineering, Volume 2, SPE Textbook Series. Richardson, TX, USA: Society of Petroleum Engineers.

Bradley, N.D., Low, E., Aas, B., Rommetveit, R. and Larsen, H.F. 2002. Gas Diffusion - its Impact on a Horizontal HPHT Well. Presented at the SPE Annual Technical Conference and Exhibition, San Antonio, Texas, 29 September-2 October. http://dx.doi.org/10.2118/77474-MS.

Brito, R., Pereyra, E. and Sarica, C. 2016a. Effect of Well Trajectory on Liquid Removal in Horizontal Gas Wells. Presented at the SPE Annual Technical Conference and Exhibition, Dubai, UAE, 26-28 September. http://dx.doi.org/10.2118/181423-MS.

Brito, R., Pereyra, E. and Sarica, C. 2016b. Existence of Severe Slugging in Toe-Up Horizontal Gas Wells. Presented at the SPE North America Artificial Lift Conference and Exhibition, The Woodlands, Texas, USA, 25-27 October. http://dx.doi.org/10.2118/181217-MS.

Browning, S. and Jayakumar, R. 2016. Effects of Toe-Up Vs Toe-Down Wellbore Trajectories on Production Performance in the Cana Woodford. Presented at the Unconventional Resources Technology Conference, San Antonio, Texas, USA, 1-3 August. URTEC-2461175-MS.

Can, B., Gilbert, C., Leal, L., Hirsch, S., Rosenzweig, J., Huber, N., Rudolph, S. et al. 2014. Design and Execution of a Holistic Data Acquisition Program and Data Evaluation for Utica Shale. Presented at the Unconventional Resources Technology Conference, Denver, Colorado, USA, 25-27 August. http://dx.doi.org/10.15530/urtec-2014-1923095.

Carr, T.R., Wang, G. and McClain, T. 2013. Petrophysical Analysis and Sequence Stratigraphy of the Utica Shale and Marcellus Shale, Appalachian Basin, USA. Presented at the International Petroleum Technology Conference, Beijing, China, 26-28 March. http://dx.doi.org/10.2523/IPTC-16935Abstract.

Choe, J. 2001. Advanced Two-Phase Well Control Analysis. Journal of Canadian Petroleum Technology 40 (05) doi: http://dx.doi.org/10.2118/01-05-02.

Choe, J., Schubert, J. and Juvkam-Wold, H. 2005. Well-Control Analyses on Extended-Reach and Multilateral Trajectories. SPE Drilling \& Completion 20 (02): 101 - 108. doi: http://dx.doi.org/10.2118/97465-PA. 
Choe, J. 1995. Dynamic Well Control Simulation Models for Water-Based Muds and their Computer Applications. Ph.D. Dissertation, Texas A\&M University, TX, USA.

CS INC. Model DS-20FS/W/P: Full size Drilling, Production and Workover Simulator. 2011.

Duncan, I. 2016. Likelihood and Environmental Consequences of Blowouts of Shale Gas and Shale Oil Wells. Burean of Economic Geology, February 26, 2016, http://www.beg.utexas.edu/presentations/seminars/duncan-blowouts-636 (accessed 5 2016).

EIA 2016. EIA - Annual Energy Outlook 2016 (AEO2016) Early Release, Report Number: DOE/EIA-0383ER (May 17, 2016). , http://www.eia.gov/forecasts/aeo/er/index.cfm 6/2016).

Ekrann, S. and Rommetveit, R. 1985. A Simulator for Gas Kicks in Oil-Based Drilling Muds. Presented at the SPE Annual Technical Conference and Exhibition, Las Vegas, NV, USA, 22-26 September. http://dx.doi.org/10.2118/14182-MS.

El Hakam, C., Davis, E., Serdy, A.M. and Spencer, R. 2014. Rotary Steerable System with Optimized Functionally Integrated System-Specific Drill Bits Reduces Drilling Days and Extends Laterals in Northeastern US Horizontal Shale Plays. Presented at the SPE/CSUR Unconventional Resources Conference, Calgary, Alberta, Canada, 30 September-2 October. http://dx.doi.org/10.2118/171619-MS.

Elshehabi, T. 2015. Investigation of Well Control Procedures for Casing Drilling in Horizontal Wells. Presented at the AADE National Technical Conference \& Exhibition, San Antonio, TX, 8-9 April. Poster Presentation.

Elshehabi, T. and Bilgesu, I. 2017. Drilling Unconventional Shales with Upward Or Downward Laterals: What are the Hydraulics and Well Control Consequences?. Presented at the National Technical Conference \& Exhibition, Houston, Texas, April 11-12. AADE-17-NTCE-115.

Elshehabi, T. and Bilgesu, I. 2016. What are the Well Control Complications while Drilling with Casing Or Liner? Presented at the AADE Fluids Technical Conference and Exhibition, Houston, Texas, April 12-13. AADE-16-FTCE-79.

Elshehabi, T. and Bilgesu, I. 2015a. Impact of Drilling with Oil Based Mud on Well Control in Horizontal Shale Gas Wells. Presented at the SPE Eastern Regional Meeting, Morgantown, West Virginia, USA, 13-15 October. http://dx.doi.org/10.2118/177294-MS.

Elshehabi, T. and Bilgesu, I. 2015b. Well Control Operations for Horizontally Drilled Wells and its Complications. Presented at the Istanbul Technical University (ITU) Petroleum and Natural Gas Seminar and Exhibition, Istanbul, Turkey, 18-19 June.

Flatab, G., Torsvik, A., Oltedal, V.M., Bjorkvik, B., Grimstad, A. and Linga, H. 2015. Experimental Gas Absorption in Petroleum Fluids at HPHT Conditions. Presented at the SPE Bergen One Day Seminar, Bergen, Norway, 22 April. http://dx.doi.org/10.2118/173865-MS.

Fontenot, K., Highnote, J., Warren, T. and Houtchens, B. 2003. Casing Drilling Activity Expands in South Texas. Presented at the SPE/IADC Drilling Conference, Amsterdam, Netherlands, 19-21 February. http://dx.doi.org/10.2118/79862-MS.

Fruhwirth, R.K., Thonhauser, G. and Mathis, W. 2006. Hybrid Simulation using Neural Networks to Predict Drilling Hydraulics in Real Time. Presented at the SPE Annual Technical Conference and Exhibition, San Antonio, Texas, 24-27 September. http://dx.doi.org/10.2118/103217-MS.

Galloway, G. 2004. Cement in Place Drilling with Casing System Provides Safe, Reliable Method for Improving Drilling Efficiency. Presented at the Offshore Technology Conference, Houston, Texas, 3-6 May. http://dx.doi.org/10.4043/16565-MS.

Ghiselin, D. 2012. Casing drilling marks a century of progress. Offshore(Tulsa) 72 (10): 60-2.

Gjorv, B. 2003. Well Control Procedures for Extended Reach Wells. MS Thesis, Texas A\&M University, TX, USA.

Grace, R.D. 2003. Blowout and Well Control Handbook. USA: Gulf Professional Publishing.

Guner, S., Elshehabi, T. and Bilgesu, I. 2016. Pressure Variations due to Migration of Gas Kick Bubbles in Deep Vertical, Deviated and Horizontal Wells. Presented at the Istanbul Technical University (ITU) Petroleum and Natural Gas Seminar and Exhibition, Istanbul, Turkey, 23-24 June. 
Guo, B. and Liu, G. 2011. Chapter Two - Mud Hydraulics Fundamentals. In Applied Drilling Circulation Systems, ed. B. Guo and G. Liu, Chap. 19-59. Boston: Gulf Professional Publishing.

Guo, Q., Ji, L., Rajabov, V., Friedheim, J.E., Portella, C. and Wu, R. 2012a. Shale Gas Drilling Experience and Lessons Learned from Eagle Ford. Presented at the SPE Americas Unconventional Resources Conference, Pittsburgh, Pennsylvania USA, 5-7 June. http://dx.doi.org/10.2118/155542-MS.

Guo, Q., Ji, L., Rajabov, V., Friedheim, J.E. and Wu, R. 2012b. Marcellus and Haynesville Drilling Data: Analysis and Lessons Learned. Presented at the SPE Asia Pacific Oil and Gas Conference and Exhibition, Perth, Australia, 22-24 October. http://dx.doi.org/10.2118/158894-MS.

Gupta, A.K. 2006. Drilling with Casing: Prospects and Limitations. Presented at the SPE Western Regional/AAPG Pacific Section/GSA Cordilleran Section Joint Meeting, Anchorage, Alaska, USA, 8-10 May. http://dx.doi.org/10.2118/99536-MS.

Jardine, S.I., Johnson, A.B., White, D.B. and Stibbs, W. 1993. Hard Or Soft Shut-in: Which is the Best Approach? Presented at the SPE/IADC Drilling Conference, Amsterdam, Netherlands, 22-25 February. http://dx.doi.org/10.2118/25712-MS.

Johnson, A., Rezmer-Cooper, I., Bailey, T. and McCann, D. 1995. Gas Migration: Fast, Slow Or Stopped. Presented at the SPE/IADC Drilling Conference, Amsterdam, Netherlands, 28 February2 March. http://dx.doi.org/10.2118/29342-MS.

Johnson, A., Leuchtenberg, C., Petrie, S. and Cunningham, D. 2014. Advancing Deepwater Kick Detection. Presented at the IADC/SPE Drilling Conference and Exhibition, Fort Worth, Texas, USA, 4-6 March. http://dx.doi.org/10.2118/167990-MS.

Karimi, M., Moellendick, T.E. and Holt, C. 2011. Plastering Effect of Casing Drilling; a Qualitative Analysis of Pipe Size Contribution. Presented at the SPE Annual Technical Conference and Exhibition, Denver, Colorado, USA, 30 October-2 November. http://dx.doi.org/10.2118/147102-MS.

Kaufman, P., Atwood, K., Forrest, G., Walker, K., Wutherich, K., Delozier, D., Perakis, A., Borchardt, S. and Hauser, K. 2013. Marcellus Shale Gas Asset Optimization Driven by Technology Integration. Presented at the SPE Middle East Oil and Gas show and Conference, Manama, Bahrain, 10-13 March. http://dx.doi.org/10.2118/164345-MS.

Kiran, R., Salehi, S. and Karimi, M. 2014. Finite Element Analysis of Casing Drilling Smearing Effect. Presented at the SPE Deepwater Drilling and Completions Conference, Galveston, Texas, USA, 10-11 September. http://dx.doi.org/10.2118/170314-MS.

Krauss, R.F. 2013. Addressing Well and Field Infrastructure Siting Challenges in the Wetlands and Streams of the Haynesville, Marcellus, Utica, and Eagle Ford Shale Plays. Presented at the SPE Americas E\&P Health, Safety, Security and Environmental Conference, Galveston, Texas, USA, 18-20 March. http://dx.doi.org/10.2118/163804-MS.

Lima, H.R., Barrufet, M.A. and Juvkam-Wold, H. 1999. Pressure Calculations and Kick Detection with Synthetic-Based Muds in a Riserless Drilling Configuration. Presented at the Offshore Technology Conference, Houston, Texas, 3-6 May. http://dx.doi.org/10.4043/10897-MS.

Livingston, D.A., Andes, D., Czerneski, M., Bauer, S., Castro, B., Gorr, K., Coffman, R. and Beebe, L. 2016. Team Approach to Horizontal Drilling Optimization in the Marcellus Delivers Record Setting Performance. Presented at the IADC/SPE Drilling Conference and Exhibition, Fort Worth, Texas, USA, 1-3 March. http://dx.doi.org/10.2118/178875-MS.

Lopez, E.A. and Bonilla, P.A. 2010. Casing-Drilling Application in the Depleted La Cira Infantas Mature Field, Colombia. Presented at the SPE Latin American and Caribbean Petroleum Engineering Conference, Lima, Peru, 1-3 December. http://dx.doi.org/10.2118/139020-MS.

Lyons, W., Carter, T. and Lapeyrousse, N.J. 2012. Formulas and Calculations for Drilling, Production, and Workover - all the Formulas You Need to Solve Drilling and Production Problems, Third Edition: Gulf Professional Publishing, Elsevier. 
Maranuk, C., Rodriguez, A., Trapasso, J. and Watson, J. 2014. Unique System for Underbalanced Drilling using Air in the Marcellus Shale. Presented at the SPE Eastern Regional Meeting, Charleston, WV, USA, 21-23 October. http://dx.doi.org/10.2118/171024-MS.

Matthews, J.L. and Bourgoyne, A.T., J. 1983. Techniques for Handling Upward Migration of Gas Kicks in a Shut-in Well. Presented at the IADC/SPE Drilling Conference, New Orleans, Louisiana, 20-23 February. http://dx.doi.org/10.2118/11376-MS.

McDaniel, J., Watters, L. and Shadravan, A. 2014. Cement Sheath Durability: Increasing Cement Sheath Integrity to Reduce Gas Migration in the Marcellus Shale Play. Presented at the SPE Hydraulic Fracturing Technology Conference, The Woodlands, Texas, USA, 4-6 February. http://dx.doi.org/10.2118/168650-MS.

Mitchell, R.F. and Miska, S.Z. 2011. Fundamentals of Drilling Engineering, 12, SPE Textbook: Richardson, TX.: Society of Petroleum Engineers.

Mokhtari, M., Tutuncu, A.N. and Weldu Teklu, T.W. 2013. A Numerical Modeling Study for the Impact of Casing Drilling on Wellbore Stability. Presented at the SPE Unconventional Resources Conference Canada, Calgary, Alberta, Canada, 5-7 November. http://dx.doi.org/10.2118/167166MS.

Monteiro, E.N., Ribeiro, P.R. and Lomba, R.F.T. 2010. Study of the PVT Properties of Gas--SyntheticDrilling-Fluid Mixtures Applied to Well Control. SPE Drilling \& Completion 25 (01): 45 - 52. doi: http://dx.doi.org/10.2118/116013-PA.

Nas, S. 2011. Kick Detection and Well Control in a Closed Wellbore. Presented at the IADC/SPE Managed Pressure Drilling and Underbalanced Operations Conference \& Exhibition, Denver, Colorado, USA, 5-6 April. http://dx.doi.org/10.2118/143099-MS.

Naveen, V. and Babu, V. 2014. Experimental Study of Plastering Effect during Casing while Drilling. Presented at the Abu Dhabi International Petroleum Exhibition and Conference, Abu Dhabi, UAE, 10-13 November. http://dx.doi.org/10.2118/171997-MS.

Ng, F. 2005. Well Control Simulation - A Tool for Engineering and Operations. Presented at the National Technical Conference and Exhibition, Houston, Texas, April 5-7. AADE-05-NTCE-51.

O'Bryan, P.L., Bourgoyne, A.T., Jr., Monger, T.G. and Kopcso, D.P. 1988. An Experimental Study of Gas Solubility in Oil-Based Drilling Fluids. SPE Drilling Engineering 3 (01): 33 - 42. doi: http://dx.doi.org/10.2118/15414-PA.

Olawoyin, R., Wang, J.Y. and Oyewole, S.A. 2012. Environmental Safety Assessment of Drilling Operations in the Marcellus-Shale Gas Development. SPE Drilling \& Completion 18 (02): 212 - 220. doi: http://dx.doi.org/10.2118/163095-PA.

Ozkan, S. and Duman, R. 2015. Economic Evaluation of Marcellus and Utica Under the Effects of Dynamic Market and Development Conditions. Presented at the SPE Eastern Regional Meeting, Morgantown, West Virginia, USA, 13-15 October. http://dx.doi.org/10.2118/177321-MS.

Rader, D.W., Bourgoyne, A.T., J. and Ward, R.H. 1975. Factors Affecting Bubble-Rise Velocity Of Gas Kicks. Journal of Petroleum Technology 27 (05): 571 - 584. doi: http://dx.doi.org/10.2118/4647-PA.

Radwan, A.M. and Karimi, M. 2011. Feasibility Study of Casing Drilling Application in HPHT Environments; a Review of Challenges, Benefits, and Limitations. Presented at the SPE/IADC Middle East Drilling Technology Conference and Exhibition, Muscat, Oman, 24-26 October. http://dx.doi.org/10.2118/148433-MS.

Ribeiro, P.R., Pessôa-Filho, P.A., Lomba, R.F.T. and Bonet, E.J. 2006. Measurement and modeling of methane dissolution in synthetic liquids applied to drilling fluid formulation for deep and ultradeep water wells. Journal of Petroleum Science and Engineering 51 (1-2): 37-44. doi: http://dx.doi.org/10.1016/i.petrol.2005.11.007.

Ridley, K.M., Billa, R.J., Mota, J.F. and Jurgens, M. 2013. Eagle Ford Shale Well Control: Drilling and Tripping in Unconventional Oil and Gas Plays. Presented at the SPE Unconventional Gas Conference and Exhibition, Muscat, Oman, 28-30 January. http://dx.doi.org/10.2118/163984-MS. 
Rommetveit, R., Bjorkevoll, K.S., Bach, G.F., Aas, B., Hy-Billiot, J., Maglione, R. and Gie, P. 1995. Full Scale Kick Experiments in Horizontal Wells. Presented at the SPE Annual Technical Conference and Exhibition, Dallas, Texas, 22-25 October. http://dx.doi.org/10.2118/30525-MS.

Salehi, S., Aladsani, A., Shahri, M.P., Karimi, M. and Ezeakacha, C. 2013. All in One for Casing while Drilling Technology: Numerical, Analytical, and Experimental Results and Field Observations. Presented at the SPE Annual Technical Conference and Exhibition, New Orleans, Louisiana, USA, 30 September-2 October. http://dx.doi.org/10.2118/166112-MS.

Sánchez, F.J., Said, H., Turki, M. and Cruz, M. 2012. Casing While Drilling (CwD): A New Approach To Drilling Fiqa Formation in he Sultanate of Oman-A Success Story. SPE Drilling \& Completion 27 (02): 223 - 232. doi: http://dx.doi.org/10.2118/136107-PA.

Santos, O.L.A. 1991a. Important Aspects of Well Control for Horizontal Drilling Including Deepwater Situations. Presented at the SPE/IADC Drilling Conference, Amsterdam, Netherlands, 11-14 March. http://dx.doi.org/10.2118/21993-MS.

Santos, O.L.A. 1991b. Well-Control Operations in Horizontal Wells. SPE Drilling Engineering 6 (02): 111 - 117. doi: http://dx.doi.org/10.2118/21105-PA.

Satkan, C. 2013. Equivalent Circulating Density Contribution to the Plastering Effect of Casing while Drilling Technology: Analysis of Annular Fluid Velocity and Annular Pressure through Computational Fluid Dynamics. MS Thesis, Colorado School of Mines, Colorado, USA.

Silva, C.T., Mariolani, J.R.L., Bonet, E.J., Lomba, R.F.T., Santos, O.L.A. and Ribeiro, P.R. 2004. Gas Solubility in Synthetic Fluids: A Well Control Issue. Presented at the SPE Annual Technical Conference and Exhibition, Houston, TX, USA, 26-29 September. http://dx.doi.org/10.2118/91009-MS.

Swanson, B.W., Gilvary, B. and McEwan, F. 1988. Experimental Measurement and Modeling of Gas Solubility in Invert Emulsion Drilling Fluids Explains Surface Observations during Kicks. Presented at the European Petroleum Conference, London, United Kingdom, 16-19 October. http://dx.doi.org/10.2118/18371-MS.

Tarvin, J.A., Walton, I., Wand, P. and White, D.B. 1991. Analysis of a Gas Kick Taken in a Deep Well Drilled with Oil-Based Mud. Presented at the SPE Annual Technical Conference and Exhibition, Dallas, Texas, 6-9 October. http://dx.doi.org/10.2118/22560-MS.

Thomas, D.C., Lea, J.F., Jr. and Turek, E.A. 1984. Gas Solubility in Oil-Based Drilling Fluids: Effects on Kick Detection. Journal of Petroleum Technology 36 (06): 959 - 968. doi: http://dx.doi.org/10.2118/11115-PA.

Turley, J.A. 2014. An Engineering Look at the Cause of the 2010 Macondo Blowout. Presented at the IADC/SPE Drilling Conference and Exhibition, Fort Worth, TX, USA, 4-6 March. http://dx.doi.org/10.2118/167970-MS.

van Oort, E. and Razavi, O.S. 2014. Wellbore Strengthening and Casing Smear: The Common Underlying Mechanism. Presented at the IADC/SPE Drilling Conference and Exhibition, Fort Worth, Texas, USA, 4-6 March. http://dx.doi.org/10.2118/168041-MS.

Wang, Y. and Salehi, S. 2015. Drilling Hydraulics Optimization using Neural Networks. Presented at the SPE Digital Energy Conference and Exhibition, The Woodlands, Texas, 3-5 March. http://dx.doi.org/10.2118/173420-MS.

Wang, Z., Peden, J.M. and Lemanczyk, R.Z. 1994. Gas Kick Simulation Study for Horizontal Wells. Presented at the SPE/IADC Drilling Conference, Dallas, Texas, 15-18 February. http://dx.doi.org/10.2118/27498-MS.

Watson, D., Brittenham, T. and Moore, P. 2003. Advanced Well Control, Vol. 10, SPE Textbook Series. Richardson, TX: Society of Petroleum Engineers.

Zhang, J. and Wieseneck, J. 2011. Challenges and Surprises of Abnormal Pore Pressures in the Shale Gas Formations. Presented at the SPE Annual Technical Conference and Exhibition, Denver, Colorado, USA, 30 October-2 November. http://dx.doi.org/10.2118/145964-MS. 


\section{APPENDIX (A)}

Results of vertical, directional, and horizontal wells drilled with pipes, casing, and liner in terms of well type are presented in this section.

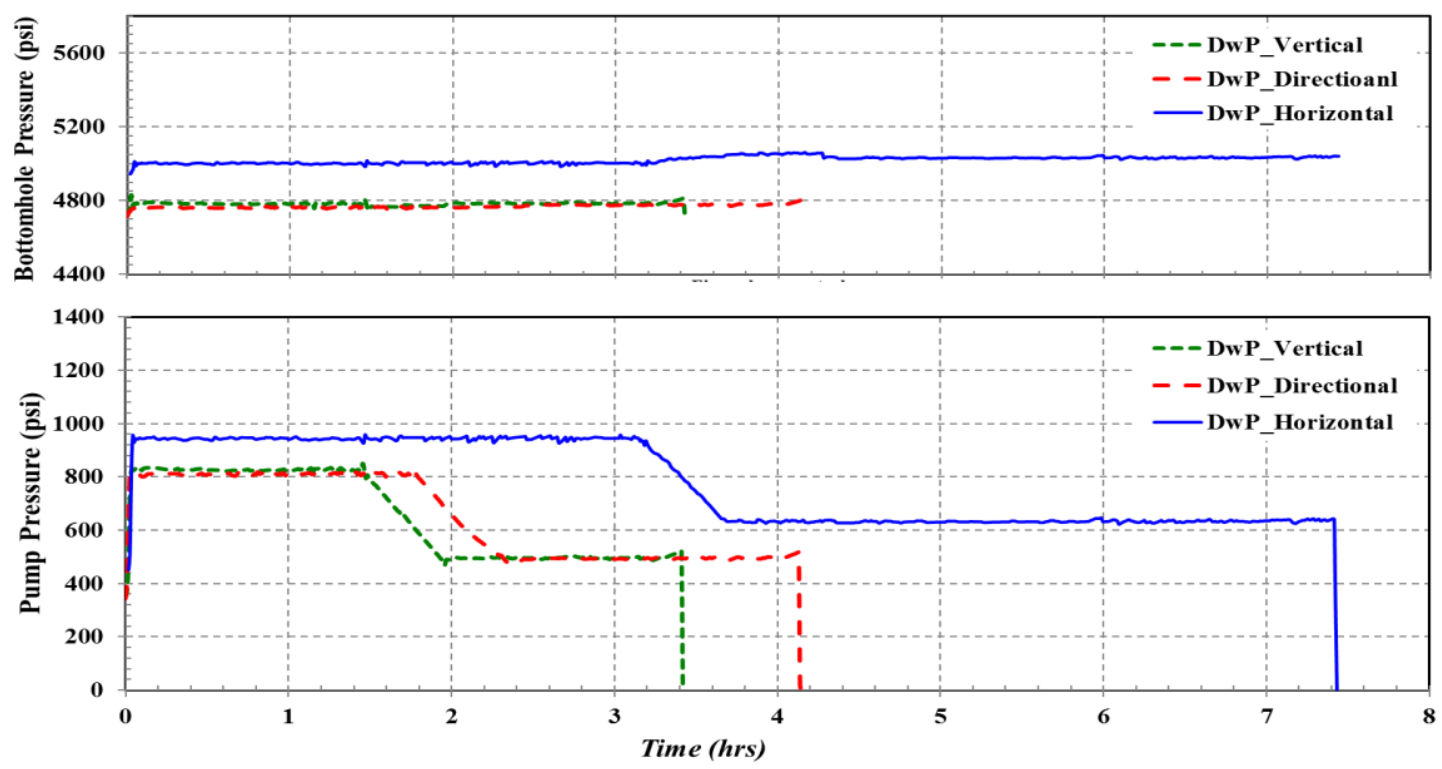

Figure A.1: Pump and bottomhole pressures for vertical, directional, and horizontal wells drilled with pipes and controlled with Driller's method at 40 spm WBM.
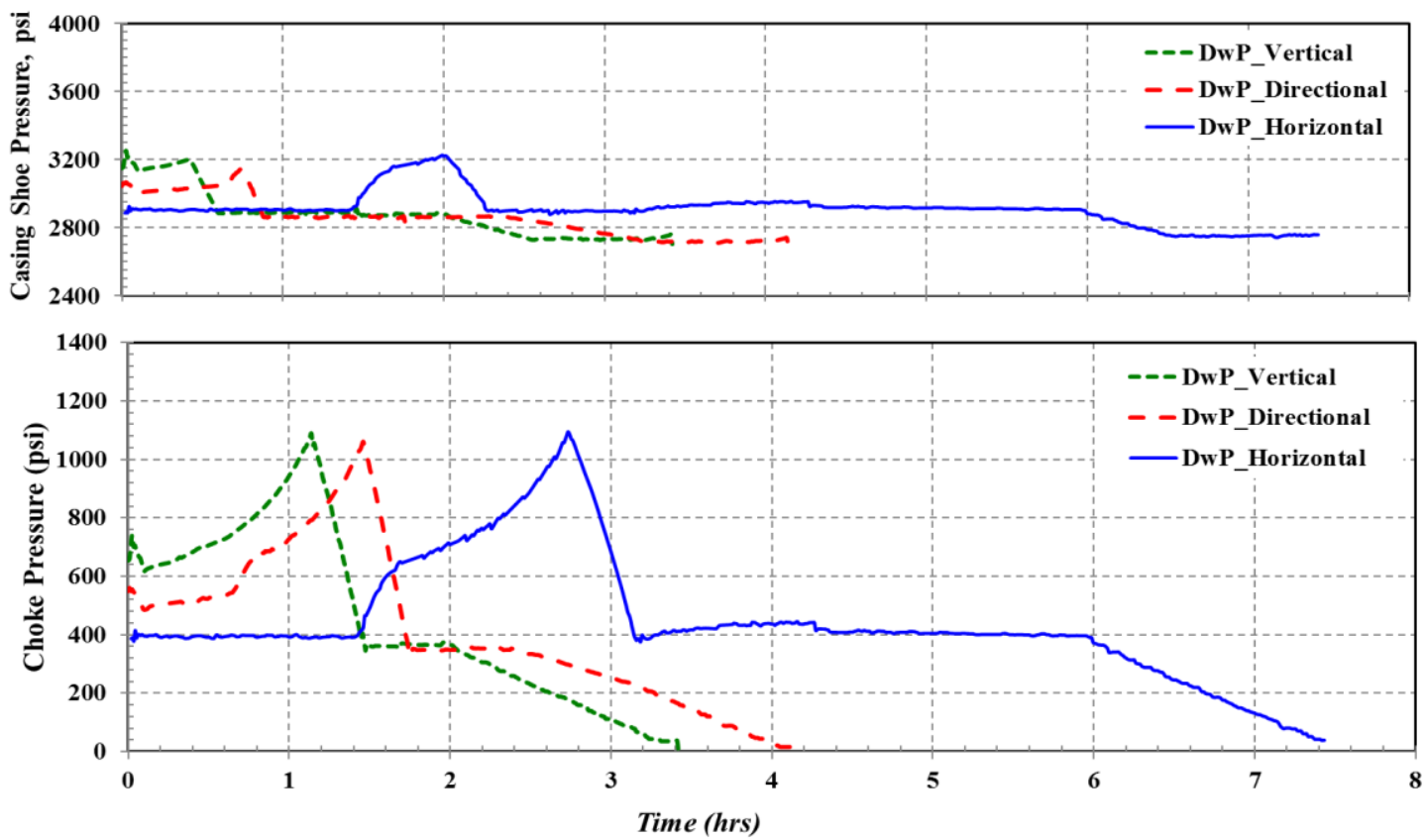

Figure A.2: Choke and casing shoe pressures for vertical, directional, and horizontal wells drilled with pipes and controlled with Driller's method at 40 spm WBM. 


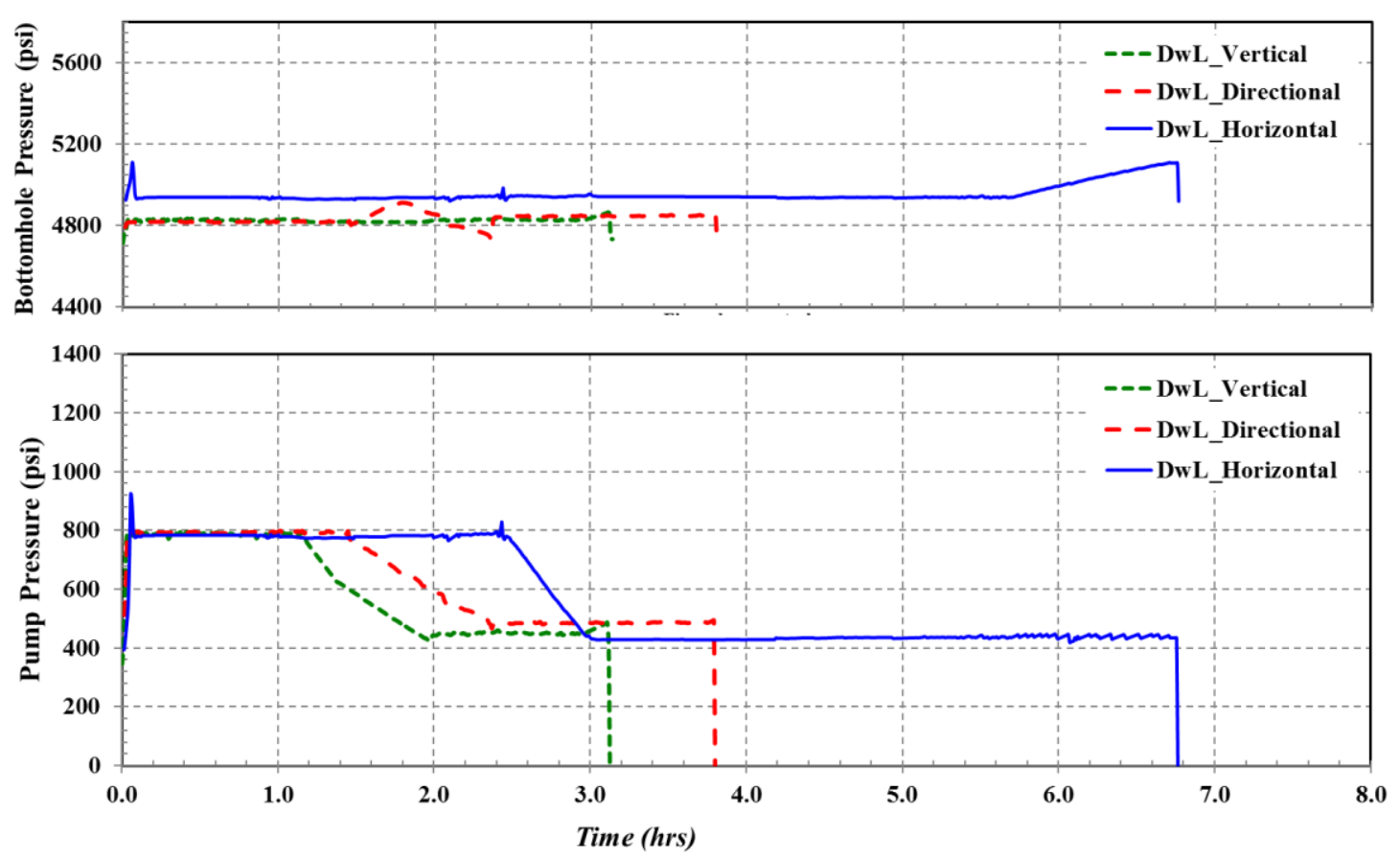

Figure A.3: Pump and bottomhole pressures for vertical, directional, and horizontal wells drilled with liner and controlled with Driller's method at 40 spm WBM.
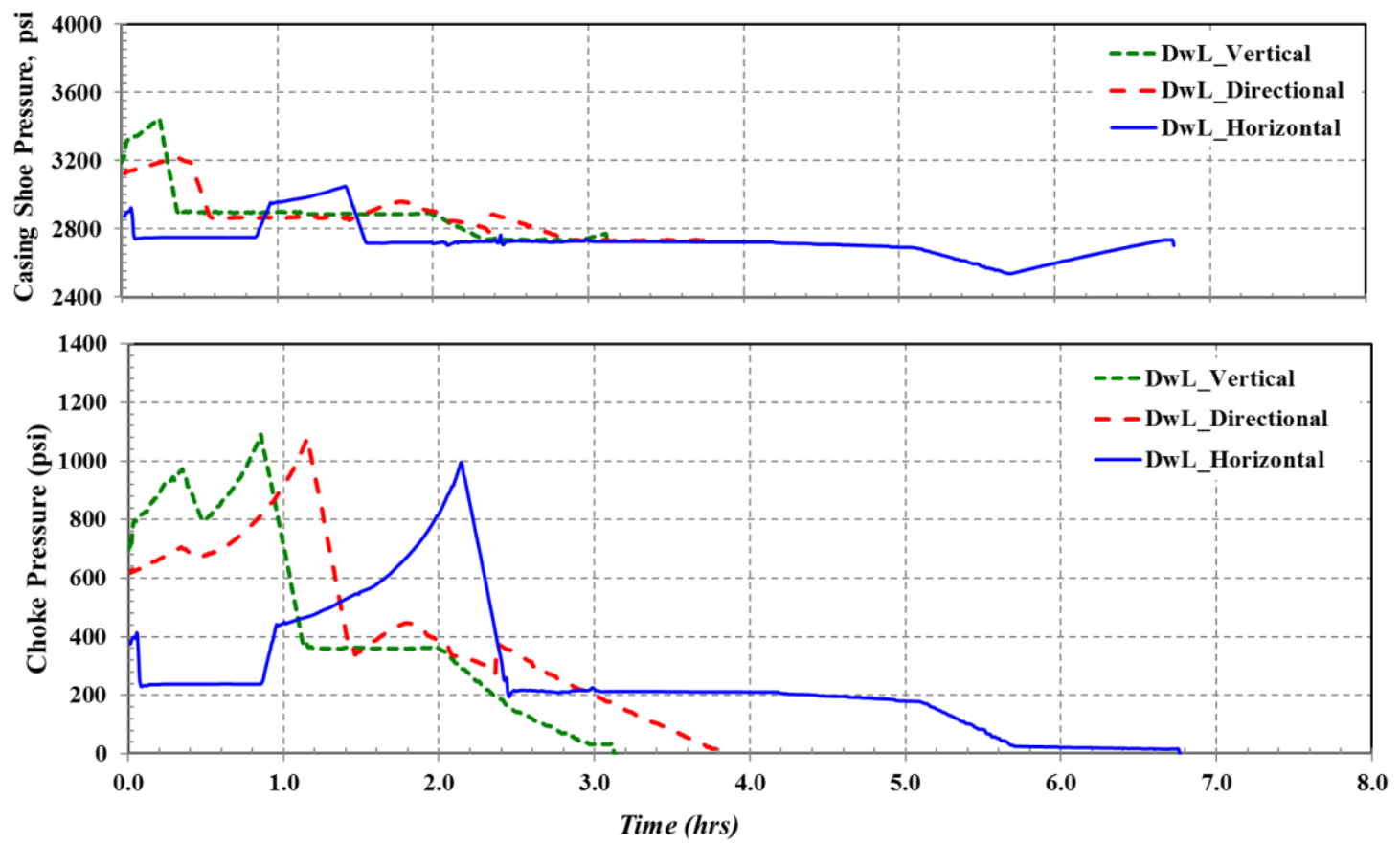

Figure A.4: Choke and casing shoe pressures for vertical, directional, and horizontal wells drilled with liner and controlled with Driller's method at 40 spm WBM. 


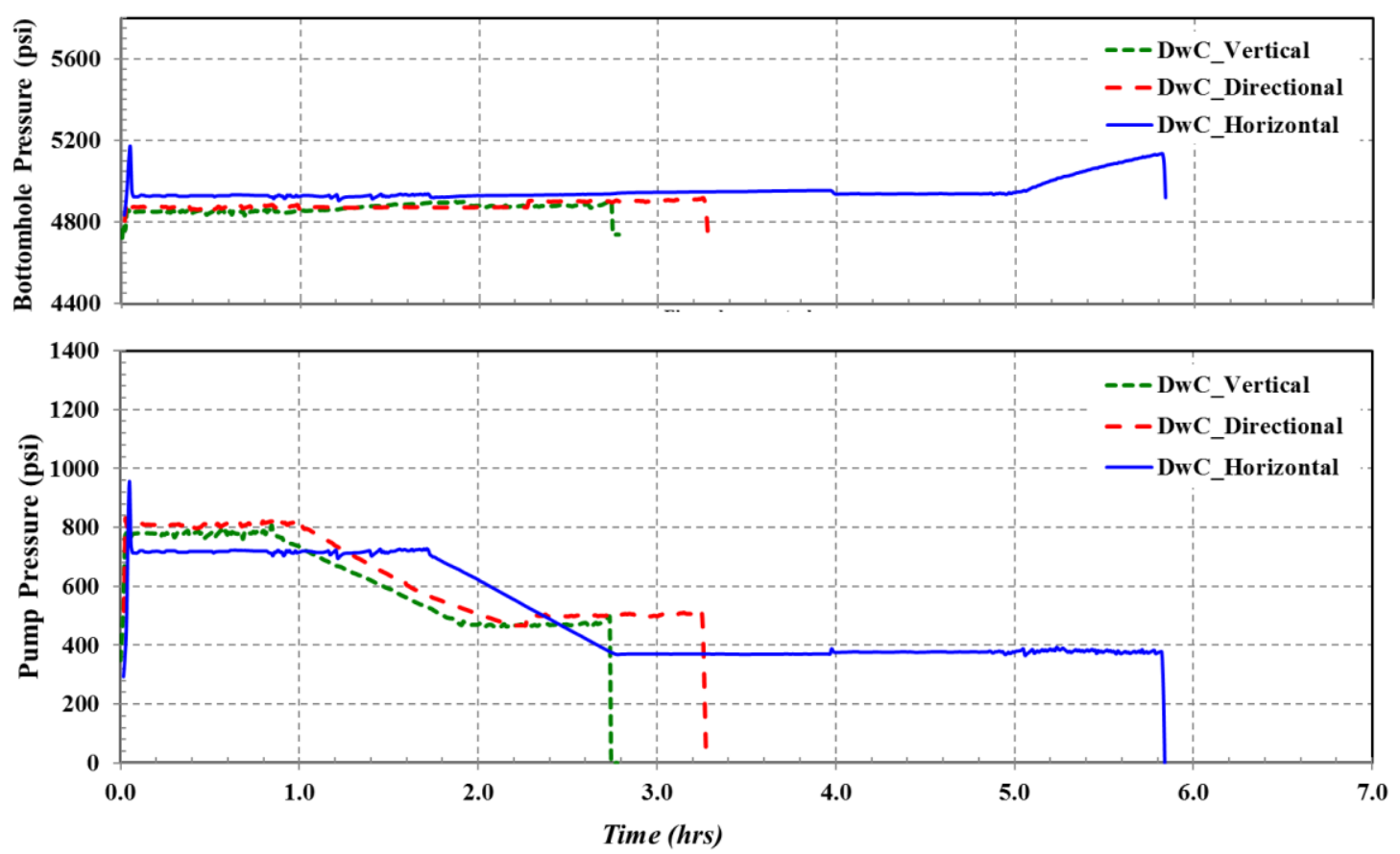

Figure A.5: Pump and bottomhole pressures for vertical, directional, and horizontal wells drilled with casing and controlled with Driller's method at 40 spm WBM.
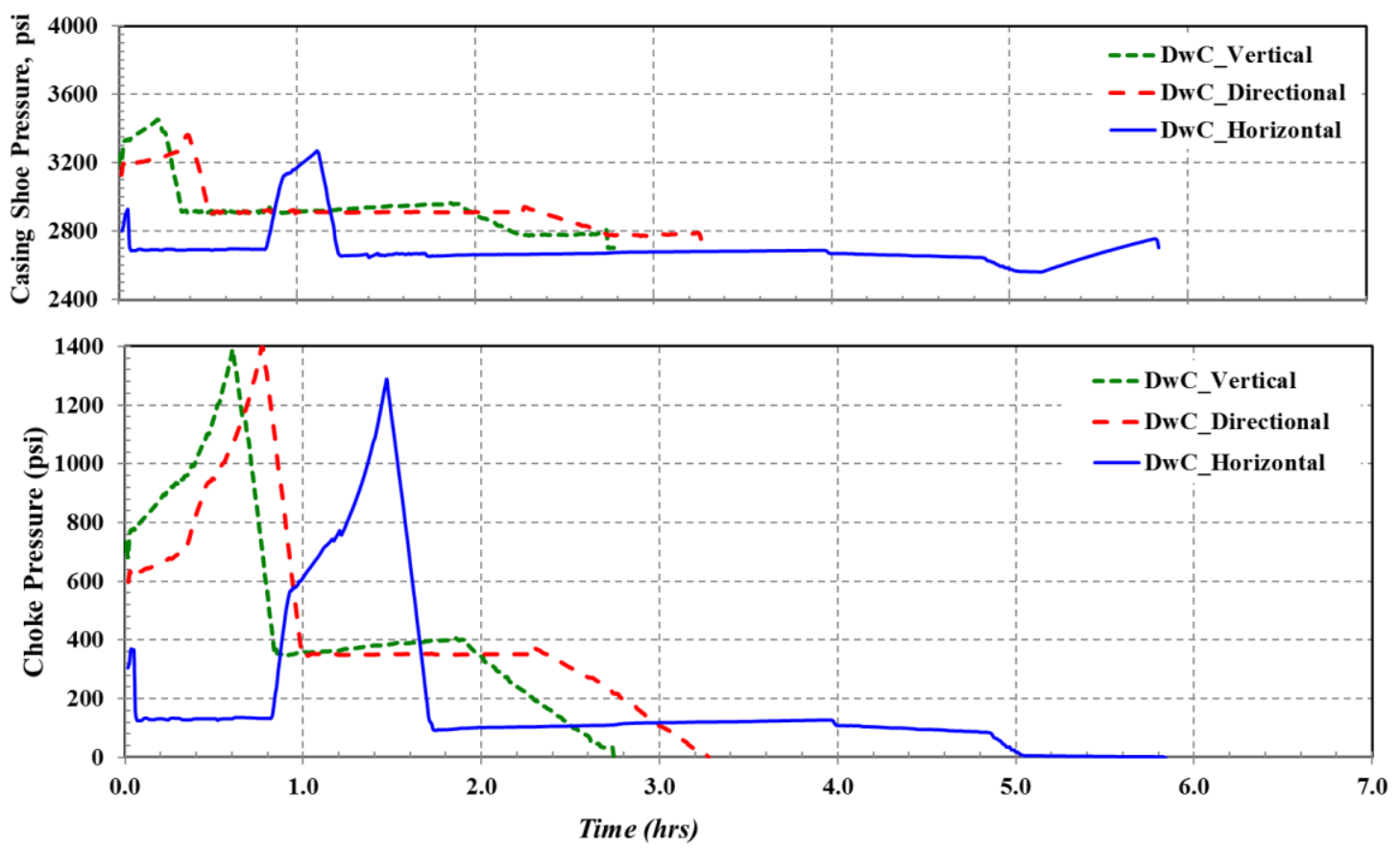

Figure A.6: Choke and casing shoe pressures for vertical, directional, and horizontal wells drilled with casing and controlled with Driller's method at 40 spm WBM. 


\section{APPENDIX (B)}

Data sample from the simulator with 35 recorded parameters for a 20 bbls kick in WBM circulated with Driller's method at $40 \mathrm{spm}$.

\begin{tabular}{|c|c|c|c|c|c|c|c|c|c|}
\hline $\begin{array}{c}1 \\
\text { simulation } \\
\text { time } \\
\text { minutes }\end{array}$ & $\begin{array}{c}\mathbf{2} \\
\text { Elapsed } \\
\text { pump } \\
\text { strokes }\end{array}$ & $\begin{array}{c}\text { Elapsed } \\
\text { barrels } \\
\text { bbls }\end{array}$ & $\begin{array}{c}\text { Bottomhole } \\
\text { Press } \\
\text { psi }\end{array}$ & $\begin{array}{c}\mathbf{4} \\
\text { Casing } \\
\text { Pressure } \\
\mathbf{p s i}\end{array}$ & $\begin{array}{c}\text { Casing Shoe } \\
\text { Press } \\
\mathbf{p s i}\end{array}$ & $\begin{array}{c}\mathbf{6} \\
\text { DrillPipe } \\
\text { press } \\
\text { psi }\end{array}$ & $\begin{array}{c}\text { Formation } \\
\text { press } \\
\text { psi }\end{array}$ & $\begin{array}{c}\mathbf{9} \\
\text { Pit } \\
\text { Deviation } \\
\text { bbls }\end{array}$ & $\begin{array}{c}10 \\
\text { Pump } \\
\text { flow } \\
\text { bbls/min }\end{array}$ \\
\hline 1.2 & 4 & 0.40 & 4943 & 386 & 2889 & 450 & 4906 & 20.0 & 0.98 \\
\hline 1.7 & 12 & 1.16 & 4958 & 389 & 2895 & 521 & 4906 & 20.0 & 1.72 \\
\hline 2.2 & 26 & 2.56 & 4971 & 378 & 2890 & 809 & 4906 & 19.9 & 3.55 \\
\hline 2.7 & 45 & 4.52 & 5012 & 414 & 2927 & 949 & 4906 & 19.7 & 3.94 \\
\hline 3.2 & 65 & 6.50 & 4987 & 388 & 2900 & 926 & 4906 & 19.7 & 3.94 \\
\hline 3.7 & 85 & 8.48 & 5000 & 400 & 2913 & 939 & 4906 & 19.6 & 3.94 \\
\hline
\end{tabular}

\begin{tabular}{|c|c|c|c|c|c|c|c|c|c|c|c|}
\hline $\begin{array}{c}11 \\
\begin{array}{c}\text { Pump stroke } \\
\text { rate } \\
\text { SPM }\end{array}\end{array}$ & $\begin{array}{c}12 \\
\text { choke } \\
\text { position } \\
\% \text { open }\end{array}$ & $\begin{array}{c}13 \\
\text { Hook load } \\
\text { lbf }\end{array}$ & $\begin{array}{c}14 \\
\text { lost flow } \\
\text { bbls/min }\end{array}$ & $\begin{array}{c}15 \\
\text { Drilled depth } \\
\mathrm{ft}\end{array}$ & $\begin{array}{c}16 \\
\text { Rotary torque } \\
\text { amps }\end{array}$ & $\begin{array}{c}17 \\
\text { WOB } \\
\text { Ibfs }\end{array}$ & $\begin{array}{c}18 \\
\text { Rotations per } \\
\text { minute } \\
\text { RPM }\end{array}$ & $\begin{array}{c}19 \\
\text { Pump } \\
\text { Press } \\
\text { psi }\end{array}$ & $\begin{array}{c}20 \\
\text { ROP } \\
\text { ft/hr }\end{array}$ & $\begin{array}{c}21 \\
\text { total bit } \\
\text { time } \\
\text { hours }\end{array}$ & $\begin{array}{c}22 \\
\text { Bit hydraulic } \\
\text { horse power } \\
\text { hp }\end{array}$ \\
\hline 10 & $33 \%$ & 284171 & 0 & 15013 & 0 & 0 & 0 & 450 & 0 & 0.33 & 0.4 \\
\hline 17 & $47 \%$ & 283992 & 0 & 15013 & 0 & 0 & 0 & 521 & 0 & 0.33 & 2.2 \\
\hline 36 & $62 \%$ & 283830 & 0 & 15013 & 0 & 0 & 0 & 810 & 0 & 0.33 & 19.5 \\
\hline 40 & $62 \%$ & 283343 & 0 & 15013 & 0 & 0 & 0 & 954 & 0 & 0.33 & 26.6 \\
\hline 40 & $68 \%$ & 283644 & 0 & 15013 & 0 & 0 & 0 & 929 & 0 & 0.33 & 26.6 \\
\hline 40 & $65 \%$ & 283493 & 0 & 15013 & 0 & 0 & 0 & 942 & 0 & 0.33 & 26.6 \\
\hline
\end{tabular}

\begin{tabular}{|c|c|c|c|c|c|c|c|c|c|c|c|c|}
\hline $\begin{array}{c}23 \\
\begin{array}{c}\text { Bit jet } \\
\text { velocity } \\
\text { ft/sec }\end{array}\end{array}$ & $\begin{array}{c}\mathbf{2 4} \\
\text { Gas units }\end{array}$ & $\begin{array}{c}\mathbf{2 5} \\
\text { kill line } \\
\text { press } \\
\mathbf{p s i}\end{array}$ & $\begin{array}{c}\mathbf{2 6} \\
\text { TVD } \\
\mathbf{f t}\end{array}$ & $\begin{array}{c}\mathbf{2 7} \\
\text { Density } \\
\text { in } \\
\mathbf{p p g}\end{array}$ & $\begin{array}{c}\mathbf{2 8} \\
\text { Density } \\
\text { out } \\
\mathbf{p p g}\end{array}$ & $\begin{array}{c}\mathbf{2 9} \\
\text { Pit flow } \\
\text { bbls/min }\end{array}$ & $\begin{array}{c}30 \\
\text { cement head } \\
\text { installeld }\end{array}$ & $\begin{array}{c}31 \\
\text { cmt head plug } \\
\text { indicator }\end{array}$ & $\begin{array}{c}32 \\
\text { Event write }\end{array}$ & $\begin{array}{c}33 \\
\text { ECD } \\
\text { ppg }\end{array}$ & $\begin{array}{c}34 \\
\text { well head } \\
\text { press } \\
\text { psi }\end{array}$ & $\begin{array}{c}35 \\
\text { total pit } \\
\text { volume } \\
\text { bbls }\end{array}$ \\
\hline 40 & 0.0 & 0 & 7280 & 12.0 & 12.0 & 0.9 & 0 & 1 & 0 & 13.1 & 386 & 820.0 \\
\hline 70 & 0.0 & 0 & 7280 & 12.0 & 12.0 & 2.0 & 0 & 1 & 0 & 13.1 & 389 & 820.0 \\
\hline 144 & 0.0 & 0 & 7280 & 12.0 & 12.0 & 3.3 & 0 & 1 & 0 & 13.1 & 378 & 819.9 \\
\hline 160 & 0.0 & 0 & 7280 & 12.0 & 12.0 & 3.5 & 0 & 1 & 0 & 13.2 & 414 & 819.7 \\
\hline 160 & 0.0 & 0 & 7280 & 12.0 & 12.0 & 3.9 & 0 & 1 & 0 & 13.2 & 388 & 819.7 \\
\hline 160 & 0.0 & 0 & 7280 & 12.0 & 12.0 & 3.8 & 0 & 1 & 0 & 13.2 & 400 & 819.6 \\
\hline
\end{tabular}

